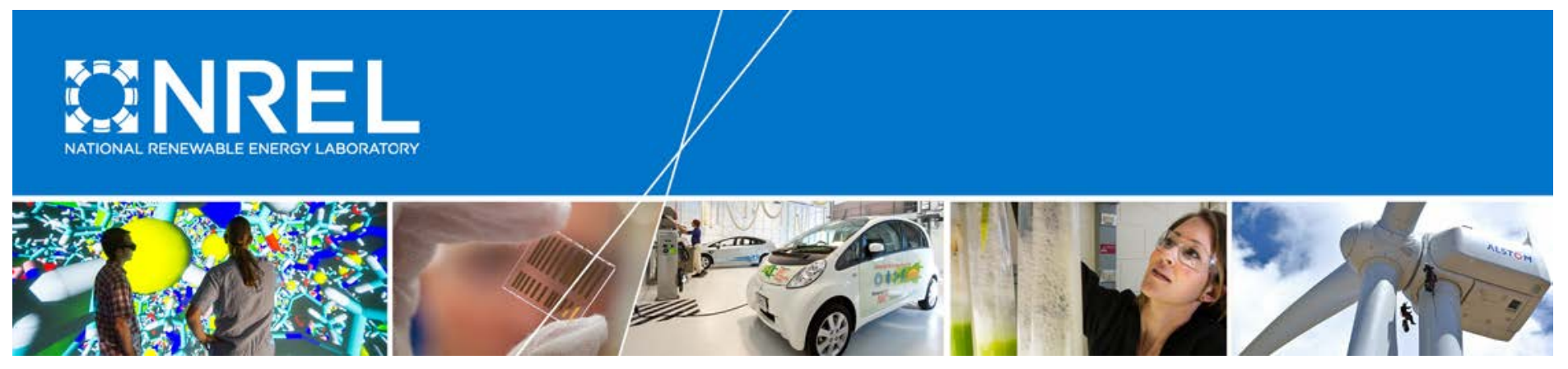

\title{
EnergyPlus and SEEM Modeling Enhancements via Software-to- Software Comparison Using NREL's BEopt Test Suite
}

Scott Horowitz, Jeff Maguire, Paulo Cesar Tabares-Velasco, Jon Winkler, and Craig Christensen

Produced under direction of Bonneville Power Administration (BPA) by the National Renewable Energy Laboratory (NREL) under Interagency Agreement IAG-13-1885 and Task No WFT3.1000.

NREL is a national laboratory of the U.S. Department of Energy Office of Energy Efficiency \& Renewable Energy Operated by the Alliance for Sustainable Energy, LLC

This report is available at no cost from the National Renewable Energy Laboratory (NREL) at www.nrel.gov/publications.

Technical Report

NREL/TP-5500-61489

August 2016 
EnergyPlus and SEEM Modeling Enhancements via Software-to-Software Comparison Using NREL's BEopt Test Suite

Scott Horowitz, Jeff Maguire, Paulo Cesar Tabares-Velasco, Jon Winkler, and Craig Christensen

Prepared under Task No. WFT3.1000
NREL is a national laboratory of the U.S. Department of Energy Office of Energy Efficiency \& Renewable Energy Operated by the Alliance for Sustainable Energy, LLC

This report is available at no cost from the National Renewable Energy Laboratory (NREL) at www.nrel.gov/publications.

Technical Report

NREL/TP-5500-61489

August 2016

Contract No. DE-AC36-08G028308
National Renewable Energy Laboratory 15013 Denver West Parkway

303-275-3000 • www.nrel.gov 


\section{NOTICE}

This manuscript has been authored by employees of the Alliance for Sustainable Energy, LLC (“Alliance") under Contract No. DE-AC36-08GO28308 with the U.S. Department of Energy ("DOE”).

This report was prepared as an account of work sponsored by an agency of the United States government. Neither the United States government nor any agency thereof, nor any of their employees, makes any warranty, express or implied, or assumes any legal liability or responsibility for the accuracy, completeness, or usefulness of any information, apparatus, product, or process disclosed, or represents that its use would not infringe privately owned rights. Reference herein to any specific commercial product, process, or service by trade name, trademark, manufacturer, or otherwise does not necessarily constitute or imply its endorsement, recommendation, or favoring by the United States government or any agency thereof. The views and opinions of authors expressed herein do not necessarily state or reflect those of the United States government or any agency thereof.

This report is available at no cost from the National Renewable Energy Laboratory (NREL) at www.nrel.gov/publications.

Available electronically at SciTech Connect http:/www.osti.gov/scitech

Available for a processing fee to U.S. Department of Energy and its contractors, in paper, from:

U.S. Department of Energy

Office of Scientific and Technical Information

P.O. Box 62

Oak Ridge, TN 37831-0062

OSTI http://www.osti.gov

Phone: 865.576.8401

Fax: 865.576.5728

Email: reports@osti.gov

Available for sale to the public, in paper, from:

U.S. Department of Commerce

National Technical Information Service

5301 Shawnee Road

Alexandria, VA 22312

NTIS http://www.ntis.gov

Phone: 800.553 .6847 or 703.605 .6000

Fax: 703.605.6900

Email: orders@ntis.gov 


\section{Acknowledgments}

This work was funded by the Bonneville Power Administration (BPA) and the U.S. Department of Energy.

The authors wish to acknowledge Ben Larson, Nick Kvaltine, and Michael Logsdon (Ecotope Inc.) for their critical Simple Energy and Enthalpy Model (SEEM) technical support as well as others who contributed with their critical review: RTF SEEM committee members, Ben Polly (National Renewable Energy Laboratory [NREL]), Joe Robertson (NREL) and Eric Wilson (NREL). Special thanks to Dave Roberts (NREL), Mira Vowles (BPA), and Robert Weber (BPA) for planning and supporting this project. 


\section{Nomenclature}

AIM-2

$\mathrm{ACH}$

AFUE

ASHRAE

ASHP

BEopt

BPA

$\mathrm{C}_{\mathrm{D}}$

$\mathrm{cfm}$

COP

DOE

DHP

ENH

EMS

FIX

GSHP

HPWH

HSP

HSPF

HVAC

LBL

MSHP

NREL

OAT

PV

REC

SEEM

SEER

TARP
Alberta Air Infiltration Model

Air changes per hour

Annual fuel utilization efficiency

American Society of Heating, Refrigerating and Air

Conditioning Engineers

Air source heat pump

Building Energy Optimization Tool

Bonneville Power Administration

Degradation coefficient

Cubic feet per minute

Coefficient of Performance

Department of Energy

Ductless heat pump (aka MSHP)

Modeling enhancement

Energy Management System

Bug fix

Ground source heat pump

Heat pump water heater

House Simulation Protocols (for Building America)

Heating Seasonal Performance Factor

Heating, ventilation, and air conditioning

Lawrence Berkeley National Laboratory

Mini-split heat pump (aka DHP)

National Renewable Energy Laboratory

Outdoor air temperature

Photovoltaics

Recommendation

Simple Energy and Enthalpy Model

Seasonal Energy Efficiency Ratio

Thermal Analysis Research Program 


\section{Executive Summary}

This two-phase study involved comprehensive comparative testing of EnergyPlus and SEEM to determine the differences in energy consumption predictions between these two programs and to reconcile prioritized discrepancies through bug fixes, modeling improvements, and/or consistent inputs and assumptions. Phases I and II occurred in sequential years, with the results/discussion sections for a given phase written upon its conclusion.

Phase I focused on identifying significant discrepancies between the two residential simulation engines. Investigating causes and fixing discrepancies were not explicit objectives of Phase I. NREL used the Building Energy Optimization (BEopt) Test Suite capabilities to automatically compare simulation results from EnergyPlus and SEEM for tens of thousands of equivalent building models, and employed additional diagnostic tools to identify and categorize discrepancies between the energy simulation programs. In collaboration with Ecotope, some discrepancies were partially investigated to determine causes and effects, and, in a few cases, fully investigated to the point where SEEM developers were able to make fixes.

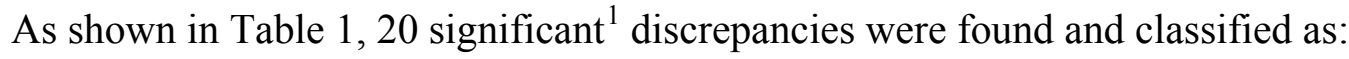

- Three discrepancies resolved. The NREL and Ecotope teams worked together to identify and fix errors in SEEM.

- Seven discrepancies partially investigated. The NREL and Ecotope teams initially studied these discrepancies, but these require more work to determine the appropriate resolution.

- Ten discrepancies not yet investigated. These discrepancies have not been analyzed, but their magnitude makes them important to analyze.

Phase II focused on deeper investigations of categories prioritized by BPA in terms of significant discrepancies identified in Phase I and regional importance. The five areas chosen for investigation were: mini-split heat pumps, heat pump water heaters, air leakage, ducts, and foundation heat transfer.

As shown in Table 2, a number of modeling enhancements and bug fixes have been implemented in both simulation engines across the categories. As a result, the final assessment of the discrepancies for five categories is:

- Four categories resolved. Mini-split heat pumps, heat pump water heaters, air leakage, and ducts.

- One category partially resolved. Foundation heat transfer. Due to inherent differences in the EnergyPlus and SEEM models, as well as lack of empirical data with which to assess the accuracy of the models, no further reconciliation can be achieved.

Additional recommendations have been made for potential future improvements.

\footnotetext{
${ }^{1}$ Discrepancies between simulation engines occur across many building components because of inherent differences in modeling algorithms, inputs, and assumptions. In Phase I, this report focuses on the subset of components with the most significant differences.
} 
Table 1. Phase I Significant Discrepancies Identified Between BEopt/EnergyPlus and SEEM

\begin{tabular}{|c|c|c|c|c|}
\hline Category & Option(s) & Discrepancy & Magnitude $^{2}$ & Status \\
\hline Crawlspace & Unvented & No sensitivity in SEEM & +++ & \multirow{3}{*}{ Resolved } \\
\hline $\begin{array}{l}\text { Unheated } \\
\text { Basement }\end{array}$ & All & No sensitivity in SEEM & +++ & \\
\hline Slab & $\begin{array}{l}\text { Whole slab } \\
\text { insulation }\end{array}$ & Little sensitivity in SEEM & ++ & \\
\hline $\begin{array}{l}\text { Mini-Split Heat } \\
\text { Pumps }\end{array}$ & All & Higher energy use in SEEM & +++ & \multirow{7}{*}{ Partially investigated } \\
\hline $\begin{array}{l}\text { Heated } \\
\text { Basement }\end{array}$ & All & Higher energy use in SEEM & +++ & \\
\hline $\begin{array}{l}\text { Vaulted } \\
\text { Ceiling }\end{array}$ & All & Different trends & ++ & \\
\hline Ducts & All & $\begin{array}{l}\text { SEEM does not run for some } \\
\text { duct configurations }\end{array}$ & ++ & \\
\hline Windows & All & Higher energy use in SEEM & ++ & \\
\hline Roof Material & Low emissivity & Higher energy use in SEEM & + & \\
\hline $\begin{array}{l}\text { Mechanical } \\
\text { Ventilation }\end{array}$ & All & Different trends & + & \\
\hline Attic & \begin{tabular}{|l} 
Ceiling \\
insulation
\end{tabular} & Lower energy use in SEEM & +++ & \multirow{10}{*}{ Not yet investigated } \\
\hline Walls & Low insulation & Lower energy use in SEEM & +++ & \\
\hline Crawlspace & Wall insulation & Lower energy use in SEEM & ++ & \\
\hline $\begin{array}{l}\text { Unheated } \\
\text { Basement }\end{array}$ & Wall insulation & Lower energy use in SEEM & ++ & \\
\hline Slab & $\begin{array}{l}\text { Perimeter } \\
\text { insulation }\end{array}$ & Higher energy use in SEEM & ++ & \\
\hline Air Leakage & All & Lower energy use in SEEM & ++ & \\
\hline $\begin{array}{l}\text { Interior } \\
\text { Shading }\end{array}$ & All & Different trends & ++ & \\
\hline Attic & Roof insulation & Different trends/energy use & ++ & \\
\hline Internal gains & All & Higher energy use in SEEM & + & \\
\hline Floor mass & All & Higher energy use in SEEM & + & \\
\hline
\end{tabular}

\footnotetext{
${ }^{2}$ Discrepancy magnitudes vary depending on weather/building configuration from largest (+++) to smallest discrepancy $(+)$. Even the smallest discrepancies listed here are considered important; numerous discrepancies considered less significant are not included in this table.
} 
Table 2. Phase II Overall Status of Pacific Northwest Prioritized Categories

\begin{tabular}{|c|c|c|c|c|c|}
\hline Category & \multicolumn{2}{|c|}{ BEopt/EnergyPlus } & \multicolumn{2}{|c|}{ SEEM } & Status \\
\hline $\begin{array}{l}\text { Mini-Split } \\
\text { Heat Pumps }\end{array}$ & $\begin{array}{l}\mathrm{ENH}^{\mathrm{a}} \\
\mathrm{ENH} \\
\text { FIX }^{\mathrm{b}} \\
\text { REC }^{\mathrm{c}}\end{array}$ & $\begin{array}{l}\text { Updated coefficient of degradation, } C_{D} \\
\text { Updated heating indices } \\
\text { Defrost model } \\
\text { Assess latest variable-speed model }\end{array}$ & & & Resolved \\
\hline $\begin{array}{l}\text { Heat Pump } \\
\text { Water Heaters }\end{array}$ & $\begin{array}{l}\text { ENH } \\
\text { ENH } \\
\text { ENH } \\
\text { ENH } \\
\text { ENH } \\
\text { FIX } \\
\text { FIX } \\
\text { FIX } \\
\text { FIX } \\
\text { FIX }\end{array}$ & $\begin{array}{l}\text { New res. wrapped condenser model } \\
\text { Supply/exhaust/balanced ducting } \\
\text { Temperature depression } \\
\text { HVAC interaction factor } \\
\text { Connection to stratified tank model } \\
\text { Energy balance issues } \\
\text { Part load ratio convergence } \\
\text { Possible negative heat transfer to tank } \\
\text { Coil bypass factor crash } \\
\text { High energy use at larger timesteps }\end{array}$ & $\begin{array}{l}\text { FIX } \\
\text { FIX }\end{array}$ & $\begin{array}{l}\text { Heat gain energy instead of power } \\
\text { Incorrect accumulation of gains over hour }\end{array}$ & Resolved \\
\hline Air Leakage & $\begin{array}{l}\text { ENH } \\
\text { REC }\end{array}$ & $\begin{array}{l}\text { Updated vented crawl leakage dist. } \\
\text { Assess Airflow Network model }\end{array}$ & $\begin{array}{l}\text { REC } \\
\text { REC } \\
\text { REC }\end{array}$ & $\begin{array}{l}\text { Update leakage dist. for all foundation types } \\
\text { Add terrain input; use ASHRAE definitions } \\
\text { Add shelter input; use ASHRAE definitions }\end{array}$ & Resolved \\
\hline Ducts & $\mathrm{ENH}$ & Applied cylindrical geometry insulation effect & $\begin{array}{l}\text { REC } \\
\text { REC }\end{array}$ & $\begin{array}{l}\text { Reduce uninsulated duct R-value to } \mathrm{R}-1.7 \\
\text { Fix possible errors with unvented crawlspaces }\end{array}$ & Resolved \\
\hline Other & & & $\begin{array}{l}\text { FIX } \\
\text { FIX }\end{array}$ & $\begin{array}{l}\text { "Ghost" heat gain for high-R envelope } \\
\text { Hourly vs. annual output }\end{array}$ & Resolved \\
\hline $\begin{array}{l}\text { Foundation } \\
\text { Heat Transfer }\end{array}$ & REC & Assess enhanced model & & & $\begin{array}{l}\text { Partially } \\
\text { Resolved }\end{array}$ \\
\hline
\end{tabular}

${ }^{a}$ ENH: Modeling Enhancement

${ }^{b}$ FIX: Bug Fix

${ }^{c}$ REC: Recommendation 


\section{Table of Contents}

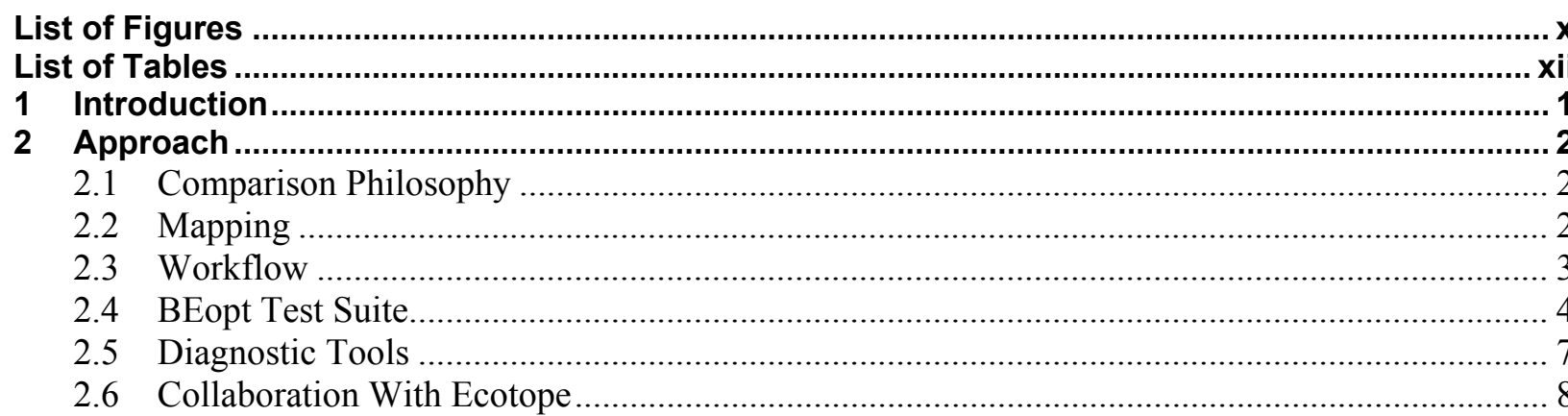

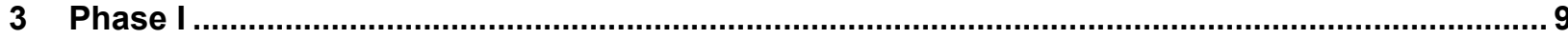

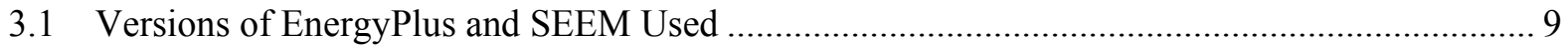

3.2 Overall SEEM Versus EnergyPlus Comparison Scatter Plots ................................................... 9

3.3 Identified Discrepancies Between SEEM and EnergyPlus …………………………….......... 10

3.3.1 Discrepancies Resolved................................................................................ 12

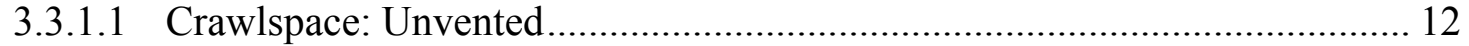

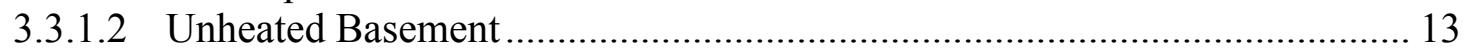

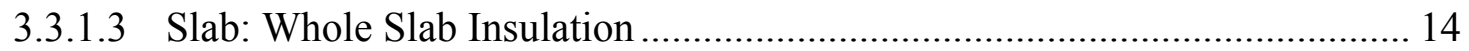

3.3.2 Discrepancies Partially Investigated ................................................................... 15

3.3.2.1 Mini-Split Heat Pumps .......................................................................... 15

3.3.2.2 Heated Basement ................................................................................ 15

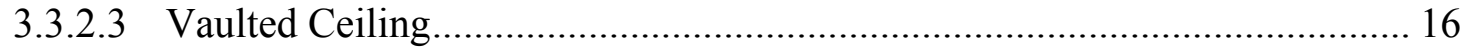

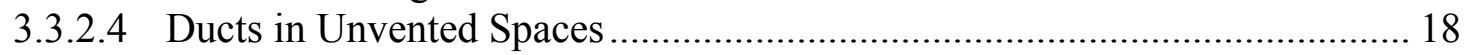

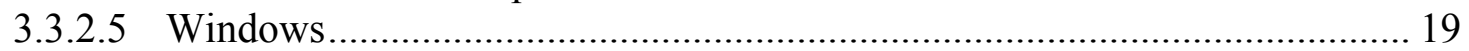

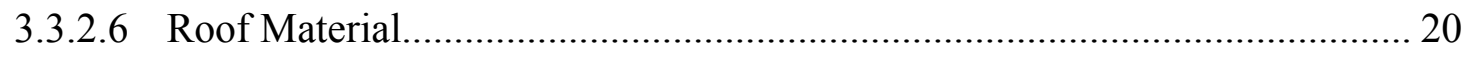

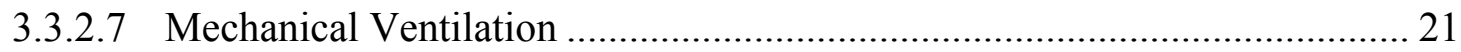

3.3.3 Discrepancies Not Yet Investigated ...................................................................... 22

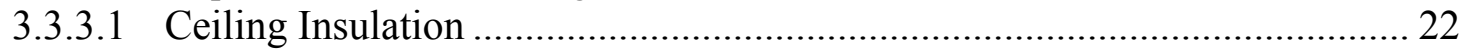

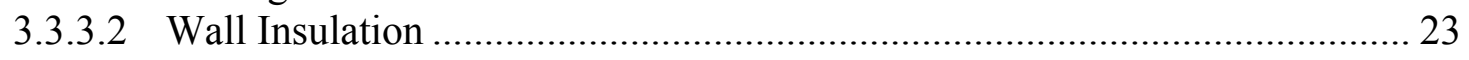

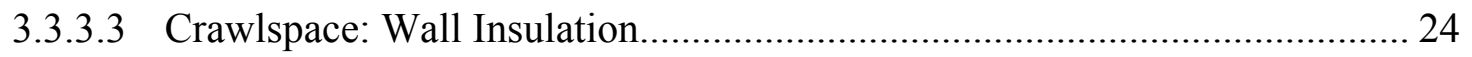

3.3.3.4 Unheated Basement: Wall Insulation ...................................................... 25

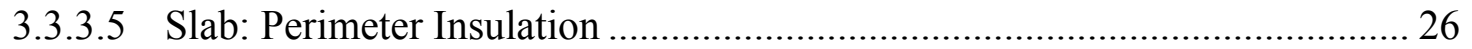

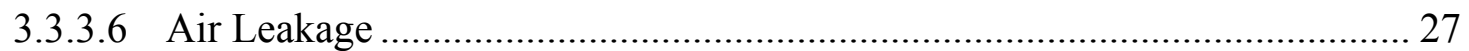

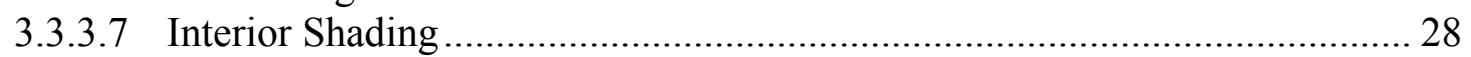

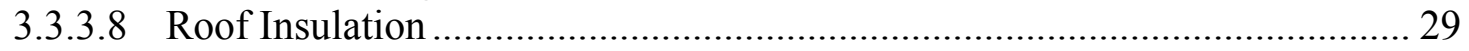

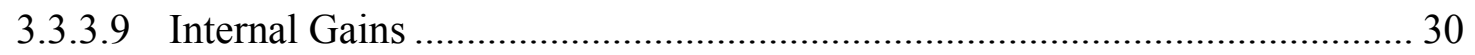

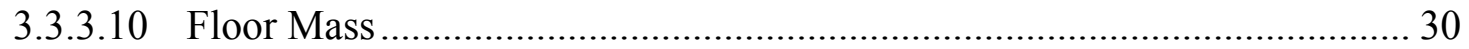

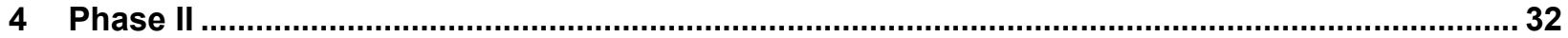

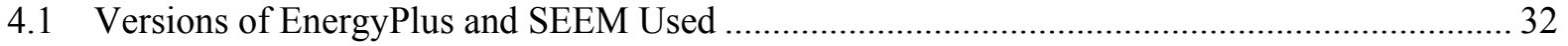

4.2 Overall Assessment of Prioritized Categories ....……………………………………………... 32

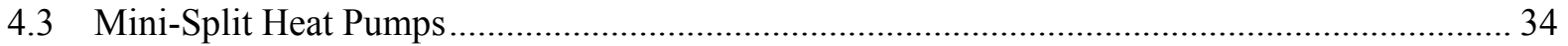

4.3.1 BEopt/EnergyPlus Model................................................................................... 34

4.3.2 SEEM Model............................................................................................ 34

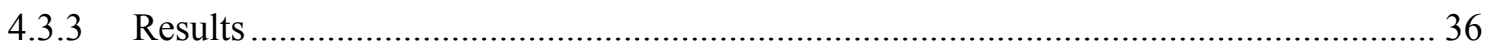

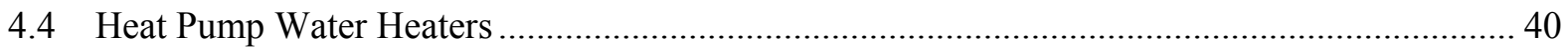

4.4.1 BEopt/EnergyPlus Model................................................................................. 40

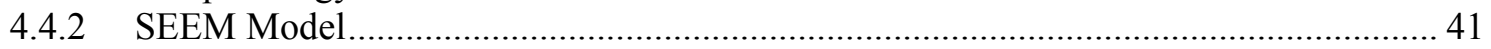

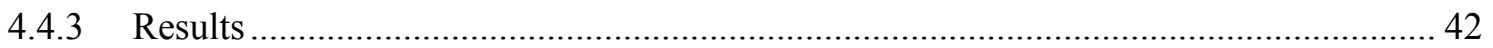




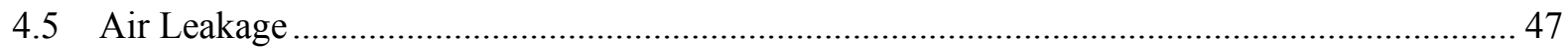

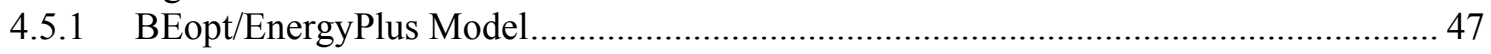

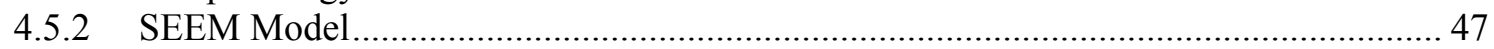

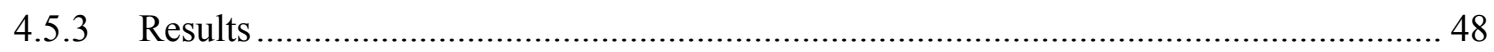

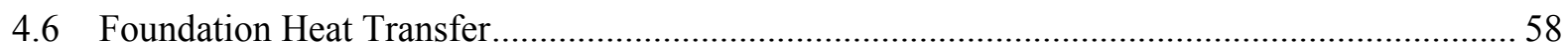

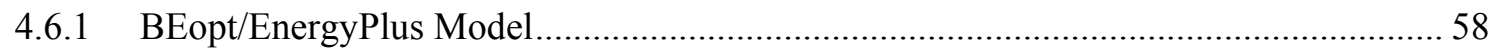

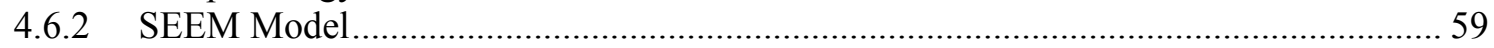

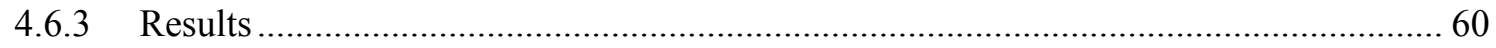

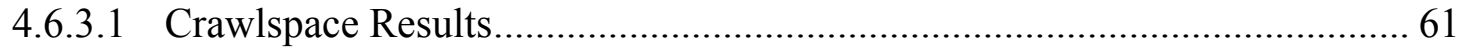

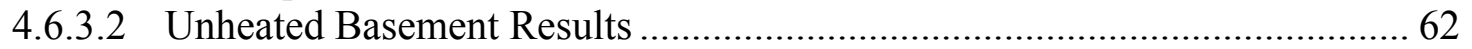

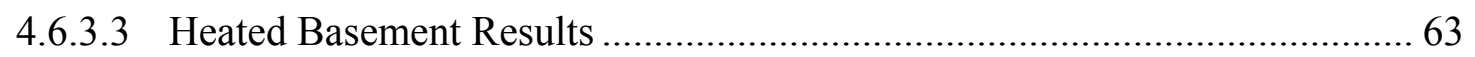

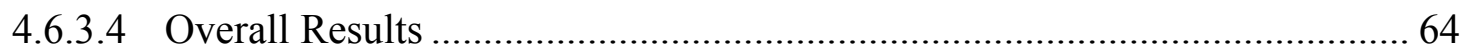

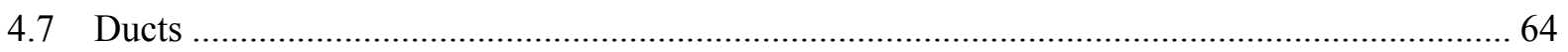

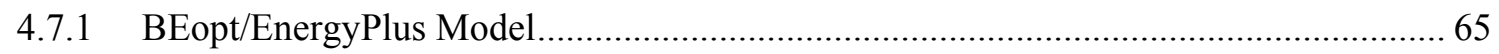

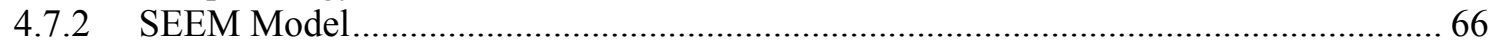

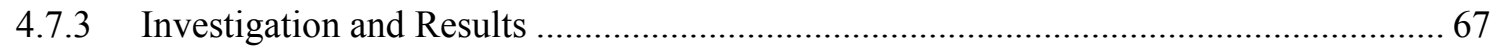

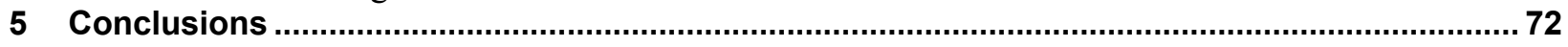

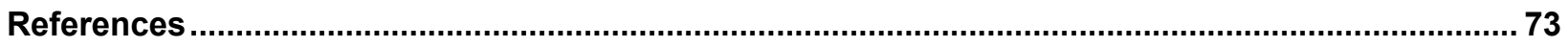

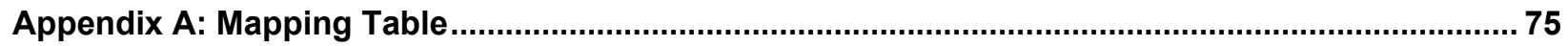

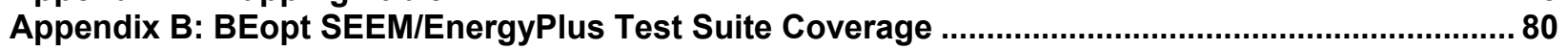

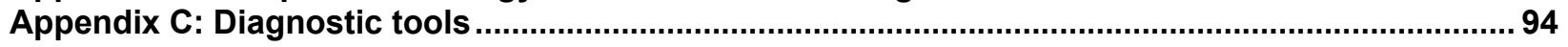

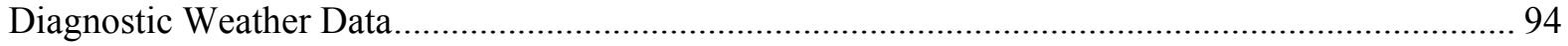

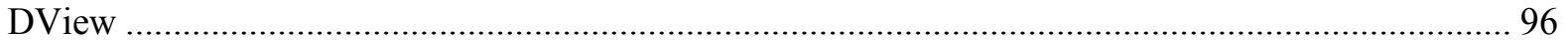

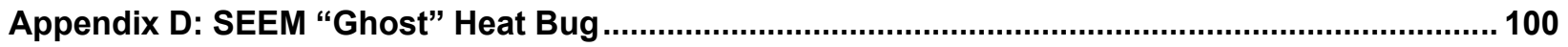




\section{List of Figures}

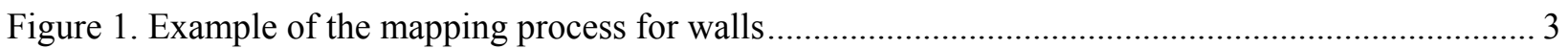

Figure 2. Workflow for BEopt simulations using (a) EnergyPlus and (b) SEEM .................................. 4

Figure 3. BEopt Test Suite Viewer ................................................................................... 7

Figure 4. Test Suite results for new construction homes in Seattle (a) before and (b) after fixes ............... 9

Figure 5. Test Suite results for existing homes in Seattle (a) before and (b) after fixes .......................... 10

Figure 6. Before fix: Crawlspace results for diagnostic building ..................................................... 12

Figure 7. After fix: Crawlspace results for diagnostic building ...................................................... 12

Figure 8. Before fix: Unheated basement results for diagnostic building ............................................. 13

Figure 9. After fix: Unheated basement results for diagnostic building ............................................. 13

Figure 10. Before fix: Slab results for diagnostic building ................................................................ 14

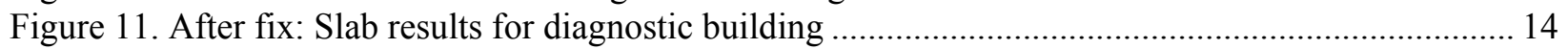

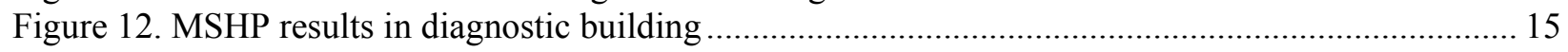

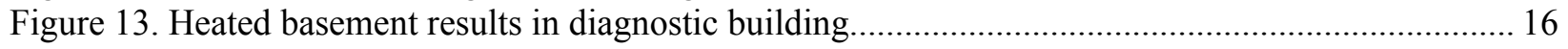

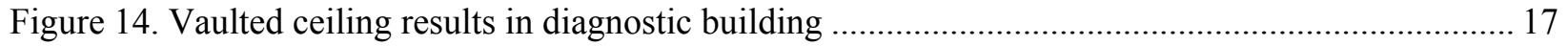

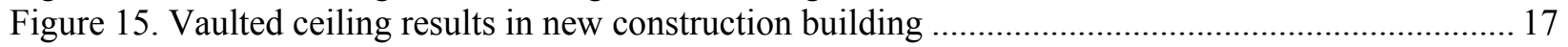

Figure 16. Duct results in new construction building with a vented crawlspace .................................... 18

Figure 17. Duct results in diagnostic building with an unvented crawlspace ......................................... 19

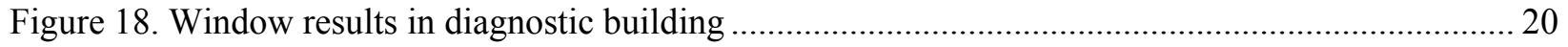

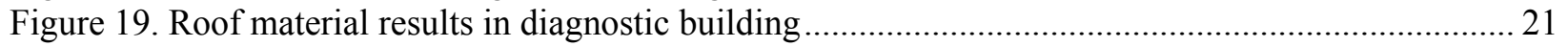

Figure 20. Mechanical ventilation results in new construction building .............................................. 22

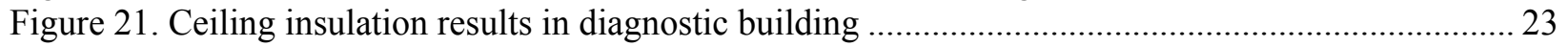

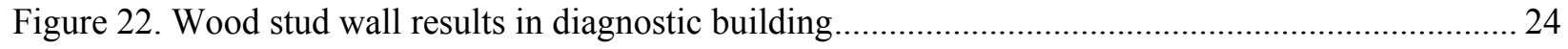

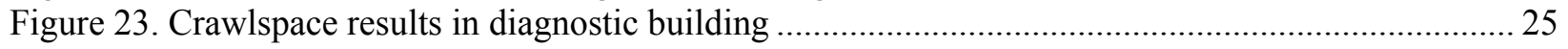

Figure 24. Unheated basement results in diagnostic building.......................................................... 26

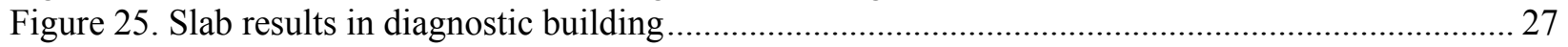

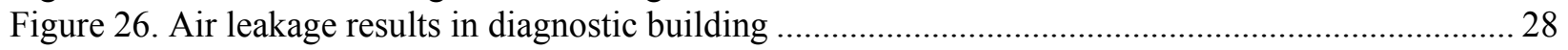

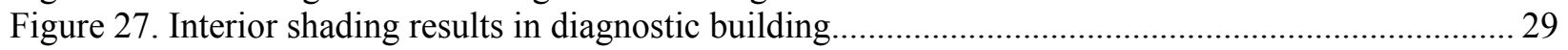

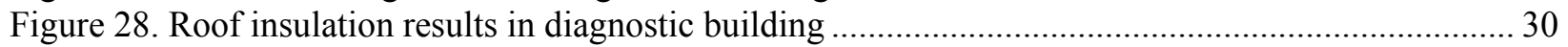

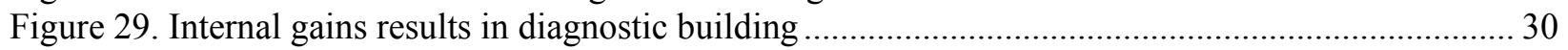

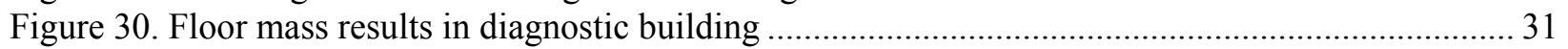

Figure 31. SEEM MSHP performance curves (Ecotope 2013) ............................................................ 35

Figure 32. Field test data and SEEM average performance for DHP1 (Ecotope 2013)........................... 35

Figure 33. Frequency of measured MSHP heating power consumption for sites with DHP1 .................. 37

Figure 34. MSHP COP vs. OAT for a range of $\mathrm{C}_{\mathrm{D}}$ and heating indices ............................................. 38

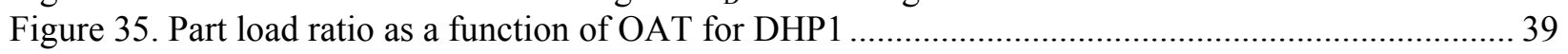

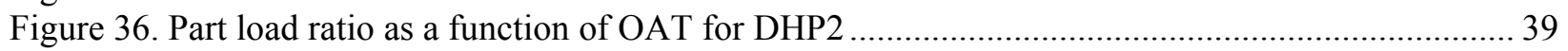

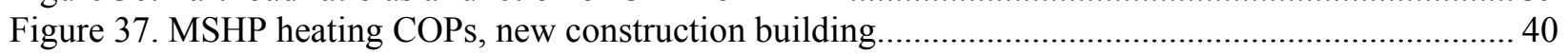

Figure 38. Fifty-gallon HPWH model validation data; EnergyPlus vs. laboratory testing....................... 43

Figure 39. Eighty-gallon HPWH model validation data; EnergyPlus vs. laboratory testing ...................... 44

Figure 40. Water heater results in a new construction building, water heating end use only .................... 45

Figure 41. Water heater results in a diagnostic building, all end uses ................................................ 46

Figure 42. Water heater results in a diagnostic building, delivered hot water energy ............................ 46

Figure 43. Initial air leakage discrepancies, diagnostic buildings .................................................... 48

Figure 44. BEopt/EnergyPlus vs. SEEM, stack-only infiltration, initial (left) vs. modified (right) ........... 53

Figure 45. BEopt/EnergyPlus vs. SEEM, wind-only infiltration, initial (left) vs. modified (right) ........... 54

Figure 46. BEopt/EnergyPlus vs. SEEM, total infiltration, initial (left) vs. modified (right).................... 55

Figure 47. Modified BEopt/EnergyPlus vs. SEEM air leakage discrepancies, diagnostic buildings ......... 56

Figure 48. BEopt/EnergyPlus vs. SEEM sensitivity analysis, diagnostic buildings ................................ 57

Figure 49. Schematic of the overall wall construction from the Winkelmann method .............................59 


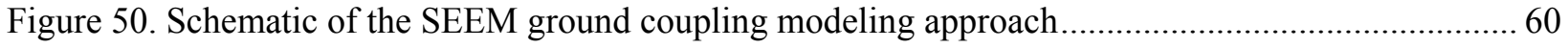

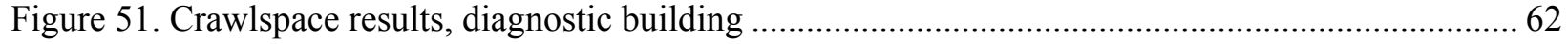

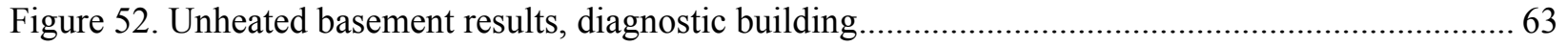

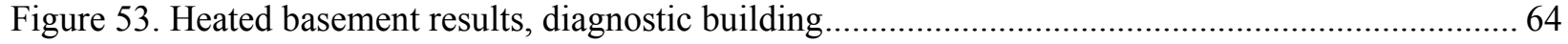

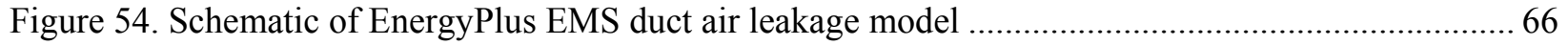

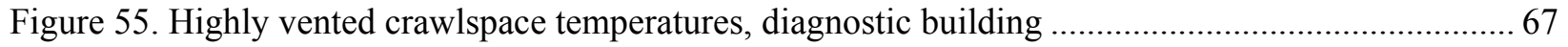

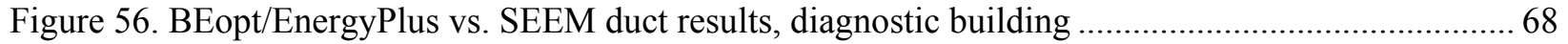

Figure 57. Initial BEopt/EnergyPlus vs. SEEM duct heating results, diagnostic building ........................ 68

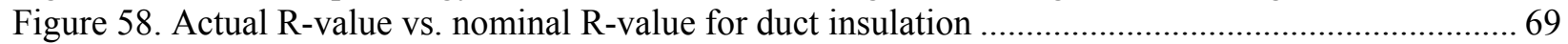

Figure 59. Actual U-value vs. nominal R-value for duct insulation ................................................... 70

Figure 60. Modified BEopt/EnergyPlus vs. SEEM duct heating results, diagnostic building................... 70

Figure 61. Test weather data outdoor temperature, wind speed and solar horizontal ............................ 95

Figure 62. Diagnostic TMY results for a house with only infiltration, only attic losses/gains, and only

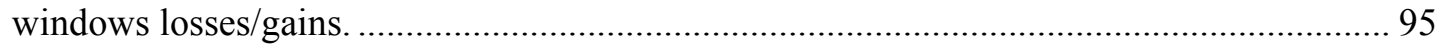

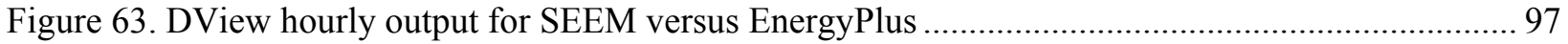

Figure 64. DView average monthly profiles for SEEM versus EnergyPlus ........................................... 98

Figure 65. DView scatter plot of SEEM versus EnergyPlus 8760 heating energy values........................ 99 


\section{List of Tables}

Table 1. Phase I Significant Discrepancies Identified Between BEopt/EnergyPlus and SEEM ................vi

Table 2. Phase II Overall Status of Pacific Northwest Prioritized Categories ...........................................vii

Table 3. Characteristics for New Construction and Existing Buildings ................................................. 6

Table 4. Significant Discrepancies Identified Between BEopt/EnergyPlus and SEEM ........................... 11

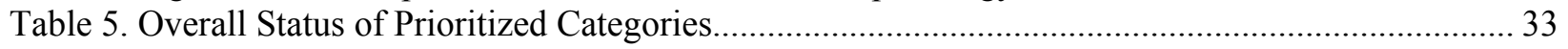

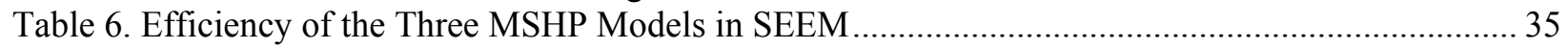

Table 7. Run Descriptors for Diagnostic Buildings Used in the Air Leakage Comparison........................ 48

Table 8. Air Leakage Sources of Discrepancy between BEopt/EnergyPlus and SEEM ........................ 49

Table 9. BEopt/EnergyPlus Air Leakage Modifications for Consistency with SEEM............................51

Table 10. Final Recommendations for Air Leakage Modeling Enhancements .......................................5 57

Table 11. Summary of BEopt Inputs Mapped to SEEM..................................................................... 75

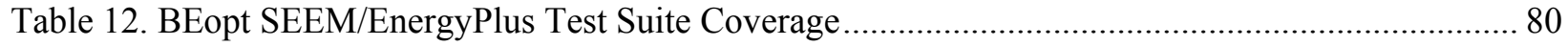

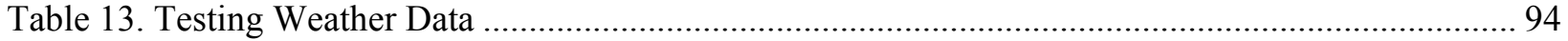




\section{Introduction}

Residential building energy models can be used to estimate the energy savings and cost effectiveness of various retrofit measures, aid in the design of new homes that meet energy targets, and determine the impact of installing more efficient equipment across an entire region. Several simulation engines are available for residential buildings. The goal of this project is to compare two of these tools, EnergyPlus and the Simple Energy and Enthalpy Model (SEEM), to determine the differences in their energy consumption predictions and make modeling enhancements where significant discrepancies are identified. This task is important because verification and validation are crucial software quality control procedures and are important when accuracy is desirable in developing and implementing models (Tabares-Velasco and Griffith 2012). Thus, reducing the uncertainty of energy savings estimates and having a better understanding of simulation engine limitations will result in more robust savings estimates of efficiency measures and regional potential.

SEEM is a building simulation engine developed by Ecotope to model residential single-family buildings and is used in the Northwest. EnergyPlus, the U.S. Department of Energy's flagship simulation engine, is designed to model commercial and residential buildings. Comparisons were performed using the Building Energy Optimization Tool (BEopt), the National Renewable Energy Laboratory's (NREL) residential building simulation and optimization program, which can use a variety of engines. Comparing these two engines within the BEopt framework allows their differences to be quickly identified and thoroughly investigated. This can help quantify the impact of differing modeling algorithms used in the engines, assess the importance of different inputs/assumptions, and identify bugs. 


\section{Approach}

Inspired by American Society of Heating, Refrigerating and Air Conditioning Engineers (ASHRAE) Standard 140 and by NREL's methods to improve the accuracy of residential energy calculations, this study performed comparative testing of the building envelope and mechanical equipment to identify discrepancies in energy results between EnergyPlus and SEEM (Judkoff and Neymark 2006; Polly et al. 2011). BEopt was used to automate the process of running equivalent building models in the two simulation engines. BEopt is a "meta" program that can interface with multiple simulation engines. It also provides an easy-to-use graphical user interface for entering building geometry; option characteristics (wall construction; heating, ventilation, and air conditioning [HVAC] equipment; etc.); and site characteristics, including economic inputs.

BEopt was already configured to run the EnergyPlus simulation engine; however, additional work was required to connect to SEEM as a simulation engine. The BEopt source code was modified to allow BEopt to automatically call the SEEM executable file with the appropriate inputs. Code was written to map all building component specifications from BEopt into SEEM inputs and to process the SEEM output into the BEopt database.

\subsection{Comparison Philosophy}

A comparison philosophy was established to capture all causes of discrepancies that would occur for typical SEEM and BEopt/EnergyPlus users. These discrepancies can be caused by differences in:

- Recommended inputs

- Available options

- Built-in assumptions and values

- Physics models and algorithms

- Coding errors in simulation engines.

The first two causes are related to inputs based on the workarounds from unavailable options (e.g., vaulted ceiling) and the inputs recommended by SEEM (e.g., R-value for wall assemblies). Appendix A (in the "Mapping Notes/Issues" column) shows current BEopt/EnergyPlus technologies that are not available in SEEM. The last three are related to more fundamental differences and, as shown later in this study, can result in significant differences.

\subsection{Mapping}

Mapping is the process of creating equivalent inputs in both SEEM and EnergyPlus for a given BEopt option. This is important to ensure we are comparing the engines as consistently as possible. Figure 1 shows the mapping process for walls. An actual wall assembly was selected in BEopt based on properties of each layer: exterior finish, sheathing, cavity insulation, stud dimensions, and drywall. From there, scripts were used to map this wall to SEEM using an equivalent R-value from the SEEM R-value tables based on the stud spacing, stud dimensions, and cavity insulation R-value. Likewise, this wall assembly is mapped to EnergyPlus by creating a construction object with each layer (exterior finish, sheathing, and equivalent stud/cavity 
material and drywall layers) and their thermophysical properties (thermal conductivity, density, and specific heat), and thickness.

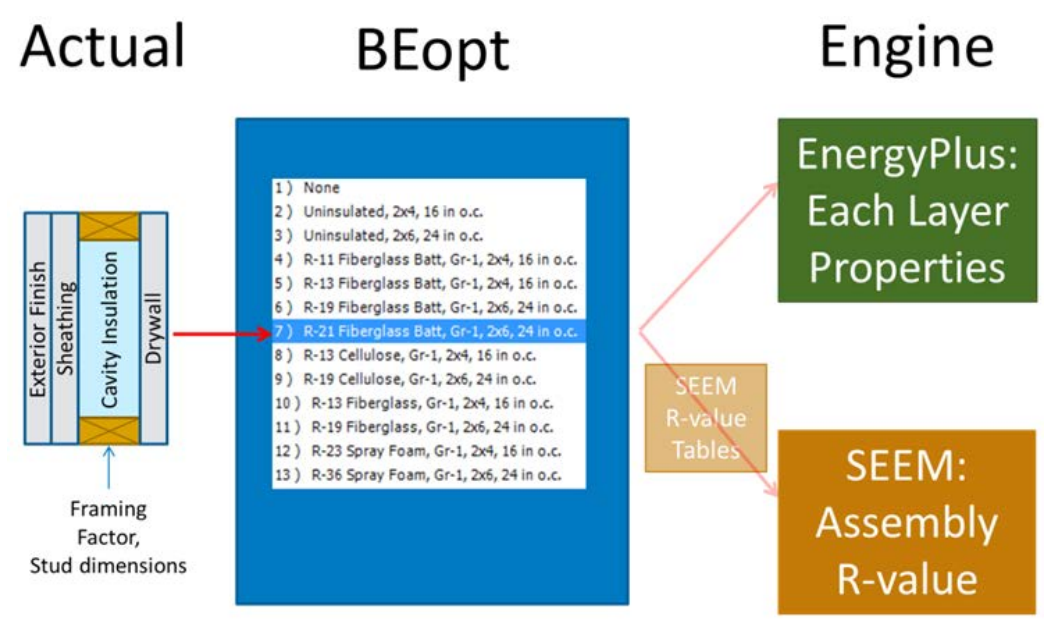

Figure 1. Example of the mapping process for walls

The level of difficulty in mapping the range of building components can vary significantly. Windows, for example, are very straightforward to map and only require passing the same U-value and solar heat gain coefficient to both engines' input files even though SEEM and EnergyPlus have different windows models. Appendix A summarizes which components were mapped, provides some details of the mapping, and shows the technologies that are available in BEopt/EnergyPlus but not in SEEM (e.g., photovoltaics [PV] and solar water heaters).

\subsection{Workflow}

Figure 2(a) shows the typical BEopt workflow when running EnergyPlus. The BEopt options library is a SQLite database that houses all the technologies modeled in BEopt and their properties. Each building, characterized by a set of technologies across various categories, is written to an .xml file. The .xml files are provided to an EPlusInput.py python script, which performs various calculations and logic statements to create the EnergyPlus input file (.idf) specific to the building's description. After the input file is run through the EnergyPlus simulation, the resulting output files are processed by the EPlusOutput.py python script. This script parses the output data and summarizes the results into an Output.xml file, to be processed and stored by BEopt.

A number of modifications were made to this workflow to connect the SEEM simulation engine to BEopt. Figure 2(b) shows the workflow when BEopt and SEEM were used instead. Changes made to the workflow include:

- Modifying the options library to include only technologies based on SEEM's capabilities

- Creating a SEEMInput.py python script to map BEopt inputs to SEEM input files

- Creating a SEEMOutput.py python script to map SEEM annual/hourly outputs to BEopt annual/hourly outputs

- Modifying BEopt to automate the calling of the SEEM simulation engine executable. 


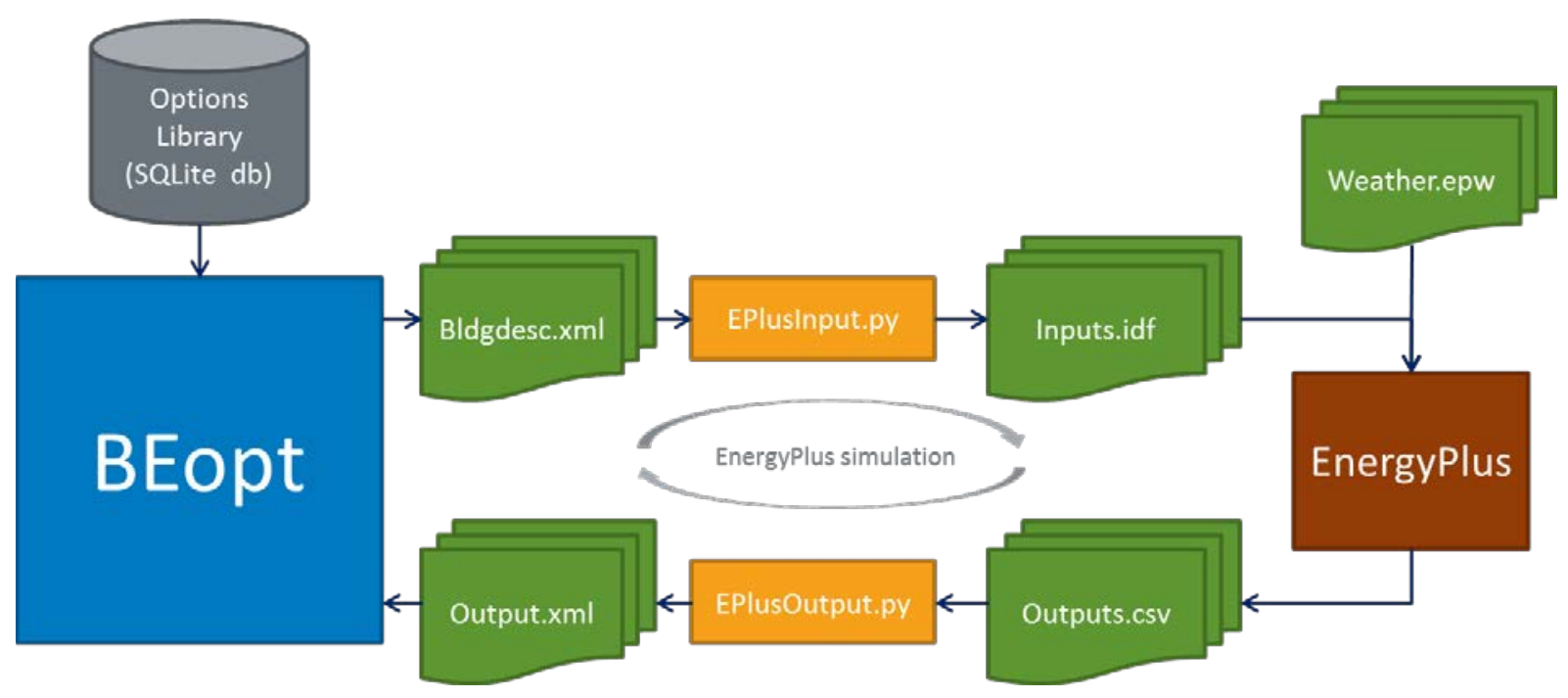

(a)

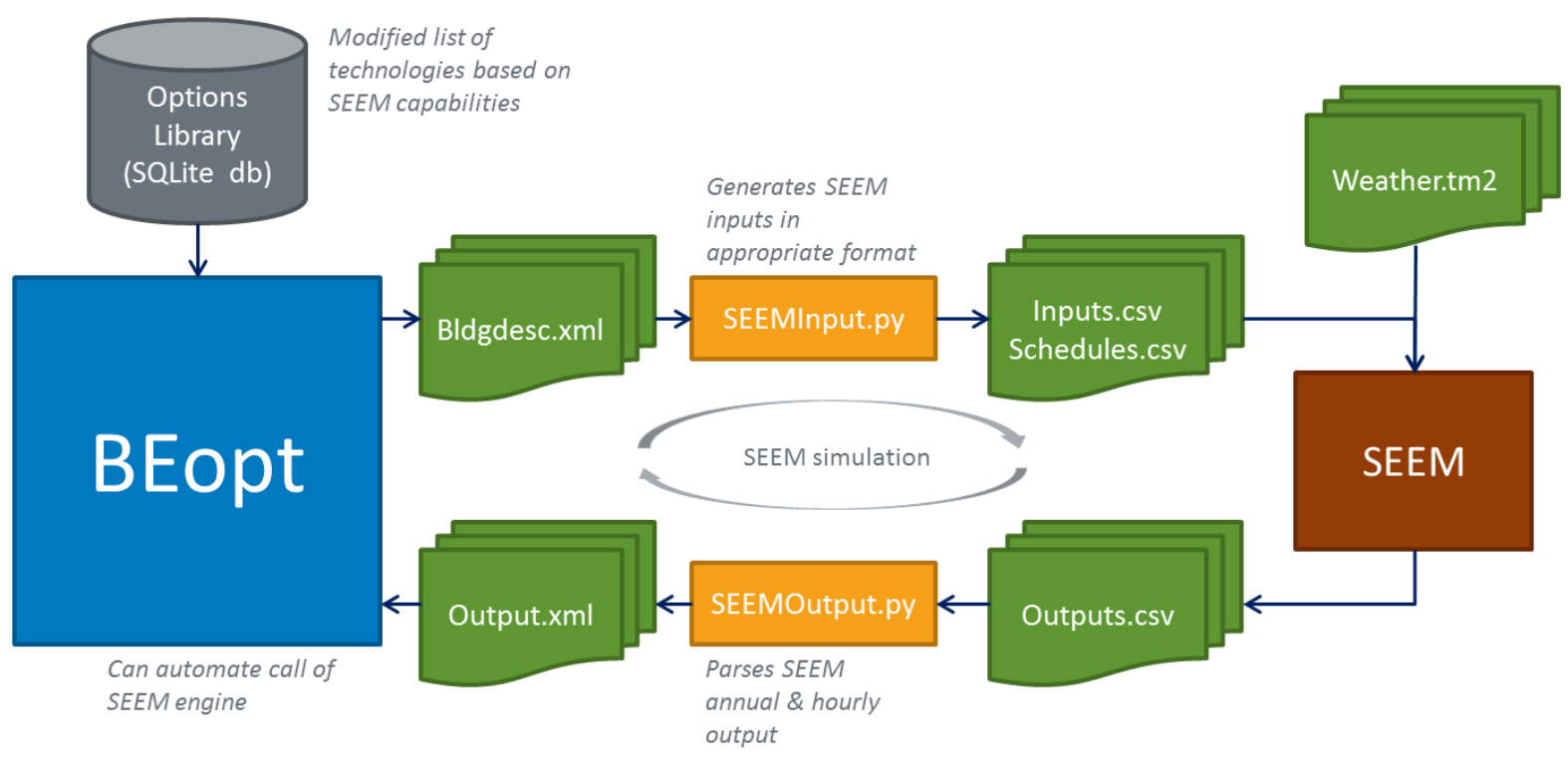

(b)

Figure 2. Workflow for BEopt simulations using (a) EnergyPlus and (b) SEEM

\subsection{BEopt Test Suite}

The BEopt Test Suite is an automated tool that facilitates the comparative simulation results between SEEM and EnergyPlus for tens of thousands of equivalent buildings. It systematically sweeps through all technology categories in BEopt (e.g., walls and air conditioners) and evaluates each option one at a time. Thus, it is essentially a sensitivity study over a large parameter space (Polly et al. 2012). The BEopt Test Suite has been used historically to compare DOE-2.2 against EnergyPlus (Booten et al. 2012). 
For this study, NREL modified the test suite to accommodate prototype buildings, technologies, and climates that are typical to the Northwest. The modified test suite consists of:

- Three building types

○ Diagnostic building

○ New construction building

○ Existing building.

\section{- Two climates}
- Seattle
○ Boise.

\section{- Ten geometries}
○ $1,350 \mathrm{ft}^{2}$, one story, crawlspace, attic
○ $1,350 \mathrm{ft}^{2}$, one story, crawlspace, vaulted ceiling
- $1,350 \mathrm{ft}^{2}$, one story, unheated basement, attic
○ $1,350 \mathrm{ft}^{2}$, one story, unheated basement, vaulted ceiling
- $1,350 \mathrm{ft}^{2}$, one tory, slab, attic
○ $1,350 \mathrm{ft}^{2}$, one story, slab, vaulted ceiling
○ $2,224 \mathrm{ft}^{2}$, two story, crawlspace, attic, garage
○ 2,224 $\mathrm{ft}^{2}$, two story, crawlspace, vaulted ceiling, garage
○ $2,688 \mathrm{ft}^{2}$, one story, heated basement, attic
○ $2,688 \mathrm{ft}^{2}$, one story, heated basement, vaulted ceiling.

The combination of these parameters results in 60 buildings for which every BEopt option ( 500, see Appendix B) was evaluated within the context of each building, one at a time, for a total of roughly 30,000 building simulations in each engine.

Diagnostic building. The diagnostic building is used to isolate the source of a discrepancy between two equivalent buildings in different simulation engines. The idea is to eliminate the effects from all other building components while running a parametric through the options of interest. For example, if windows are being analyzed, all other surfaces in the building are superinsulated, infiltration is minimized, and all internal gains are eliminated so that the only heat transfer gain/loss occurs through windows.

New construction building. The new construction test building (Table 3) has a complete set of options typically found in new homes in the Northwest. These are generally based on the singlefamily detached definitions from the RTF workbook

"ExistingResidentialSingleFamily_SEEMRuns_v05.xlsm”. 
Existing building. The existing test building (Table 3 ) has a complete set of options typically found in existing homes in the Northwest. These are generally based on the single-family detached definitions from the RTF workbook "ExistingResidentialSingleFamily_SEEMRuns_v05.xlsm”.

Table 3. Characteristics for New Construction and Existing Buildings

\begin{tabular}{|c|c|c|}
\hline & New Construction & Existing \\
\hline Walls & $\mathrm{R}-19$ & Uninsulated \\
\hline Attic & R-38, Vented & Uninsulated, Vented \\
\hline Basement Walls & $\mathrm{R}-21$ & Uninsulated \\
\hline Crawlspace Ceiling & R-30, Vented & Uninsulated, Vented \\
\hline Slab & Uninsulated & Uninsulated \\
\hline Window Type & Double Pane, Low-e & Single Pane \\
\hline Window Area & $15 \%$ of Wall Area & $15 \%$ of Wall Area \\
\hline Infiltration & $10 \mathrm{ACH} 50^{\mathrm{a}}$ & $15 \mathrm{ACH} 50$ \\
\hline Appliances & Standard & Old \\
\hline Air Conditioner & SEER $^{\mathrm{b}} 13$ & SEER 10 \\
\hline Furnace & $78 \%$ AFUE $^{\mathrm{c}}$, Gas & $78 \%$ AFUE, Gas \\
\hline Ducts & 7.5\% leakage, R-6 & $30 \%$ leakage, $\mathrm{R}-0$ \\
\hline
\end{tabular}

${ }^{a}$ Air changes per hour at 50 pascals

${ }^{b}$ Seasonal energy efficiency ratio

${ }^{\mathrm{c}}$ Annual fuel utilization efficiency

All new and existing buildings were modeled to follow the Building America House Simulation Protocols (HSP) (Hendron and Engebrecht 2010). After all the models are built, the BEopt Test Suite runs all the simulations and stores the results in a database where differences can be quickly visualized and filtered using NREL's Test Suite Viewer, as shown in Figure 3. Items 1 and 2 in the Test Suite Viewer contain information on the analyzed simulation engines (in this case EnergyPlus and SEEM) and the date when the test suite was performed. The vertical axis shows the energy differences between SEEM and EnergyPlus; the categories and category options run along the horizontal axis. All the energy use is disaggregated by end use (heating energy, cooling energy, ventilation fan, etc.). Users can also filter down the results as it is done in Section 3.3 by:

- Building type

- Climate/geometry 
- BEopt category (all categories or zoom in to a specific category; e.g., heating set point)

- Data (energy use, loads not met, HVAC capacities)

- Graph type (bar or line graphs plotting differences between engines or actual values).

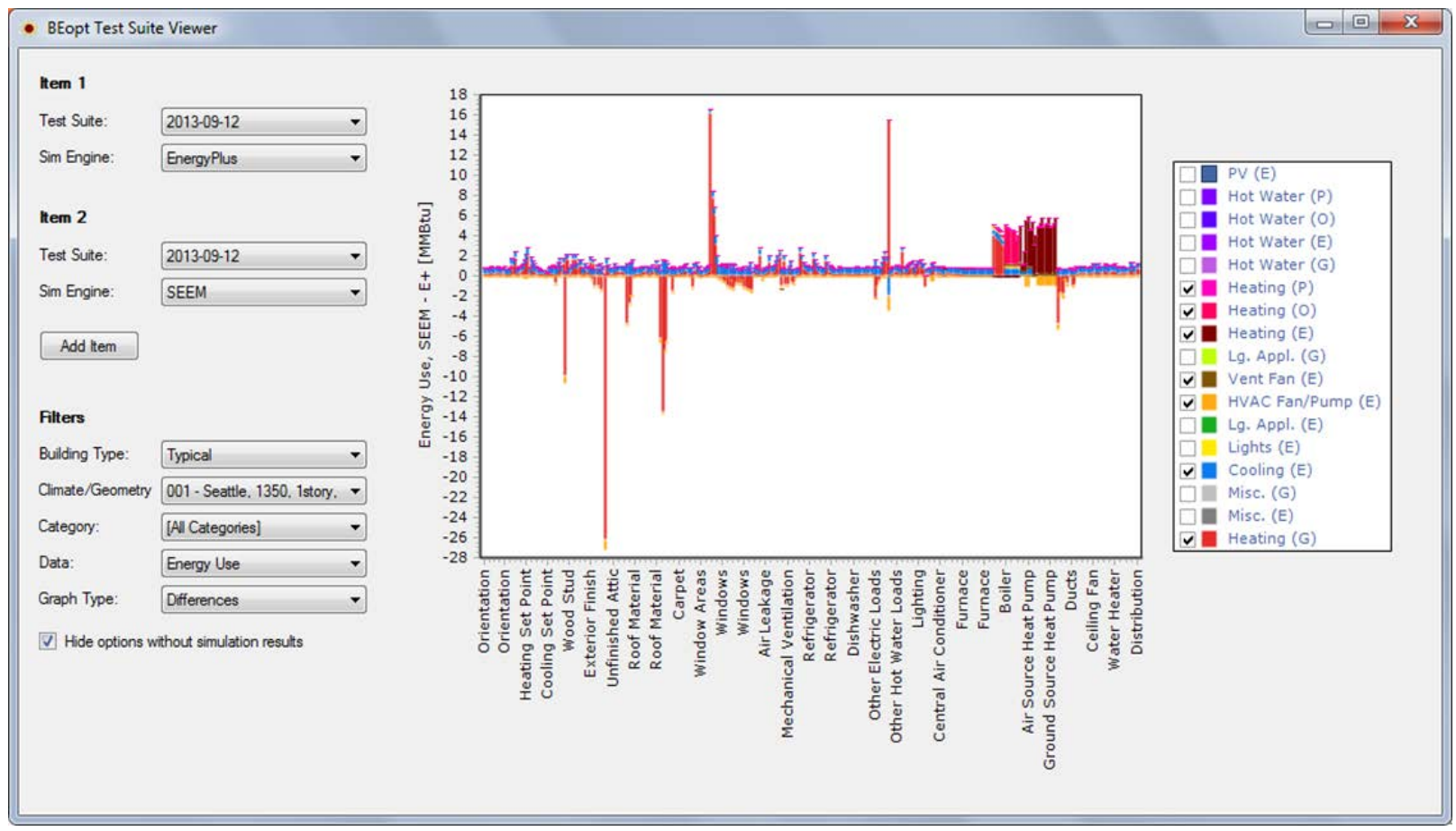

Figure 3. BEopt Test Suite Viewer

\subsection{Diagnostic Tools}

The BEopt Test Suite is a powerful screening tool that quickly identifies discrepancies between simulation engines from tens of thousands of energy predictions. However, although it is very useful for detecting discrepancies, it rarely contains enough useful information at this level to enable us to discern the cause of the discrepancy. Therefore, the NREL team has developed several diagnostic tools to help pinpoint the cause of the discrepancies or to investigate cause and effect.

- Diagnostic Weather Data: detailed quasi-steady-state comparisons between programs. This is done by keeping weather parameters such as air temperature and wind speed constant for two-week periods. This tool then allows the testing of building component models while keeping weather parameters constant, making it easier to identify differences between engines and to understand their behavior.

- Hourly Output: rapid access to hourly data through DView, a visualization tool that allows plotting of multiple variables for the two engines at the same time/graph.

Appendix $\mathrm{C}$ includes more information about these diagnostic capabilities. 


\subsection{Collaboration With Ecotope}

NREL and Ecotope worked very closely from October through December 2013 (Phase I) and March through September 2015 (Phase II) by conducting weekly meetings and maintaining a constant line of communication between the teams. Ecotope's role was to provide technical support, critical review of work related to the use of SEEM in this study, and fixes to some of the identified discrepancies. SEEM does not have a comprehensive reference guide, so Ecotope's technical support for questions related to inputs, assumptions, and modeling limitations in SEEM was extremely valuable. 


\section{Phase I}

Phase I targets a broad look across all building components in order to identify significant discrepancies between the EnergyPlus and SEEM simulation engines. Discrepancies between simulation engines occur across nearly all technologies because of the inherent differences in modeling algorithms, inputs, and assumptions. The results described here focus on the subset of technologies with the most significant differences.

\subsection{Versions of EnergyPlus and SEEM Used}

Initial results for Phase I are based on SEEM94, the most recent version available at this time. As discrepancies were identified and subsequently fixed by Ecotope, a couple of interim versions were shared with NREL. The most recent, labeled SEEM95, has:

- $\quad$ Bug fixes as described in Section 3.3.1

- Hourly output variables that were requested by NREL to investigate discrepancies

- New input variables to investigate the discrepancies with window models (inner and outer thermal emissivity).

EnergyPlus results are based on version 8.1.

\subsection{Overall SEEM Versus EnergyPlus Comparison Scatter Plots}

Results from the BEopt Test Suite produced thousands of equivalent buildings simulated in SEEM and EnergyPlus. Figure 4 shows heating energy use between EnergyPlus (x-axis) and SEEM (y-axis). Figure 4(a) shows results for the new construction type in Seattle before fixes. Figure 4(b) shows results for the new construction type after bug fixes made to the SEEM engine. Each dot represents a single building with energy consumption calculated by both SEEM and EnergyPlus. The dark sloped line indicates results with perfect agreement; the two lighter lines to each side represent the $\pm 25 \%$ range for purposes of visualizing the magnitude of the discrepancies. The agreement between engines is significantly closer after SEEM fixes, because the number of buildings that fall outside the $\pm 25 \%$ range is reduced significantly.

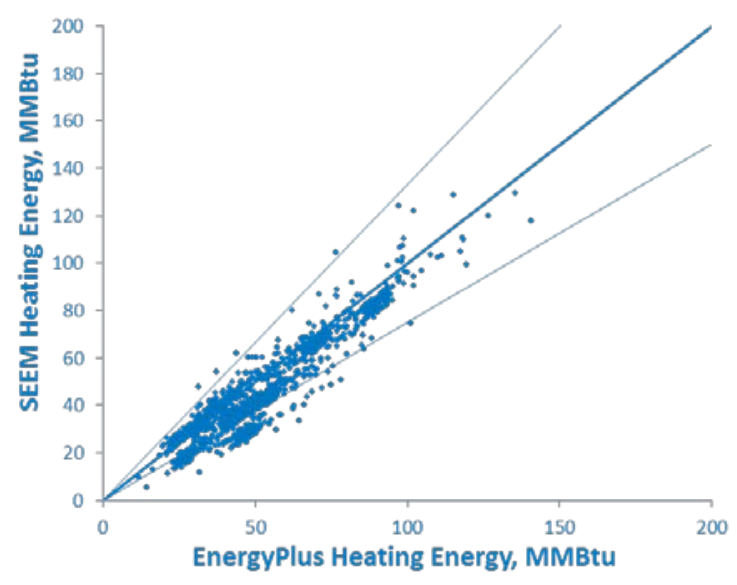

(a)

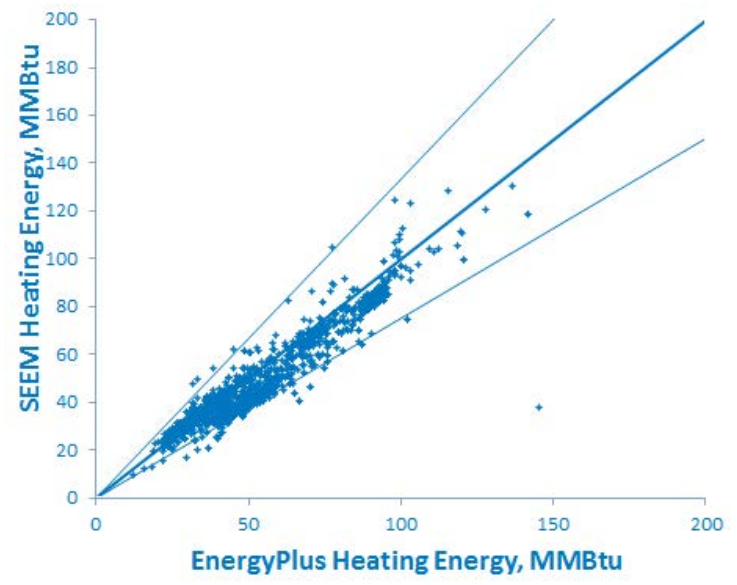

(b)

Figure 4. Test Suite results for new construction homes in Seattle (a) before and (b) after fixes 
Figure 5(a) and Figure 5(b) show the same comparison for existing buildings. Although the discrepancies between SEEM and EnergyPlus decreased after SEEM fixes, numerous buildings still fall outside the $\pm 25 \%$ range. In general, SEEM shows significantly less heating energy consumption for these buildings than EnergyPlus. Additional work is required to identify the cause of, and propose a solution for, these remaining discrepancies.

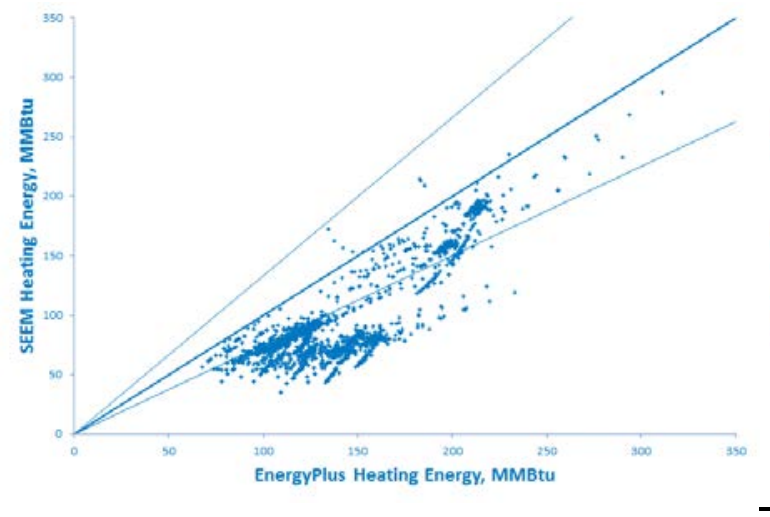

(a)

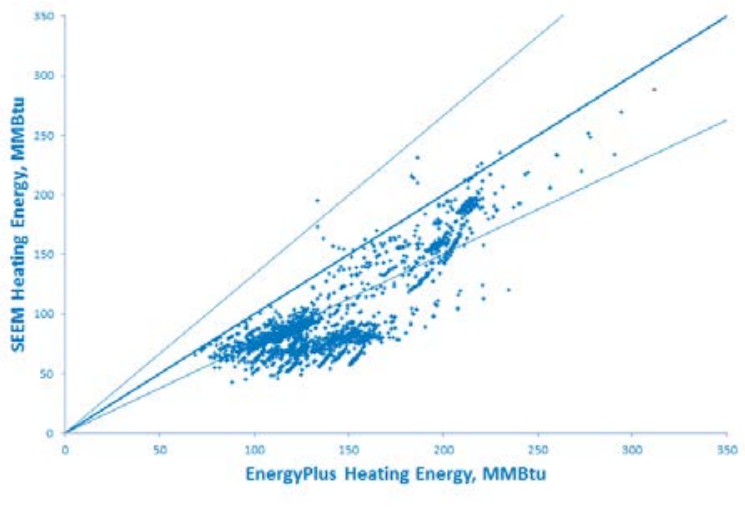

(b)

Figure 5. Test Suite results for existing homes in Seattle (a) before and (b) after fixes

\subsection{Identified Discrepancies Between SEEM and EnergyPlus}

Figure 4 and Figure 5 are useful as high-level snapshots of the differences between SEEM and EnergyPlus. However, they are less useful for diagnosing the root cause of a given discrepancy. Instead, the BEopt Test Suite visualization capabilities can be used to slice the data in various ways to isolate discrepancies (see Table 4). These discrepancies generally affect the results of new and existing buildings; however, they are more easily observed when viewed in the context of the diagnostic building, which isolates building components from the rest of the building. Thus, most of the BEopt Test Suite results to follow demonstrate discrepancies in the diagnostic building.

Table 4 shows the statuses of the discrepancies, which have been classified as:

- Three discrepancies resolved. The NREL and Ecotope teams worked together to identify and fix errors in SEEM.

- Seven discrepancies partially investigated. The NREL and Ecotope teams initially studied these discrepancies, but these require more work to determine the appropriate resolution.

- Ten discrepancies not yet investigated. These discrepancies have not been analyzed, but their magnitude makes them important to analyze. 
Table 4. Significant Discrepancies Identified Between BEopt/EnergyPlus and SEEM

\begin{tabular}{|c|c|c|c|c|}
\hline Category & Option(s) & Discrepancy & Magnitude $^{3}$ & Status \\
\hline Crawlspace & Unvented & No sensitivity in SEEM & +++ & \multirow{3}{*}{ Fixed } \\
\hline Unheated Basement & All & No sensitivity in SEEM & +++ & \\
\hline Slab & Whole slab insulation & Little sensitivity in SEEM & ++ & \\
\hline Mini-Split Heat Pumps & All & Higher energy use in SEEM & +++ & \multirow{7}{*}{ Partially investigated } \\
\hline Heated Basement & All & Higher energy use in SEEM & +++ & \\
\hline Vaulted Ceiling & All & Different trends & ++ & \\
\hline Ducts & All & $\begin{array}{l}\text { SEEM does not run for some duct } \\
\text { configurations }\end{array}$ & ++ & \\
\hline Windows & All & Higher energy use in SEEM & ++ & \\
\hline Roof Material & Low emissivity & Higher energy use in SEEM & + & \\
\hline Mechanical Ventilation & All & Different trends & + & \\
\hline Attic & Ceiling insulation & Lower energy use in SEEM & +++ & \multirow{10}{*}{ Not yet investigated } \\
\hline Walls & Low insulation & Lower energy use in SEEM & +++ & \\
\hline Crawlspace & Wall insulation & Lower energy use in SEEM & ++ & \\
\hline Unheated Basement & Wall insulation & Lower energy use in SEEM & ++ & \\
\hline Slab & Perimeter insulation & Higher energy use in SEEM & ++ & \\
\hline Air Leakage & All & Lower energy use in SEEM & ++ & \\
\hline Interior Shading & All & Different trends & ++ & \\
\hline Attic & Roof insulation & Different trends/energy use & ++ & \\
\hline Internal gains & All & Higher energy use in SEEM & + & \\
\hline Floor mass & All & Higher energy use in SEEM & + & \\
\hline
\end{tabular}

\footnotetext{
${ }^{3}$ Discrepancy magnitudes vary depending on weather/building configuration from largest $(+++)$ to smallest discrepancy $(+)$. Even the smallest discrepancies listed here are considered important; numerous discrepancies considered less significant are not included in this table.
} 


\subsubsection{Discrepancies Resolved}

Table 4 shows three discrepancies related to building foundations (unvented crawlspaces, unheated basements, and whole slab insulation) that were discussed with Ecotope and fixed in a SEEM95 internal version. For each discrepancy discussed in the following sections, two sets of charts are displayed: results before any SEEM fixes and results after the fixes.

\subsubsection{Crawlspace: Unvented}

Figure 6 and Figure 7 show the results for the diagnostic building focusing on crawlspaces. The $\mathrm{y}$-axis displays energy use (MMBtu) and the $\mathrm{x}$-axis enumerates the insulation and venting strategies analyzed. Initial results indicated that SEEM predicted nearly zero heating energy use for unvented crawlspaces. Discussions with Ecotope identified this as a bug in the SEEM engine code where any time the ventilation rate in the crawlspace was lower than $2 \mathrm{ACH}$, some of the floor leakage distribution parameters were incorrectly initialized. Figure 7 shows the results after the bug fix with improved trends. Remaining discrepancies for uninsulated crawlspaces will be discussed in Section 3.3.3.3.

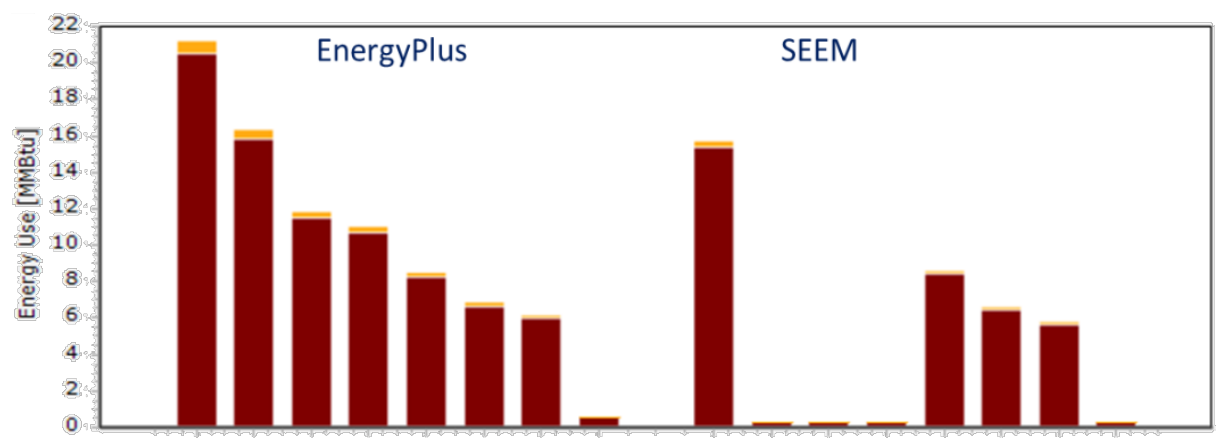

Figure 6. Before fix: Crawlspace results for diagnostic building

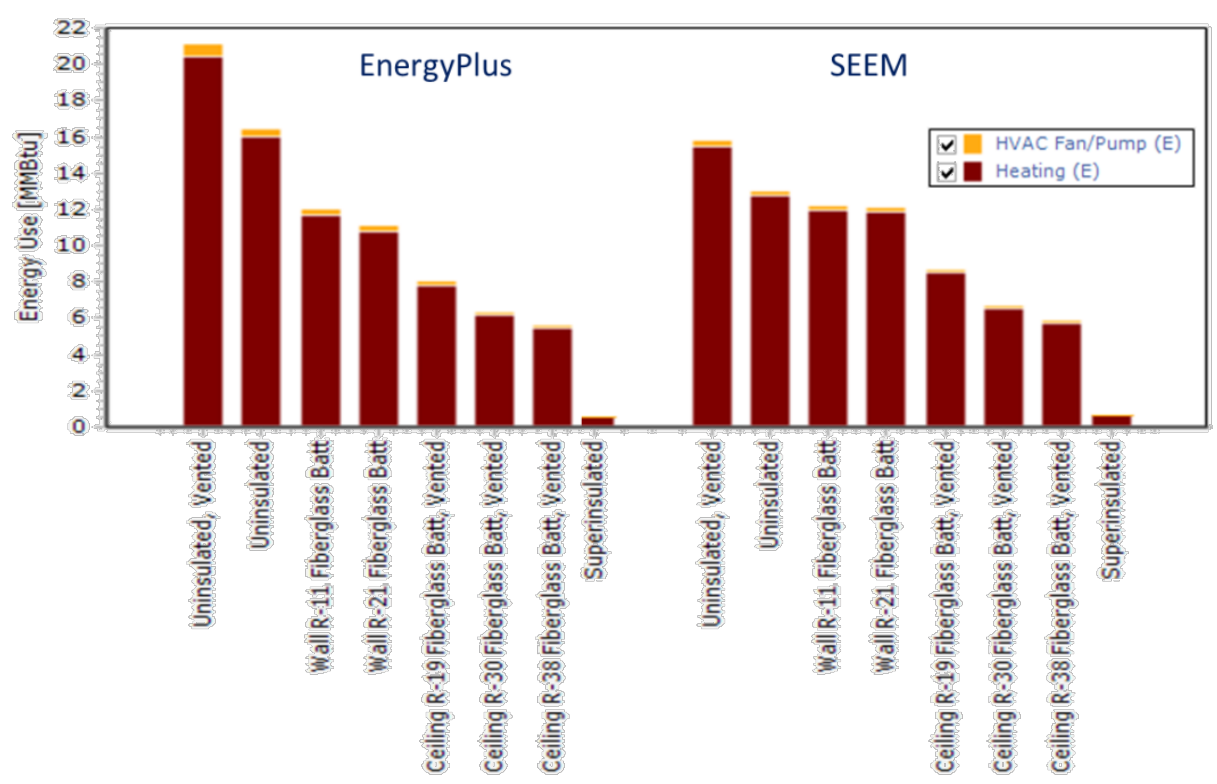

Figure 7. After fix: Crawlspace results for diagnostic building 


\subsubsection{Unheated Basement}

Figure 8 and Figure 9 show the results for the diagnostic building focusing on unheated basements. Unheated basements are modeled in SEEM in an equivalent fashion to unvented crawlspaces (i.e., low ACH); thus, the initial results from SEEM indicated a similar problem. The SEEM fix for the crawlspace also fixed the problems for unheated basements (Figure 9). Remaining discrepancies for uninsulated, unheated basements will be discussed in Section 3.3.3.4.

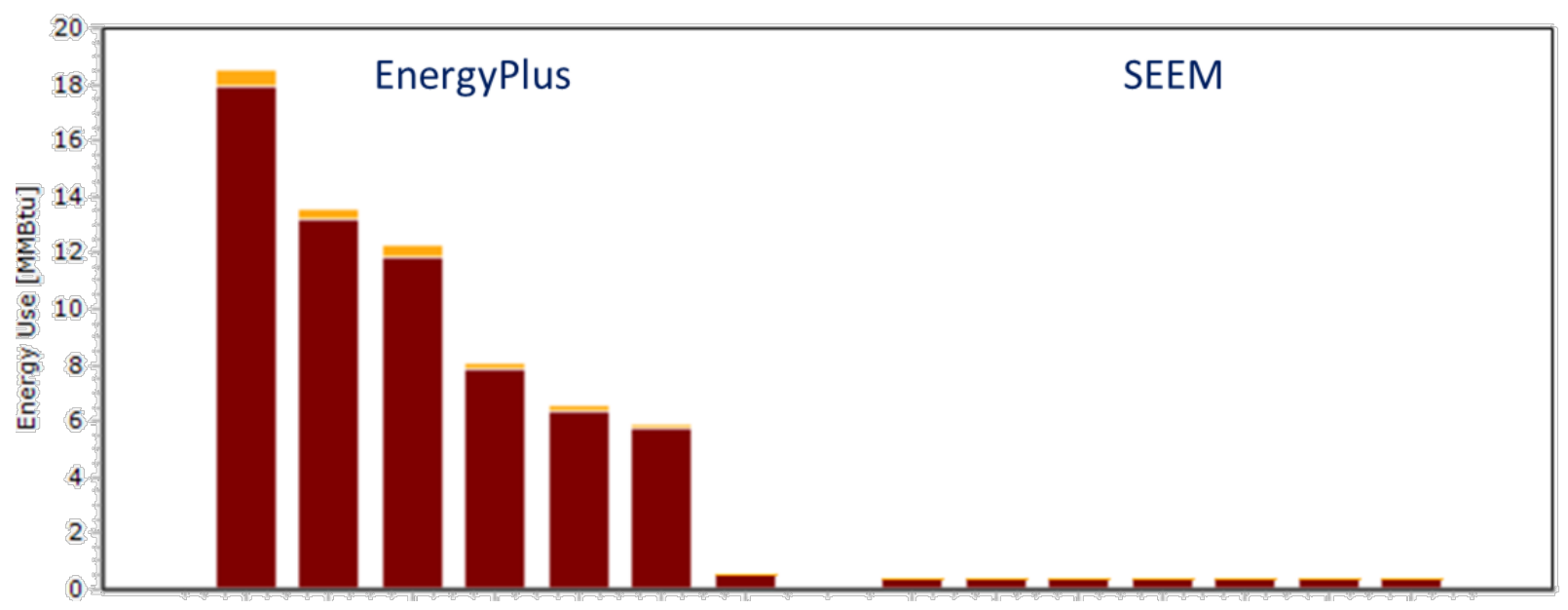

Figure 8. Before fix: Unheated basement results for diagnostic building

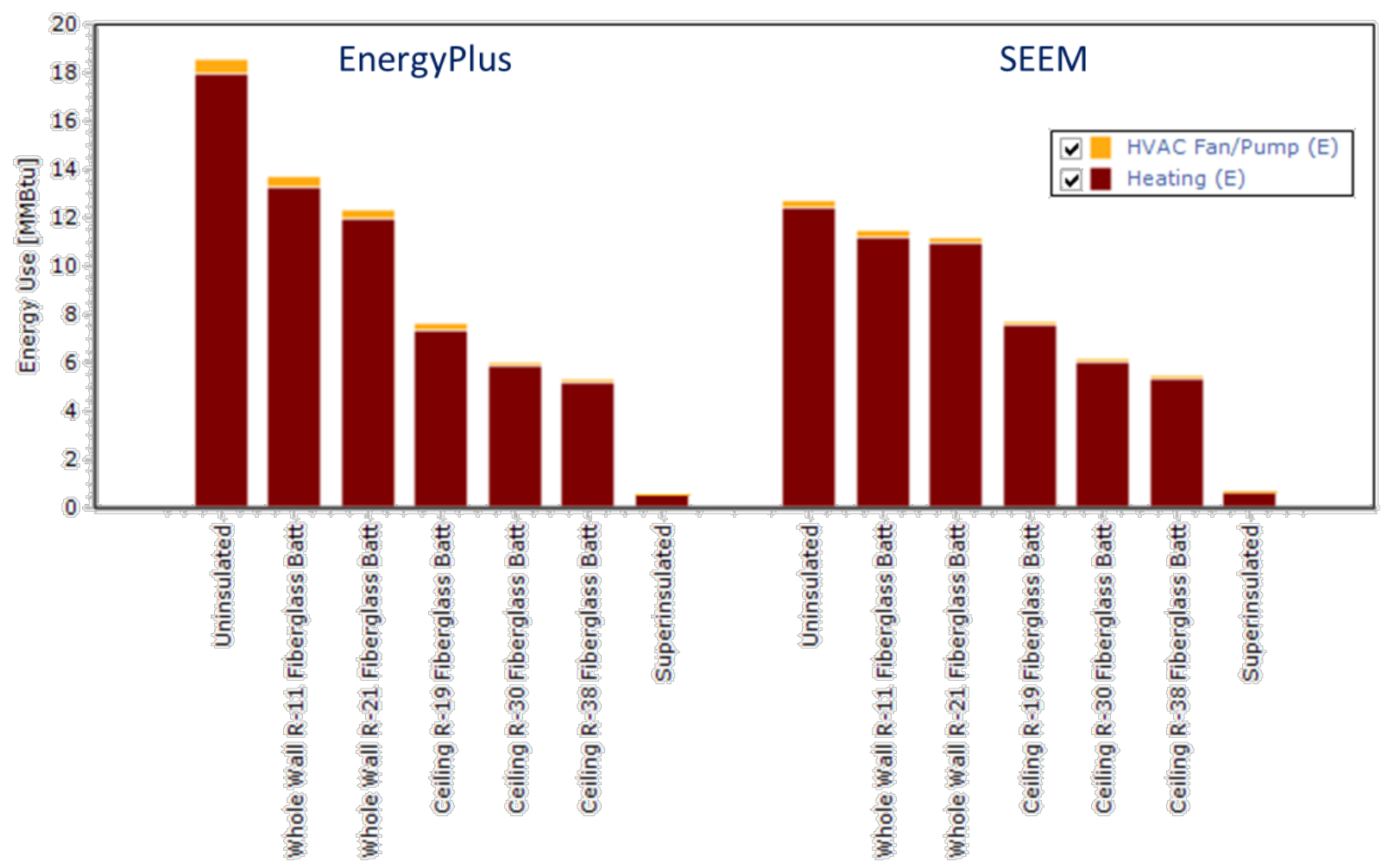

Figure 9. After fix: Unheated basement results for diagnostic building 


\subsubsection{Slab: Whole Slab Insulation}

The third fixed discrepancy was for slab-on-grade foundations (see Figure 10 and Figure 11). Initial results from SEEM indicated that the heat losses through the slab were nearly independent of the slab insulation level, in contrast to EnergyPlus. Discussion with Ecotope revealed a bug in the SEEM calculation for heat loss to the ground that relies on the relationship of perimeter to slab area. For uncommonly large values of perimeter and/or area, the relationship did not work well. Thus, SEEM had previously set a lower limit to the slab heat loss rate. Ecotope addressed this issue by removing the lower limit; the improved results in Figure 11 show that SEEM now follows the same trend as EnergyPlus. Remaining discrepancies for slab perimeter insulation will be discussed in Section 3.3.3.5.

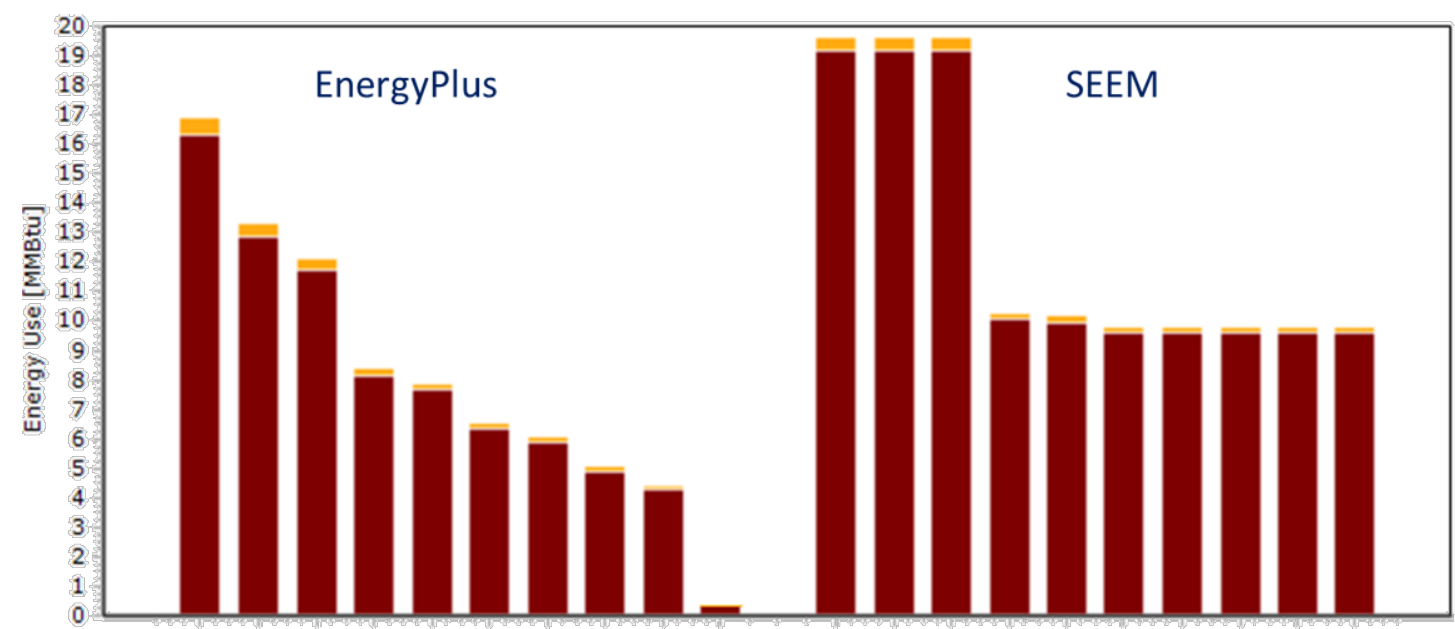

Figure 10. Before fix: Slab results for diagnostic building

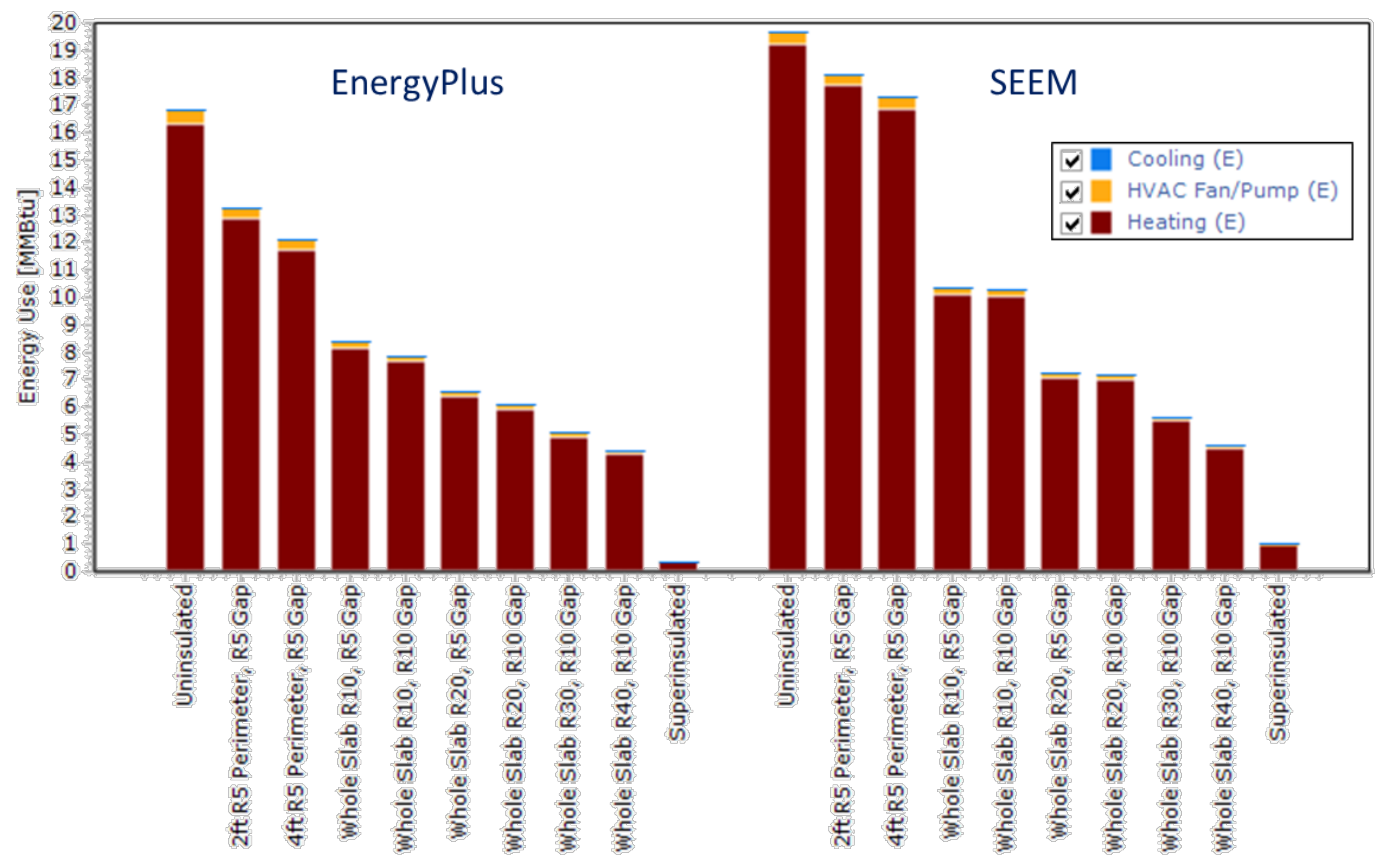

Figure 11. After fix: Slab results for diagnostic building 


\subsubsection{Discrepancies Partially Investigated}

The root causes of the following eight discrepancies have been partially investigated, but more work is needed to determine the appropriate resolution.

\subsubsection{Mini-Split Heat Pumps}

Figure 12 shows the difference in energy consumption for mini-split heat pumps (MSHPs) in a diagnostic building. (In early testing, the MSHPs caused significant discrepancies because they tried to heat and cool different fractions of the conditioned space. These discrepancies have since been resolved and are reflected in the figure.) There are some remaining differences in the models in terms of the exact performance maps used, $C_{D}$ factors, and other specific equipment parameters. However, the remaining energy consumption discrepancies are much larger than the modeling differences would suggest.

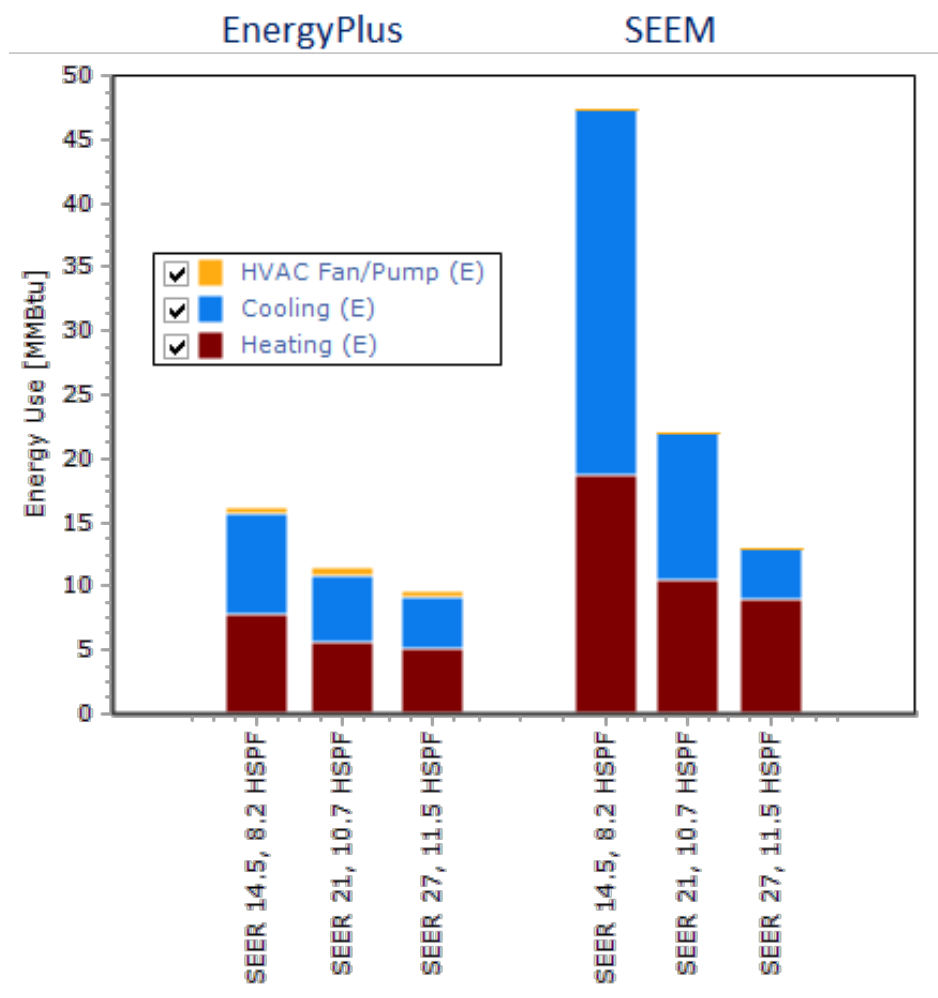

Figure 12. MSHP results in diagnostic building

\subsubsection{Heated Basement}

Figure 13 shows the results for the diagnostic building with heated basement options. Across all insulation levels, SEEM results in higher foundation heat losses. These discrepancies are not trivial and have been partially investigated; there are potential issues with the R-value used in SEEM from the worksheet "ExistingResidentialSingleFamily_SEEMRuns_v05.xlsm", as discussed with Ecotope. Also, different ground-coupling models are being used in the two simulation engines. Although the SEEM model is based on ISO 13370-1998 (ISO 1998), BEopt/EnergyPlus uses the Winkelmann model originally developed for DOE-2 (Winkelmann 2002). 


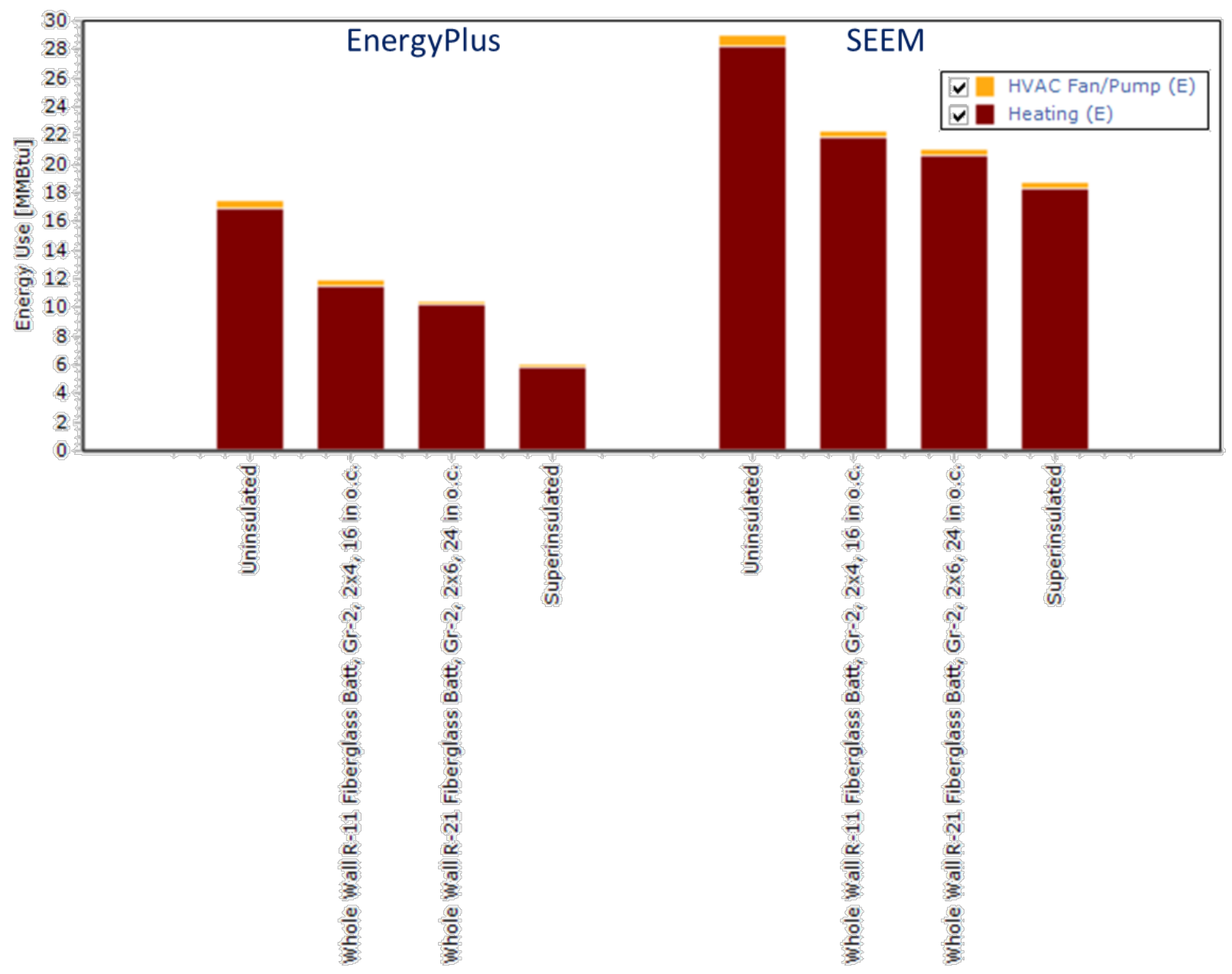

Figure 13. Heated basement results in diagnostic building

\subsubsection{Vaulted Ceiling}

Figure 14 shows the results for a diagnostic building with a vaulted ceiling and Figure 15 shows the results for a new construction building with a vaulted ceiling. SEEM does not have a model for vaulted ceilings; rather, the recommended workaround is to use an attic with low ventilation. Figure 14 shows that in the diagnostic building EnergyPlus and SEEM following the same trend for the three analyzed insulation levels: R-19, R-30, and R-38. For the new construction building (Figure 15), the trend in SEEM reverses compared to EnergyPlus and conventional wisdom: the heating energy use decreases as the vaulted ceiling insulation level increases. Ecotope confirmed that this unexpected behavior was caused by a problem with its infiltration model for the workaround approach to modeling vaulted ceilings. The behavior is not seen in the diagnostic building for which there is no infiltration. 


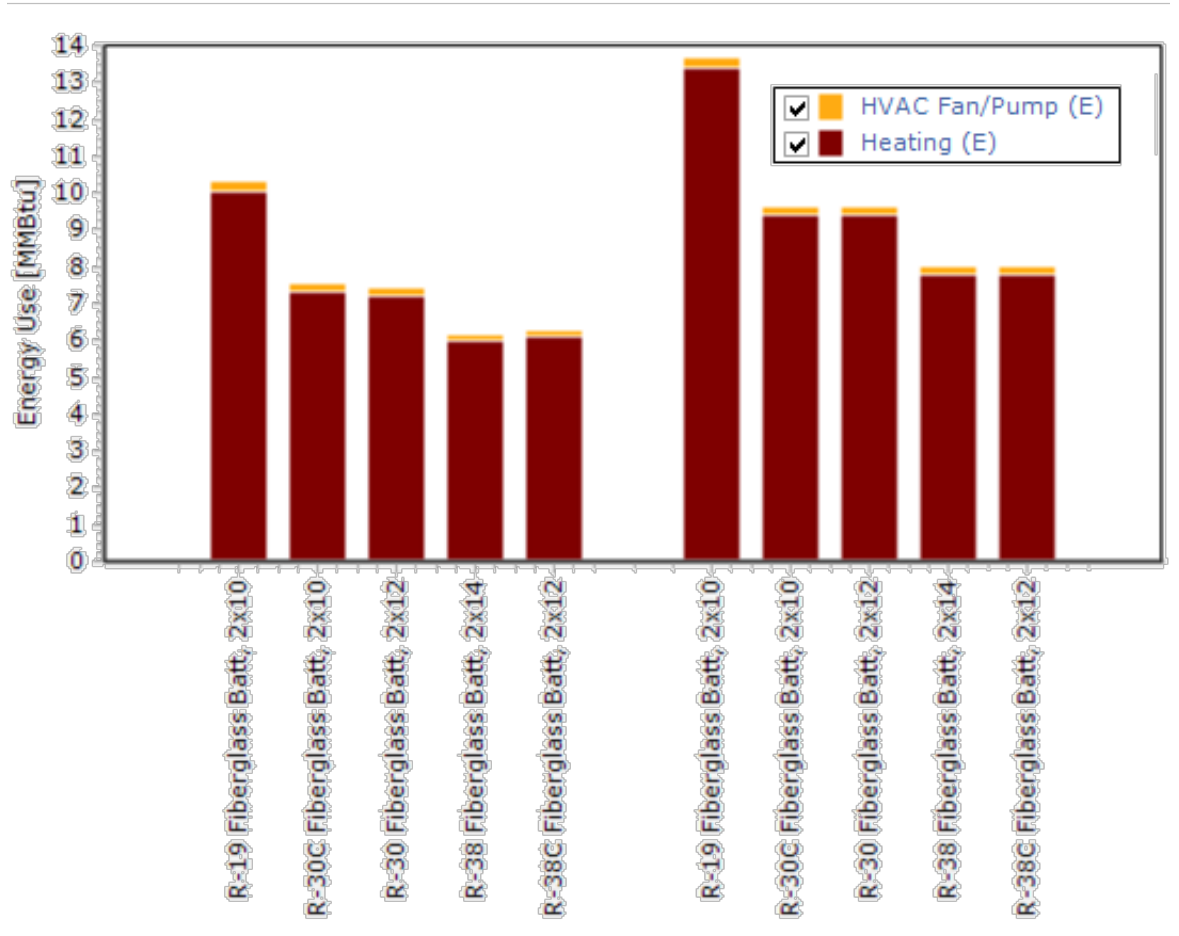

Figure 14. Vaulted ceiling results in diagnostic building

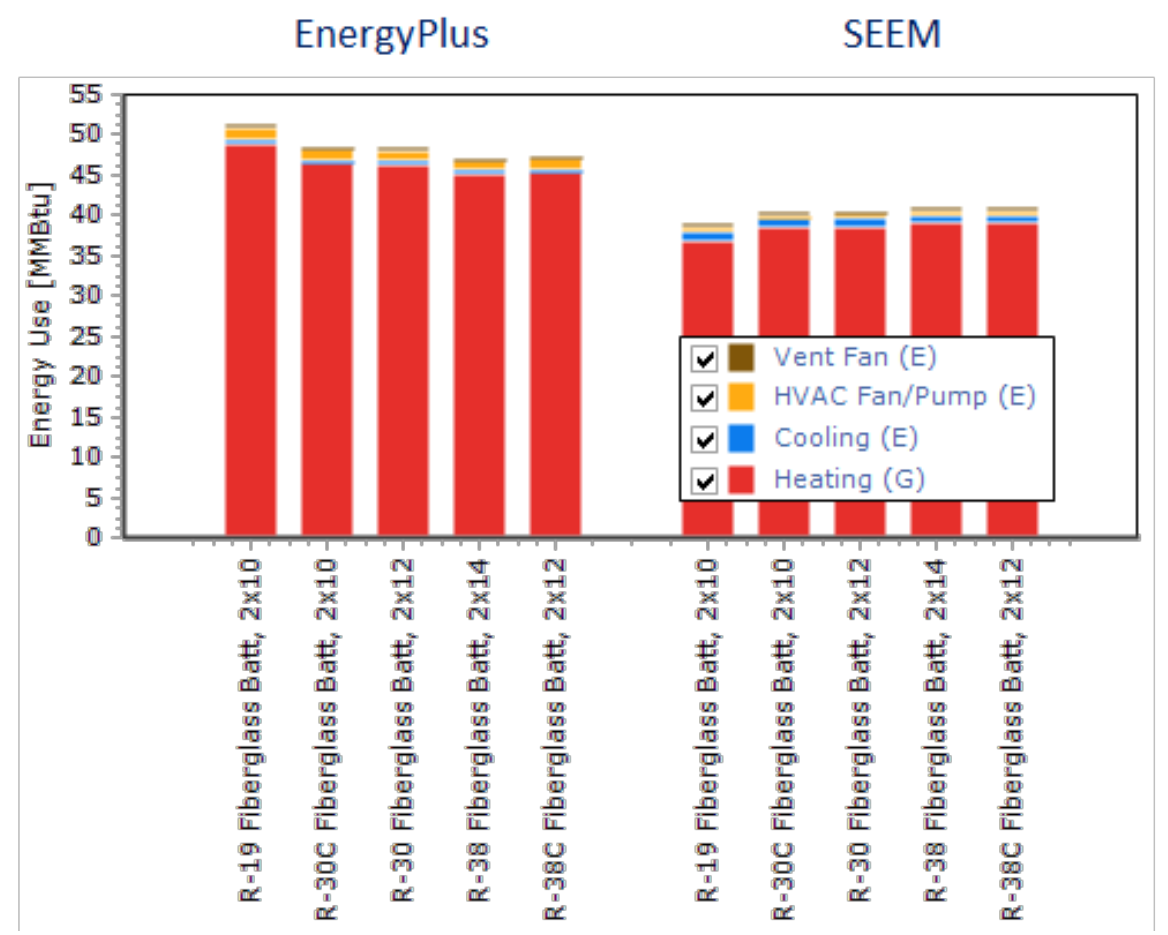

Figure 15. Vaulted ceiling results in new construction building 


\subsubsection{Ducts in Unvented Spaces}

Figure 16 shows results for cases where ducts are located in a vented crawlspace in a new construction building; Figure 17 shows results for cases where ducts are located in an unvented crawlspace in a diagnostic building. The building type changes from new construction to diagnostic; however, the key difference is the vented versus unvented crawlspace. Different buildings are shown only because duct options are always evaluated in a vented crawlspace for the new construction building and an unvented crawlspace for the diagnostic building. In cases where the ducts are located in an unvented unconditioned space, a potential mass balance issue may prevent SEEM from running successfully. Unconditioned spaces in SEEM use a single fixed $\mathrm{ACH}$ value for the whole year as opposed to the more detailed infiltration model used for the conditioned space. In cases where there are ducts with leakage in a space with a low annual $\mathrm{ACH}$ value specified (such as unvented crawlspaces and unconditioned basements), the interaction between the duct leakage and infiltration may lead to an error in the mass balance in the space, which prevents SEEM from running. This is due to a larger volume of air entering the space (caused by duct leakage) than what leaves through infiltration. Ecotope has confirmed that this is a known issue with SEEM.

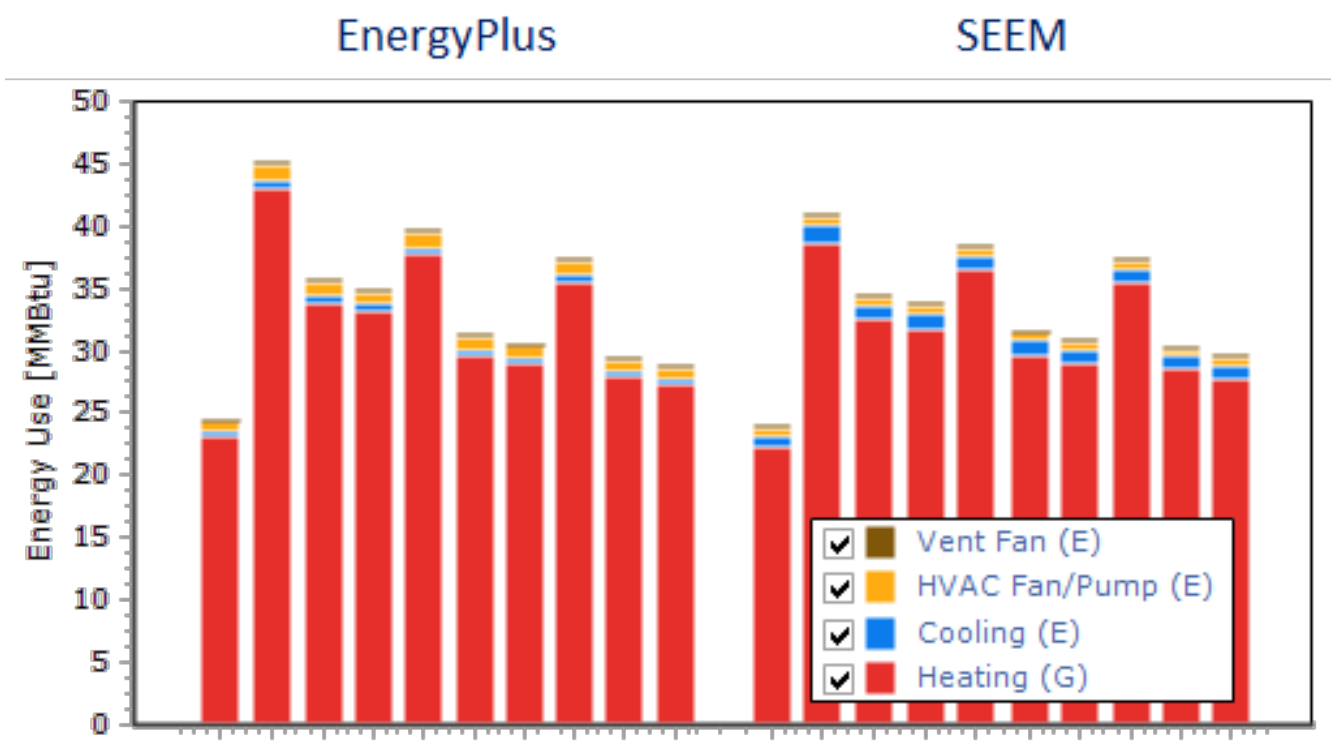

Figure 16. Duct results in new construction building with a vented crawlspace 


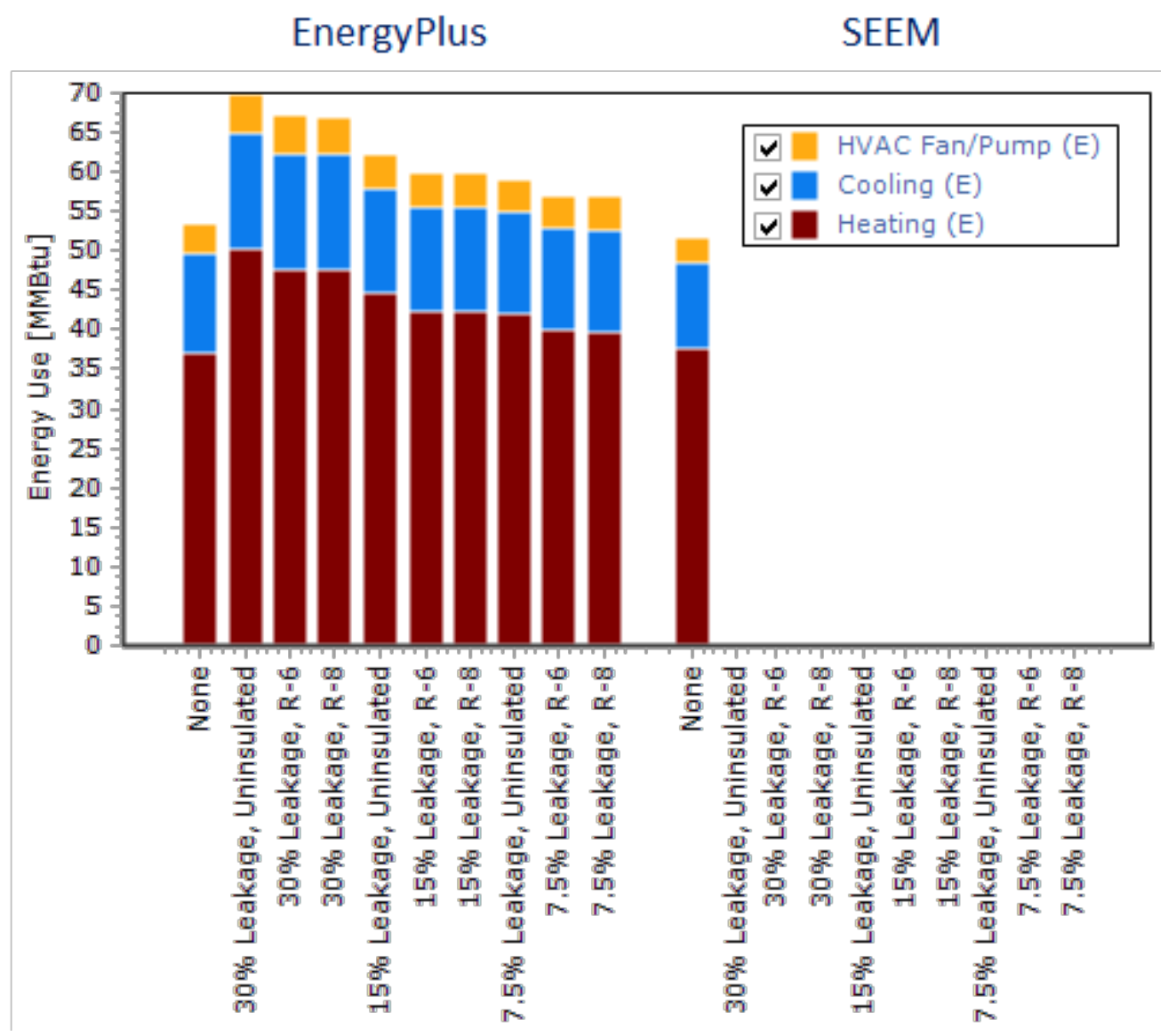

Figure 17. Duct results in diagnostic building with an unvented crawlspace

\subsubsection{Windows}

Figure 18 shows the results for a diagnostic building across the window options. The largest differences between SEEM and EnergyPlus occur for single-pane and double-plane clear windows with low U-values. NREL and Ecotope investigated these discrepancies in great detail and uncovered several modeling differences between SEEM and EnergyPlus for window heat transfer. The complexity of these models precludes a definitive conclusion at this time. However, reasons for the discrepancies include: (1) differences in convection algorithms; and (2) differences in radiative exchange between the sky, walls, and windows' inner and outer surfaces. 


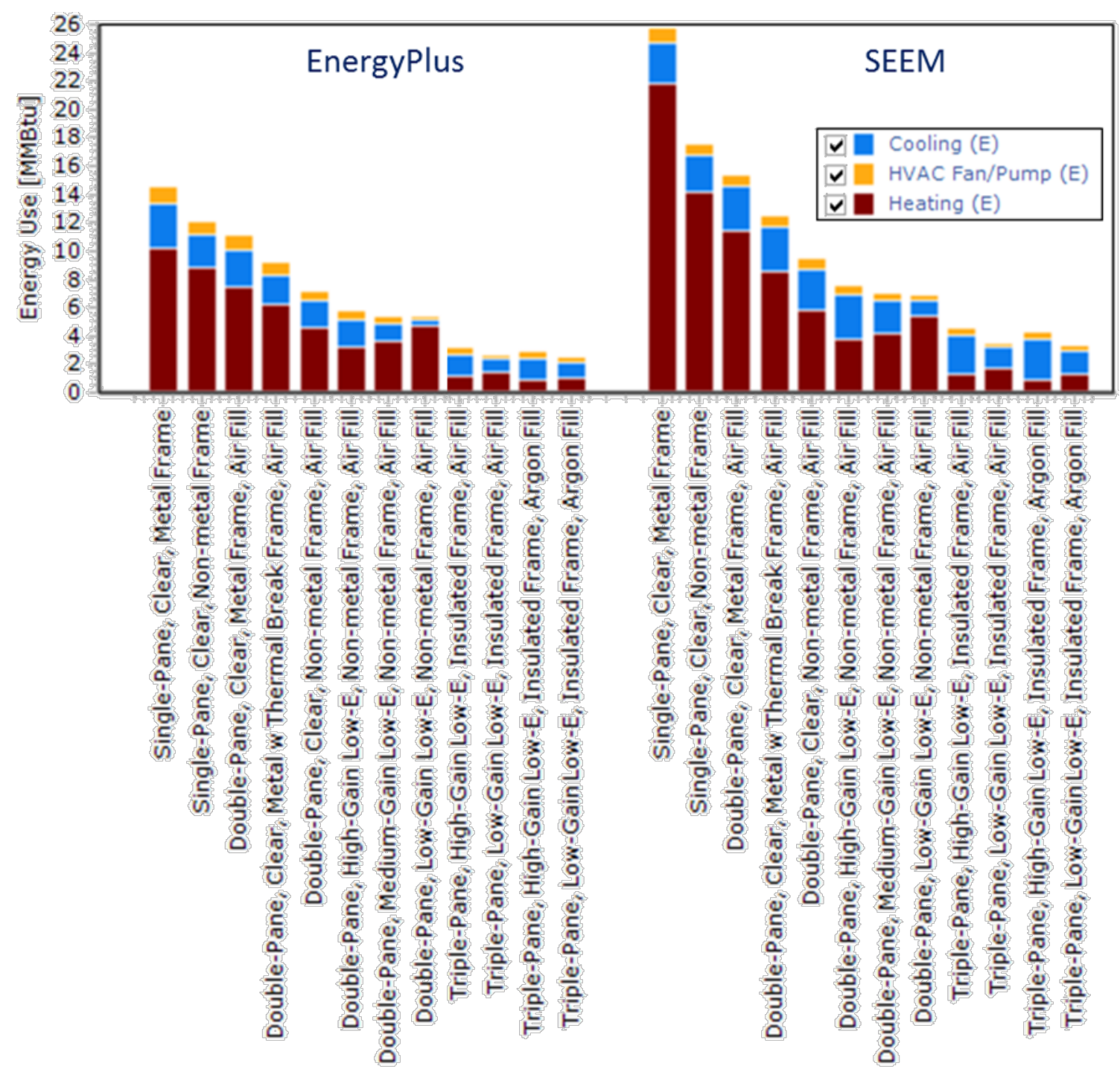

Figure 18. Window results in diagnostic building

\subsubsection{Roof Material}

Figure 19 shows the results for EnergyPlus and SEEM for roof material options in a diagnostic building. Although both engines follow the same trend, the differences are exacerbated for roofs with a lower emissivity. This is because SEEM does not have an input for surface emissivity and for roofs this value is hardcoded to 0.9; it is an input variable in EnergyPlus. These differences are less significant than other issues considered in this report, but it is another source of discrepancy, especially when dealing with roof emissivity values lower than 0.9. 


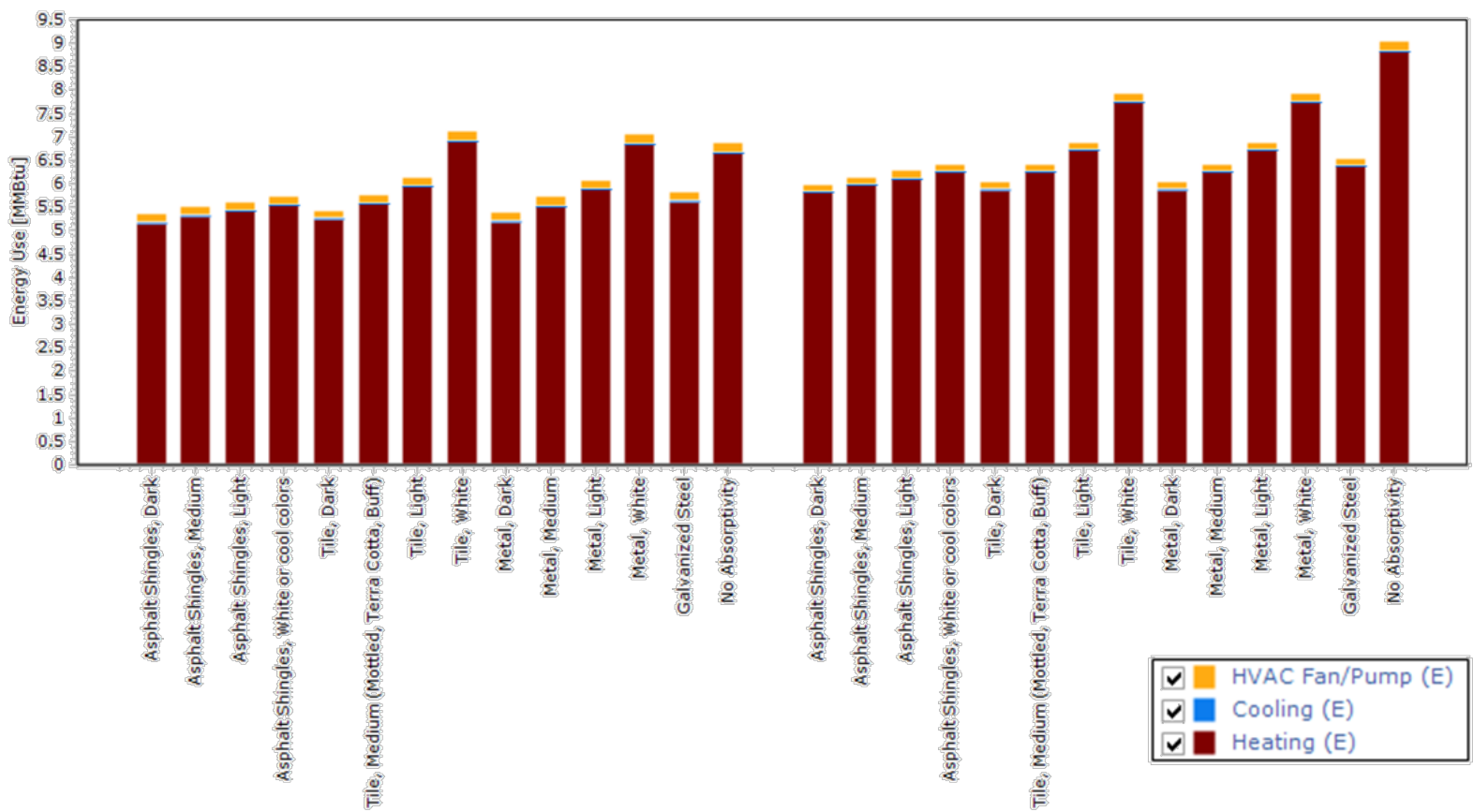

Figure 19. Roof material results in diagnostic building

\subsubsection{Mechanical Ventilation}

Figure 20 shows the results for mechanical ventilation systems in a new construction building. In this case, there is a different trend between the engines when changing from exhaust ventilation to supply ventilation, with energy consumption decreasing in EnergyPlus and increasing in SEEM. This behavior was determined to occur only in new construction buildings and is likely tied to differences in how airflow interactions (i.e., mechanical ventilation + infiltration) are calculated in the two simulation engines. However, the exact cause of this discrepancy has not been determined. 


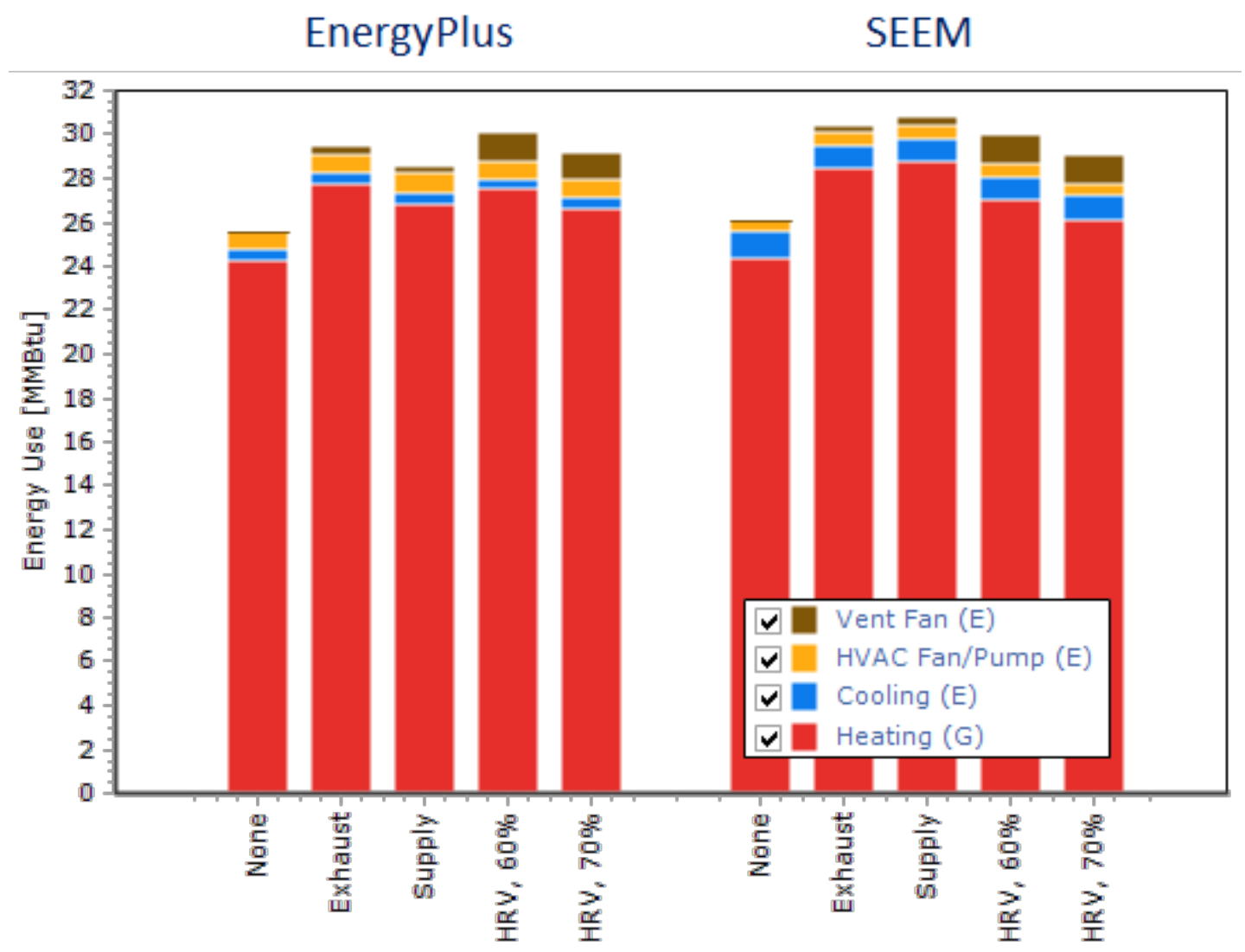

Figure 20. Mechanical ventilation results in new construction building

\subsubsection{Discrepancies Not Yet Investigated}

The following discrepancies have been found using the BEopt Test Suite, but their root causes have not yet been investigated. They are ordered from most important to least important in terms of the magnitude of the discrepancy (see Table 4).

\subsubsection{Ceiling Insulation}

Figure 21 shows the results for ceiling insulation in the diagnostic building. Significant differences between SEEM and EnergyPlus for varying levels of ceiling insulation can be observed, especially for uninsulated options. There are few possible reasons for these differences:

- The SEEM-recommended R-value for uninsulated attics is significantly higher than that used in BEopt/EnergyPlus.

- Poorly insulated building components are more susceptible to the differences in convection coefficient algorithms (SEEM uses a constant convection coefficient while BEopt uses a variable model).

- Poorly insulated building components are more susceptible to differences in boundary conditions such as sky radiation. 


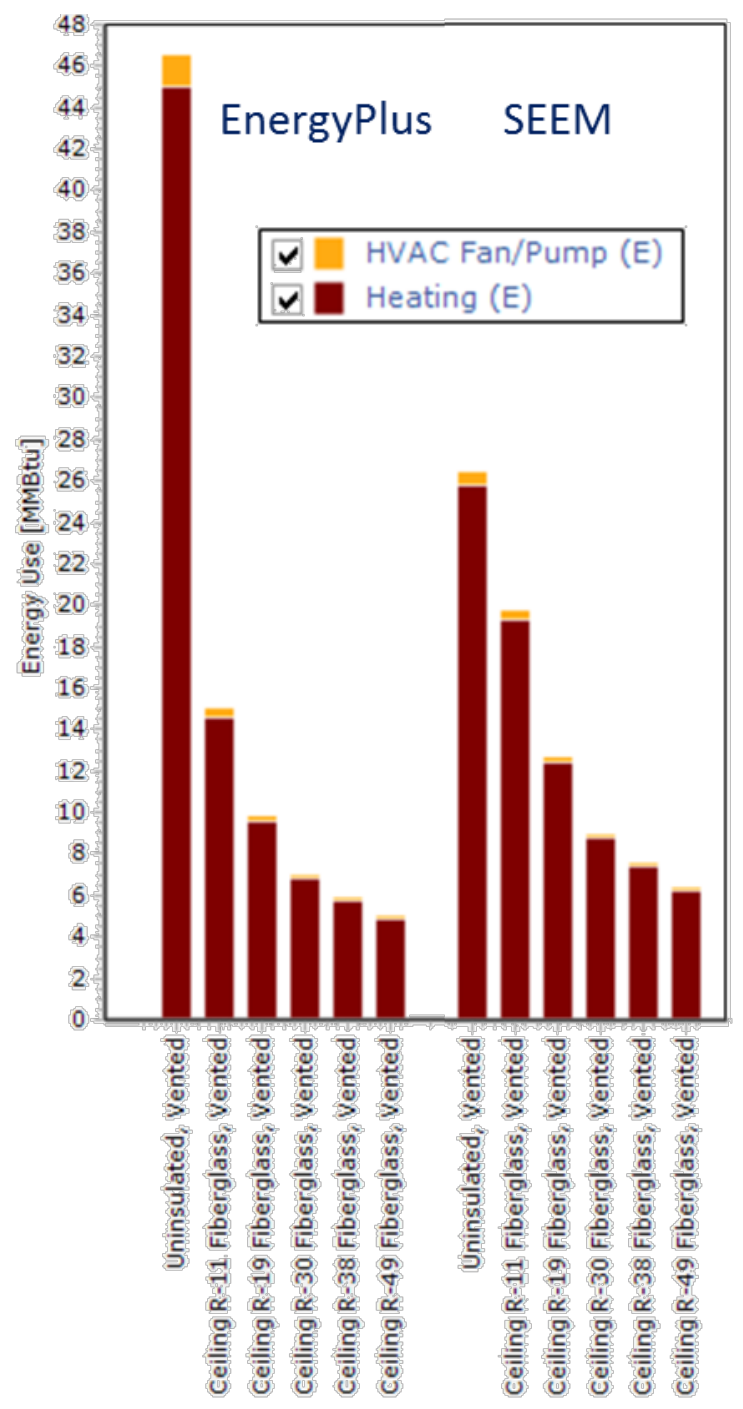

Figure 21. Ceiling insulation results in diagnostic building

\subsubsection{Wall Insulation}

Figure 22 shows the results for wood stud walls with fiberglass batt insulation in the diagnostic building. Significant differences occur between SEEM and EnergyPlus, especially for uninsulated walls. Possible reasons for this discrepancy are similar to those for uninsulated attics. 


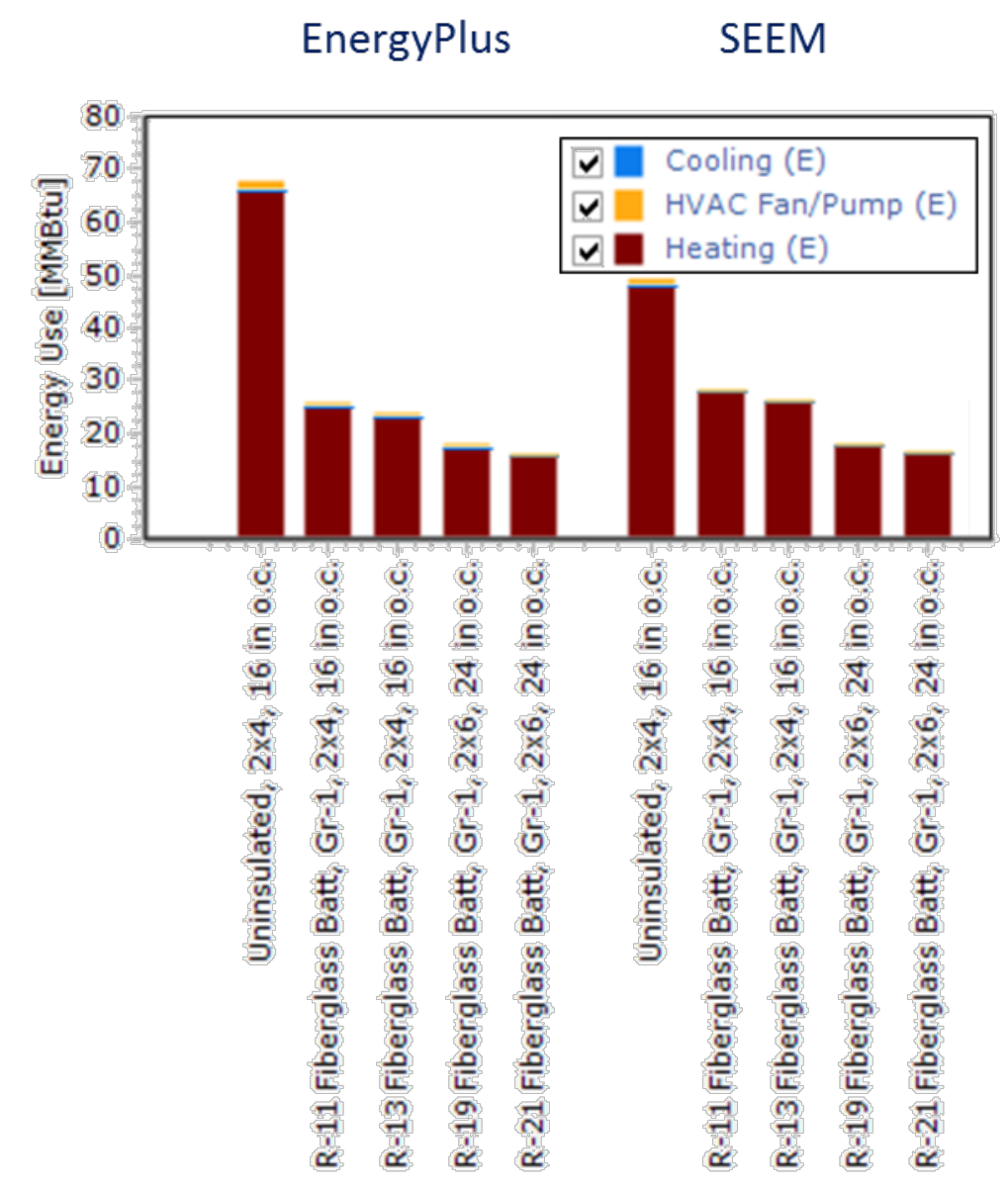

Figure 22. Wood stud wall results in diagnostic building

\subsubsection{Crawlspace: Wall Insulation}

Figure 23 shows the results for crawlspace wall insulation in the diagnostic building. Significant differences occur for uninsulated crawlspaces even after the bug fixes described in Section 3.3.1.1. Possible reasons for this discrepancy are:

- The SEEM-recommend R-value for uninsulated crawlspaces is significantly higher than that used in BEopt/EnergyPlus.

- Poorly insulated building components are more susceptible to differences in boundary conditions such as ground-coupling. 


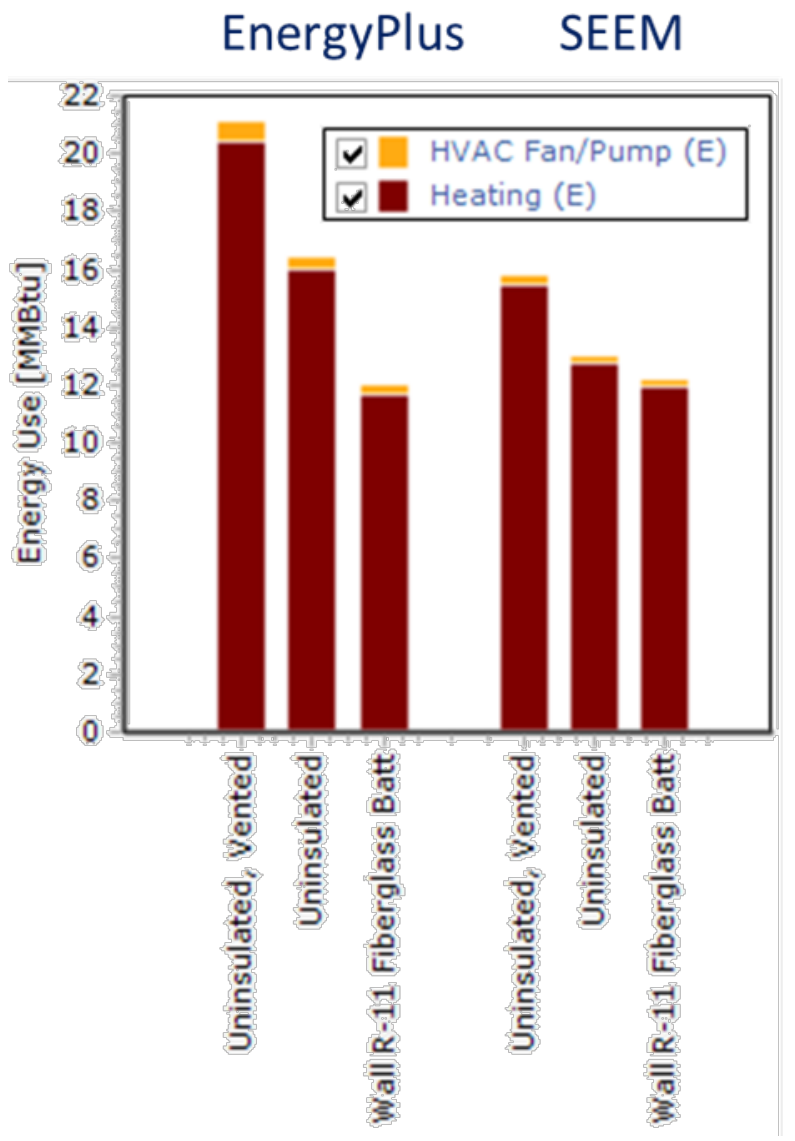

Figure 23. Crawlspace results in diagnostic building

\subsubsection{Unheated Basement: Wall Insulation}

Figure 24 shows the results for unheated basement wall insulation levels in the diagnostic building. Significant differences occur, especially for uninsulated cases, in unheated basements even after the bug fixes described in Section 3.3.1.2. Possible reasons for this discrepancy are similar to those for crawlspaces. 


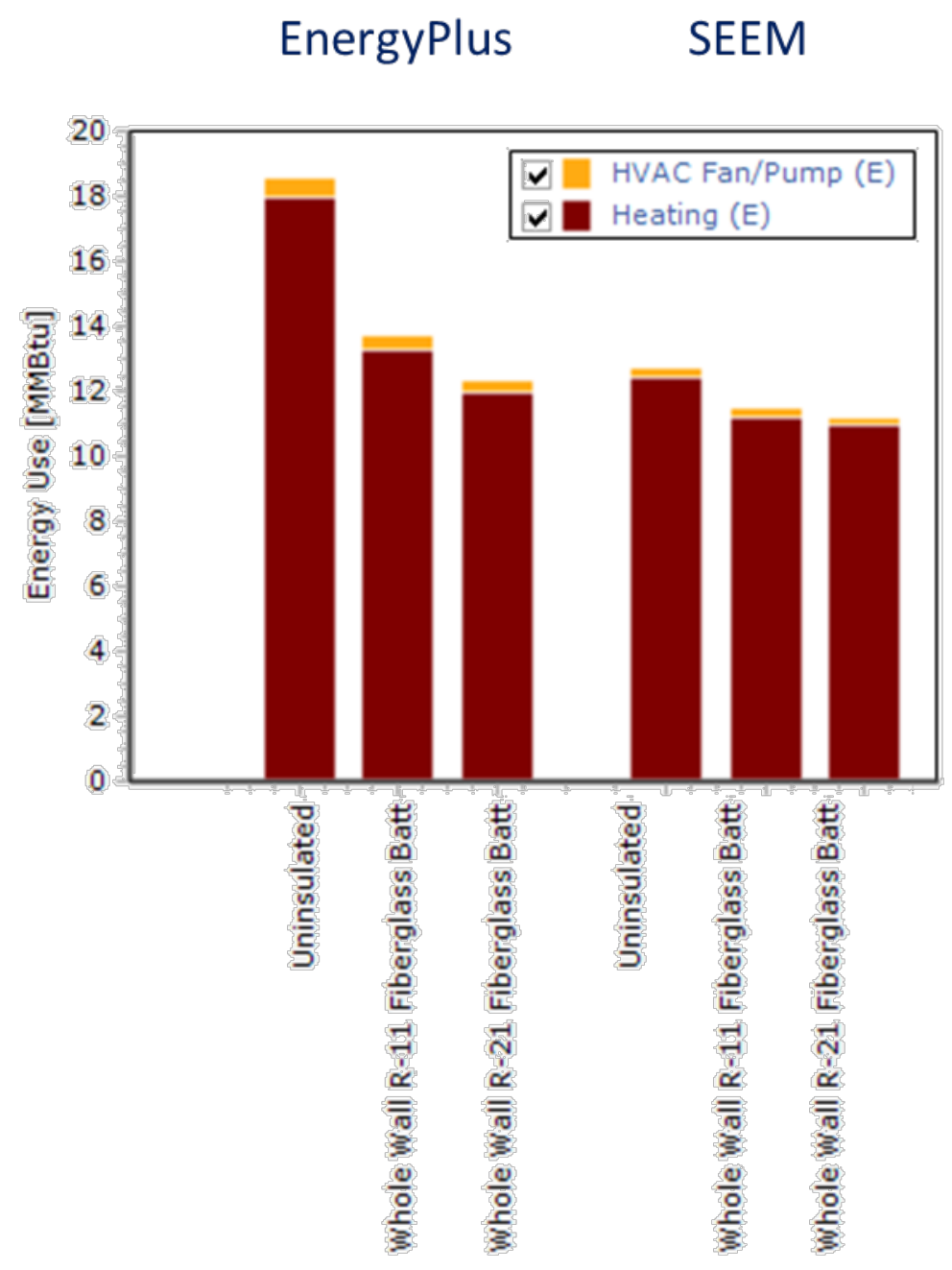

Figure 24. Unheated basement results in diagnostic building

\subsubsection{Slab: Perimeter Insulation}

Figure 25 shows the results for uninsulated and perimeter slab insulation in the diagnostic building. SEEM heating energy use shows less sensitivity to insulation level compared to EnergyPlus even after the bug fixes described in Section 3.3.1.3. Further work is required to look into the ground-coupling models used by both simulation engines. 


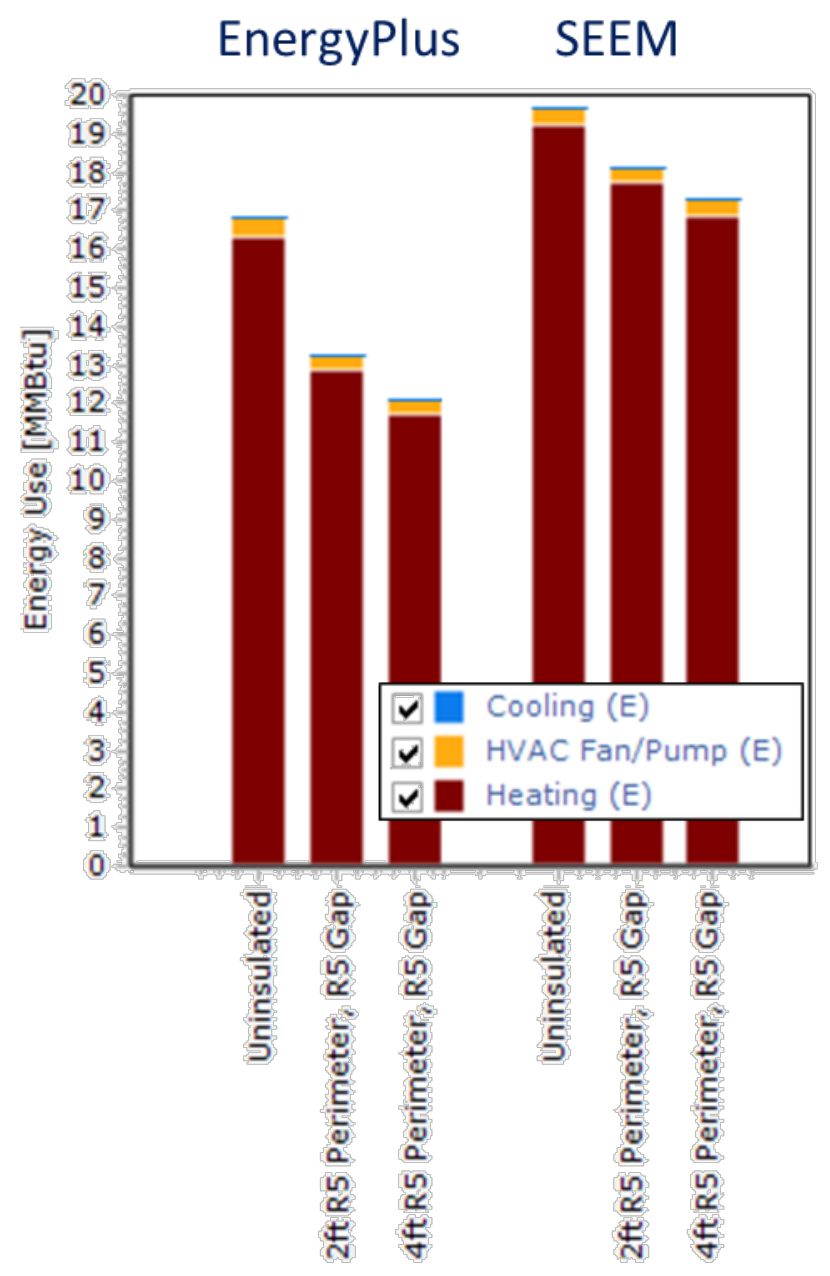

Figure 25. Slab results in diagnostic building

\subsubsection{Air Leakage}

Figure 26 shows the energy use for the diagnostic building with different air leakage levels. BEopt uses the Alberta Air Infiltration Model (AIM-2); the SEEM infiltration algorithm was developed based on AIM-2 (the internal testing showed similar results to AIM-2; Logsdon and Larson 2011). Differences between SEEM and EnergyPlus range from about 25\% for the buildings with high ACH to $16 \%$ for the buildings with low ACH. SEEM uses a constant sheltering factor of 0.7, whereas BEopt/EnergyPlus calculates the sheltering factor based on the distance from the neighbor houses and building height. BEopt also has a separate terrain input that defaults to suburban. The disparate sheltering/terrain approaches could explain some of the discrepancy between simulation engines. In addition, SEEM models air leakage between foundation (crawlspace and unheated basement), living space, and attic; BEopt/EnergyPlus neglects air leakage between zones. Further investigation is required to address this issue. 


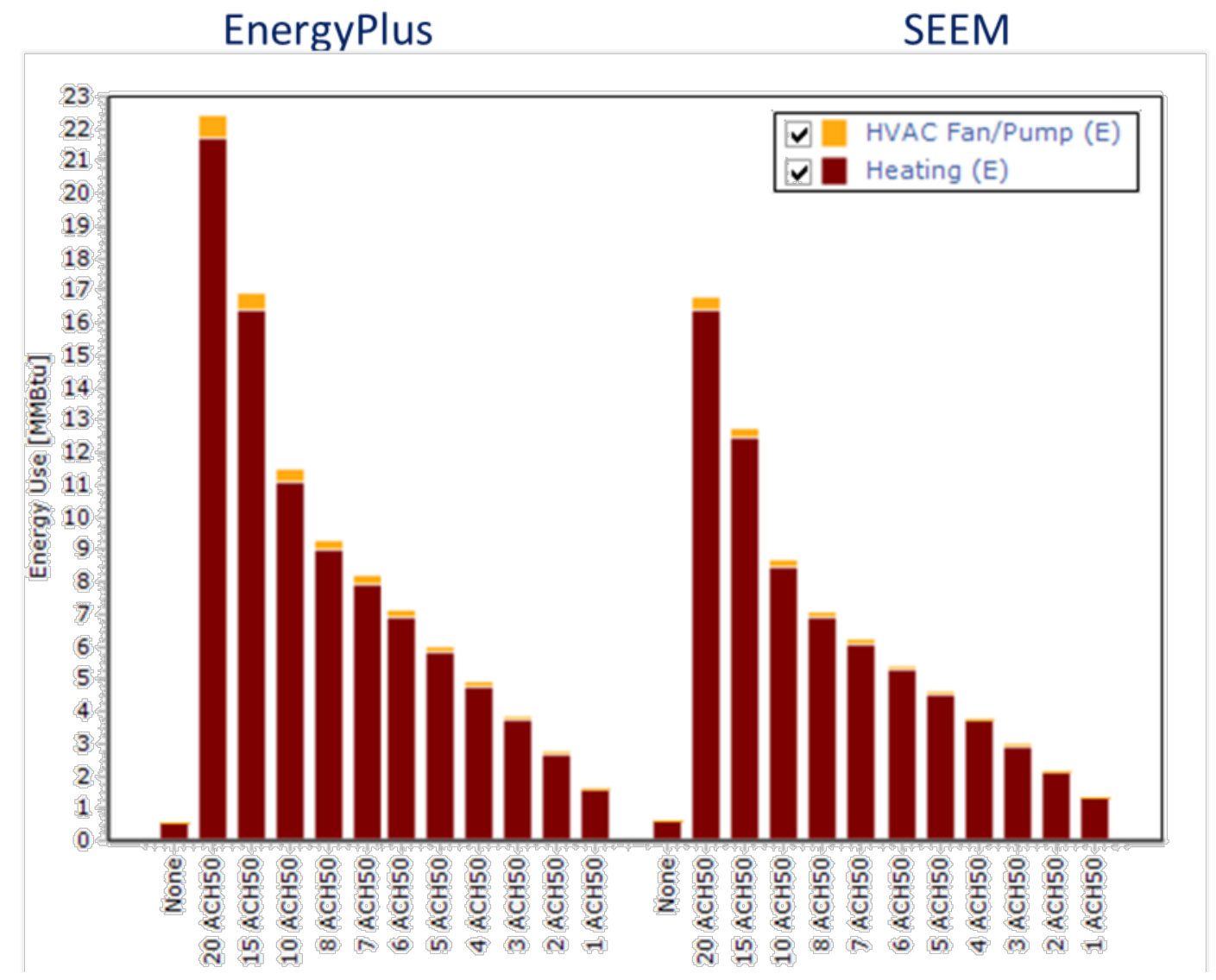

Figure 26. Air leakage results in diagnostic building

\subsubsection{Interior Shading}

Figure 27 shows the results for the diagnostic building with interior shading options. SEEM and EnergyPlus show varying trends based on changes to summer and winter shading multipliers. SEEM has an input for an average interior shading multiplier only; in BEopt the interior shading multiplier can have different values in winter and summer. Thus, SEEM uses the average value of the winter and summer months (see Appendix A). These differences could also be related to the discrepancies found with windows (for example, as observed in the "None" bar results below), but this has not been explored. 


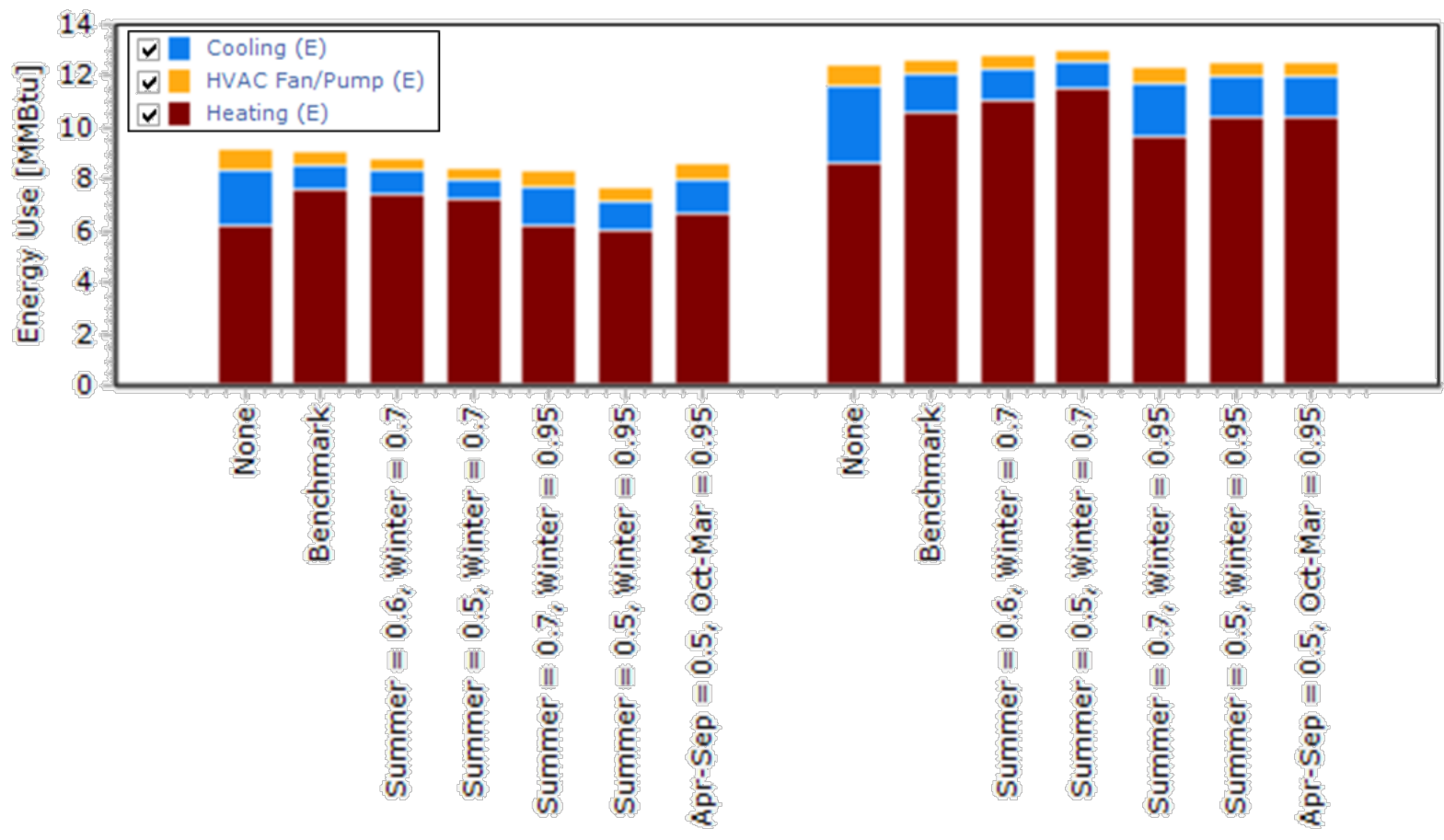

Figure 27. Interior shading results in diagnostic building

\subsubsection{Roof Insulation}

Figure 28 shows the results for roof insulation in the attic of the diagnostic building. Although EnergyPlus and SEEM agree closely for R-19 roof insulation, they show varying sensitivity to increasing insulation levels. A possible reason for this disagreement is the limited inputs in SEEM. The only SEEM input for roof insulation is an assembly R-value for the ceiling. This is based on the air-to-air R-value from the house to the attic. In contrast, BEopt/EnergyPlus has detailed inputs for roof insulation including framing factors, installation quality, and specification of separate layers for roofing material, roof sheathing, and drywall, which may not result in the identical assembly $\mathrm{R}$-value. The boundary conditions also are not identical because sky temperature and convection coefficient models are different, which would affect the trends observed from low to high insulation levels. 


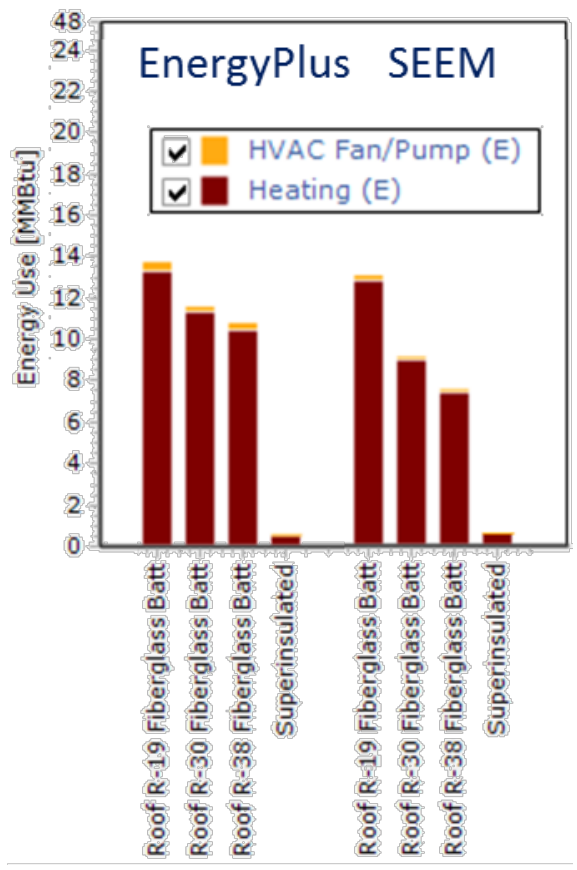

Figure 28. Roof insulation results in diagnostic building

\subsubsection{Internal Gains}

SEEM does not simulate disaggregated internal gains; rather, all internal gains are lumped into average internal sensible and latent gains (see Appendix A). Figure 29 shows results for varying internal gains levels, entered as multipliers of the Building America HSP miscellaneous electric load baseline value. Both engines follow the same trend, but there are discrepancies in the magnitude of cooling energy required to extract the heat introduced by the internal gains.

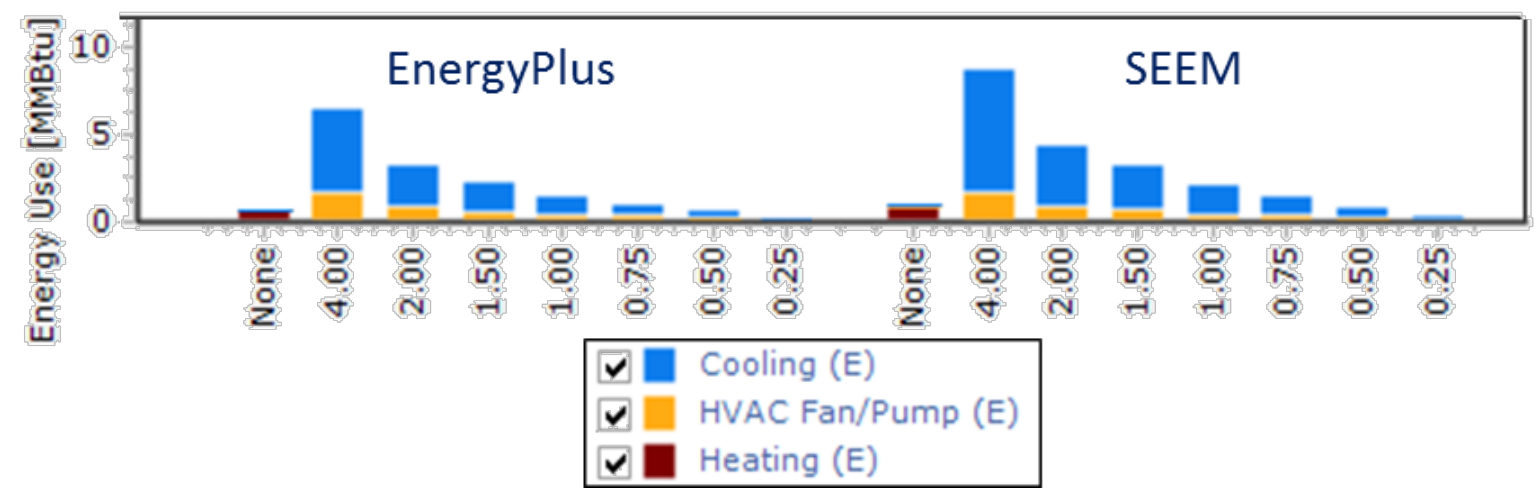

Figure 29. Internal gains results in diagnostic building

\subsubsection{Floor Mass}

Figure 30 shows the results for the floor mass options in the diagnostic building. EnergyPlus results show a decrease in heating energy for buildings with higher mass; SEEM results show no sensitivity. The reason is that the SEEM specification for the foundation/floor is an R-value with no inputs for additional mass (i.e., SEEM assumes fixed mass); BEopt/EnergyPlus allows 
additional flexibility for defining the floor mass. Also, EnergyPlus and SEEM use different ground-coupling models.

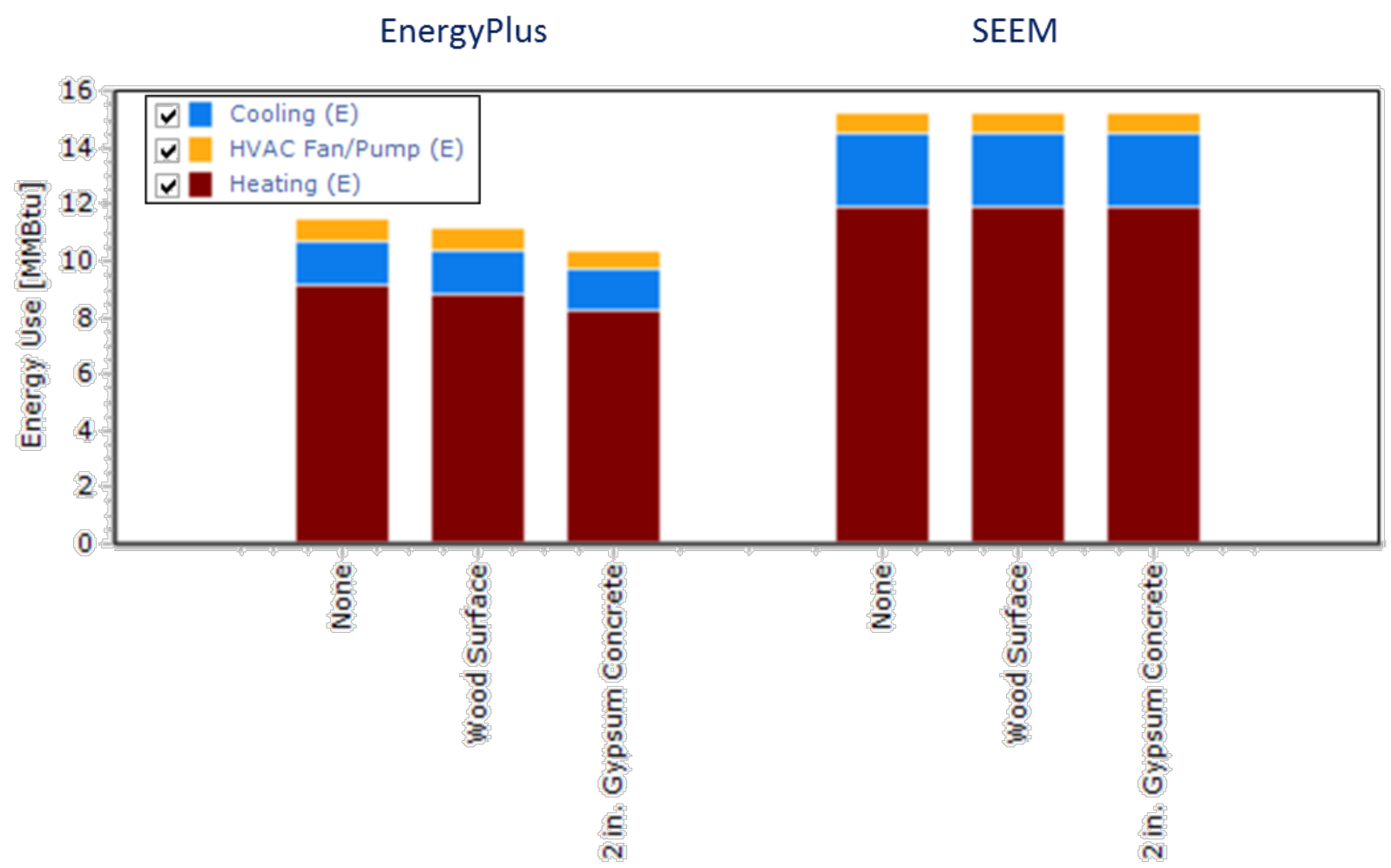

Figure 30. Floor mass results in diagnostic building 


\section{Phase II}

Phase II targeted model enhancements for the BEopt/EnergyPlus simulation engine platform to further reduce discrepancies compared to SEEM. In coordination with Bonneville Power Administration (BPA), five categories were identified as prime candidates for deeper investigation based on Phase I results, technology priorities in the Pacific Northwest, and new capabilities recently made available in the SEEM engine. These five categories were:

1. Mini-split heat pump (MSHPs)

2. Heat pump water heaters (HPWHs)

3. Air leakage

4. Ducts

5. Foundation heat transfer.

In each area, NREL and Ecotope conducted thorough investigations of the EnergyPlus and SEEM models, inputs, and assumptions.

\subsection{Versions of EnergyPlus and SEEM Used}

Initial results for Phase II are based on SEEM97, the most recent version available at the time. Among other changes, SEEM97 includes a new HPWH model. As discrepancies were identified and subsequently fixed by Ecotope, or for testing purposes, a number of interim versions were shared with NREL. The most recent version used in this report has:

- Bug fixes as described in subsequent sections.

- Fixed a "ghost" heat source when walls, floors, or ceiling R-values were above certain values (e.g., Rwall > 34.25); see Appendix D for more detail.

- Fixed hourly output (was previously output from the last sub-hourly timestep only, which could result in differences of up to 5\% between annual and the sum of hourly output).

Initial results for EnergyPlus are based on EnergyPlus 8.1. Final results are based on a development build of EnergyPlus 8.4.1, which includes all of the enhancements and bug fixes detailed in subsequent sections.

\subsection{Overall Assessment of Prioritized Categories}

Table 5 provides an overall status of the five prioritized categories upon completion of Phase II and enumerates the list of modeling enhancements, bug fixes, and recommendations. As a result of these implementations/recommendations, the final assessment of the discrepancies for these five categories is:

- Four categories resolved. MSHPs, HPWHs, air leakage, and ducts.

- One category partially resolved. Foundation heat transfer.

The results for each category are described in more detail in the sections that follow. 
Table 5. Overall Status of Prioritized Categories

\begin{tabular}{|c|c|c|c|c|c|}
\hline Category & \multicolumn{2}{|c|}{ BEopt/EnergyPlus } & \multicolumn{2}{|c|}{ SEEM } & \multirow{2}{*}{$\begin{array}{l}\text { Status } \\
\text { Resolved }\end{array}$} \\
\hline $\begin{array}{l}\text { Mini-Split } \\
\text { Heat Pumps }\end{array}$ & $\begin{array}{l}\mathrm{ENH}^{\mathrm{a}} \\
\text { ENH } \\
\text { FIX }^{\mathrm{b}} \\
\text { REC }^{\mathrm{c}}\end{array}$ & $\begin{array}{l}\text { Updated coefficient of degradation, } C_{D} \\
\text { Updated heating indices } \\
\text { Defrost model } \\
\text { Assess latest variable-speed model }\end{array}$ & & & \\
\hline $\begin{array}{l}\text { Heat Pump } \\
\text { Water Heaters }\end{array}$ & $\begin{array}{l}\text { ENH } \\
\text { ENH } \\
\text { ENH } \\
\text { ENH } \\
\text { ENH } \\
\text { FIX } \\
\text { FIX } \\
\text { FIX } \\
\text { FIX } \\
\text { FIX }\end{array}$ & $\begin{array}{l}\text { New res. wrapped condenser model } \\
\text { Supply/exhaust/balanced ducting } \\
\text { Temperature depression } \\
\text { HVAC interaction factor } \\
\text { Connection to stratified tank model } \\
\text { Energy balance issues } \\
\text { Part load ratio convergence } \\
\text { Possible negative heat transfer to tank } \\
\text { Coil bypass factor crash } \\
\text { High energy use at larger timesteps }\end{array}$ & $\begin{array}{l}\text { FIX } \\
\text { FIX }\end{array}$ & $\begin{array}{l}\text { Heat gain energy instead of power } \\
\text { Incorrect accumulation of gains over hour }\end{array}$ & Resolved \\
\hline Air Leakage & $\begin{array}{l}\text { ENH } \\
\text { REC }\end{array}$ & $\begin{array}{l}\text { Updated vented crawl leakage dist. } \\
\text { Assess Airflow Network model }\end{array}$ & $\begin{array}{l}\text { REC } \\
\text { REC } \\
\text { REC }\end{array}$ & $\begin{array}{l}\text { Update leakage dist. for all foundation types } \\
\text { Add terrain input; use ASHRAE definitions } \\
\text { Add shelter input; use ASHRAE definitions }\end{array}$ & Resolved \\
\hline Ducts & ENH & Applied cylindrical geometry insulation effect & $\begin{array}{l}\text { REC } \\
\text { REC }\end{array}$ & $\begin{array}{l}\text { Reduce uninsulated duct R-value to } \mathrm{R}-1.7 \\
\text { Fix possible errors with unvented crawlspaces }\end{array}$ & Resolved \\
\hline Other & & & $\begin{array}{l}\text { FIX } \\
\text { FIX }\end{array}$ & $\begin{array}{l}\text { "Ghost" heat gain for high-R envelope } \\
\text { Hourly vs. annual output }\end{array}$ & Resolved \\
\hline $\begin{array}{l}\text { Foundation } \\
\text { Heat Transfer }\end{array}$ & REC & Assess enhanced model & & & $\begin{array}{l}\text { Partially } \\
\text { Resolved }\end{array}$ \\
\hline
\end{tabular}

${ }^{a}$ ENH: Modeling Enhancement

${ }^{b}$ FIX: Bug Fix

${ }^{c}$ REC: Recommendation 


\subsection{Mini-Split Heat Pumps}

Results in Phase I showed a significant discrepancy in the energy consumption of MSHPs between SEEM and BEopt/EnergyPlus in the diagnostic building.

\subsubsection{BEopt/EnergyPlus Model}

In BEopt/EnergyPlus, generalized MSHP models exist that are based on detailed laboratory testing of three MSHPs (Winkler 2011). These data were used to generate the necessary model inputs for the multiple speed DX heating and cooling coil models in EnergyPlus. Of the three units used to derive the BEopt/EnergyPlus model, two of them have corresponding SEEM models (DHP1 and DHP2). The laboratory testing consisted of both steady state and cycling tests at different loads, indoor air temperatures, and outdoor air temperatures (OATs) to capture the full range of conditions under which the MSHPs can operate. A single generalized set of EnergyPlus model inputs, including rated capacity, coefficient of performance (COP), airflow rate, and curves representing the capacity and efficiency at different indoor and outdoor air conditions were developed based on this testing. The generalized model representing the average performance is modified by the heating seasonal performance factor (HSPF) and seasonal energy efficiency rating (SEER) of the selected option to allow the full range of MSHPs to be simulated. Prior to the comparison with the SEEM model, no corrections were made to the performance of the model based on field test data.

Although MSHPs are variable-speed units and the laboratory testing was able to derive performance data for 10 discrete speeds, a bug with the variable speed DX coil model in EnergyPlus prevented the model from being used. Therefore, a multi-speed model, capable of modeling four speeds, was used instead. The performance at speeds 1, 3, 6, and 10 of the 10 speeds derived from laboratory test data were used as the heating indices that represent the full range of performance of the MSHP. This generalized approach allows the model to show sensitivity to the equipment sizing as it will operate at different speeds depending on building load and ambient conditions.

\subsubsection{SEEM Model}

In SEEM, MSHP models are based on a large field testing study of MSHPs throughout the Pacific Northwest (Baylon et al. 2012). From this field study, three representative models of MSHPs were identified and their performance was characterized using the results from a limited number (three to five) of homes per unit that were subject to detailed monitoring. A summary of the MSHP (also known as ductless heat pump [DHP]) models in SEEM is given in

Table 6, and the performance curves (Ecotope 2013) used in SEEM are shown in Figure 31. This approach ensures that the models accurately reflect the average performance that was seen in the field, but, at the same time, is limited to only what was seen in this field study. Performance variability, which may or may not exist, beyond what was seen in this study is necessarily not reflected in the simulation. Some sources of that variability could be attributed to how occupants choose to operate their MSHP or equipment size. This field data variability (Ecotope 2013) is illustrated in Figure 32, which shows the measured performance for the four sites used to derive the performance of DHP1 as well as the corresponding average curve used in SEEM. 
Table 6. Efficiency of the Three MSHP Models in SEEM

\begin{tabular}{|l|l|l|l|l|}
\hline SEEM Name & Manufacturer & Model \# & SEER & HSPF \\
\hline DHP1 & Fujitsu & 12RLS & 25.0 & 12.0 \\
\hline DHP2 & Mitsubishi & FD12NA & 23.0 & 10.6 \\
\hline DHP3 & Mitsubishi & A24NA & 16.0 & 8.2 \\
\hline
\end{tabular}

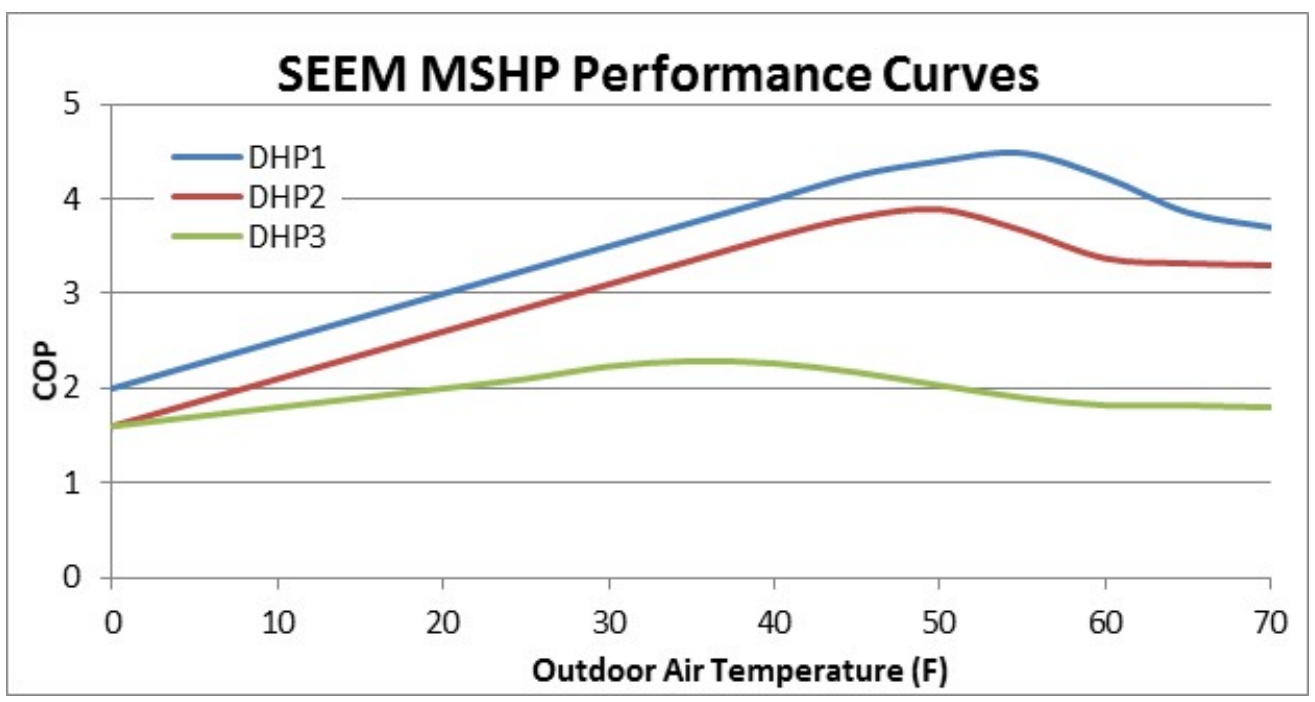

Figure 31. SEEM MSHP performance curves (Ecotope 2013)

\section{Field Test Data and SEEM Average COP, DHP1}

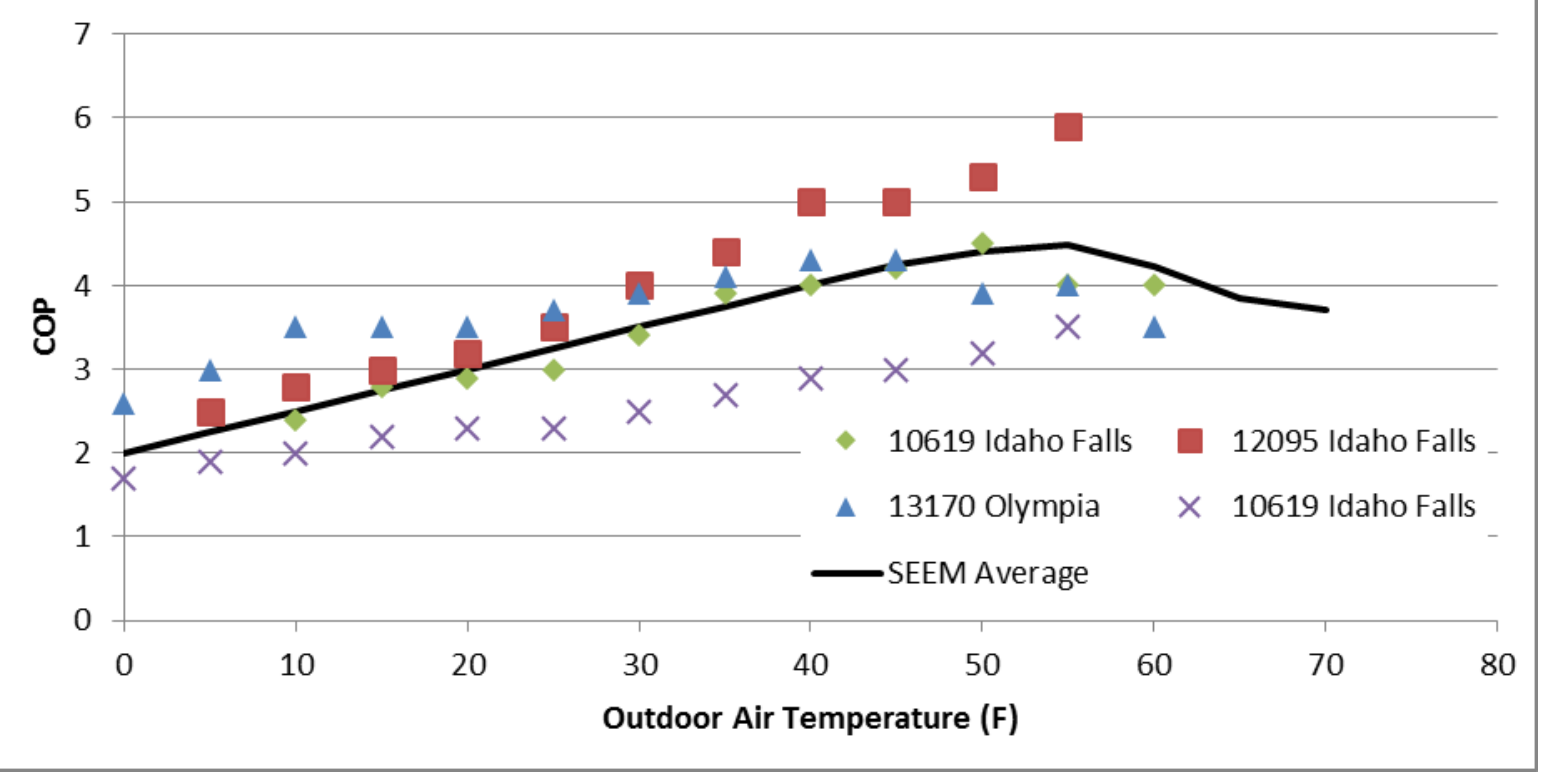

Figure 32. Field test data and SEEM average performance for DHP1 (Ecotope 2013) 
The equipment efficiencies available in SEEM for MSHPs are therefore the three models that have been tested/calibrated. Due to the variability in performance at any given installation, they represent a range of MSHP models with similar $( \pm 1)$ HSPF values.

\subsubsection{Results}

Phase II focuses on MSHP model performance in the context of new construction test buildings rather than the diagnostic test buildings. In the diagnostic building, a large weekly sinusoidal load is imposed on the living space that leads to much less cycling than would be seen in a typical MSHP installation, impacting the performance of the BEopt/EnergyPlus model. (As the SEEM model subsumes cycling degradation in its performance curves and does not explicitly model this effect, it would not see any such performance impact.)

Based on detailed investigation of the hourly performance of the EnergyPlus and SEEM MSHPs, a bug related to the modeling of defrost in EnergyPlus was identified. This bug increased, rather than decreased, the COP of the MSHP during times when defrost was active. When EnergyPlus was calculating the COP when reverse cycle defrost was active (which was used by all of the MSHPs tested in the lab and in the field test study), it was incorrectly applying the heat capacity adjustment due to defrost to the COP calculation. After this bug was resolved, the COP of the MSHPs went down when defrost was active as expected. This bug fix has been included in the most recent version of EnergyPlus (8.4).

After the defrost bug was fixed, additional changes to the MSHP model in BEopt/EnergyPlus were explored to try to get more consistent results between the two engines. Two model parameters were identified as potential sources of discrepancy: 1) $C_{D}$, the degradation coefficient for the MSHP due to cycling, and 2) the choice of four heating indices used to represent the variable speed performance of the MSHP.

Laboratory testing demonstrated that different MSHP models had significantly different values for $C_{D}$, and $C_{D}$ was highly dependent on whether the unit was cycling to a high or low compressor speed. Measured $C_{D}$ values ranged from 0.02 to 0.45 . BEopt/EnergyPlus has been using an average $C_{D}$ of 0.25 for all MSHP models, but alternative values may yield better alignment with field data.

Figure 33 shows the range of power consumption seen at each site used to derive the performance curves for DHP1, as well as BEopt/EnergyPlus simulated performance using the initial assumptions for heating indices $([1,3,6,10])$ and $C_{D}(0.25)$. Power consumption is the variable in the measured field data most closely related to the equipment's speed. The simulation results show reasonable agreement with how the unit operated at one of the sites (10619 Idaho Falls), but in general the units in the field spent more time operating at higher power consumption, and therefore higher speeds. Using higher heating indices for the lowest possible speeds in the BEopt/EnergyPlus model could shift the simulated results to more closely match the average performance seen in the field. 


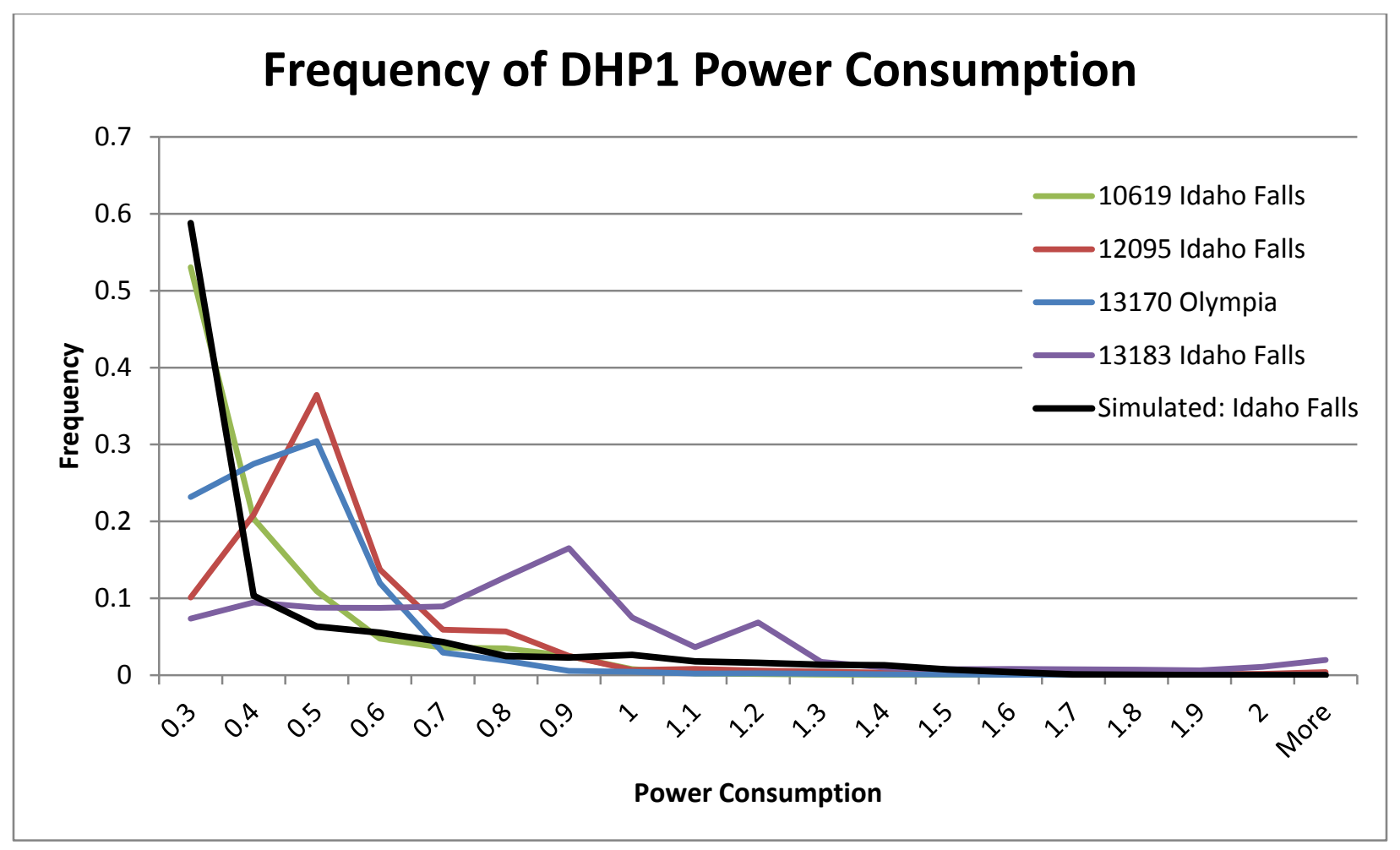

Figure 33. Frequency of measured MSHP heating power consumption for sites with DHP1

To explore how the choice of $\mathrm{C}_{\mathrm{D}}$ and the heating indices affect the model, parametric simulations were run with $\mathrm{C}_{\mathrm{D}}$ values ranging from 0 (no cycling losses) to 0.4 (maximum value measured in the laboratory) combined with three choices for heating indices: $[1,3,6,10],[2,4$, $6,10]$, and $[3,4,6,10]$. Results from the parametric runs are provided in Figure 34. These results show COP as a function of OAT for the DHP1, DHP2, and DHP3 models. COP is used rather than energy consumption to eliminate any discrepancies resulting from residual differences in building loads between SEEM and BEopt/EnergyPlus. 
$[1,3,6,10]$
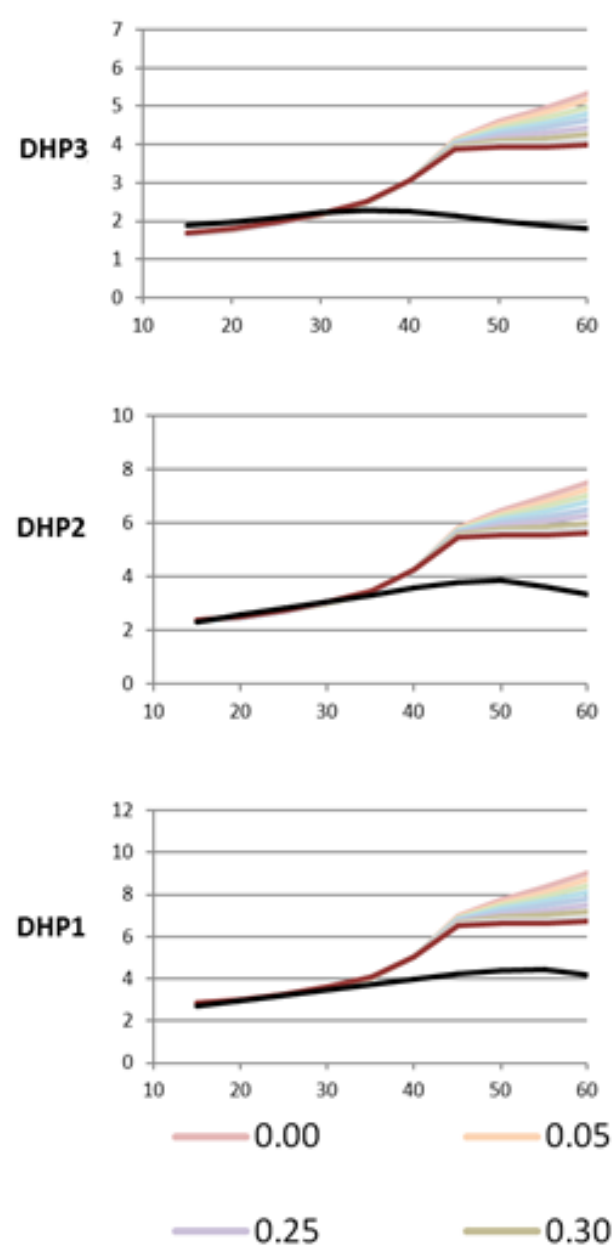

$[2,4,6,10]$
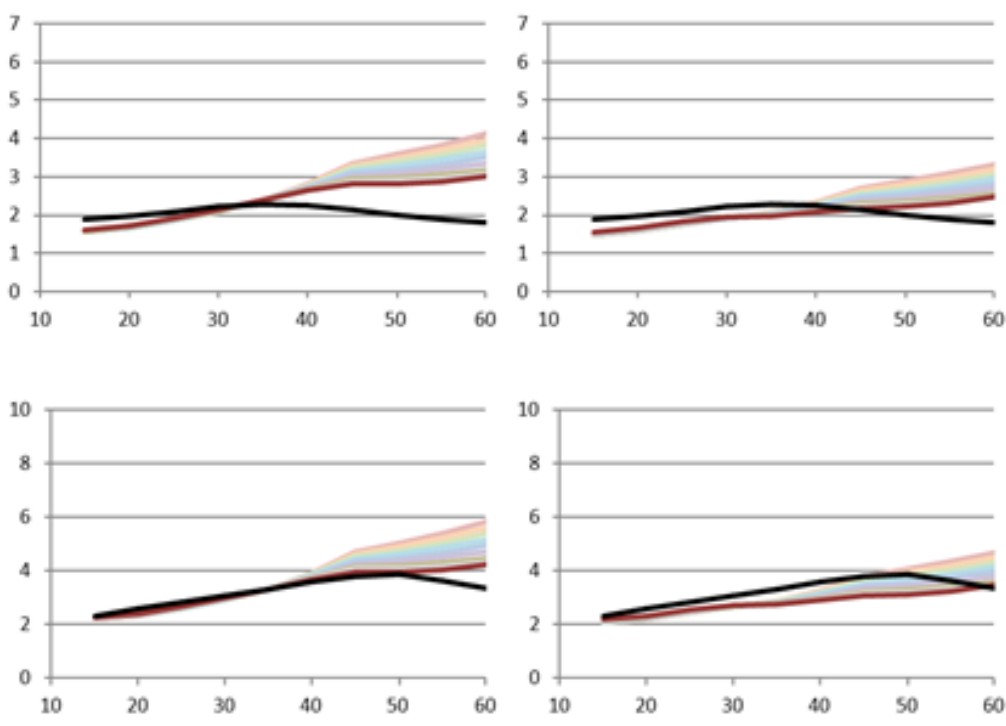

Figure 34. MSHP COP vs. OAT for a range of $C_{D}$ and heating indices

The choice of $\mathrm{C}_{\mathrm{D}}$ generally impacts MSHP performance at OATs higher than $45^{\circ} \mathrm{F}$, when cycling starts occurring more frequently, and has a negligible impact at lower OATs. The choice of heating indices tends to shift the entire curve down when using higher values for the first two indices, although the effect is more pronounced at higher OATs as the unit tends to operate at its lowest speed more often as OAT increases. Since the same curves for performance as a function of outdoor and indoor air temperature are used for all cases and the shape of the SEEM curves varies significantly (particularly between DHP3 and the other two units), it was not possible to exactly match the performance of all of the units. Priority was given to matching the performance of the higher efficiency units, DHP1 and DHP2. Based on the results of this parametric, a $C_{D}$ value of 0.40 and heating indices of $[2,4,6,10]$ were selected in BEopt as giving the best overall match to the SEEM curves.

To ensure a fair comparison between the BEopt/EnergyPlus and SEEM models, part load ratio as a function of temperature in the BEopt/EnergyPlus simulations was compared to the Ecotope field data. Results of this comparison for DHP1 are given in Figure 35, and results for DHP2 are given in Figure 36. In these figures, the BEopt/EnergyPlus results are for a case with heating indices $[2,4,6,10]$ and a $C_{D}$ of 0.40 , although the curves were not significantly changed for other heating indices and $\mathrm{C}_{\mathrm{D}}$ values. While there is some discrepancy at the lower OATs, the 
model shows good overall agreement with the field test data. Thus the model is accurately capturing the benefit at operating at lower speeds and warmer ambient temperatures.

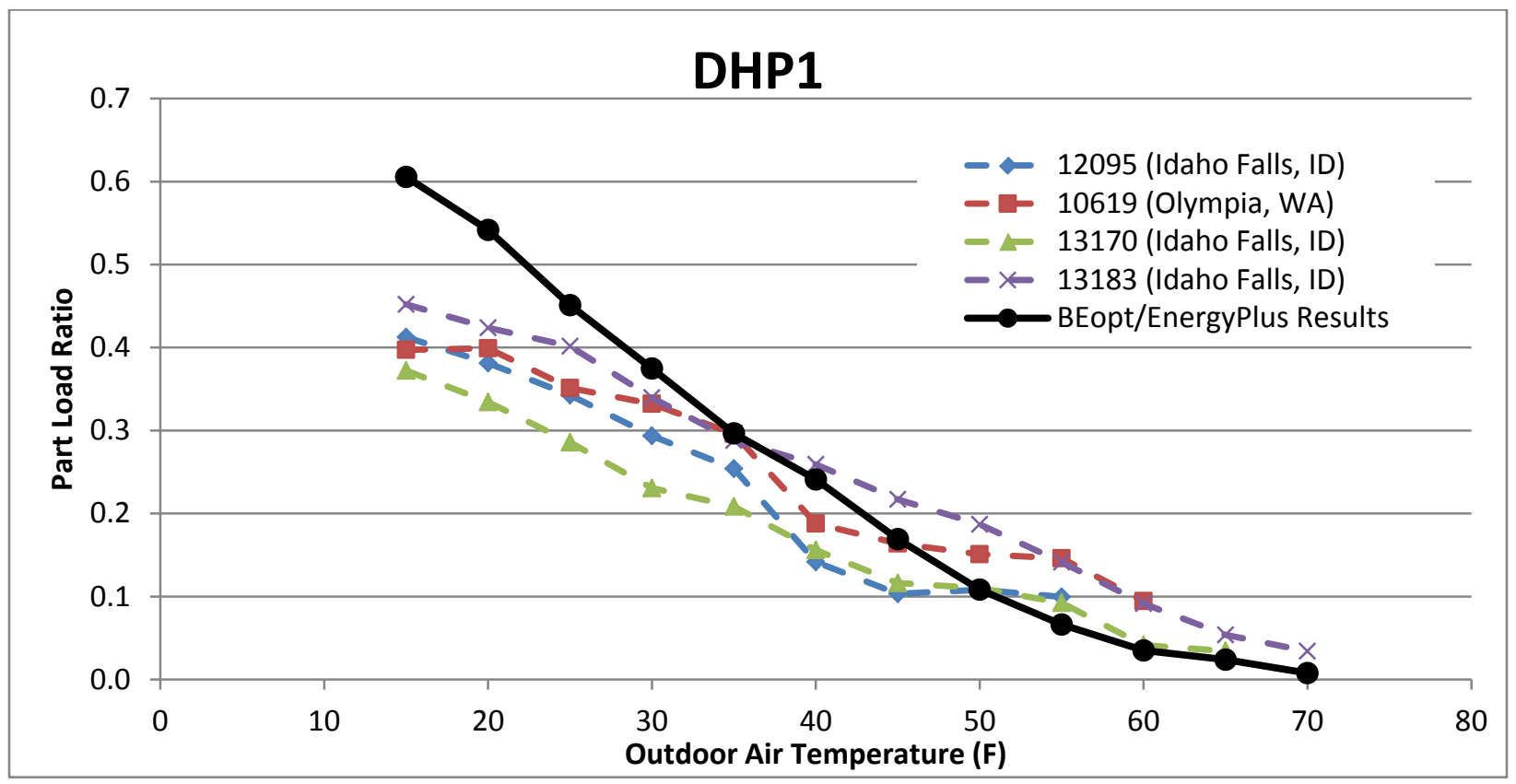

Figure 35. Part load ratio as a function of OAT for DHP1

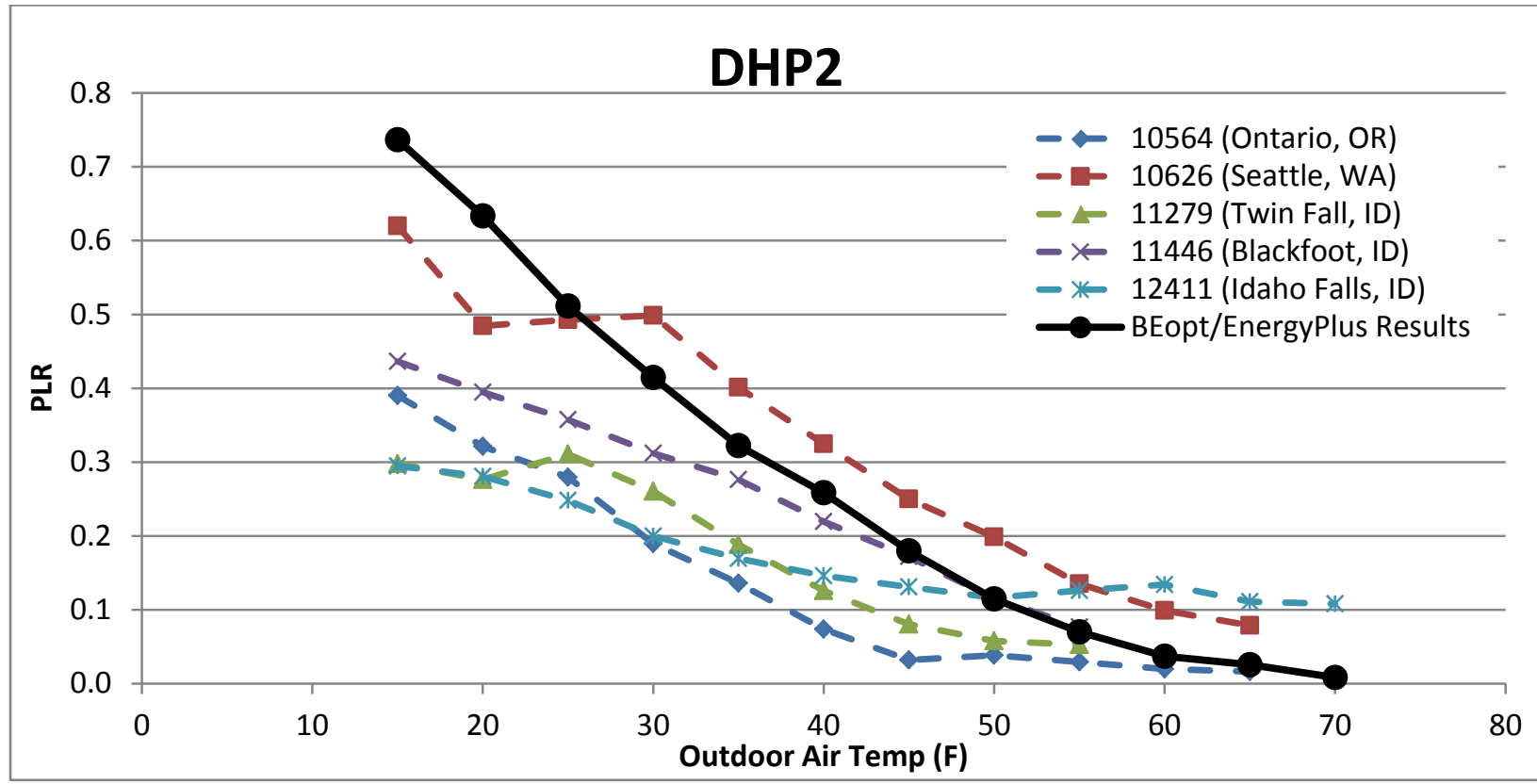

Figure 36. Part load ratio as a function of OAT for DHP2

With a new set of heating indices and $\mathrm{C}_{\mathrm{D}}$ selected, test suite runs for new construction test buildings were performed to compare the results between the initial BEopt/EnergyPlus results, the final BEopt/EnergyPlus results, and SEEM. Comparisons of the annual average heating COP (including both the MSHP and any backup baseboard energy consumption) are given in Figure 37. The heating COPs were calculated by comparing the results from the MSHP test suite runs to runs with $100 \%$ efficient electric baseboard heating and no distribution losses. 


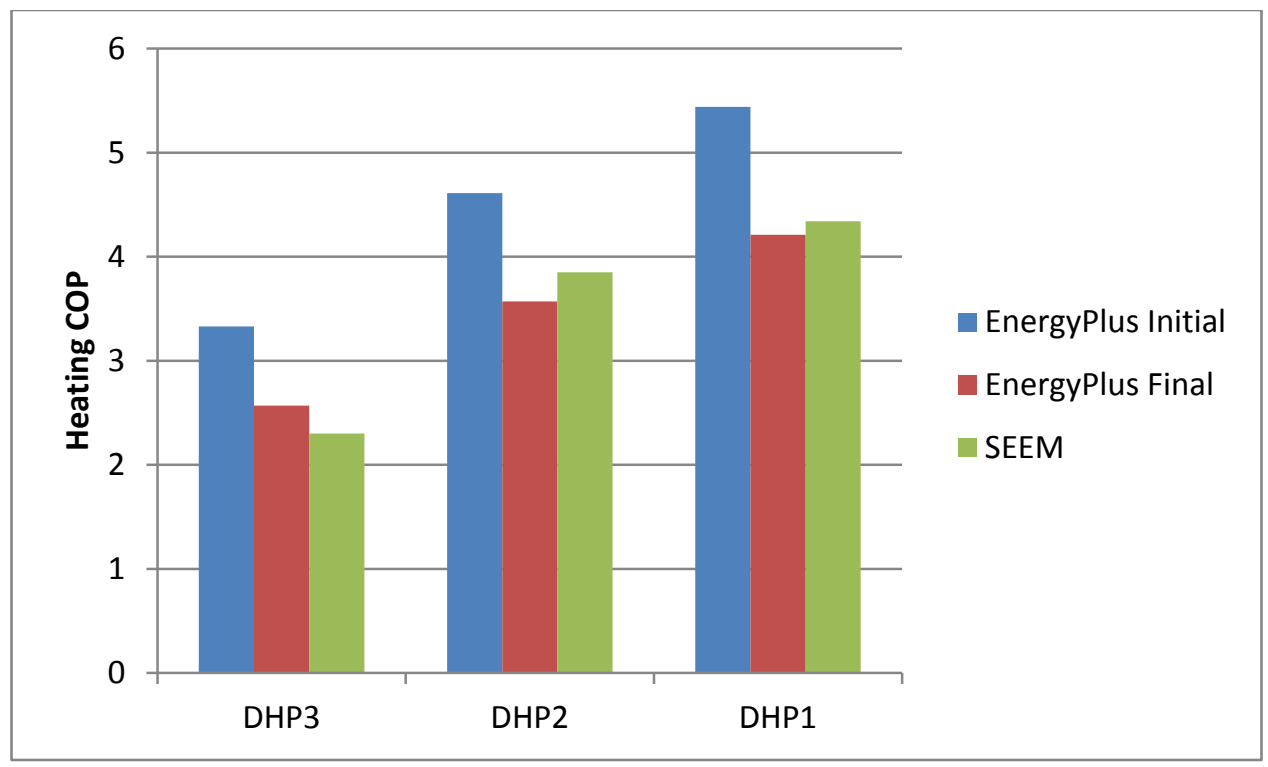

Figure 37. MSHP heating COPs, new construction building

The changes for $\mathrm{C}_{\mathrm{D}}$ and heating indices led to a much closer match in the performance of the MSHPs. Since these changes led to a better match to the SEEM model, and therefore field test results, they have been incorporated into the latest released version of BEopt (2.5).

If additional field test data for MSHPs becomes available, these adjustments may be revisited to determine if they are representative for all climates and all MSHP units available on the market. In addition, very recent fixes/improvements to the EnergyPlus variable speed DX coil model have been made that may allow it to become a suitable replacement for the multi speed model currently used by BEopt.

\subsection{Heat Pump Water Heaters}

During Phase I of this project, the HPWH model in SEEM was still under development. As of SEEM96, the model is now available for use. Because of the increasing adoption of such technologies in the Pacific Northwest, HPWH model comparisons between BEopt/EnergyPlus and SEEM were prioritized.

\subsubsection{BEopt/EnergyPlus Model}

The original HPWH model in BEopt/EnergyPlus (Wilson and Christensen 2012) used a substantial workaround to get around limitations of EnergyPlus for residential HPWHs. The workaround consisted of using two mixed tanks connected in series (plus a third tankless water heater to ensure the set point is always met) to model the HPWH's performance. The EnergyPlus limitations included: 1) models could only connect to the mixed tank model and not the stratified tank model, and 2) only pumped condenser configurations could be modeled, not wrapped condensers.

The new EnergyPlus model uses a more physical approach that can better reflect the performance of this technology. 
First, the ability to connect a HPWH to a stratified tank model in EnergyPlus was implemented. This capability became available in EnergyPlus 8.2.

Second, the capability to model a wrapped condenser rather than a pumped condenser was implemented. While pumped condensers are used for some commercial HPWHs, all of the residential HPWHs on the market today use a wrapped condenser. From a modeling perspective, using a pumped condenser to model a wrapped condenser causes several issues: all of the heat from the condenser must be added to one node, the flow into and out of the tank to the condenser affects mixing between nodes, and the pump consumes energy and can add additional heat to the water. The wrapped condenser uses the same performance map approach to calculate the heat pump COP and capacity, but uses the average tank temperature across its length rather than the temperature of a single node to determine its performance. In addition, it distributes heat evenly across all nodes adjacent to the condenser and does not affect the mixing flow rate between nodes. Several other features were added to make the modeling of HPWHs easier. These included a way to specify whether or not the heat pump and electric resistance elements could run simultaneously, as well as the ability to control the HPWH using a weighted average temperature of two nodes. Both of these features are used by some HPWH manufacturers and building them into EnergyPlus simplifies modeling these products.

Finally, three enhanced capabilities were implemented in BEopt/EnergyPlus that allow users more control over how the HPWH interacts with the building:

- Ducting: The HPWH can be ducted to the outside (but not to other spaces in the building such as a basement or garage) in either a supply, exhaust or balanced configuration. While exhaust ducting is by far the most common ducting configuration (and the only ducting configuration available in SEEM), other configurations were added to give users additional flexibility.

- Temperature depression: Ambient air temperature depression reduces the air temperature around the HPWH (affecting both the tank losses and the heat pump performance) when the unit is running. This can be used to simulate the impact the HPWH has on its own performance when it is installed in a confined space such as a utility closet. The degree of ambient air temperature depression can be specified by the user. SEEM also models the temperature depression, though users cannot change this amount.

- HVAC interaction factor: The interaction factor determines how much of tank losses and cooling (both sensible and latent) from the HPWH affect the building loads. This is designed to be used in conjunction with the ambient air temperature depression to more accurately model installations in confined spaces. SEEM also provides the ability to specify the interaction factor.

\subsubsection{SEEM Model}

The current HPWH model ${ }^{4}$ in SEEM is in many ways similar to the model used in EnergyPlus. Both engines use a stratified tank with 12 nodes (a number that adequately captures stratification in the tank while being easy to compare to lab test data, which frequently measures the tank

\footnotetext{
${ }^{4}$ Ecotope is in the process of revising the HPWH model at the moment, primarily to increase flexibility in the inputs.
} 
temperature at six locations). Both models also use performance curves to determine the performance of the heat pump at different conditions. However, there are some slight differences between the models, including:

- Tank losses: The SEEM water heater models use the average tank temperature to determine the tank losses from a node, while the BEopt/EnergyPlus model uses each individual node's temperature in determining the losses from that node.

- Mixing between nodes: The SEEM model handles mixing between nodes differently, with mixing occurring only in the bottom third of the tank after a draw, while the BEopt/EnergyPlus model uses the same algorithm for mixing between all nodes at all times.

- Control logic: The SEEM control logic depends on the temperature of the upper third of the tank, bottom third of the tank, the outlet node, and the ambient air temperature. The BEopt/EnergyPlus control logic depends on the temperature of one or two nodes on the tank (depending on how many thermocouples are installed in the actual unit) and the ambient air temperature

- Heat pump heat distribution: The SEEM model uses an equation to determine how to distribute heat to all nodes in the tank, while the BEopt/EnergyPlus model evenly distributes heat across the height of the condenser coil.

- Element heating: In the SEEM model, the heat from an electric element will go to the highest node above the element not yet at set point, then into the next highest, until the entire tank reaches set point. In BEopt/EnergyPlus, heat from an element is added directly to the node in which the element is located and then distributed through the tank by the node mixing algorithm.

Overall, these differences are relatively minor and did not appear to cause significant discrepancies between the two engines.

\subsubsection{Results}

To generate consistent results, the SEEM hot water draw profile and mains water temperature were implemented in BEopt/EnergyPlus for consistency. While SEEM has several algorithms for mains water temperature depending on the source (city surface, well, etc.) (Ecotope 2015), the algorithm for city surface mains water was used in both engines (though all of the algorithms were implemented in BEopt/EnergyPlus). The draw profile used in both engines was a weekly draw profile, which was determined to be representative of typical hot water use as part of the field test study. Using a weekly draw profile rather than daily profile allows more of the variability typical of residential hot water use to be captured and gives a more robust comparison of the models. The impact of having different default assumptions (for mains water temperature algorithms and draw profiles) between BEopt/EnergyPlus and SEEM has not been explored here.

In addition, specific equipment models representing 50-gallon and 80-gallon HPWHs were created and validated for EnergyPlus. These units were chosen due to the extensive field and laboratory data that exist on their performance, as well as the fact that there are existing models of these water heaters in both BEopt/EnergyPlus and SEEM (Sparn et al. 2011; Ecotope 2015). While many of the model inputs (such as the performance map and tank R-value) were available from the existing HPWH models, new control logics had to be derived for the stratified tanks. To 
derive the control logics, the models were compared to detailed laboratory data for a day with a typical residential hot water draw profile.

The validation results for the two EnergyPlus HPWH models are shown in Figure 38 and Figure 39. These figures demonstrate a very good match for power consumption between the models and measured data. There are some slight differences in tank temperatures due to the difficulties in modeling real tank dynamics through a one-dimensional stratified tank, but in both cases the measured and modeled consumed and delivered energy matched within 5\%. Additional comparisons to field data were performed to assess the electric resistance elements and ensure that the dead-bands and set points used for the elements were accurate.

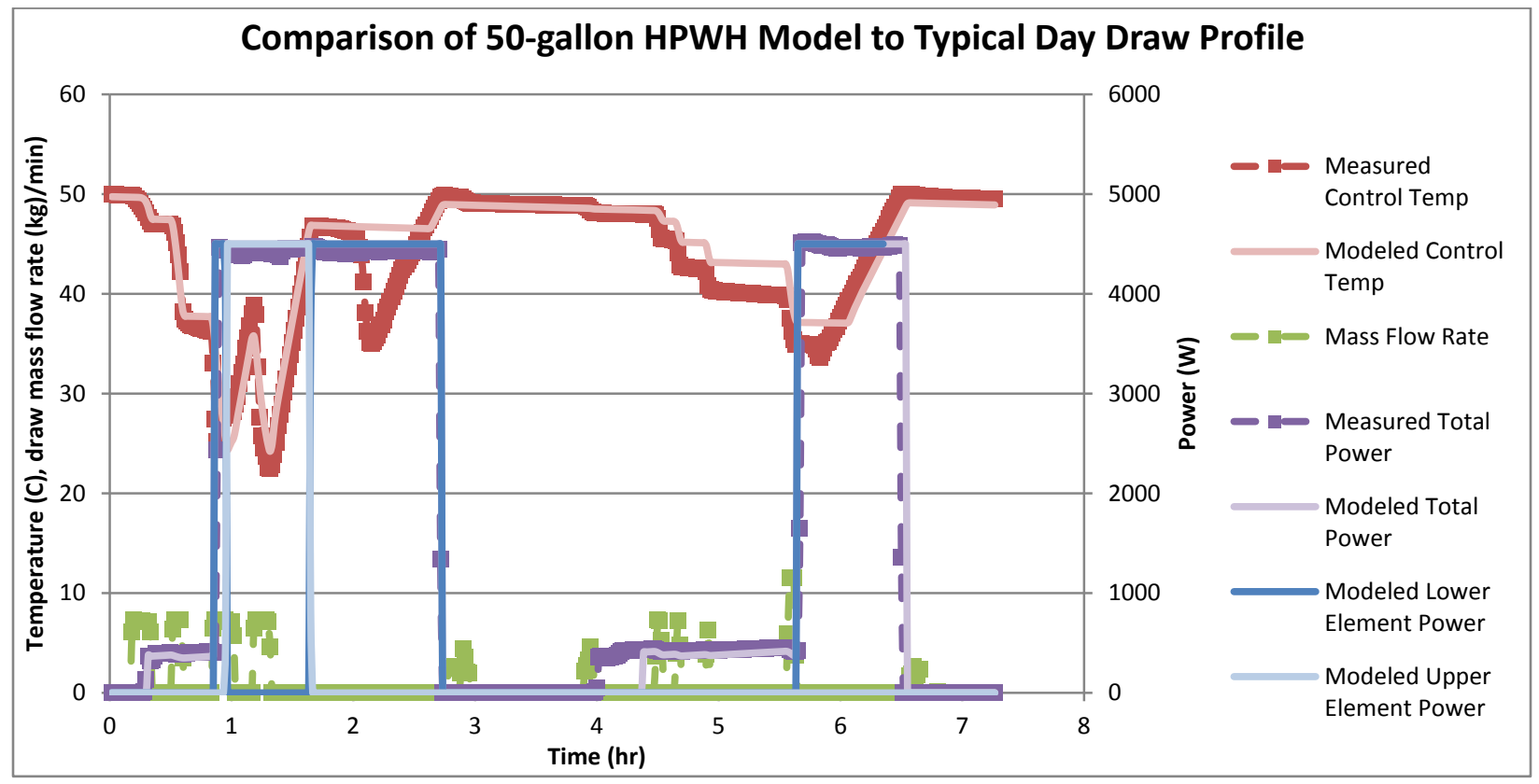

Figure 38. Fifty-gallon HPWH model validation data; EnergyPlus vs. laboratory testing 


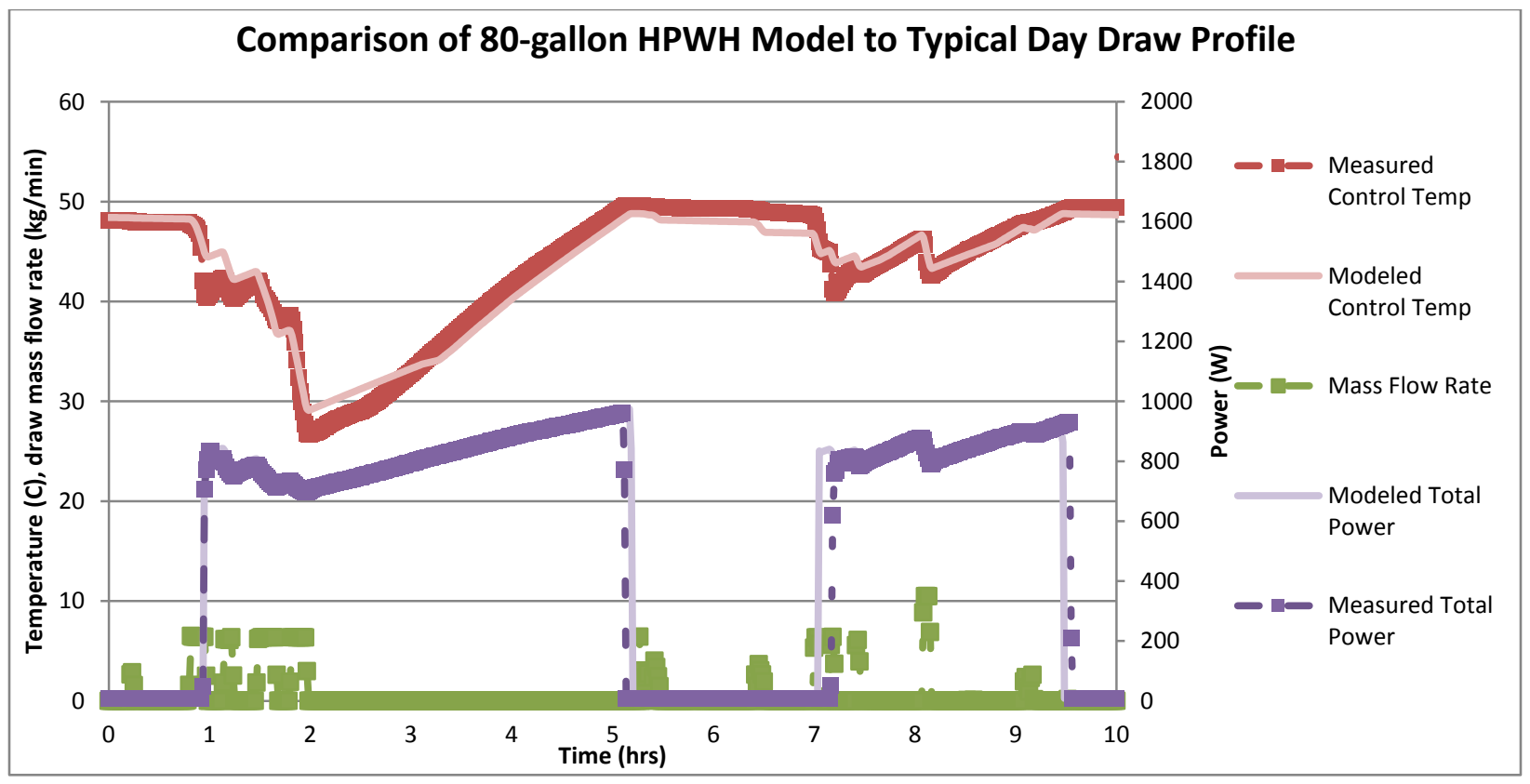

Figure 39. Eighty-gallon HPWH model validation data; EnergyPlus vs. laboratory testing

In the process of performing model validation, several EnergyPlus bugs or deficiencies were identified and fixed in EnergyPlus version 8.4 (or the upcoming EnergyPlus v8.4.1). These include:

- Energy balance errors in the existing HPWH model

- Part load ratio convergence issues for the heat pump

- Negative heat transfer from the heat pump to the tank during time steps with large draws

- Crashes due to coil bypass factor calculations failing at elevations higher than sea level

- Over-prediction of energy consumption at timesteps larger than 1 minute (v8.4.1)

- Substantial negative impact on runtime due to stratified tank model (v8.4.1).

Likewise, two bugs in SEEM were identified and fixed. These include:

- Adding HPWH heat gain (tank losses and heat removed by the heat pump) to the space in units of energy instead of power

- Gains not getting reset every 20-min timestep, but rather every hour, so that gains were allowed to accumulate over the course of an hour.

Coincidentally, these SEEM bugs had roughly counterbalancing effects, making them difficult to notice for runs in a typical building. However, for the diagnostic test building, they resulted in the building model violating conservation of energy. After fixing these bugs, energy was conserved in all cases when running SEEM.

Once the models were fully implemented, improved, and validated, test suite runs were performed to compare the new BEopt/EnergyPlus models to the new SEEM models. Water heating energy consumption results in a new construction building are shown in Figure 40. To 
best assess the impact on space conditioning, whole building results for the diagnostic test building, where the only impact on space conditioning is due to the heat pump water heater, are shown in Figure 41.

Overall, there is good agreement between the models in SEEM and EnergyPlus, with the water heating energy consumption generally matching within $10 \%$. In addition, the impact of the HPWH on the building's HVAC energy consumption matches well. The delivered energy consumption by the water heaters is shown in Figure 42. There was overall good agreement on the delivered energy, which also matched within 10\%. EnergyPlus had slightly higher delivered energy than SEEM.

Note that in these figures, the HPWH electric element usage is broken out as "Hot Water, Suppl." in EnergyPlus, but is not available as a disaggregated output in SEEM. ${ }^{5}$

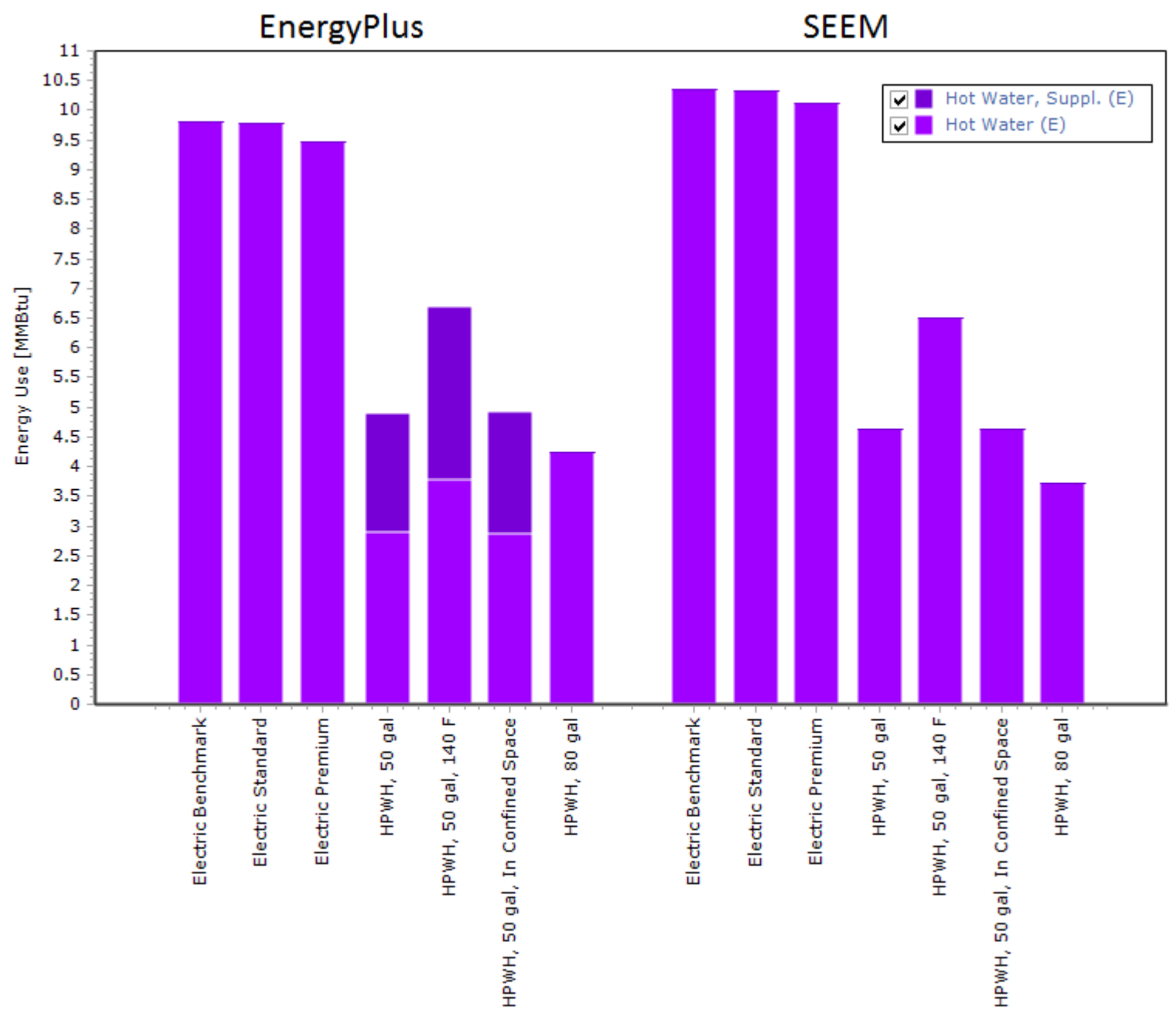

Figure 40. Water heater results in a new construction building, water heating end use only

\footnotetext{
${ }^{5}$ More recent versions of SEEM separate out the electric element usage from heat pump electricity usage.

Regardless, there would be large discrepancies between the two simulation engines in total HPWH energy use if the electric element usage did not agree well.
} 


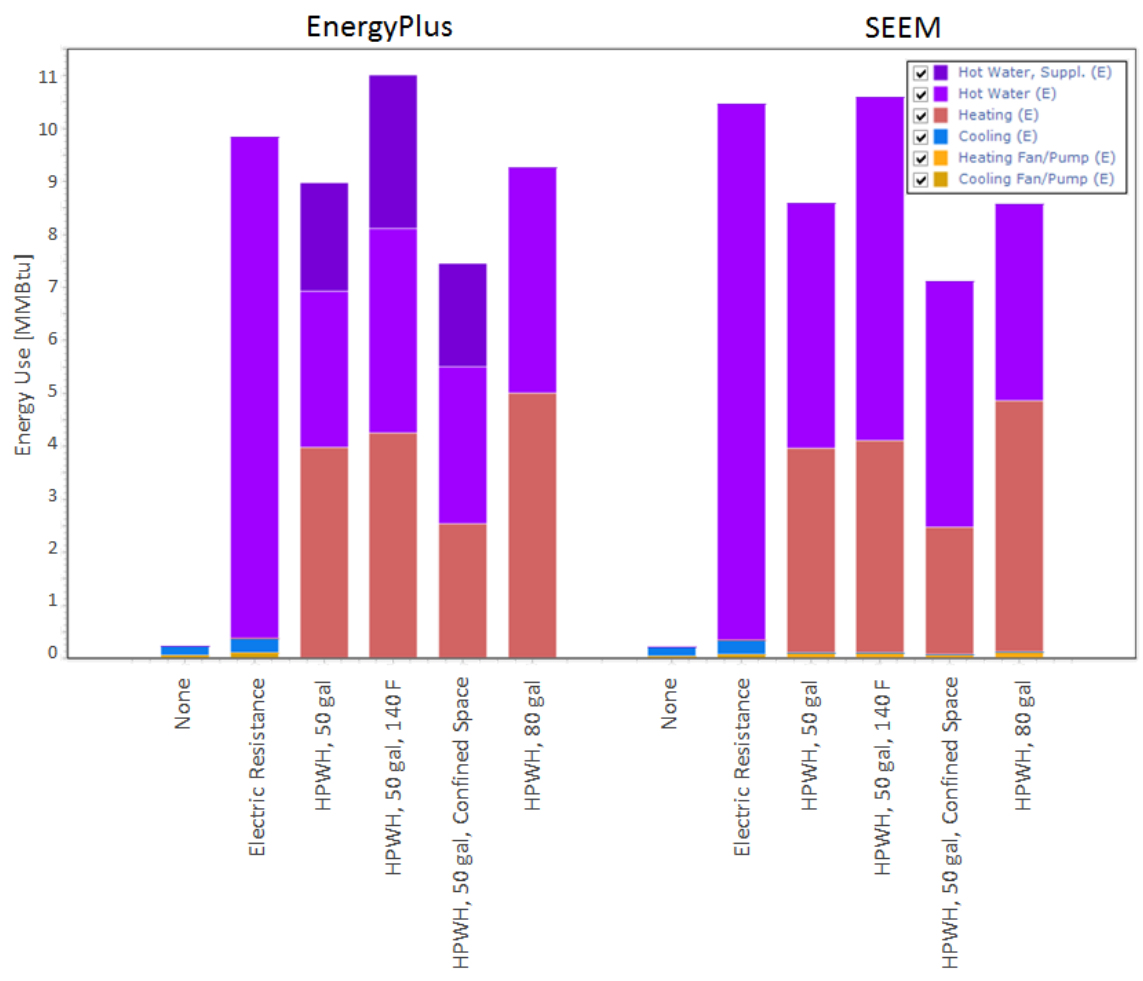

Figure 41. Water heater results in a diagnostic building, all end uses

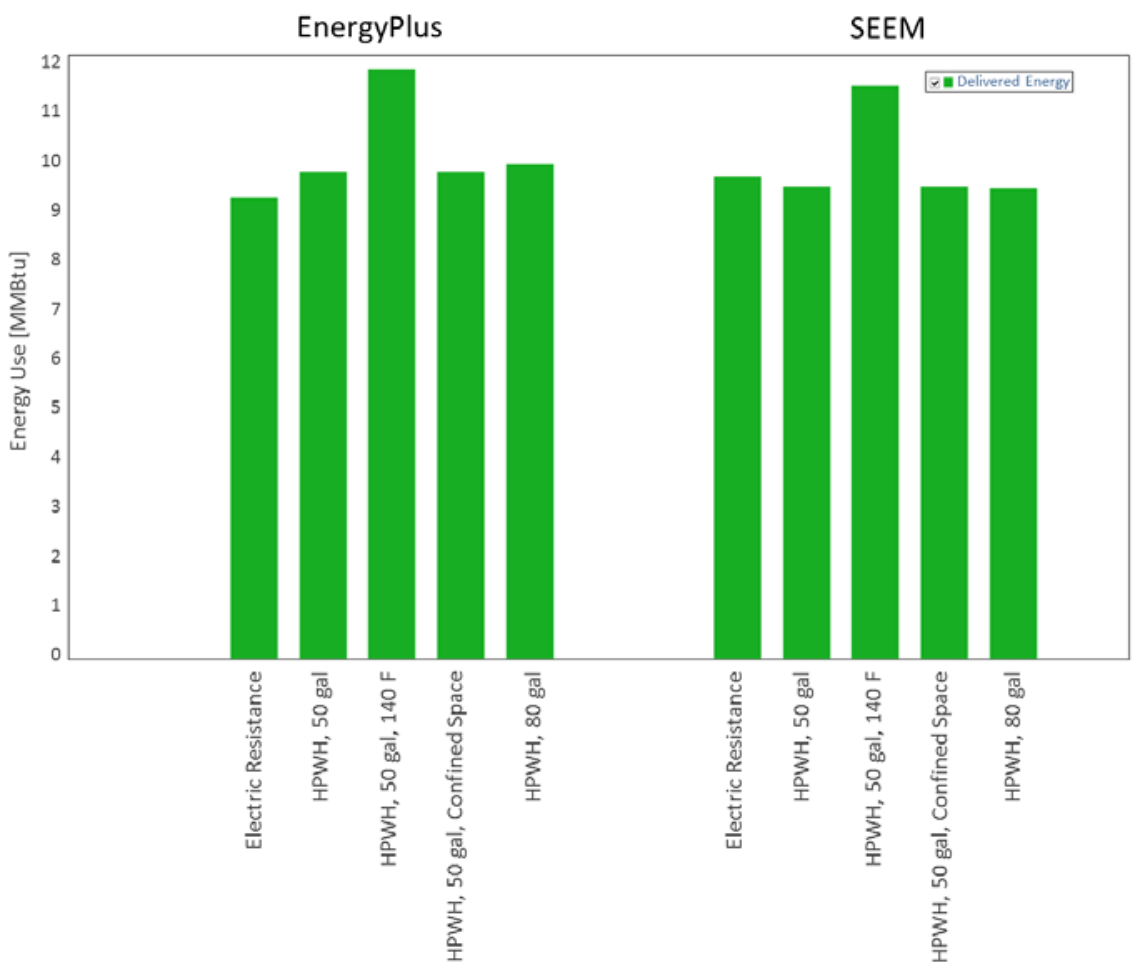

Figure 42. Water heater results in a diagnostic building, delivered hot water energy 


\subsection{Air Leakage}

Significant air leakage discrepancies were observed in Phase I between BEopt/EnergyPlus and SEEM.

\subsubsection{BEopt/EnergyPlus Model}

EnergyPlus has several methods available for modeling air leakage:

- Design Flow Rate: This basic infiltration model is based on environmental conditions (wind and temperature) modifying a design flow rate.

- Effective Air Leakage: This model is based on the Sherman and Grimsrud (1980) model, alternatively known as the "Basic" ASHRAE infiltration model.

- Flow Coefficient: This model is based on the Walker and Wilson AIM-2 model (Walker and Wilson 1990), alternatively known as the "Enhanced" ASHRAE infiltration model.

- Airflow Network: This model provides the ability to simulate the pressure-based airflows in a multi-zone residential building caused by stack and wind, including interactions with supply/return duct leakage, mechanical ventilation (whole house and/or spot), and natural ventilation. While substantially more detailed than the previous three models, this complex model requires a larger number of building characteristics/inputs and increases simulation runtime.

Of the three non-Airflow Network models, the Flow Coefficient, or AIM-2 model, is widely considered the most accurate having undergone numerous validation studies by Lawrence Berkeley National Laboratory (LBL). This is the model currently used by BEopt. However, the built-in EnergyPlus model cannot yet handle all of the interactions with other airflows that occur in residential buildings (duct leakage, mechanical ventilation, natural ventilation, etc.). Thus, the BEopt AIM-2 model is implemented using Energy Management System (EMS) routines, which essentially allows custom code to be executed during the EnergyPlus timestep calculation to handle these airflow interactions.

While preliminary BEopt connections to the Airflow Network model have been made, no final conclusions can be drawn at this time. With the U.S. Department of Energy's (DOE's) interest, NREL will be continuing to assess the model's applicability and accuracy for residential buildings in the upcoming year.

\subsubsection{SEEM Model}

With SEEM94, Ecotope implemented a new, detailed infiltration model derived from the same principles as two widely used models for natural infiltration that employ analytical approximations:

- The LBL model developed by Sherman and Grimsrud

- The AIM-2 model developed by Walker and Wilson.

SEEM uses a computational framework that allows iterative solutions to solve for infiltration flow rates, taking into account both stack and wind-driven effects. Prior to this enhancement, SEEM93 assumed a constant annual air change rate. 


\subsubsection{Results}

The initial discrepancies observed for a series of 20 diagnostic test buildings is summarized in Figure 43. The descriptions for these 20 buildings are given in Table 7. Because diagnostic test buildings are used, all heating energy is solely due to the heat transfer caused by air leakage; there are no HVAC inefficiencies, duct losses, internal gains, or heat transfer through the building envelope. The figure shows EnergyPlus simulations with 5\%-25\% higher annual heating energy use than SEEM. (Note that Run \#19 gave erroneous results in SEEM, indicating a simulation failure; the twentieth run therefore shows up as Run \#19.)

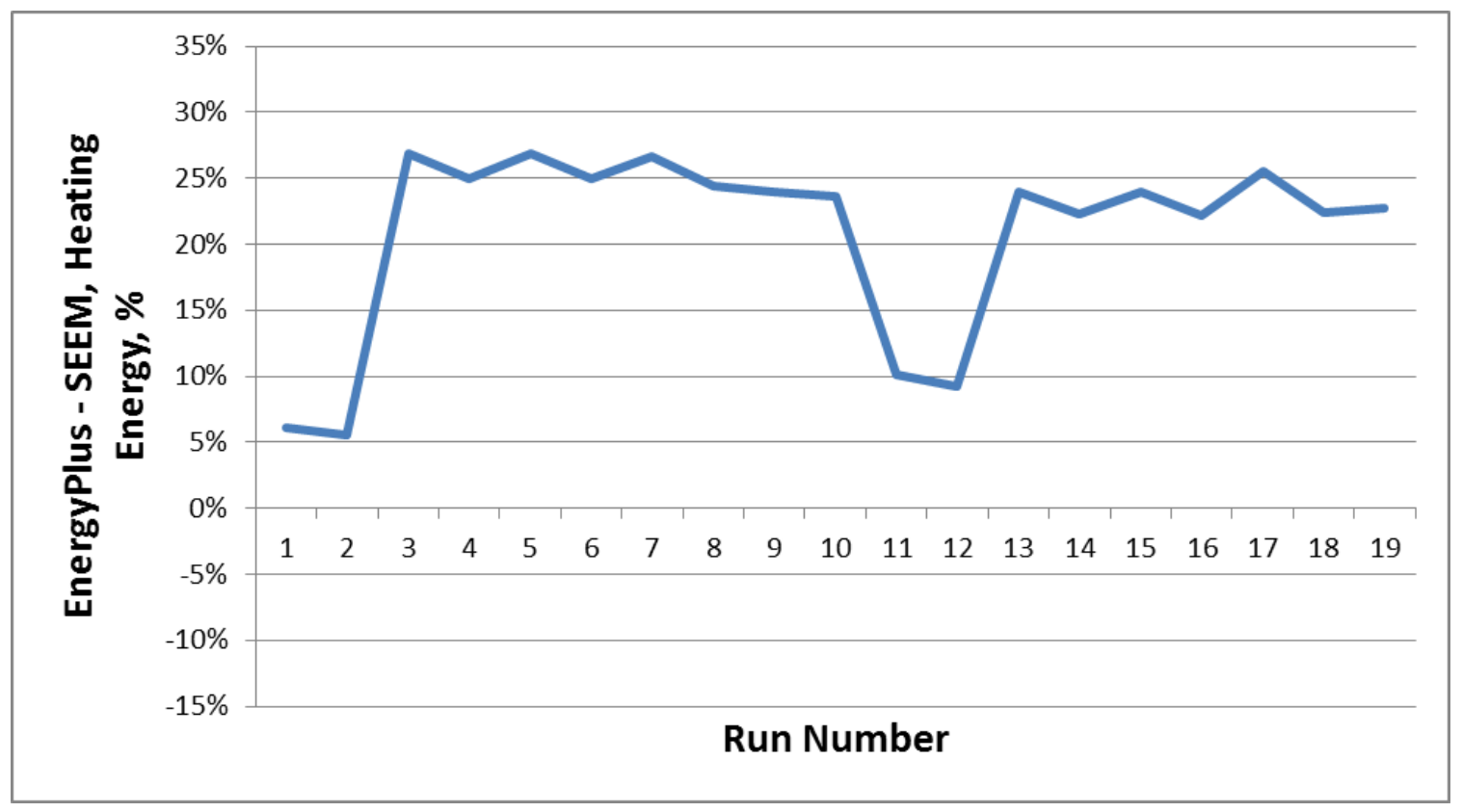

Figure 43. Initial air leakage discrepancies, diagnostic buildings

Table 7. Run Descriptors for Diagnostic Buildings Used in the Air Leakage Comparison

\begin{tabular}{|lllll|}
\hline Run \# & Location & \# Stories & Foundation & ACH50 \\
\hline 1 & Seattle & 1 & Vented Crawl & 20 \\
\hline 2 & Seattle & 1 & Vented Crawl & 7 \\
\hline 3 & Seattle & 1 & Unvented Crawl & 20 \\
\hline 4 & Seattle & 1 & Unvented Crawl & 7 \\
\hline 5 & Seattle & 1 & Basement & 20 \\
\hline 6 & Seattle & 1 & Basement & 7 \\
\hline 7 & Seattle & 1 & Slab & 20 \\
\hline 8 & Seattle & 1 & Slab & 7 \\
\hline 9 & Seattle & 2 & Unvented Crawl & 20 \\
\hline 10 & Seattle & 2 & Unvented Crawl & 7 \\
\hline
\end{tabular}




\begin{tabular}{|lllll|}
\hline Run \# & Location & \# Stories & Foundation & ACH50 \\
\hline 11 & Boise & 1 & Vented Crawl & 20 \\
\hline 12 & Boise & 1 & Vented Crawl & 7 \\
\hline 13 & Boise & 1 & Unvented Crawl & 20 \\
\hline 14 & Boise & 1 & Unvented Crawl & 7 \\
\hline 15 & Boise & 1 & Basement & 20 \\
\hline 16 & Boise & 1 & Basement & 7 \\
\hline 17 & Boise & 1 & Slab & 20 \\
\hline 18 & Boise & 1 & Slab & 7 \\
\hline$X X^{\text {a }}$ & Boise & 2 & Unvented Crawl & 20 \\
\hline 19 & Boise & 2 & Unvented Crawl & 7 \\
\hline
\end{tabular}

a Unsuccessful simulation in SEEM; excluded from all figures.

A thorough audit of the simulation inputs, assumptions, and model equations driving the EnergyPlus and SEEM air leakage models was conducted. The sources of discrepancy resulting from this audit are detailed in Table 8. Most of the discrepancies involve different inputs or assumptions, often from ambiguous or conflicting recommendations in the literature due to the difficulty of characterizing weather phenomena and buildings from sparse empirical data and a large number of unknown quantities (e.g., variety of shielding objects like buildings, trees, and hills in the nearby vicinity). The Literature column in the table illustrates some of this complexity and ambiguity.

Table 8. Air Leakage Sources of Discrepancy between BEopt/EnergyPlus and SEEM

\begin{tabular}{|c|c|c|c|c|}
\hline \multicolumn{2}{|c|}{ Source of Discrepancy } & SEEM Model & BEopt/EnergyPlus & Literature \\
\hline $\begin{array}{l}\text { Wind } \\
\text { Effect }\end{array}$ & $\begin{array}{l}\text { Terrain } \\
\text { power law } \\
\text { exponent }\end{array}$ & $\begin{array}{l}\text { Meteorological } \\
\text { (weather) station: } \\
\text { AIM-2 Terrain Class } 2 \\
\text { ("Suburban Detached } \\
\text { Housing, Mixed Woods } \\
\text { and Fields") } \\
p_{m}=0.16 \text { for }>3 \mathrm{~m} / \mathrm{s} \\
p_{m}=0.32 \text { for }<3 \mathrm{~m} / \mathrm{s} \\
\text { Site (building): AIM-2 } \\
\text { Terrain Class } 3 \text { ("Dense } \\
\text { Urban Housing with } \\
\text { Multi Story Buildings, } \\
\text { Heavy Forests") } \\
p_{s}=0.27 \text { for }>3 \mathrm{~m} / \mathrm{s} \\
p_{s}=0.38 \text { for }<3 \mathrm{~m} / \mathrm{s}\end{array}$ & $\begin{array}{l}\text { Meteorological } \\
\text { (weather) station: } \\
\text { ASHRAE Terrain } \\
\text { Category } 3 \text { ("Flat open } \\
\text { country typical of } \\
\text { meteorological station } \\
\text { surroundings") } \\
p_{m}=0.14 \\
\text { Site (building): } \\
\text { ASHRAE Terrain Class } \\
\text { per input } \\
p_{s}=0.10 \text { for ocean } \\
p_{s}=0.14 \text { for flat } \\
\text { country } \\
p_{s}=0.22 \text { for urban } \\
p_{s}=0.33 \text { for } \\
\text { towns/cities }\end{array}$ & $\begin{array}{l}\text { Walker \& Wilson } \\
\text { (1998): "For typical } \\
\text { urban housing } p \sim 0.3 \text {, } \\
\text { and for meteorological } \\
\text { stations located at } \\
\text { airports or other } \\
\text { exposed sites } p \sim 0.15 \text { " }\end{array}$ \\
\hline
\end{tabular}




\begin{tabular}{|c|c|c|c|c|}
\hline \multicolumn{2}{|c|}{ Source of Discrepancy } & \multirow{2}{*}{$\begin{array}{l}\text { SEEM Model } \\
\text { Meteorological } \\
\text { (weather) station: } \\
\text { AIM-2 assumption } \\
\sigma_{\mathrm{m}}=600 \mathrm{~m} \\
\text { Site (building): AIM-2 } \\
\text { assumption } \\
\sigma_{\mathrm{s}}=600 \mathrm{~m}\end{array}$} & \multirow[b]{2}{*}{$\begin{array}{l}\text { BEopt/EnergyPlus } \\
\text { Model } \\
\text { Meteorological } \\
\text { (weather) station: } \\
\text { ASHRAE Terrain } \\
\text { Category } 3 \\
\sigma_{m}=270 \mathrm{~m} \\
\text { Site (building): } \\
\text { ASHRAE Terrain Class } \\
\text { per input } \\
\sigma_{m}=210 \mathrm{~m} \text { for ocean } \\
\sigma_{m}=270 \mathrm{~m} \text { for flat } \\
\text { country } \\
\sigma_{m}=370 \mathrm{~m} \text { for urban } \\
\sigma_{m}=460 \mathrm{~m} \text { for } \\
\text { towns } / \text { cities }\end{array}$} & \multirow{2}{*}{$\begin{array}{l}\text { Literature } \\
\text { Walker and Wilson } \\
\text { (1990): "if we assume } \\
\text { that the wind speed at } \\
\text { the surface influenced } \\
\text { boundary layer height } z \\
=600 \mathrm{~m} \text { is the same } \\
\text { above the airport and } \\
\text { the building site ..." }\end{array}$} \\
\hline & $\begin{array}{l}\text { Terrain } \\
\text { power law } \\
\text { boundary } \\
\text { layer height }\end{array}$ & & & \\
\hline & Shelter & $\begin{array}{l}\text { AIM-2 Shelter Class } 3 \\
\text { ("Heavy shielding, } \\
\text { many large obstructions } \\
\text { within two house } \\
\text { heights") } \\
S_{w}=0.7\end{array}$ & $\begin{array}{l}\text { AIM-2 Shelter Class } \\
\text { based on building } \\
\text { height and neighbor } \\
\text { distance } \\
\mathrm{S}_{\mathrm{w}}=0.5 \text { to } 0.9\end{array}$ & \\
\hline & $\begin{array}{l}\text { Wind } \\
\text { direction }\end{array}$ & $\begin{array}{l}\text { Simiu and Scanlan } \\
\text { (1996): Two regimes: } \\
\text { 1) perpendicular to and } \\
\text { 2) oblique to house } \\
\text { orientation }\end{array}$ & $\begin{array}{l}\text { AIM-2 } \\
\text { Not explicitly } \\
\text { incorporated }\end{array}$ & \\
\hline $\begin{array}{l}\text { Stack } \\
\text { Effect }\end{array}$ & $\begin{array}{l}\text { Leakage } \\
\text { distribution }\end{array}$ & $\begin{array}{l}25 \% \text { ceiling, } 50 \% \text { walls, } \\
25 \% \text { floor for vented } \\
\text { crawl } \\
R=0.5 \\
X=0 \\
33 \% \text { ceiling, } 67 \% \text { walls, } \\
0 \% \text { floor for slab, } \\
\text { basement, and } \\
\text { unvented crawl } \\
R=0.33 \\
X=0.33\end{array}$ & $\begin{array}{l}\text { ASHRAE: } 25 \% \text { ceiling, } \\
50 \% \text { walls, } 25 \% \text { floor } \\
\text { for all foundation types } \\
\begin{array}{l}R=0.5 \\
X=0\end{array}\end{array}$ & $\begin{array}{l}\text { Walker and Wilson } \\
\text { (1998): } \\
\text { "Sherman and } \\
\text { Grimsrud ... defined the } \\
\text { "floor" leakage as those } \\
\text { leakage sites that are } \\
\text { located at (or near) the } \\
\text { level of the building } \\
\text { floor... The "ceiling" } \\
\text { leakage are the } \\
\text { leakage sites that are at } \\
\text { (or near) the ceiling } \\
\text { level of the upper } \\
\text { storey." } \\
\text { Walker and Wilson } \\
\text { (1998): } \\
\text { House } 4 \text { (basement)- } \\
\text { "estimated leakage } \\
\text { distributions covered a } \\
\text { range of } 10 \% \text { to } 45 \% \\
\text { for floors, } 35 \% \text { to } 60 \% \\
\text { for walls and } 20 \% \text { to } \\
40 \% \text { for the ceiling." }\end{array}$ \\
\hline
\end{tabular}




\begin{tabular}{|c|c|c|c|}
\hline Source of Discrepancy & SEEM Model & BEopt/EnergyPlus & Literature \\
\hline $\begin{array}{l}\text { Pressure } \\
\text { exponent }\end{array}$ & $n=0.65$ & $n=0.67$ & $\begin{array}{l}\text { Walker and Wilson } \\
\text { (1990): "typical value of } \\
2 / 3 \text { " } \\
\text { S-G: "usually assumed } \\
\text { to be } 0.65 \text { " }\end{array}$ \\
\hline $\begin{array}{l}\text { Stack + } \\
\text { Wind } \\
\text { Comb- } \\
\text { ination }\end{array}$ & $\begin{array}{l}\text { Add pressure } \\
\text { distributions }\end{array}$ & $\begin{array}{l}\text { ASHRAE: Quadrature } \\
\text { (square root } \\
\text { dependence) }\end{array}$ & $\begin{array}{l}\text { Walker and Wilson } \\
\text { (1990): Superposition } \\
\text { equation with negative } \\
\text { wind-stack pressure } \\
\text { interaction term to } \\
\text { empirically account for } \\
\text { building internal } \\
\text { pressure }\end{array}$ \\
\hline
\end{tabular}

To determine the effect of these discrepancies, the BEopt/EnergyPlus model was modified to be as consistent with the SEEM model as possible (while the choice of which model to modify for consistency is arbitrary, it was easier for NREL to modify the BEopt/EnergyPlus model). The changes are summarized in Table 9. Inherent model differences for handling wind direction and combining stack and wind effects remained.

Table 9. BEopt/EnergyPlus Air Leakage Modifications for Consistency with SEEM

\begin{tabular}{l} 
Use SEEM's foundation-specific leakage distribution for stack effect \\
Use SEEM's shelter factor for wind speed adjustment \\
Use SEEM's pressure exponent \\
Use SEEM's terrain algorithm for wind speed adjustment \\
\hline
\end{tabular}

Hourly air leakage rates for this modified BEopt/EnergyPlus model were then compared to the SEEM model. To disaggregate the wind and stack effects, two variations of each model simulation were run. The first variation used a custom weather file where the outdoor drybulb temperature was set equal to the heating set point, isolating the wind effect. The second variation used a custom weather file where the wind speed was set to zero, isolating the stack effect. The hourly results for stack-only infiltration, wind-only infiltration, and total infiltration, respectively, are shown in Figure 44, Figure 45, and Figure 46 for Runs \#2, \#4, and \#10, respectively. These three runs exercise the most important parameters across the full set of runs that influence air leakage, namely foundation type and number of stories. The figures also include the hourly results for these runs before the BEopt/EnergyPlus modifications were made.

Figure 44 shows excellent agreement between BEopt/EnergyPlus and SEEM for stack-only infiltration as a function of outdoor temperature. Figure 45 generally shows good agreement between BEopt/EnergyPlus and SEEM for wind-only infiltration as a function of meteorological wind speed, though SEEM has two regions of infiltration rates based on wind direction (perpendicular vs. oblique to house orientation) whereas the BEopt/EnergyPlus model does not 
explicitly capture wind direction. The combining of wind and stack infiltration into total infiltration, seen in Figure 46, illustrates good agreement between the two models for the first 1,000 hours of the year, though inherent model differences are reflected in the higher BEopt/EnergyPlus total infiltration rates in Runs \#4 and \#10, despite the fact that BEopt/EnergyPlus had lower wind-only infiltration rates in these runs. ${ }^{6}$

\footnotetext{
${ }^{6}$ There is similar agreement between the models for the rest of the hours in the year. For illustration purposes, only the first 1,000 hours are plotted.
} 
Run \#2
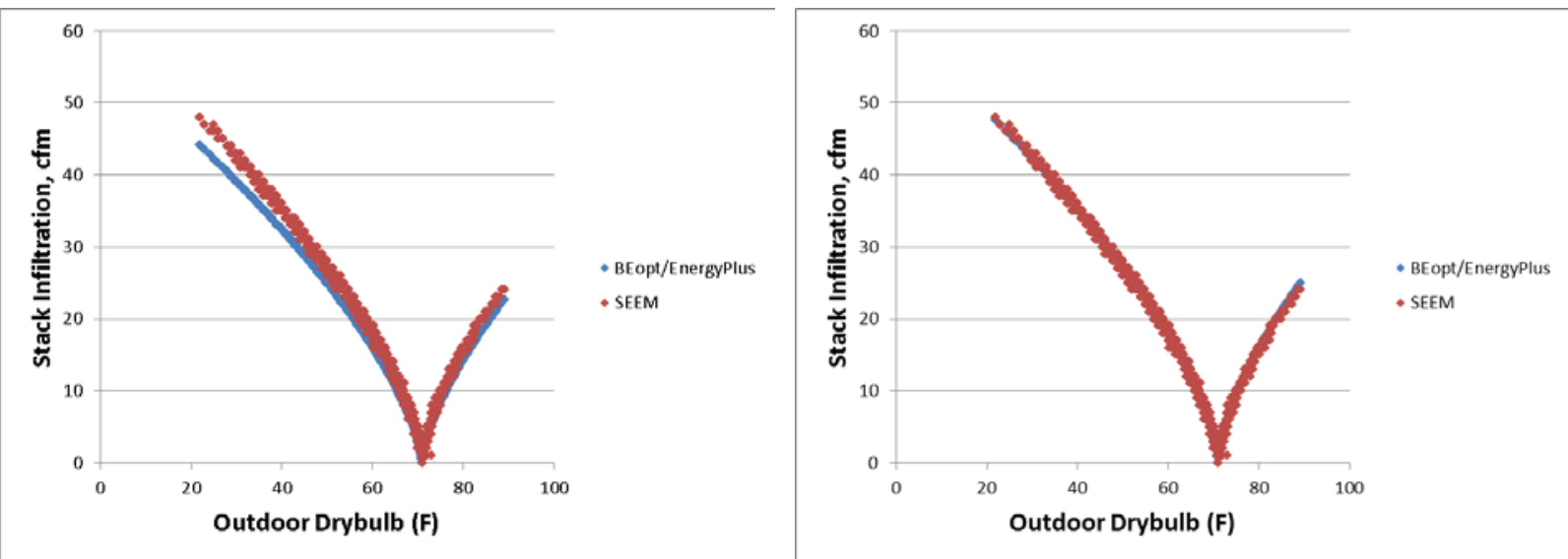

Run \#4
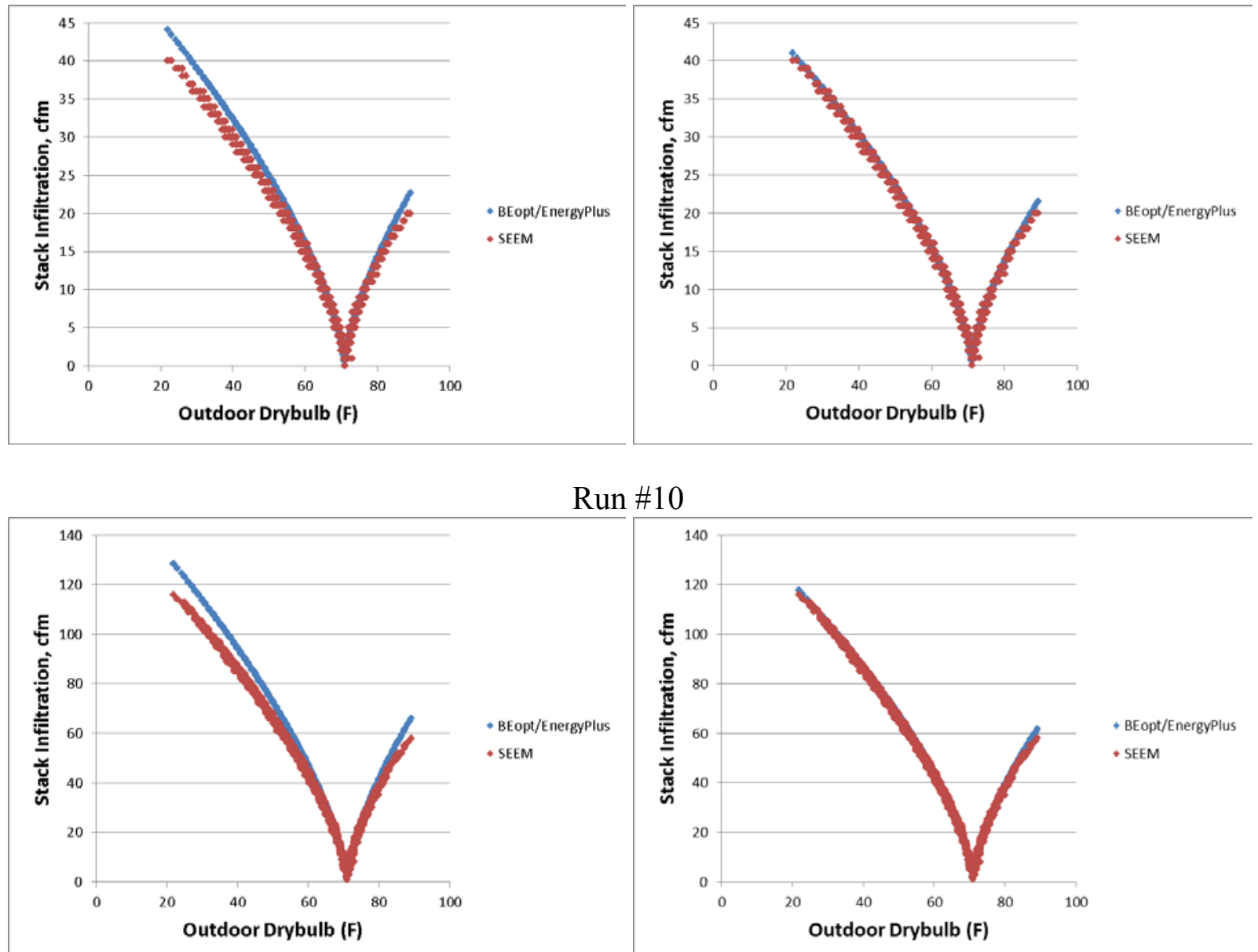

Figure 44. BEopt/EnergyPlus vs. SEEM, stack-only infiltration, initial (left) vs. modified (right) 
Run \#2
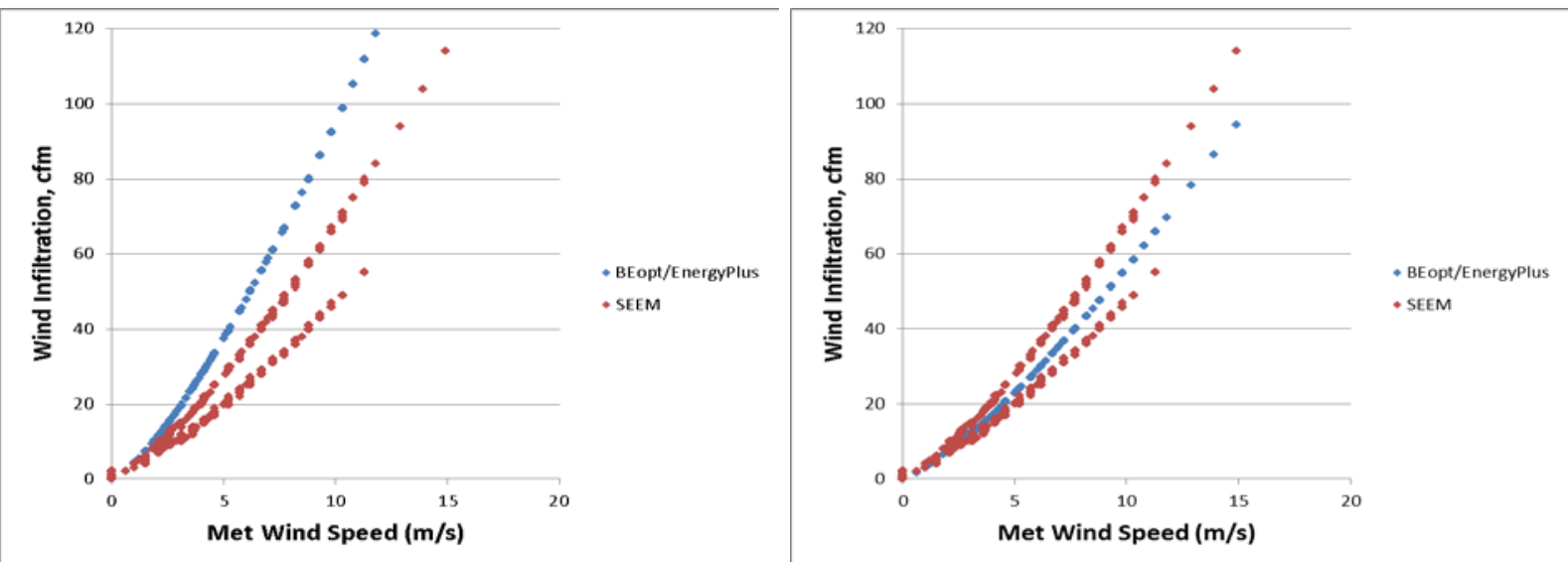

Run \#4
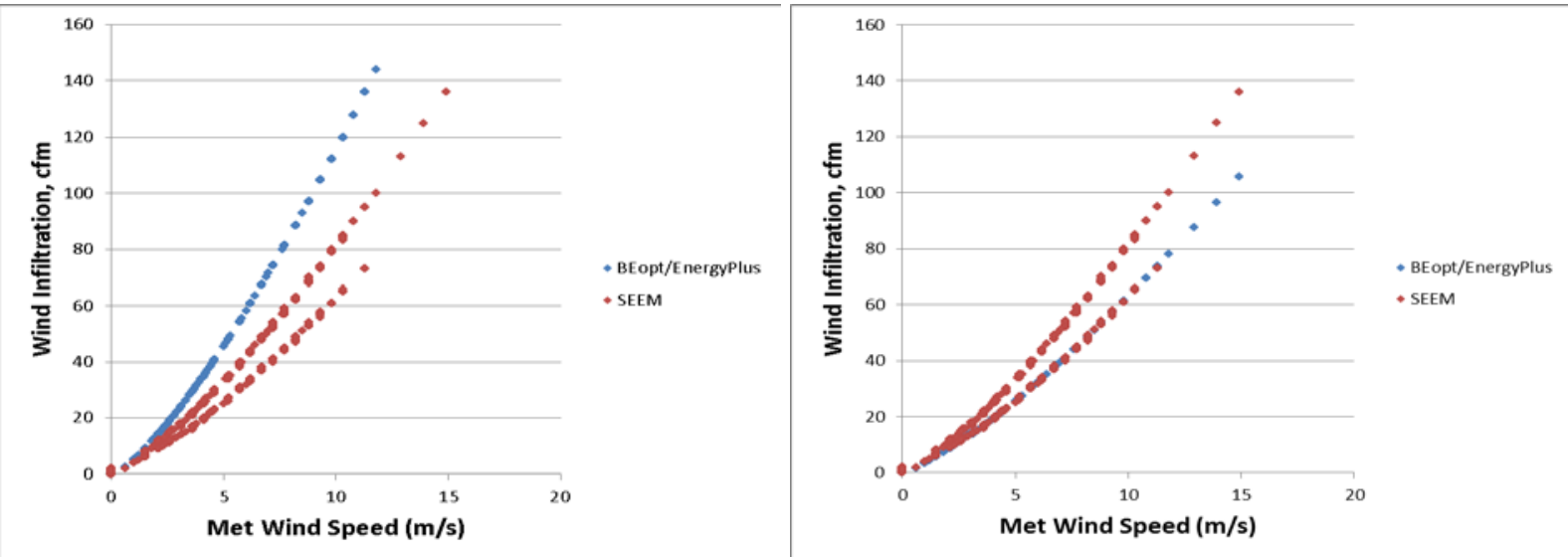

Run \#10
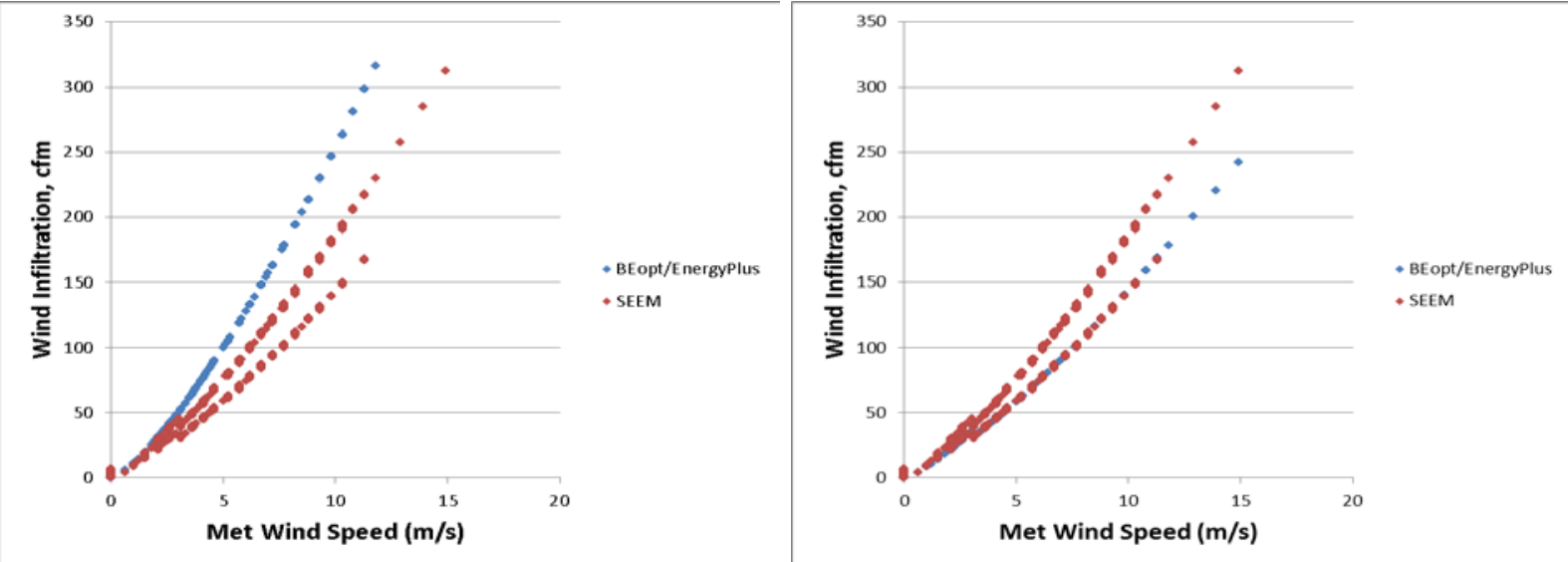

Figure 45. BEopt/EnergyPlus vs. SEEM, wind-only infiltration, initial (left) vs. modified (right) 
Run \#2
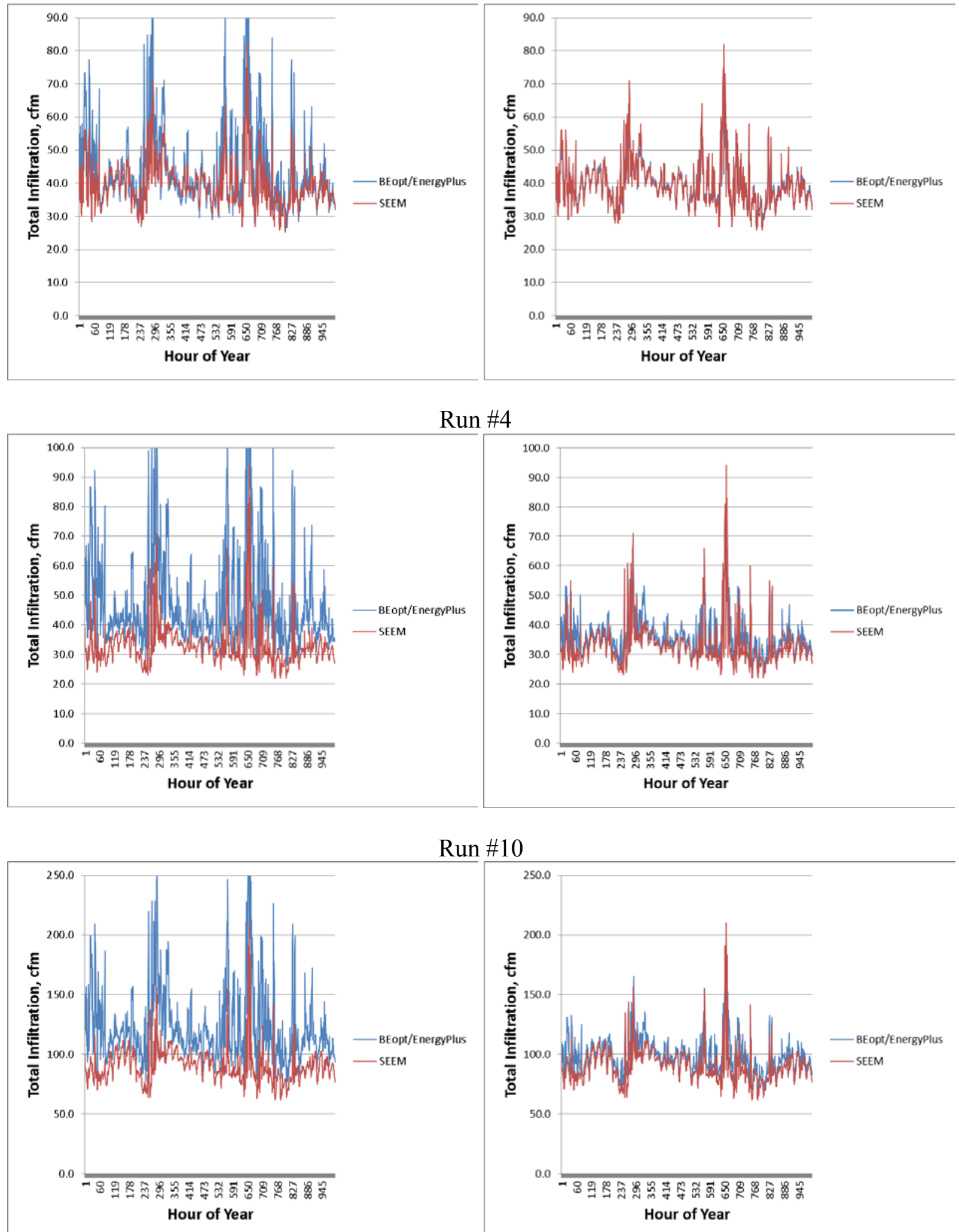

Figure 46. BEopt/EnergyPlus vs. SEEM, total infiltration, initial (left) vs. modified (right)

This report is available at no cost from the National Renewable Energy Laboratory (NREL) at www.nrel.gov/publications. 
Using the modified BEopt/EnergyPlus model across all the runs yields the annual heating energy discrepancies shown in Figure 47.

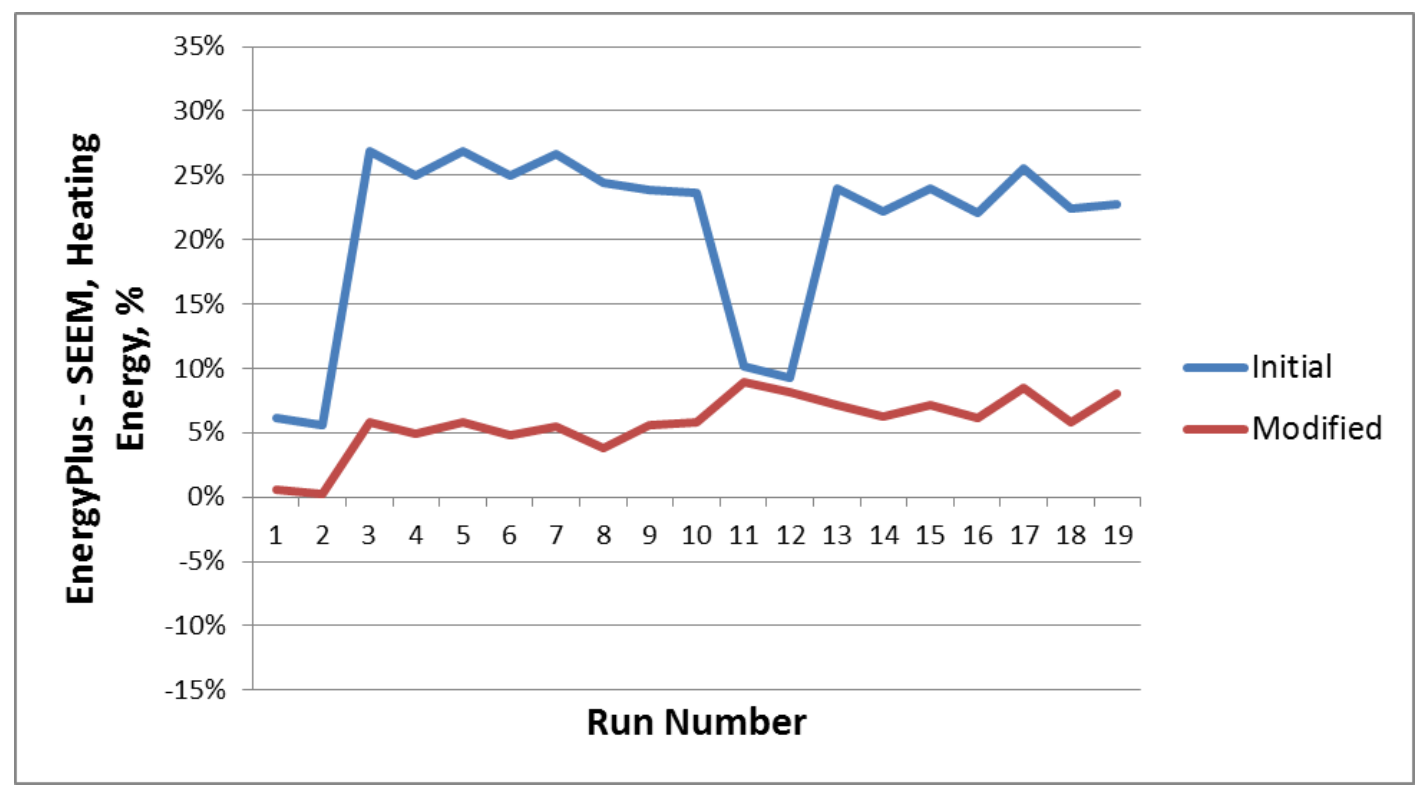

Figure 47. Modified BEopt/EnergyPlus vs. SEEM air leakage discrepancies, diagnostic buildings

By making many inputs, assumptions, and calculations consistent, the air leakage discrepancy was reduced significantly, from $5 \%-27 \%$ to $0 \%-9 \%$. This implies that even for these fundamentally different simulation engine models, a high degree of consistency can still be achieved in heating energy consumption over a broad range of building types and locations.

While the models can show good agreement using the modified BEopt/EnergyPlus model, there is still the question of which model inputs/assumptions/algorithms ought to be used. To understand the relative importance of each model change described in Table 9, the changes were removed from the modified model one at a time and the simulations were run again. The difference between BEopt/EnergyPlus and SEEM results for the modified results above were subtracted from the results for each of these new simulation runs to show the sensitivity to each parameter. The results, shown in Figure 48, suggest that each of these four changes is fairly equally important (all impact the heating energy due to air leakage by roughly $7 \%$ to $15 \%$ ). 


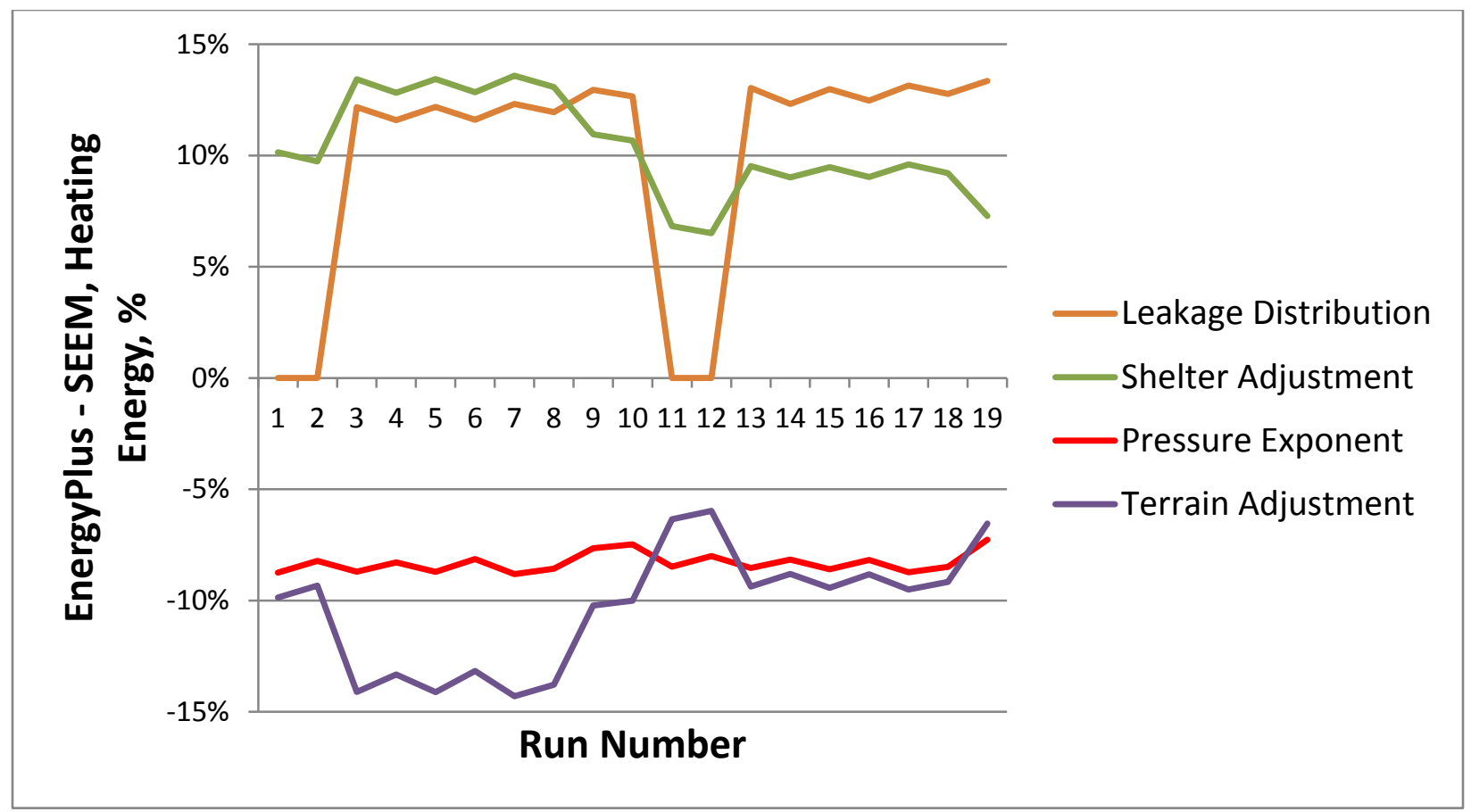

Figure 48. BEopt/EnergyPlus vs. SEEM sensitivity analysis, diagnostic buildings

After combing through the literature, discussing with Ecotope, and reaching out to LBL, NREL developed the recommendations described in Table 10. Note the difficulty in developing these recommendations, as all four sources of discrepancies are significant (sometimes even for seemingly small differences in inputs), and there is general ambiguity in the literature surrounding many of these parameters. For example, the pressure exponent was very similar in the two models $(0.65$ and 0.67$)$, and both inputs were reasonable given values in the literature, yet the choice of input can impact the model results by approximately $7 \%$.

Table 10. Final Recommendations for Air Leakage Modeling Enhancements

\begin{tabular}{|l|l|l|l|}
$\begin{array}{l}\text { Source of } \\
\text { Discrepancy }\end{array}$ & $\begin{array}{l}\text { Recommendations for } \\
\text { SEEM }\end{array}$ & \multicolumn{1}{|l|}{$\begin{array}{l}\text { Recommendations for } \\
\text { BEopt/EnergyPlus }\end{array}$} & \multicolumn{1}{|l|}{ Notes } \\
\hline & $\begin{array}{l}\text { Add terrain category as } \\
\text { an input. } \\
\text { Update terrain category } \\
\text { definitions per ASHRAE. }\end{array}$ & None & $\begin{array}{l}\text { Choice of terrain category } \\
\text { can have significant impact. }\end{array}$ \\
\cline { 2 - 4 } & $\begin{array}{l}\text { Add neighbor distance } \\
\text { input to auto-calculate } \\
\text { shelter class, or provide } \\
\text { shelter class as an } \\
\text { input. } \\
\text { Update shelter class } \\
\text { definitions per ASHRAE }\end{array}$ & None & $\begin{array}{l}\text { Choice of shelter class can } \\
\text { have signicant impact. }\end{array}$ \\
\hline
\end{tabular}




\begin{tabular}{|l|l|l|l|}
$\begin{array}{l}\text { Source of } \\
\text { Discrepancy }\end{array}$ & $\begin{array}{l}\text { Recommendations for } \\
\text { SEEM }\end{array}$ & $\begin{array}{l}\text { Recommendations for } \\
\text { BEopt/EnergyPlus }\end{array}$ & Notes \\
\hline Stack Effect & $\begin{array}{l}\text { Use 25\% ceiling, 50\% } \\
\text { walls, 25\% floor leakage } \\
\text { distribution for } \\
\text { slab/basement/unvented } \\
\text { crawl. } \\
\text { Use 15\% ceiling, 35\% } \\
\text { walls, 50\% floor leakage } \\
\text { distribution for vented } \\
\text { crawl. }\end{array}$ & $\begin{array}{l}\text { Use 15\% ceiling, 35\% } \\
\text { walls, 50\% floor } \\
\text { leakage distribution for } \\
\text { vented crawl. }\end{array}$ & $\begin{array}{l}\text { Leakage distribution } \\
\text { recommendations per email } \\
\text { correspondence with lain } \\
\text { Walker at LBL. }\end{array}$ \\
\hline $\begin{array}{l}\text { Pressure } \\
\text { exponent }\end{array}$ & None & None & \\
\hline
\end{tabular}

The BEopt/EnergyPlus modeling recommendation (for leakage distribution of houses with vented crawlspaces) has been included in the latest BEopt 2.5 release.

Finally, there are a couple additional potential improvements that could be made to both of these models looking forward. These potential improvements have not been thoroughly evaluated at this time.

- Both BEopt/EnergyPlus and SEEM assume buildings have no flue. The AIM-2 model includes corrections specifically for buildings with flues.

- Both BEopt/EnergyPlus and SEEM use the power law equation, widely used in North America and Japan, to adjust wind speed for terrain. There are several more complex alternatives available, generally cited as being more accurate, including:

○ Log-law model, used in much of Europe

- Deaves and Harris logarithmic model, adopted by the UK, Australia, and New Zealand

○ Davenport model, used in the Canadian HOT2000 software.

\subsection{Foundation Heat Transfer}

Another area of significant discrepancies in Phase I was foundation heat transfer.

\subsubsection{BEopt/EnergyPlus Model}

BEopt/EnergyPlus uses the Winkelmann method (Winkelmann 2002), where overall perimeter conductance factors for different foundation types, wall heights, and insulation levels and configurations have been pre-calculated using a two-dimensional finite-difference program (Huang et al. 1988). To use this approach, the EnergyPlus foundation constructions (floor for slabs, walls for basements or crawlspaces) are modeled with an underground surface; 1 foot of soil; and a fictitious, massless insulating layer. The R-value of this fictitious layer is calculated based on the overall perimeter conductance factor and the R-values of the soil and wall construction. As all of the building's foundation heat transfer is meant to be captured by this 
fictitious wall construction for a basement or crawlspace, the floor can be modeled to include capacitance, but as a super-insulated surface. The Winkelmann method is designed to work with the Kusuda ground temperature algorithm.

EnergyPlus explicitly models radiation between surfaces, and so a radiation film coefficient does not need to be provided. For convection, EnergyPlus has several algorithms available. In BEopt/EnergyPlus, the Thermal Analysis Research Program (TARP) algorithm is used for interior surfaces (Walton 1983) and the DOE-2 algorithm is used for exterior surfaces (Yazdanian and Klems 1994).

All crawlspaces and basements are modeled in BEopt/EnergyPlus as a separate zone from the above-grade living space.

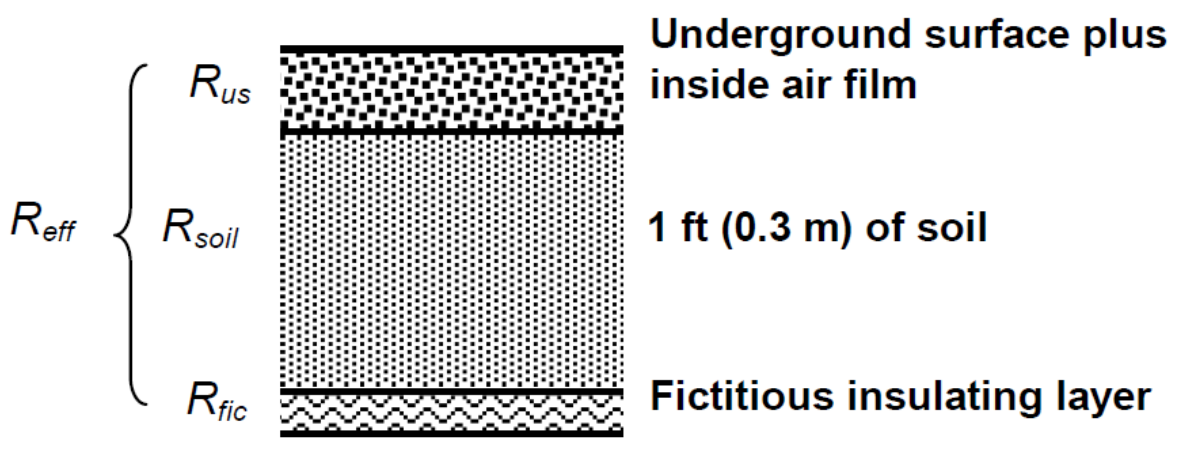

Figure 49. Schematic of the overall wall construction from the Winkelmann method

More recent versions of EnergyPlus include enhanced heat transfer algorithms ${ }^{7}$ and as well as several new ground temperature models. Preliminary connections to these models have been made, but no final conclusions can be drawn at this time. With DOE's interest, NREL will be continuing to assess the model's applicability and accuracy for residential buildings in the upcoming year.

\subsubsection{SEEM Model}

The SEEM model, inspired by the work of Joe Carroll (Carroll and Clinton 1980) at the University of California - San Diego Energy Center, calculates the heat transfer between a series of four nodes with thermal capacitance located successively deeper underground to calculate the foundation heat transfer. The lowest node temperature is calculated as a weighted average between the assumed deep ground temperature and the node above. The next highest node transfers heat between the nodes above and below it, with the amount of heat transferred dependent on the soil properties, as well as to the outdoors. The UA value used for calculating how much heat is transferred to the outdoors is based on ISO 13370, which provides analytic approximations for three-dimensional ground heat transfer. The next highest node is a weighted average of the nodes above and below it. The highest node transfers heat into the space

\footnotetext{
${ }^{7}$ At the time of publication, EnergyPlus includes a foundation model called Ground Domain, adapted from its active fluid-to-ground models used for ground loop heat exchangers, foundation heat exchangers, and earth tubes. However, there is work underway to replace this model with 1) a regression-based model, BASESIMP (BeausoleilMorrison and Mitalas 1997), used widely in Canada's HOT2000 software and 2) a detailed, two-dimensional ground heat transfer model, Kiva (Kruis 2015).
} 
(crawlspace, basement, or living space for a home with a slab) and to the node below it. A schematic of this nodal network is provided in Figure 50.

To account for convection and radiation in SEEM, the user must include combined convection plus radiation film coefficients in the surface assembly R-values. For this work, the combined film coefficients recommended by Ecotope were used for all SEEM runs. This difference relative to BEopt/EnergyPlus can lead to discrepancies in heating energy between the two models, particularly for uninsulated surfaces where convection and radiation dominate heat transfer.

SEEM models heated basements as a single zone combined with the above-grade living space, while unheated basements and crawlspaces are modeled as separate zones.

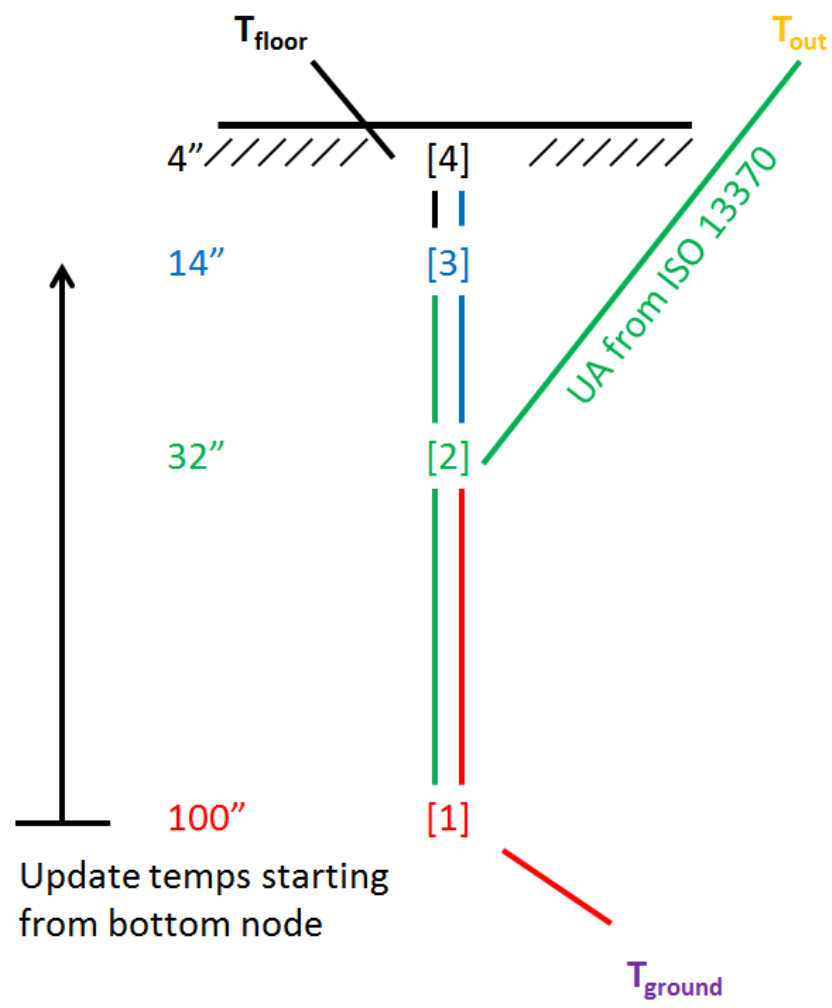

Figure 50. Schematic of the SEEM ground coupling modeling approach

\subsubsection{Results}

To aid in comparisons between the two engines, a number of modifications were made to both models to obtain as consistent a set of inputs/assumptions as possible.

First, corrections were made to the fraction of the foundation wall modeled as above ground in SEEM (to 8 inches from 12 inches) to be consistent with the assumptions in the Winkelmann methodology.

Second, for crawlspaces and basements, the SEEM-recommended ACH values (4.5 for vented crawlspaces, 0.35 for unvented crawlspaces, and 0.5 for basements) were implemented in both 
BEopt/EnergyPlus and SEEM for consistency. These values differ from the defaults used in BEopt/EnergyPlus (2.0 for vented crawlspace, $0-0.1$ for unvented crawlspaces and basements). The impact of having different default assumptions between BEopt/EnergyPlus and SEEM has not been explored here.

Finally, the EnergyPlus space heating equipment in the diagnostic test building was changed to electric baseboards rather than an electric furnace. This change was made since a fixed fraction of the heat provided by an electric furnace in BEopt/EnergyPlus goes to the basement, which leads to the basement sometimes being over/under-conditioned in the swing seasons. By using electric baseboards, both the basement and the living space would individually maintain set point, which is consistent with how heated basements are modeled in SEEM (the heated basement and living space are a single zone). As a result, the SEEM results show some heating HVAC fan/pump energy use that is not present in the BEopt/EnergyPlus results. Since the electricity consumed by the fan ultimately becomes heat that gets delivered to the conditioned space, the sum of the HVAC fan/pump energy and heating energy in SEEM can be compared to the heating energy consumption in BEopt/EnergyPlus.

Upon comparing BEopt/EnergyPlus and SEEM, a bug was discovered when mapping BEopt inputs to SEEM that affected all foundations. The bug, involving the calculation of the R-value of the floor for SEEM runs, led to the carpet R-value being incorrectly applied twice. This bug was fixed.

All of these modifications are included in the new test suite results shown in the subsequent sections.

\subsubsection{Crawlspace Results}

Results for crawlspaces are shown in Figure 51. The change in crawlspace ACH inputs increased the energy consumption across all runs compared to the Phase I results. Uninsulated cases now show good agreement, with less than $5 \%$ difference between the two engines. However, there is still a discrepancy in the sensitivity of heating energy to wall insulation level, with BEopt/EnergyPlus showing much higher sensitivity. 


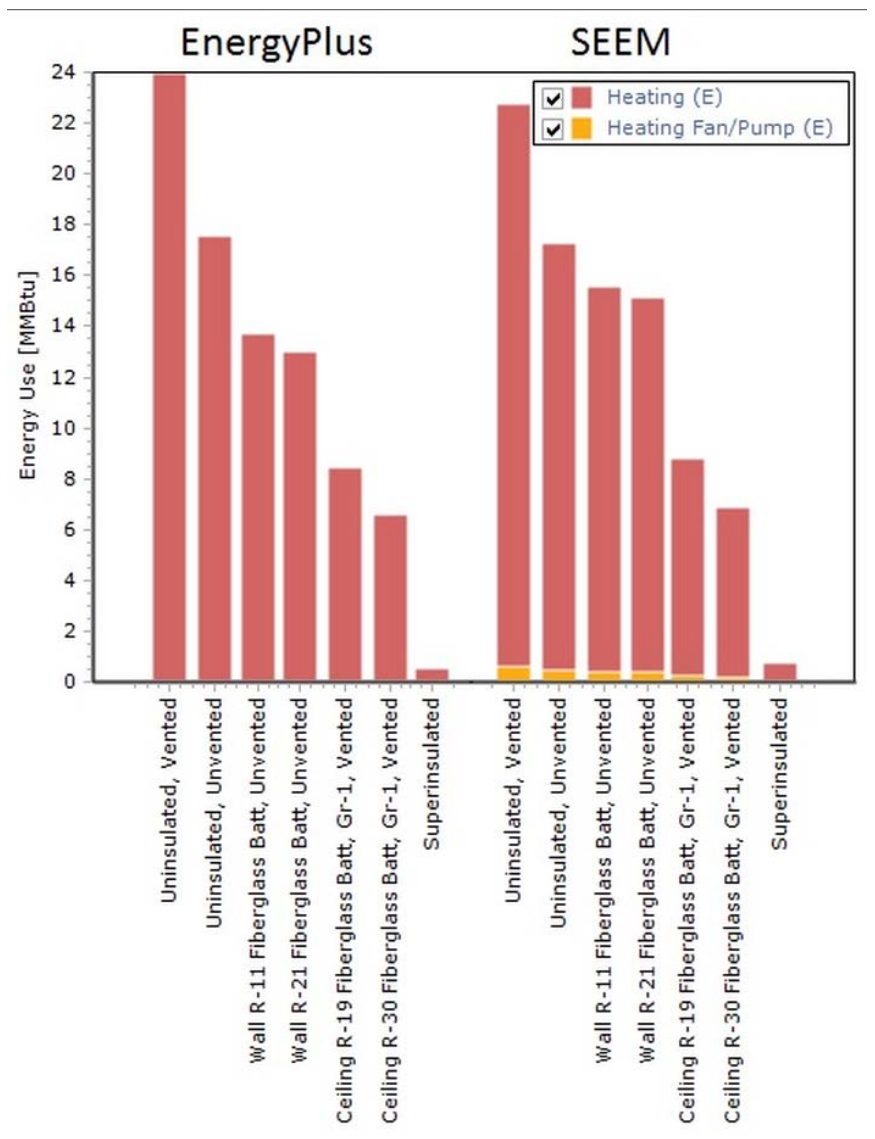

Figure 51. Crawlspace results, diagnostic building

\subsubsection{Unheated Basement Results}

New results for unheated basements are shown in Figure 52. The new ACH input for unheated basements in both cases is higher, leading to increased overall energy consumption compared to Phase I results. Uninsulated runs now have less than 10\% difference, and ceiling insulation results match to within 2\%. However, as was seen for crawlspaces, BEopt/EnergyPlus shows higher sensitivity to the impact of wall insulation. 


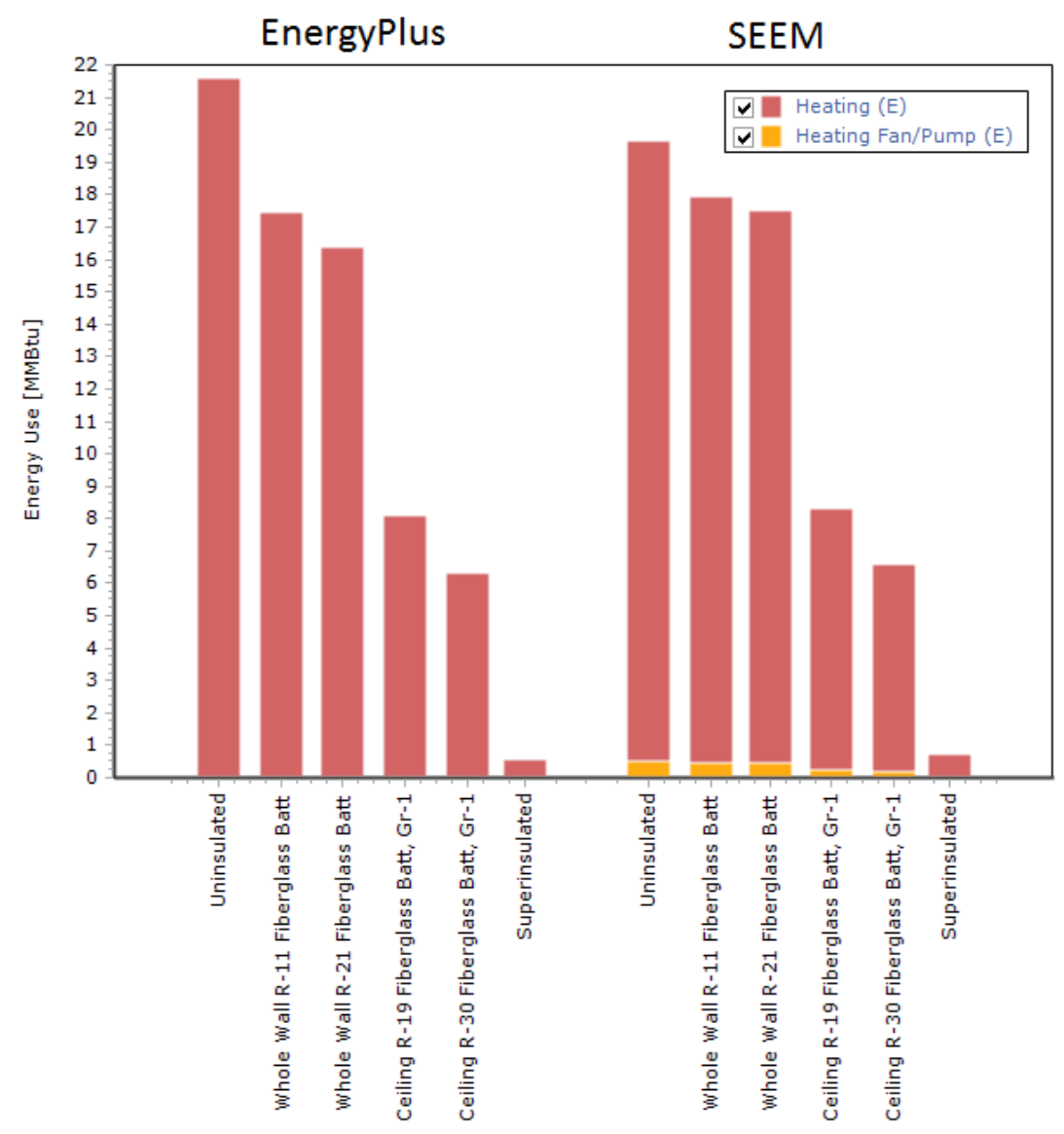

Figure 52. Unheated basement results, diagnostic building

\subsubsection{Heated Basement Results}

New results for heated basements are shown in Figure 53. The Phase I BEopt/EnergyPlus results showed significantly lower heating energy consumption than SEEM. This was in large part due to using an electric furnace in BEopt/EnergyPlus, as previously described. Once again, the new results show BEopt/EnergyPlus is much more sensitive to the level of basement insulation, with higher energy consumption in uninsulated runs and lower energy consumption in insulated runs. 


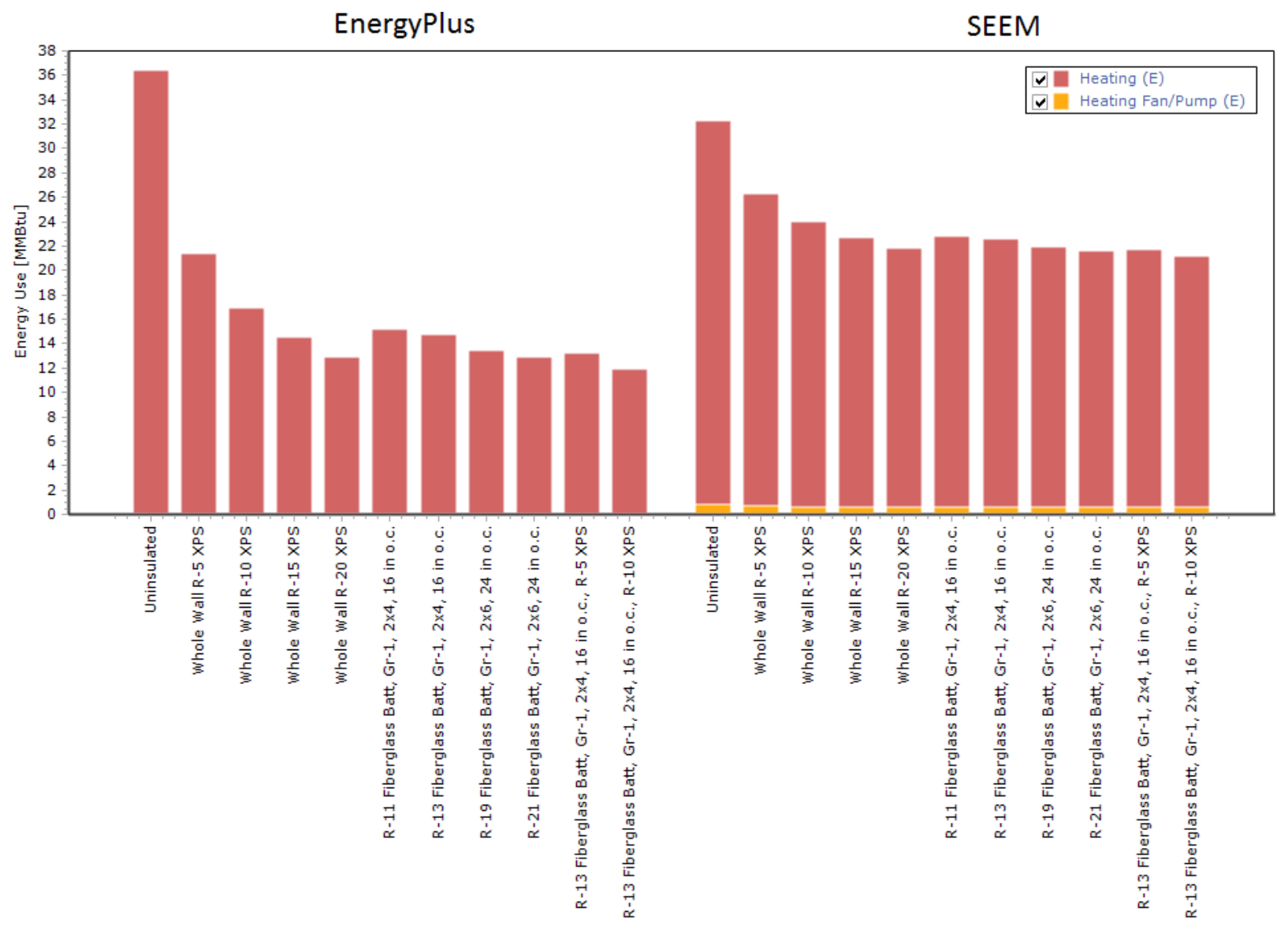

Figure 53. Heated basement results, diagnostic building

\subsubsection{Overall Results}

Even with the bug fixes and improvements made to more accurately and consistently model foundations in BEopt/EnergyPlus and SEEM, some discrepancies remain due to the fundamental differences in modeling approaches used for foundation heat transfer. These differences generally manifest as higher heating energy sensitivity in BEopt/EnergyPlus to wall insulation for all foundation types. Given sparse field data to serve as a truth standard and high sensitivity to soil properties and weather patterns (e.g., rain and snow), it is difficult to assess the accuracy of the respective simulation engines.

Looking forward, the enhanced EnergyPlus models could help to provide clarity by providing additional results that the SEEM and Winkelmann models can be compared against.

\subsection{Ducts}

In Phase I, it was difficult to assess the BEopt/EnergyPlus and SEEM duct models because the diagnostic test building with an unvented crawlspace produced simulation errors in SEEM. Results from the new construction test building with a vented crawlspace showed modest discrepancies between the two engines for leaky, uninsulated ducts, though it is hard to specifically attribute this discrepancy to the duct models given all various model differences 
(e.g., default crawlspace ventilation rates and therefore temperatures) that could contribute to discrepancies in the new construction building.

\subsubsection{BEopt/EnergyPlus Model}

BEopt contains a number of inputs to describe a duct system, including supply and return leakages, surface areas, and insulation levels as well as duct location and utilizes assumptions in the Building America HSP. While EnergyPlus does not have a simple residential duct model available, BEopt can model duct conduction, leakage, and airflow interactions (e.g., with infiltration, natural ventilation, and mechanical ventilation) via EnergyPlus EMS routines. A schematic of the air leakage model is shown in Figure 54.

The EMS duct model is a steady-state, load-based model that uses EnergyPlus Other Equipment objects to account for supply and return duct conduction and leakage. Supply and return duct losses are handled in slightly different ways - supply duct losses are added directly to the living and duct zones, whereas return duct losses are accounted for in an adiabatic plenum to account for the impact of the duct load on the return temperature at the inlet of the coil. (An adiabatic plenum is used to improve the stability of the EnergyPlus simulation for uninsulated duct assemblies.)

Conduction to or from the supply and return air streams is calculated using the log-mean temperature difference between the corresponding air stream and duct zone temperatures. For the supply conduction load, EnergyPlus Other Equipment objects placed in the living and duct zones account for the duct load on the equipment and impact on the duct zone temperature. Return duct conduction is handled in a similar way; however, the Other Equipment object is placed in the return plenum as opposed to the living space.

Duct leakage is also accounted for using EnergyPlus Other Equipment objects. Sensible and latent leakage loads are calculated based on the leakage air flow rate and temperature or humidity difference between the air stream and duct zone. The leakage imbalance and interzonal air flow rate is calculated based on the assumptions included in the Building America HSP and is accounted for using an EnergyPlus Zone Mixing object. 


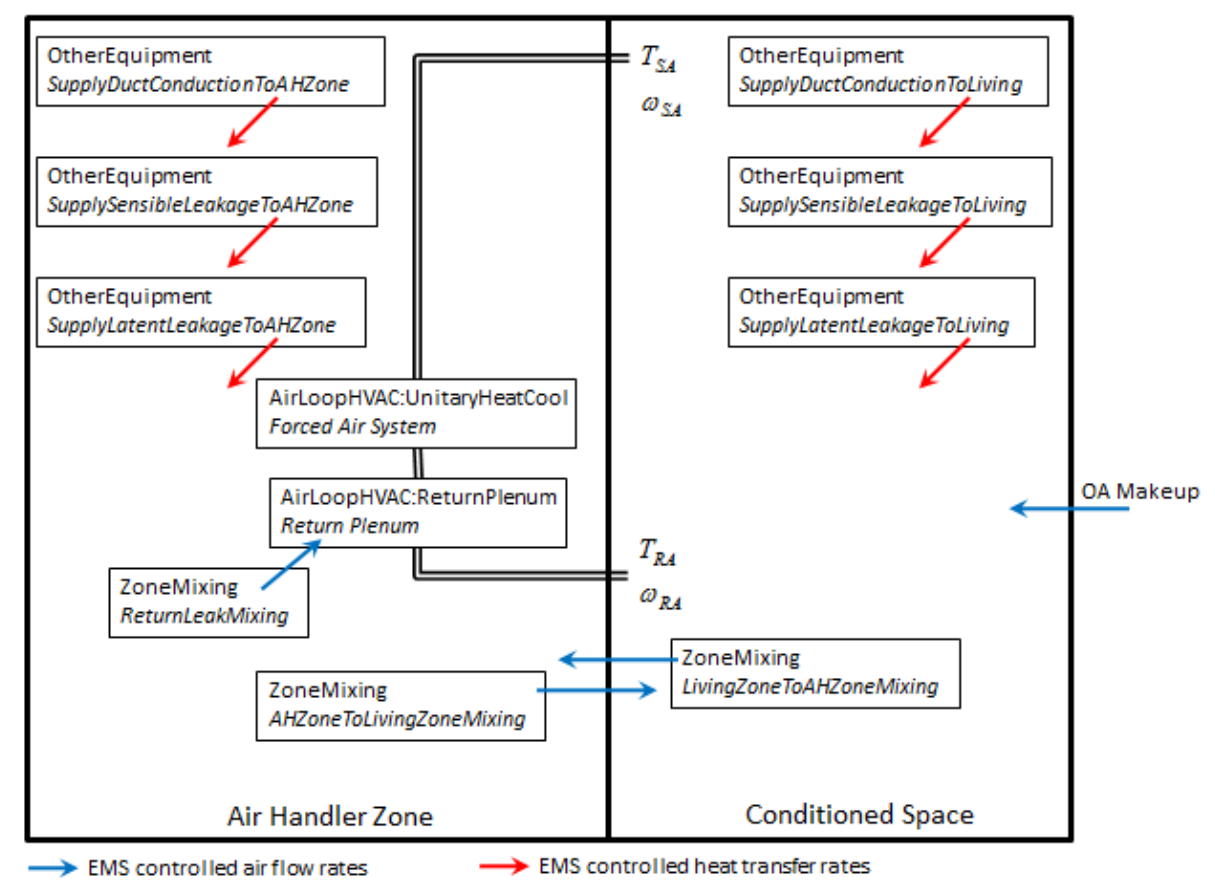

Figure 54. Schematic of EnergyPlus EMS duct air leakage model

Alternatively, EnergyPlus has a sophisticated Airflow Network model that can evaluate duct conduction, leakage, and imbalanced airflow interactions. However, the model is more complex to use, requires additional inputs/assumptions, and increases simulation runtime. In addition, the current version has limitations that prevent it from being used for multi-family buildings with individual HVAC systems, though the EnergyPlus development team considers it a high priority to relax this constraint. Preliminary connections to this model have been made and initial results compare well to the EMS model, but no final conclusions can be drawn at this time. With DOE's interest, NREL will be continuing to assess the model's applicability and accuracy for residential buildings in the upcoming year.

\subsubsection{SEEM Model}

SEEM largely contains the same input parameters for describing duct systems. Starting with SEEM94, any duct leakage imbalance is taken into account by its new pressure-based infiltration model. In lieu of a detailed description of the SEEM duct model, for which good documentation is scarce, a general overview is provided here.

The duct model was written by Larry Palmiter to implement the basic equations described in ASHRAE Standard 152. These equations, and the ones in SEEM, calculate heat transfer between the ducts and buffer spaces. They account for duct air leakage and conductive heat losses. Those heat transfers change the temperature of the buffer spaces (crawl or attic), which, in turn, change the load on the house relative to a "no ducts" scenario. Duct leakage is also tied in to the overall infiltration calculations for the house. All duct related calculations are conducted whenever the air handler is running and at every sub-hourly time step. 


\subsubsection{Investigation and Results}

The best way to isolate the energy impact of duct losses in the two simulation engines involves locating the ducts in a highly vented crawlspace in the diagnostic test building. This has two advantages: 1) it eliminates any heating energy discrepancies due to residual differences in the crawlspace temperature (e.g., due to differences in foundation heat transfer algorithms), and 2) it generally avoids the issue where SEEM yields simulation errors for ducts in unvented crawlspaces.

Therefore diagnostic building simulations were run with the crawlspace ACH set to 5 in both EnergyPlus and SEEM. This should largely decouple the crawlspace from the effects of foundation heat transfer and produce crawlspace temperatures that approximate outdoor temperatures. Figure 55 demonstrates that the EnergyPlus and SEEM crawlspace temperatures are nearly identical for a building located in Seattle, setting up a good test environment for testing duct insulation and leakage.

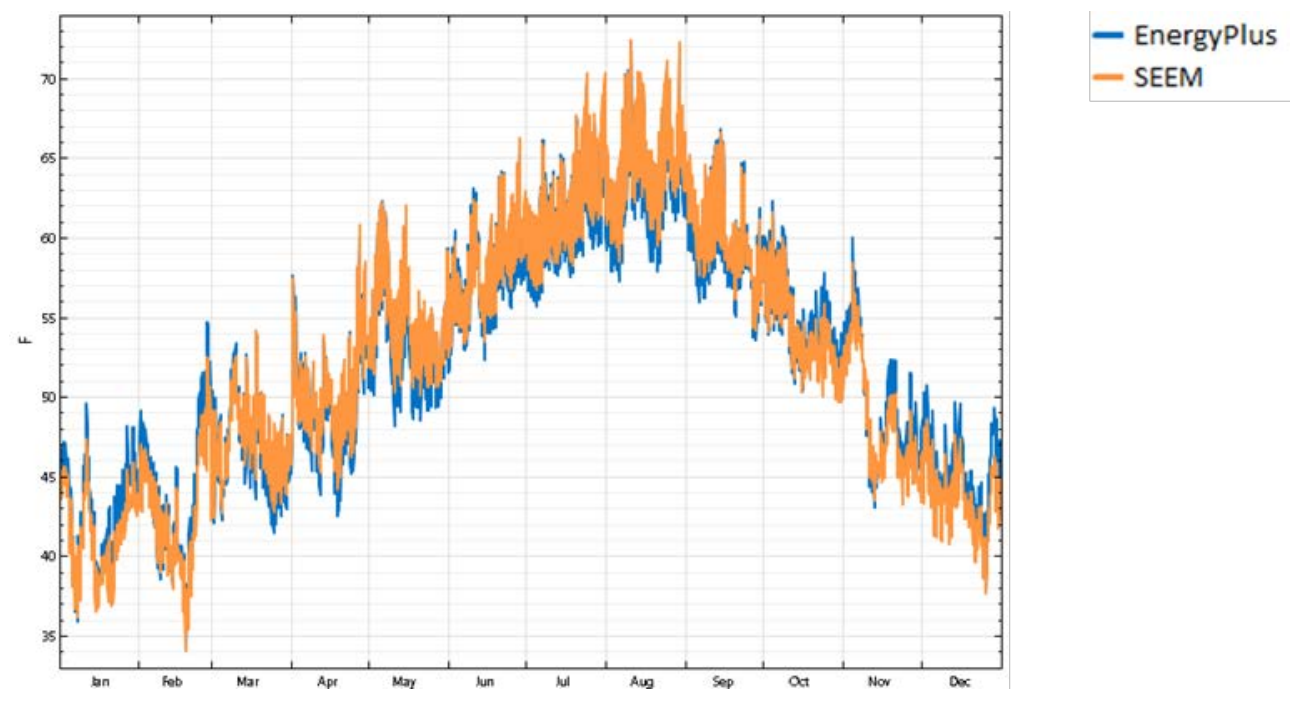

Figure 55. Highly vented crawlspace temperatures, diagnostic building

A variety of duct leakage conditions (very leaky to tight) and insulation levels (uninsulated to highly insulated) were run in this test building. Test suite results for these cases are shown in Figure 56. While the results appear to substantially agree, it is important to isolate the heating energy use associated solely with the duct models. This can be achieved by taking the difference between heating energy for any given duct case (e.g., 20\% Leakage, R-8) and the None (or perfect ducts) case; these results SEEM are shown in Figure 57. These results demonstrate a duct model discrepancy of anywhere from $-10 \%$ to $20 \%$. 


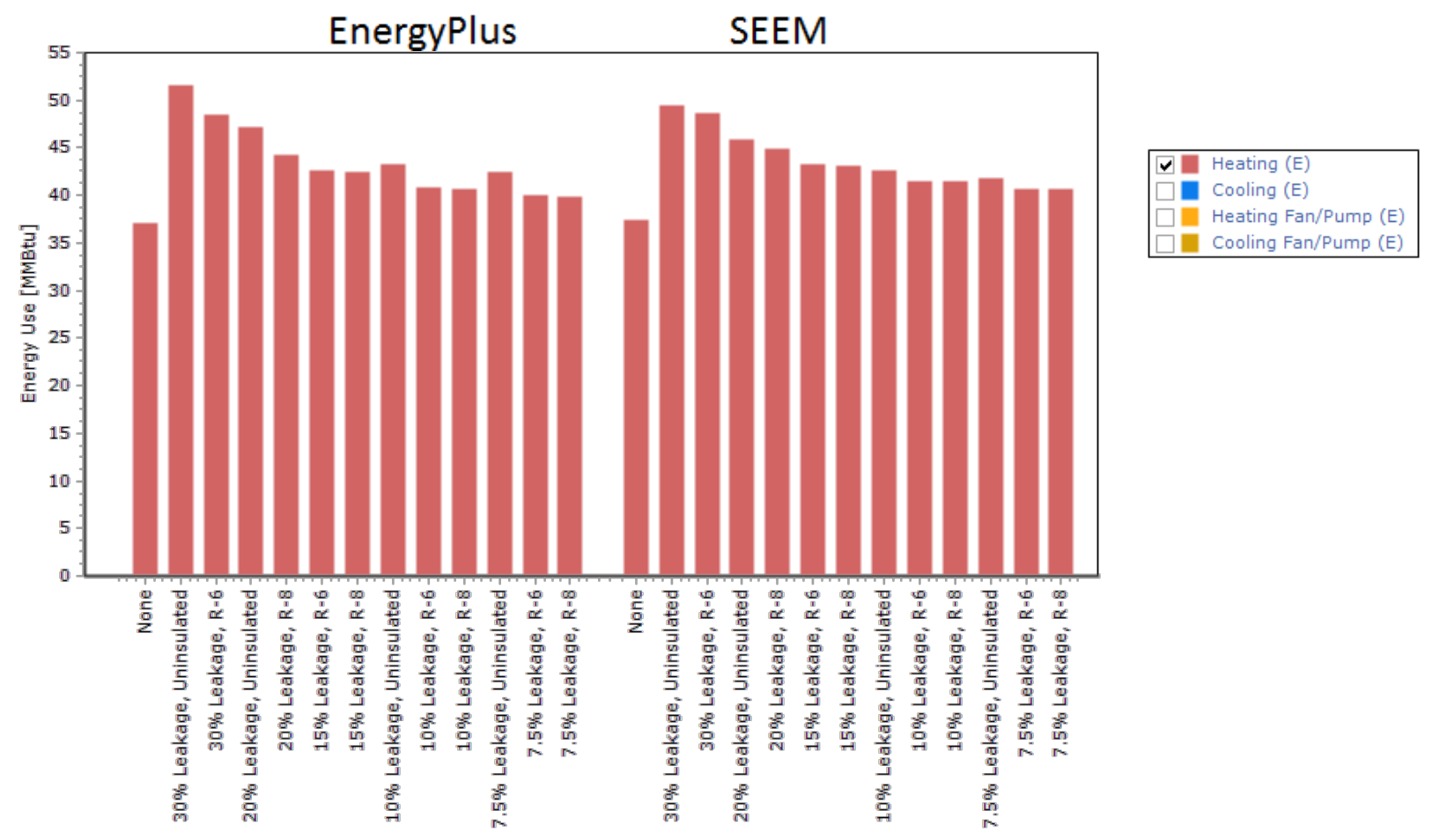

Figure 56. BEopt/EnergyPlus vs. SEEM duct results, diagnostic building

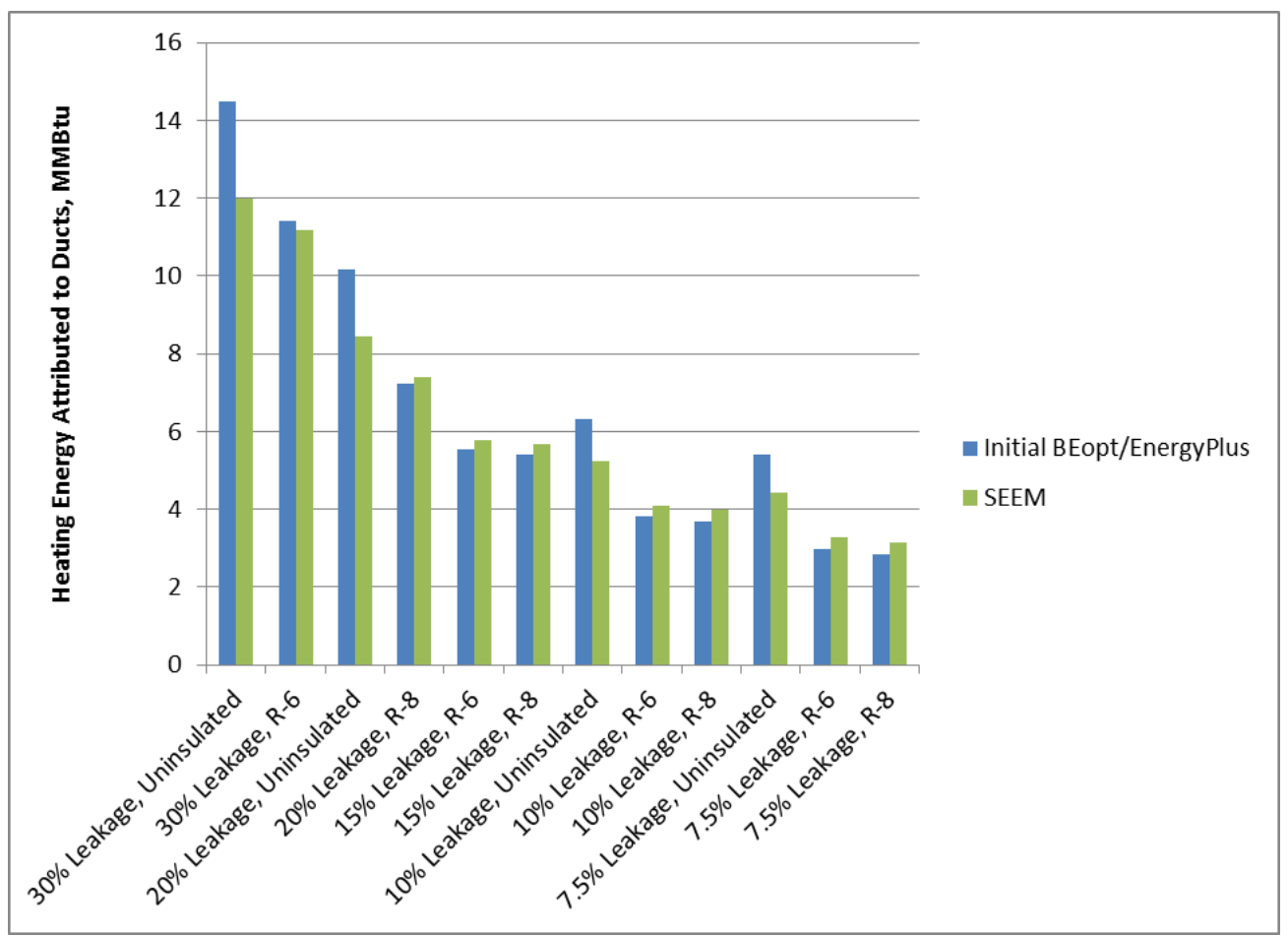

Figure 57. Initial BEopt/EnergyPlus vs. SEEM duct heating results, diagnostic building

There are two primary mechanisms by which ducts affect heating energy: 1) airflow escaping/entering (supply/return side) through leaks, holes, or unsealed joints; and 2) heat 
transfer through the ducts by conduction (and convection/radiation). For the characterization of airflow leakage, it was confirmed that BEopt/EnergyPlus and SEEM are using identical specifications/inputs for supply and return ducts. However, BEopt/EnergyPlus and SEEM were found to have significant differences in duct insulation inputs.

In both engines, nominal insulation R-values need to be converted to actual R-values used for heat transfer, taking into account convection and radiation heat transfer coefficients for example. In BEopt/EnergyPlus, the nominal insulation R-value of the duct insulation is added to the assumed interior plus exterior film coefficients (R-1.7 total). When using SEEM, it has been typical practice to assume round, flexible ducts and to correspondingly derate the nominal insulation value (nominal values are given for flat materials) to its actual value due to the effects of cylindrical geometry (Palmiter and Kruse 2006). In addition, it is common to use as SEEM inputs different R-values for supply and return ducts, given the same nominal R-value, by assuming varying runs of different duct sizes in the average home for supply (mostly 6 in. -8 in. ducts) and return (14-in. ducts). Typical uninsulated duct inputs for SEEM are R-2 (total of interior plus exterior film coefficients).

The differences between these duct insulation inputs can be seen in Figure 58. For insulated ducts, the cylindrical geometry effect in SEEM has a pronounced effect. Compared to the SEEM supply/return average, BEopt values are 20\%-30\% higher for insulated ducts. For uninsulated ducts, SEEM is higher than BEopt by $15 \%$. By looking at U-values in Figure 59, which correlate with duct heat transfer, the impact of the differences in uninsulated duct R-values can be better observed.

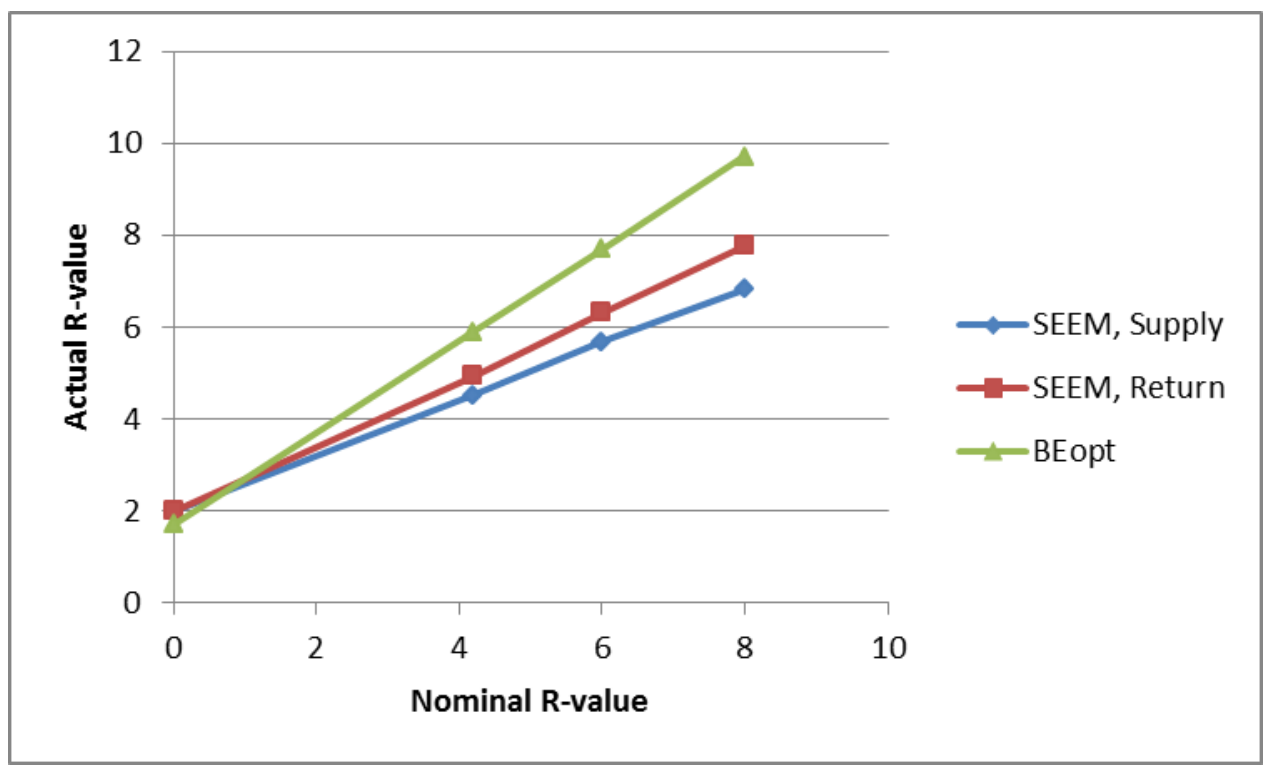

Figure 58. Actual R-value vs. nominal R-value for duct insulation 


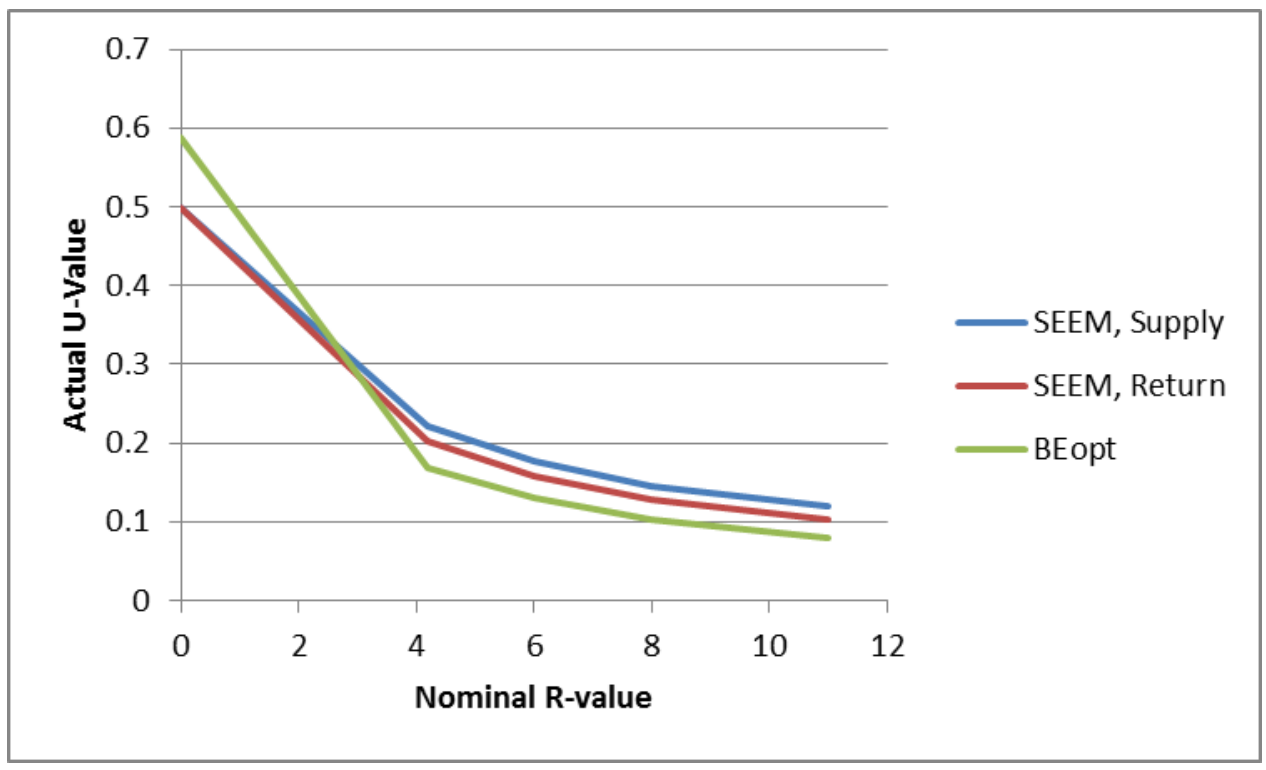

Figure 59. Actual U-value vs. nominal R-value for duct insulation

To quantify the effect of these insulation R-value differences on the heating energy discrepancy, BEopt/EnergyPlus uninsulated and insulated duct R-values, including film coefficients, were modified to be equal to those used in SEEM for consistency. These results are shown in Figure 60. Heating energy differences between the two simulations were reduced from a range of $-10 \%$ to $20 \%$ to $-3 \%$ to $14 \%$, with discrepancies for insulated ducts essentially eliminated, leaving relatively modest discrepancies for uninsulated ducts remaining.

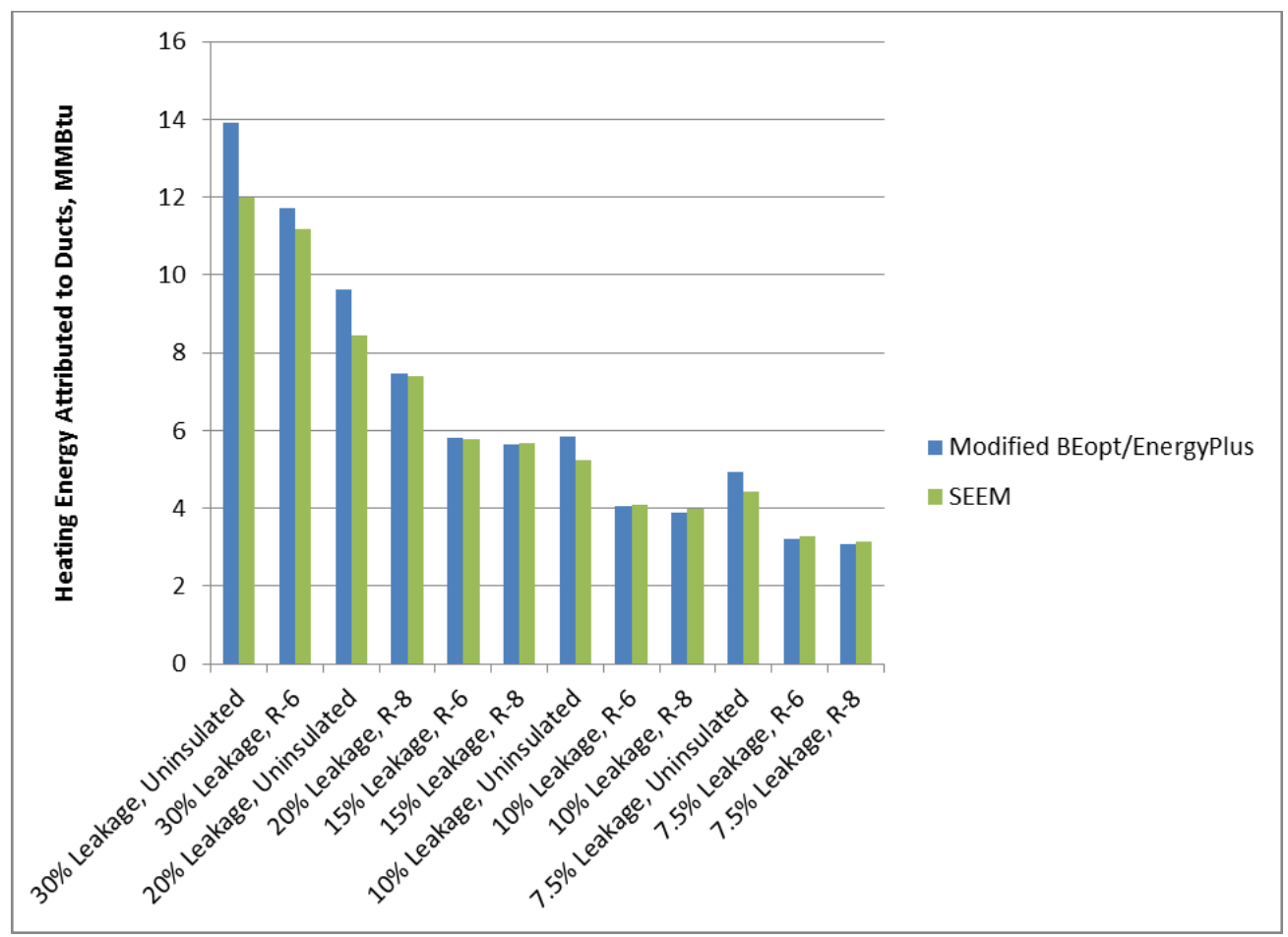

Figure 60. Modified BEopt/EnergyPlus vs. SEEM duct heating results, diagnostic building 
While the models can show very good agreement when using the same duct insulation inputs, there is still the question of which inputs ought to be used. For insulated ducts, Palmiter and Kruse (2006) provide calculations for derating nominal insulation R-values for round ducts, which are typical for supply ducts in residential buildings. Thus, changes have been made to the BEopt/EnergyPlus model to incorporate this cylindrical geometric effect and will be included in BEopt 2.5.0.1.

For uninsulated ducts, the entire thermal resistance is due to the internal and external film coefficients. Ecotope was unable to recall how an actual duct R-value of 2 was selected for SEEM. It appears likely that this value was derived by linear extrapolation from the insulated duct options, as can be easily observed in Figure 58. In BEopt/EnergyPlus, a value of R-1.7 was chosen based on the 2001 ASHRAE Handbook of Fundamentals for uninsulated sheet metal with an air velocity at $500 \mathrm{ft} / \mathrm{min}$. A review of the Palmiter and Kruse paper suggests reasonable values from R-1.46 to R-1.98 (based on a range of U-0.2 to U-0.6 for the external radiation film coefficient for shiny foil or galvanized metal exteriors, depending on the age and emissivity of the metal), with an average value of R-1.7. As the average value from Palmiter and Kruse matches the value obtained from ASHRAE, it is recommended that the R-value for uninsulated ducts in SEEM be modified from R-2 to R-1.7. 


\section{Conclusions}

As part of this multi-phase study, comprehensive comparative testing between BEopt/EnergyPlus and SEEM was performed to 1) determine the differences in energy consumption predictions between these two residential building energy simulation programs, and 2) reconcile discrepancies as possible. To perform the comparative testing, NREL used BEopt's Test Suite capabilities to automatically compare tens of thousands of equivalent buildings between SEEM and EnergyPlus. The NREL team modified the Test Suite to accommodate prototype buildings, technologies, and climates typical to the Northwest.

Phase I identified significant discrepancies between EnergyPlus and SEEM that were classified as:

- Three discrepancies resolved. The NREL and Ecotope teams worked together to identify and fix errors in SEEM.

- Seven discrepancies partially investigated. The NREL and Ecotope teams initially studied these discrepancies, but these require more work to determine the appropriate resolution.

- Ten discrepancies not yet investigated. These discrepancies have not been analyzed, but their magnitude makes them important to analyze.

Phase II demonstrated a number of modeling enhancements, bug fixes, and future recommendations across the five prioritized categories for the Pacific Northwest (mini-split heat pumps, heat pump water heaters, air leakage, foundation heat transfer, and ducts). As a result, the final assessment of the discrepancies for these categories is:

- Four categories resolved. Mini-split heat pumps, heat pump water heaters, air leakage, and ducts.

- One category partially resolved. Foundation heat transfer. Due to inherent differences in the EnergyPlus and SEEM models, as well as lack of empirical data with which to assess the accuracy of the models, no further reconciliation can be achieved.

All BEopt/EnergyPlus modeling enhancements, bug fixes, and recommendations have been implemented in the latest releases, with the exception of completed assessments of enhanced EnergyPlus models (e.g., Airflow Network). 


\section{References}

ASHRAE. (2001). 2001 ASHRAE Handbook of Fundamentals. Atlanta, GA.

Baylon, D.; Larson, B.; Storm, P.; Geraghty, K. (2012). Ductless Heat Pump Impact \& Process Evaluation: Field Metering Report. Seattle, WA.

Booten, C.; Kruis, N.; Christensen, C. (2012). Identifying and Resolving Issues in EnergyPlus and DOE-2 Window Heat Transfer Calculations. Golden, CO: National Renewable Energy Laboratory. NREL/TP-5500-55787.

Beausoleil-Morrison, I.; Mitalas, G. (1997). "BASESIMP: A Residential-Foundation Heat-Loss Algorithm for Incorporating Into Whole-Building Energy Analysis Programs." Proceedings of Building Simulation '97, Prague, Czech Republic.

Carroll, J.A.; Clinton, J.R. (1980). "A Thermal Network Model of a Passive Solar House.” Proc. 5th National Passive Solar Conference. Amherst, MA.

Ecotope, Inc. (2013). DHP UES Key Issues \& Decisions. Seattle, WA.

Ecotope, Inc. (2015). Heat Pump Water Heater Model Validation Study. Seattle, WA.

Hendron, R.; Engebrecht, C. (2010). Building America Research Benchmark Definition. Golden, CO: National Renewable Energy Laboratory. NREL/TP-550-47246.

Huang, Y.J.; Shen, L.; Bull, J.; Goldberg, L. (1988). "Whole-House Simulation of Foundation Heat Flows Using the DOE-2.1C Program." ASHRAE Transactions 94(2).

ISO Standard ISO 13370: Thermal Performance of Buildings. Heat Transfer via the Ground. Calculation Methods. (1998).

Judkoff, R.; Neymark, J. (2006). "Model Validation and Testing: The Methodological Foundation of ASHRAE Standard 140." Presented at ASHRAE 2006 Annual Meeting, 24-29 June 2006, Quebec City, Canada. Golden, CO: National Renewable Energy Laboratory. NREL/CP-550-41015.

Kruis, N. (2015). Development and Application of a Numerical Framework for Improving Building Foundation Heat Transfer Calculations. Boulder, CO.

Logsdon, M; Larson, B. (2011). SEEM: Infiltration Model Overview and Update Summary. Prepared by Ecotope, Inc. for Northwest Energy Efficiency Alliance Contract \#40218. 22 December 2011.

Palmiter, L.; Kruse, E. (2006). “True R-Values of Round Residential Ductwork.” Presented at 2006 ACEEE Summer Study on Energy Efficiency in Buildings.

Polly, B.; Horowitz, S.; Booten C.; Kruis N.; Christensen C. (2012). "Automated Comparison of Building Energy Simulation Engines." Golden, CO: National Renewable Energy Laboratory. NREL/PR-5500-52651. 
Polly, B.; Kruis, N.; Roberts, D. (2011). Assessing and Improving the Accuracy of Energy Analysis Methods for Residential Buildings. Golden, CO: National Renewable Energy Laboratory. NREL/TP-5500-50865.

Sherman, M.H.; Grimsrud, D.T. (1980). Measurement of Infiltration Using Fan Pressurization and Weather Data. Windsor, England: LBL.

Simiu, E.; Scanlan, R. (1996). Wind Effects on Structures. Third Edition, John Wiley and Sons.

Sparn, B.; Hudon, K.; Christensen, D. (2011). Laboratory Performance Evaluation of Residential Integrated Heat Pump Water Heaters. Golden, CO: National Renewable Energy Laboratory. NREL/TP-5500-52635

Tabares-Velasco, P.C.; Griffith, B. (2012). "Diagnostic Test Cases for Verifying Surface Heat Transfer Algorithms and Boundary Conditions in Building Energy Simulation Programs." Journal of Building Performance Simulation 5 (5): 329-346.

Walker, I.S.; Wilson, D.J. (1990). The Alberta Air Infiltration Model: AIM-2. The University of Alberta, Department of Mechanical Engineering. Technical Report 71.

Walker, I.S.; Wilson, D.J. (1998). "Field Validation of Algebraic Equations for Stack and Wind Driven Air Infiltration Calculations.” ASHRAE HVAC\&R Research Journal, 4 (2).

Walton, G.N. (1983). Thermal Analysis Research Program Reference Manual. NBSSIR 83-2655.

Wilson, E.; Christensen, C. (2012). "Heat Pump Water Heater Modeling in EnergyPlus." Presented at Building America Residential Energy Efficiency Stakeholder Meeting. Golden, CO: National Renewable Energy Laboratory. NREL/PR-5500-54318.

Winkler, J. (2011). Laboratory Test Report for Fujitsu 12 RLS and Mitsubishi FE12NA MiniSplit Heat Pumps. Golden, CO: National Renewable Energy Laboratory. NREL/TP-5500-52175.

Winkelmann, F. (2002). "Underground Surfaces: How To Get a Better Underground Surface Heat Transfer Calculation in DOE-2.1E.” Building Energy Simulation User News 23 (6): 5-15.

Yazdanian, M.; Klems, J. H. (1994). "Measurement of the Exterior Convective Film Coefficient for Windows in Low-Rise Buildings." ASHRAE Transactions, 11, (1). 


\section{Appendix A: Mapping Table}

This table summarizes the BEopt inputs mapped to SEEM during Phase I. This table is largely the same for Phase II, though some additional inputs (e.g., for heat pump water heaters) were mapped.

\section{Table 11. Summary of BEopt Inputs Mapped to SEEM}

\begin{tabular}{|c|c|c|c|}
\hline $\begin{array}{l}\text { Building Model } \\
\text { Category }\end{array}$ & Category Options & Mapped & Mapping Notes/lssues \\
\hline Weather & & YES & $\begin{array}{l}\text { SEEM calculates sky temperature based on air temperature and dew point } \\
\text { temperature. EnergyPlus calculates sky temperature from weather file data (epw) } \\
\text { horizontal infrared radiation from sky. }\end{array}$ \\
\hline $\begin{array}{l}\text { Material } \\
\text { Properties }\end{array}$ & & YES & Only SEEM material property input is R-value. \\
\hline Garage & & YES & Garage zone is not modeled in SEEM but it is modeled in EnergyPlus \\
\hline Geometry & Geometry Screen & YES & $\begin{array}{l}\text { Roof pitch in SEEM is fixed (1:4); in BEopt/EnergyPlus this is an input variable } \\
\text { Volume and area are mapped, but actual shape and related external shading is not } \\
\text { due to SEEM limitations. }\end{array}$ \\
\hline \multirow{3}{*}{ Building } & Orientation & YES & $\begin{array}{l}\text { SEEM has no input for wall orientation. Windows can only be oriented north, south, } \\
\text { east, or west. For cases with other orientations, the closest available orientation was } \\
\text { chosen. }\end{array}$ \\
\hline & Neighbors & YES & Houses simulated do not have neighbors because they cannot be input in SEEM. \\
\hline & Bed/Bathrooms & YES & Included in sensible and latent gain magnitude and schedules. \\
\hline \multirow{7}{*}{ Operation } & Heating Set Pt & YES & \\
\hline & Cooling Set Pt & YES & \\
\hline & Humidity Set Pt & NO & No humidity control in SEEM, humidity set points were not used for comparisons. \\
\hline & Heating Season & YES & \\
\hline & Cooling Season & YES & \\
\hline & MELs & YES & Included in sensible and latent gain magnitude and schedules. \\
\hline & MGLs & YES & Included in sensible and latent gain magnitude and schedules. \\
\hline
\end{tabular}




\begin{tabular}{|c|c|c|c|}
\hline $\begin{array}{l}\text { Building Model } \\
\text { Category }\end{array}$ & Category Options & Mapped & Mapping Notes/lssues \\
\hline & Misc HW loads & YES & Included in sensible and latent gain magnitude and schedules. \\
\hline & Occupancy & YES & Included in sensible and latent gain magnitude and schedules. \\
\hline & Schedules & YES & Can only have one weekly schedule, no monthly variation in gains. \\
\hline & DHW gains & YES & Included in sensible and latent gain magnitude and schedules. \\
\hline & Vacations & NO & No vacations in SEEM, vacations were not used in comparisons. \\
\hline & Natural Ventilation & NO & $\begin{array}{l}\text { All simulated houses did not have natural ventilation because here is no natural } \\
\text { ventilation model in SEEM. This is an input variable in BEopt/EnergyPlus }\end{array}$ \\
\hline & Interior Shading & YES & SEEM uses the average value of the winter and summer shading multipliers. \\
\hline \multirow{8}{*}{ Walls } & Wood Stud & YES & $\begin{array}{l}\text { Construction type was mapped based on stud dimensions and cavity insulation. } R \text { - } \\
\text { value and thermal mass was not } 100 \% \text { mapped as in SEEM the only input is R-value. }\end{array}$ \\
\hline & Double Wood Stud & NO & \multirow{2}{*}{$\begin{array}{l}\text { No concrete masonry unit or double wood stud models in SEEM. These are walls that } \\
\text { are hard to represent with a single R-value. }\end{array}$} \\
\hline & $\begin{array}{l}\text { Concrete Masonry } \\
\text { Unit }\end{array}$ & NO & \\
\hline & $\begin{array}{l}\text { Structural Insulated } \\
\text { Panel }\end{array}$ & YES & \\
\hline & $\begin{array}{l}\text { Insulating Concrete } \\
\text { Form }\end{array}$ & NO & $\begin{array}{l}\text { No insulating concrete form wall model in SEEM. These are walls that are hard to } \\
\text { represent with a single R-value. }\end{array}$ \\
\hline & Other & NO & No other wall models in SEEM. \\
\hline & Exterior Finish & NO & No input in SEEM. \\
\hline & Adiabatic Walls & YES & \\
\hline \multirow{3}{*}{ Ceilings/Roofs } & Finished Roof & YES & $\begin{array}{l}\text { Cathedral ceiling is modeled in SEEM as an unfinished attic with } \mathrm{ACH}=0.5 \text {. EnergyPlus } \\
\text { models an actual the vaulted ceiling. }\end{array}$ \\
\hline & $\begin{array}{l}\text { Unfinished Attic } \\
\text { (Ceiling) }\end{array}$ & YES & Same mapping method as wood stud walls. \\
\hline & Roof Material & YES & Emissivity is not an input in SEEM. \\
\hline
\end{tabular}




\begin{tabular}{|c|c|c|c|}
\hline $\begin{array}{c}\text { Building Model } \\
\text { Category }\end{array}$ & Category Options & Mapped & Mapping Notes/lssues \\
\hline & Radiant Barrier & NO & No radiant barrier model in SEEM. \\
\hline \multirow{5}{*}{$\begin{array}{l}\text { Foundations/ } \\
\text { Floors }\end{array}$} & Slab & YES & \\
\hline & Carpet & YES & \\
\hline & Crawlspace & YES & \\
\hline & Finished Basement & YES & \\
\hline & $\begin{array}{l}\text { Unfinished } \\
\text { Basement }\end{array}$ & YES & \\
\hline \multirow{4}{*}{ Thermal Mass } & Floor Mass & YES & \multirow{7}{*}{$\begin{array}{l}\text { SEEM does not have inputs for these categories. However, all of these categories } \\
\text { were set to have same thickness to SEEM. Nevertheless, the total thermal mass } \\
\text { between EnergyPlus and SEEM it not } 100 \% \text { mapped but preliminary calculations using } \\
\text { default equations in both engines showed results within } \pm 15 \% \text {. }\end{array}$} \\
\hline & Exterior Wall Mass & YES & \\
\hline & Partition Wall Mass & YES & \\
\hline & Ceiling Mass & YES & \\
\hline \multirow{3}{*}{$\begin{array}{l}\text { Internal Thermal } \\
\text { Mass }\end{array}$} & Interior walls & YES & \\
\hline & Interior floors & YES & \\
\hline & $\begin{array}{l}\text { Furniture and heavy } \\
\text { contents }\end{array}$ & NO & \\
\hline \multirow{4}{*}{$\begin{array}{l}\text { Windows and } \\
\text { Doors }\end{array}$} & Window Areas & YES & \\
\hline & Windows & YES & \\
\hline & Eaves & NO & No eaves in SEEM. \\
\hline & Overhangs & NO & No overhangs in SEEM. \\
\hline \multirow[t]{2}{*}{ Airflow } & Air Leakage & YES & $\begin{array}{l}\text { Infiltration was mapped based on the ACH50; however, the sheltering coefficient and } \\
\text { terrain were not mapped because there are no inputs related to these values in SEEM. } \\
\text { In addition, BEopt/EnergyPlus does not model infiltration from attic/crawlspace to living } \\
\text { space and SEEM does have interzonal infiltration between these zones. }\end{array}$ \\
\hline & $\begin{array}{l}\text { Mechanical } \\
\text { Ventilation }\end{array}$ & YES & Energy recovery ventilators are not included in SEEM and are not run in this study. \\
\hline
\end{tabular}




\begin{tabular}{|c|c|c|c|}
\hline $\begin{array}{l}\text { Building Model } \\
\text { Category }\end{array}$ & Category Options & Mapped & Mapping Notes/lssues \\
\hline \multirow{7}{*}{$\begin{array}{l}\text { Major } \\
\text { Appliances }\end{array}$} & Refrigerator & YES & \multirow{7}{*}{ Included in sensible and latent gain magnitude and schedules. } \\
\hline & Cooking Range & YES & \\
\hline & Dishwasher & YES & \\
\hline & Clothes Washer & YES & \\
\hline & Clothes Dryer & YES & \\
\hline & Appliance Gains & YES & \\
\hline & $\begin{array}{l}\text { Appliance } \\
\text { Schedules }\end{array}$ & YES & \\
\hline Lighting & Lighting & YES & $\begin{array}{l}\text { Included in sensible and latent gain magnitude and schedules, no garage or exterior } \\
\text { lighting are modeled in SEEM. }\end{array}$ \\
\hline \multirow{9}{*}{$\begin{array}{l}\text { Space } \\
\text { Conditioning }\end{array}$} & System Sizing & YES & HVAC sizing based on Manual $\mathrm{J}$ \\
\hline & $\begin{array}{l}\text { Central Air } \\
\text { Conditioning }\end{array}$ & YES & $\begin{array}{l}\text { SEEM models seem to be based off specific test results and not more generalized } \\
\text { equipment as is done in EnergyPlus. }\end{array}$ \\
\hline & Furnace & YES & \\
\hline & Boiler & YES & \\
\hline & $\begin{array}{l}\text { Air Source Heat } \\
\text { Pump (ASHP) }\end{array}$ & YES & $\begin{array}{l}\text { SEEM models seem to be based off specific test results and not more generalized } \\
\text { equipment as is done in EnergyPlus }\end{array}$ \\
\hline & $\begin{array}{l}\text { Ground Source } \\
\text { Heat Pump (GSHP) }\end{array}$ & YES & $\begin{array}{l}\text { GSHP simulations compared a GSHP in EnergyPlus to an ASHP in SEEM and did not } \\
\text { use the experimental GSHP model in SEEM }\end{array}$ \\
\hline & Ducts & YES & Cannot be located in a low infiltration unconditioned space. \\
\hline & Ceiling Fan & YES & Included in sensible and latent gain magnitude and schedules. \\
\hline & Dehumidifier & NO & No dehumidifiers in SEEM. \\
\hline $\begin{array}{l}\text { Water Heaters } \\
\text { and Distribution }\end{array}$ & $\begin{array}{l}\text { Mains Water } \\
\text { Temperature }\end{array}$ & NO & $\begin{array}{l}\text { No details on how this is calculated in SEEM, but would influence the heat pump water } \\
\text { heater (HPWH) results only, which is not considered here because it is still } \\
\text { experimental. }\end{array}$ \\
\hline
\end{tabular}




\begin{tabular}{|c|c|c|c|}
\hline $\begin{array}{l}\text { Building Model } \\
\text { Category }\end{array}$ & Category Options & Mapped & Mapping Notes/lssues \\
\hline & Draw Profile & NO & $\begin{array}{l}\text { Only one 24-hour draw profile, specified with } 20 \text {-minute draws, but would influence the } \\
\text { HPWH results only, which is not considered here because it is still experimental. }\end{array}$ \\
\hline & Gas Storage & YES & \multirow{5}{*}{$\begin{array}{l}\text { Included in sensible and latent gain magnitude and schedules, energy consumption of } \\
\text { this water heater is not calculated in SEEM. }\end{array}$} \\
\hline & Electric Storage & YES & \\
\hline & Oil Storage & YES & \\
\hline & Gas Tankless & YES & \\
\hline & Electric Tankless & YES & \\
\hline & HPWH & NO & $\begin{array}{l}\text { SEEM has experimental HPWH models that are under development. These were not } \\
\text { compared to the EnergyPlus models because they are not finalized. }\end{array}$ \\
\hline & Distribution & YES & \multirow{3}{*}{ Included in sensible and latent gain magnitude and schedules. } \\
\hline & $\begin{array}{l}\text { Demand } \\
\text { Recirculation }\end{array}$ & YES & \\
\hline & Timer Recirculation & YES & \\
\hline & Solar Water Heater & NO & No solar water heaters in SEEM. \\
\hline PV & PV & NO & No PV in SEEM. \\
\hline
\end{tabular}




\section{Appendix B: BEopt SEEM/EnergyPlus Test Suite Coverage}

This table lists the range of BEopt options simulated and analyzed in the BEopt Test Suite during Phase I. These options were largely the same for Phase II, though some additional options (e.g., heat pump water heaters) were evaluated.

Table 12. BEopt SEEM/EnergyPlus Test Suite Coverage

\begin{tabular}{|c|c|c|}
\hline BEopt Group & BEopt Category & BEopt Option \\
\hline \multirow{20}{*}{ Building } & \multirow{16}{*}{ Orientation } & North \\
\hline & & NNE \\
\hline & & Northeast \\
\hline & & ENE \\
\hline & & East \\
\hline & & ESE \\
\hline & & Southeast \\
\hline & & SSE \\
\hline & & South \\
\hline & & SSW \\
\hline & & Southwest \\
\hline & & WSW \\
\hline & & West \\
\hline & & WNW \\
\hline & & Northwest \\
\hline & & NNW \\
\hline & \multirow{4}{*}{ Neighbors } & None \\
\hline & & at $20 \mathrm{ft}$ \\
\hline & & at $15 \mathrm{ft}$ \\
\hline & & at $10 \mathrm{ft}$ \\
\hline \multirow{13}{*}{ Operation } & \multirow{10}{*}{ Heating Set Point } & $68 \mathrm{~F} 15 \mathrm{ft}$ \\
\hline & & $69 \mathrm{~F}$ \\
\hline & & $70 \mathrm{~F}$ \\
\hline & & $71 \mathrm{~F}$ \\
\hline & & $72 \mathrm{~F}$ \\
\hline & & $73 \mathrm{~F}$ \\
\hline & & $74 \mathrm{~F}$ \\
\hline & & $75 \mathrm{~F}$ \\
\hline & & $71^{\circ} \mathrm{F}$ w/ Setback $65^{\circ} \mathrm{F}$ \\
\hline & & $71^{\circ} \mathrm{F}$ w/ Setback $65^{\circ} \mathrm{F}$ (wkdy) \\
\hline & \multirow{3}{*}{ Cooling Set Point } & $73^{\circ} \mathrm{F}$ \\
\hline & & $74^{\circ} \mathrm{F}$ \\
\hline & & $75^{\circ} \mathrm{F}$ \\
\hline
\end{tabular}




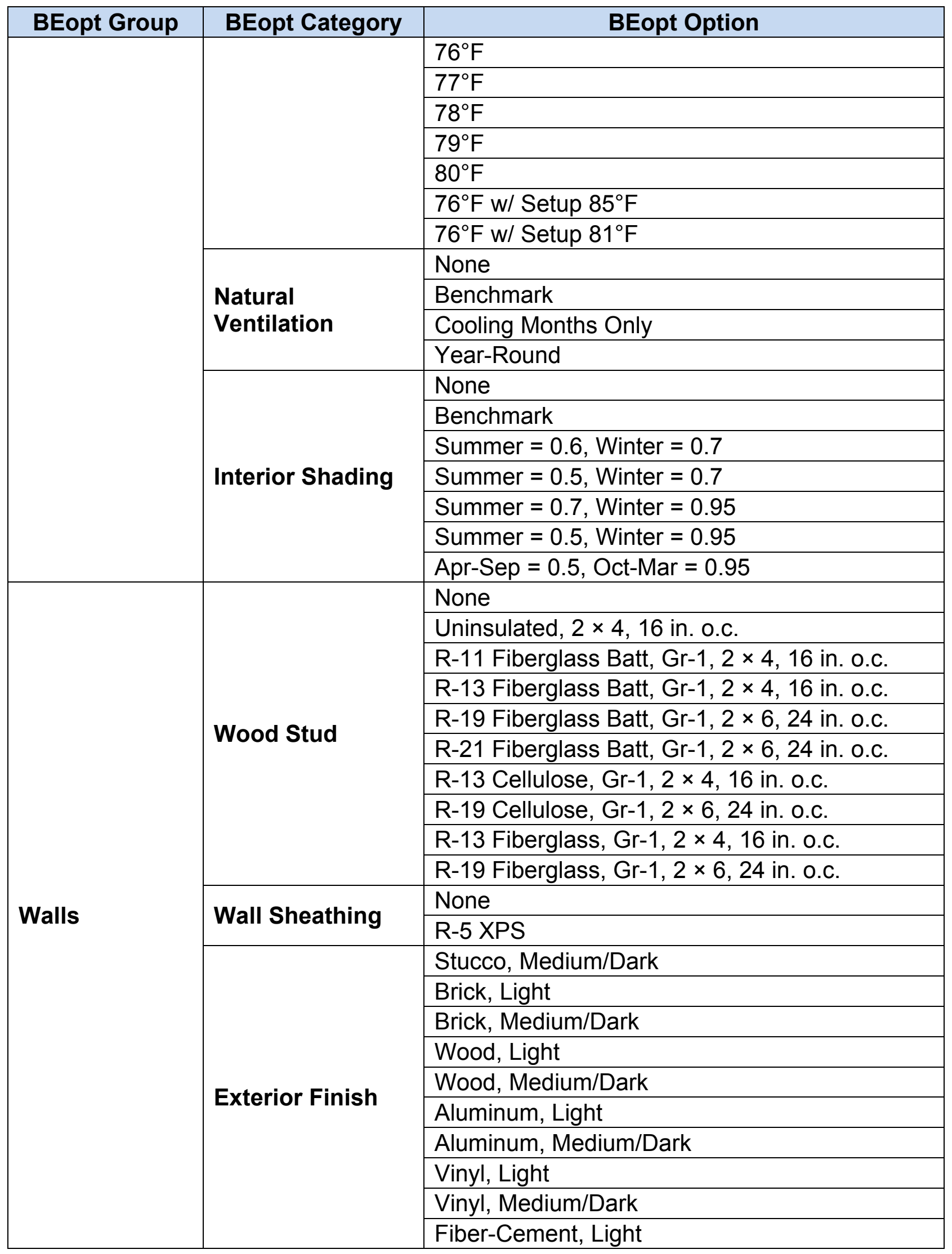




\begin{tabular}{|c|c|c|}
\hline \multirow{10}{*}{ BEopt Group } & BEopt Category & BEopt Option \\
\hline & & Fiber-Cement, Medium/Dark \\
\hline & \multirow{8}{*}{ Interzonal Walls } & Uninsulated, $2 \times 4,16$ in. o.c. \\
\hline & & R-11 Fiberglass Batt, Gr-1, $2 \times 4,16$ in. o.c. \\
\hline & & R-13 Fiberglass Batt, Gr-1, $2 \times 4,16$ in. o.c. \\
\hline & & R-19 Fiberglass Batt, Gr-1, $2 \times 6,24$ in. o.c. \\
\hline & & R-13 Cellulose, Gr-1, $2 \times 4,16$ in. o.c. \\
\hline & & R-19 Cellulose, Gr-1, $2 \times 6,24$ in. o.c. \\
\hline & & R-13 Fiberglass, Gr-1, $2 \times 4,16$ in. o.c. \\
\hline & & R-19 Fiberglass, Gr-1, $2 \times 6,24$ in. o.c. \\
\hline \multirow{31}{*}{ Ceilings/Roofs } & \multirow{21}{*}{ Unfinished Attic } & Uninsulated, Vented \\
\hline & & Ceiling R-11 Fiberglass, Vented \\
\hline & & Ceiling R-19 Fiberglass, Vented \\
\hline & & Ceiling R-30 Fiberglass, Vented \\
\hline & & Ceiling R-38 Fiberglass, Vented \\
\hline & & Ceiling R-49 Fiberglass, Vented \\
\hline & & Ceiling R-11 Cellulose, Vented \\
\hline & & Ceiling R-19 Cellulose, Vented \\
\hline & & Ceiling R-30 Cellulose, Vented \\
\hline & & Ceiling R-38 Cellulose, Vented \\
\hline & & Ceiling R-49 Cellulose, Vented \\
\hline & & Ceiling R-30 Fiberglass Batt, Vented \\
\hline & & Ceiling R-38 Fiberglass Batt, Vented \\
\hline & & Ceiling R-49 Fiberglass Batt, Vented \\
\hline & & Ceiling R-19 Closed Cell Spray Foam, Vented \\
\hline & & Ceiling R-30 Closed Cell Spray Foam, Vented \\
\hline & & Ceiling R-38 Closed Cell Spray Foam, Vented \\
\hline & & Ceiling R-49 Closed Cell Spray Foam, Vented \\
\hline & & Roof R-19 Fiberglass Batt \\
\hline & & Roof R-30 Fiberglass Batt \\
\hline & & Roof R-38 Fiberglass Batt \\
\hline & \multirow{5}{*}{ Finished Roof } & R-19 Fiberglass Batt, $2 \times 10$ \\
\hline & & R-30C Fiberglass Batt, $2 \times 10$ \\
\hline & & R-30 Fiberglass Batt, $2 \times 12$ \\
\hline & & R-38 Fiberglass Batt, 2x14 \\
\hline & & R-38C Fiberglass Batt, $2 \times 12$ \\
\hline & \multirow{5}{*}{ Roof Material } & Asphalt Shingles, Dark \\
\hline & & Asphalt Shingles, Medium \\
\hline & & Asphalt Shingles, Light \\
\hline & & Asphalt Shingles, White or cool colors \\
\hline & & Tile, Dark \\
\hline
\end{tabular}




\begin{tabular}{|c|c|c|}
\hline BEopt Group & BEopt Category & BEopt Option \\
\hline & & Tile, Medium (Mottled, Terra Cotta, Buff) \\
\hline & & Tile, Light \\
\hline & & Tile, White \\
\hline & & Metal, Dark \\
\hline & & Metal, Medium \\
\hline & & Metal, Light \\
\hline & & Metal, White \\
\hline & & Galvanized Steel \\
\hline & \multirow{2}{*}{ Radiant Barrier } & None \\
\hline & & Double-Sided, Foil \\
\hline \multirow{27}{*}{$\begin{array}{l}\text { Foundation/ } \\
\text { Floors }\end{array}$} & \multirow{9}{*}{ Slab } & Uninsulated \\
\hline & & 2ft R5 Perimeter, R5 Gap XPS \\
\hline & & 4ft R5 Perimeter, R5 Gap XPS \\
\hline & & Whole Slab R10, R5 Gap XPS \\
\hline & & Whole Slab R10, R10 Gap XPS \\
\hline & & Whole Slab R20, R5 Gap XPS \\
\hline & & Whole Slab R20, R10 Gap XPS \\
\hline & & Whole Slab R30, R10 Gap XPS \\
\hline & & Whole Slab R40, R10 Gap XPS \\
\hline & \multirow{3}{*}{$\begin{array}{l}\text { Finished } \\
\text { Basement }\end{array}$} & Uninsulated \\
\hline & & $\begin{array}{l}\text { Whole Wall R-11 Fiberglass Batt, Gr-2, } 2 \times 4 \text {, } \\
16 \text { in. o.c. }\end{array}$ \\
\hline & & $\begin{array}{l}\text { Whole Wall R-21 Fiberglass Batt, Gr-2, } 2 \times 6 \text {, } \\
24 \text { in. o.c. }\end{array}$ \\
\hline & \multirow{6}{*}{$\begin{array}{l}\text { Unfinished } \\
\text { Basement }\end{array}$} & Uninsulated \\
\hline & & $\begin{array}{l}\text { Whole Wall R-11 Fiberglass Batt, Gr-2, } 2 \times 4 \text {, } \\
16 \text { in. o.c. }\end{array}$ \\
\hline & & $\begin{array}{l}\text { Whole Wall R-21 Fiberglass Batt, Gr-2, } 2 \times 6 \text {, } \\
24 \text { in. o.c. }\end{array}$ \\
\hline & & Ceiling R-19 Fiberglass Batt \\
\hline & & Ceiling R-30 Fiberglass Batt \\
\hline & & Ceiling R-38 Fiberglass Batt \\
\hline & \multirow{9}{*}{ Crawlspace } & Uninsulated, Vented \\
\hline & & Uninsulated \\
\hline & & Wall R-11 Fiberglass Batt \\
\hline & & Wall R-21 Fiberglass Batt \\
\hline & & Ceiling R-19 Fiberglass Batt, Vented \\
\hline & & Ceiling R-30 Fiberglass Batt, Vented \\
\hline & & Ceiling R-38 Fiberglass Batt, Vented \\
\hline & & Ceiling R-19 Fiberglass Batt \\
\hline & & Ceiling R-30 Fiberglass Batt \\
\hline
\end{tabular}




\begin{tabular}{|c|c|c|}
\hline BEopt Group & BEopt Category & BEopt Option \\
\hline & & Ceiling R-38 Fiberglass Batt \\
\hline & \multirow{10}{*}{ Interzonal Floor } & Uninsulated \\
\hline & & R-19 Fiberglass Batt \\
\hline & & R-30 Fiberglass Batt \\
\hline & & R-38 Fiberglass Batt \\
\hline & & R-19 Fiberglass \\
\hline & & R-30 Fiberglass \\
\hline & & R-38 Fiberglass \\
\hline & & R-19 Cellulose \\
\hline & & R-30 Cellulose \\
\hline & & R-38 Cellulose \\
\hline & \multirow{6}{*}{ Carpet } & $0 \%$ Carpet \\
\hline & & $20 \%$ Carpet \\
\hline & & $40 \%$ Carpet \\
\hline & & $60 \%$ Carpet \\
\hline & & $80 \%$ Carpet \\
\hline & & $100 \%$ Carpet \\
\hline \multirow{3}{*}{ Thermal Mass } & \multirow{3}{*}{ Floor Mass } & None \\
\hline & & Wood Surface \\
\hline & & 2 in. Gypsum Concrete \\
\hline \multirow{19}{*}{$\begin{array}{l}\text { Windows and } \\
\text { Doors }\end{array}$} & \multirow{11}{*}{ Window Areas } & None \\
\hline & & 18.0\% F25 B25 L25 R25 \\
\hline & & 18.0\% F20 B40 L20 R20 \\
\hline & & 15.0\% F25 B25 L25 R25 \\
\hline & & $15.0 \%$ F20 B40 L20 R20 \\
\hline & & $12.0 \%$ F25 B25 L25 R25 \\
\hline & & $12.0 \%$ F20 B40 L20 R20 \\
\hline & & 15.0\% F33 B33 L0 R33 (attached L) \\
\hline & & 15.0\% F33 B33 L33 R0 (attached R) \\
\hline & & 15.0\% F50 B50 L0 R0 (attached L,R) \\
\hline & & $50 \mathrm{ft}^{2}$, all facades \\
\hline & \multirow{8}{*}{ Windows } & 1-Pane, Clear, Metal Frame \\
\hline & & 1-Pane, Clear, Non-metal Frame \\
\hline & & 2-Pane, Clear, Metal Frame, Air Fill \\
\hline & & 2-Pane, Clear, Metal w Thermal Break Frame, Air Fill \\
\hline & & 2-Pane, Clear, Non-metal Frame, Air Fill \\
\hline & & 2-Pane, High-Gain Low-E, Non-metal Frame, Air Fill \\
\hline & & 2-Pane, Medium-Gain Low-E, Non-metal Frame, Air Fill \\
\hline & & 2-Pane, Low-Gain Low-E, Non-metal Frame, Air Fill \\
\hline
\end{tabular}




\begin{tabular}{|c|c|c|}
\hline BEopt Group & BEopt Category & BEopt Option \\
\hline & & 2-Pane, High-Gain Low-E, Non-metal Frame, Argon Fill \\
\hline & & 2-Pane, Med-Gain Low-E, Non-metal Frame, Argon Fill \\
\hline & & 2-Pane, Low-Gain Low-E, Non-metal Frame, Argon Fill \\
\hline & & 2-Pane, High-Gain Low-E, Insulated Frame, Air Fill \\
\hline & & 2-Pane, Med-Gain Low-E, Insulated Frame, Air Fill \\
\hline & & 2-Pane, Low-Gain Low-E, Insulated Frame, Air Fill \\
\hline & & 2-Pane, High-Gain Low-E, Insulated Frame, Argon Fill \\
\hline & & 2-Pane, Med-Gain Low-E, Insulated Frame, Argon Fill \\
\hline & & 2-Pane, Low-Gain Low-E, Insulated Frame, Argon Fill \\
\hline & & 3-Pane, High-Gain Low-E, Non-metal Frame, Air Fill \\
\hline & & 3-Pane, Low-Gain Low-E, Non-metal Frame, Air Fill \\
\hline & & 3-Pane, High-Gain Low-E, Non-metal Frame, Argon Fill \\
\hline & & 3-Pane, Low-Gain Low-E, Non-metal Frame, Argon Fill \\
\hline & & 3-Pane, High-Gain Low-E, Insulated Frame, Air Fill \\
\hline & & 3-Pane, Low-Gain Low-E, Insulated Frame, Air Fill \\
\hline & & 3-Pane, High-Gain Low-E, Insulated Frame, Argon Fill \\
\hline & & 3-Pane, Low-Gain Low-E, Insulated Frame, Argon Fill \\
\hline & & Back Windows = High-Solar Heat Gain Coefficient \\
\hline & \multirow{4}{*}{ Eaves } & None \\
\hline & & $1 \mathrm{ft}$ \\
\hline & & $2 \mathrm{ft}$ \\
\hline & & $3 \mathrm{ft}$ \\
\hline \multirow{13}{*}{ Airflow } & \multirow{13}{*}{ Air Leakage } & None \\
\hline & & $20 \mathrm{ACH} 50$ \\
\hline & & $15 \mathrm{ACH} 50$ \\
\hline & & $10 \mathrm{ACH} 50$ \\
\hline & & $8 \mathrm{ACH} 50$ \\
\hline & & $7 \mathrm{ACH} 50$ \\
\hline & & $7 \mathrm{ACH} 50,0.5$ Shelter Coefficient \\
\hline & & $6 \mathrm{ACH} 50$ \\
\hline & & $5 \mathrm{ACH} 50$ \\
\hline & & $4 \mathrm{ACH} 50$ \\
\hline & & $3 \mathrm{ACH} 50$ \\
\hline & & $2 \mathrm{ACH} 50$ \\
\hline & & $1 \mathrm{ACH} 50$ \\
\hline
\end{tabular}




\begin{tabular}{|c|c|c|}
\hline BEopt Group & BEopt Category & BEopt Option \\
\hline & \multirow{9}{*}{$\begin{array}{l}\text { Mechanical } \\
\text { Ventilation }\end{array}$} & None \\
\hline & & Exhaust \\
\hline & & Supply \\
\hline & & $\mathrm{HRV}, 60 \%$ \\
\hline & & HRV, $70 \%$ \\
\hline & & Exhaust, $50 \%$ of 2010 ASHRAE 62.2 \\
\hline & & Supply, $50 \%$ of 2010 ASHRAE 62.2 \\
\hline & & HRV, $60 \%, 50 \%$ of 2010 ASHRAE 62.2 \\
\hline & & HRV, $70 \%, 50 \%$ of 2010 ASHRAE 62.2 \\
\hline \multirow{26}{*}{ Major Appliances } & \multirow{26}{*}{ Refrigerator } & None \\
\hline & & Benchmark \\
\hline & & $0.8 \times$ Benchmark \\
\hline & & $25 \mathrm{ft}^{3}, \mathrm{EF}=4.4$, side freezer \\
\hline & & $25 \mathrm{ft}^{3}, \mathrm{EF}=6.5$, side freezer \\
\hline & & $25 \mathrm{ft}^{3}, \mathrm{EF}=10.8$, side freezer \\
\hline & & $25 \mathrm{ft}^{3}, \mathrm{EF}=13.8$, side freezer \\
\hline & & $25 \mathrm{ft}^{3}, \mathrm{EF}=15.7$, side freezer \\
\hline & & $25 \mathrm{ft}^{3}, \mathrm{EF}=19.6$, side freezer \\
\hline & & $25 \mathrm{ft}^{3}, \mathrm{EF}=19.8$, side freezer \\
\hline & & $25 \mathrm{ft}^{3}, \mathrm{EF}=20.6$, side freezer \\
\hline & & $21 \mathrm{ft}^{3}, \mathrm{EF}=4.5$, bottom freezer \\
\hline & & $21 \mathrm{ft}^{3}, \mathrm{EF}=6.7$, bottom freezer \\
\hline & & $21 \mathrm{ft}^{3}, \mathrm{EF}=10.2$, bottom freezer \\
\hline & & $21 \mathrm{ft}^{3}, \mathrm{EF}=13.6$, bottom freezer \\
\hline & & $21 \mathrm{ft}^{3}, \mathrm{EF}=15.9$, bottom freezer \\
\hline & & $21 \mathrm{ft}^{3}, \mathrm{EF}=19.8$, bottom freezer \\
\hline & & $21 \mathrm{ft}^{3}, \mathrm{EF}=20.1$, bottom freezer \\
\hline & & $21 \mathrm{ft}^{3}, \mathrm{EF}=21.3$, bottom freezer \\
\hline & & $18 \mathrm{ft}^{3}, \mathrm{EF}=4.4$, top freezer \\
\hline & & $18 \mathrm{ft}^{3}, \mathrm{EF}=6.9$, top freezer \\
\hline & & $18 \mathrm{ft}^{3}, \mathrm{EF}=10.5$, top freezer \\
\hline & & $18 \mathrm{ft}^{3}, \mathrm{EF}=14.1$, top freezer \\
\hline & & $18 \mathrm{ft}^{3}, \mathrm{EF}=15.9$, top freezer \\
\hline & & $18 \mathrm{ft}^{3}, \mathrm{EF}=19.9$, top freezer \\
\hline & & $18 \mathrm{ft}^{3}, \mathrm{EF}=20.4$, top freezer \\
\hline
\end{tabular}




\begin{tabular}{|c|c|c|}
\hline BEopt Group & BEopt Category & BEopt Option \\
\hline & & $18 \mathrm{ft}^{3}, \mathrm{EF}=21.9$, top freezer \\
\hline & & None \\
\hline & & Benchmark \\
\hline & & $0.8 \times$ Benchmark \\
\hline & e & Electric \\
\hline & & Electric, Induction \\
\hline & & Gas, Conventional \\
\hline & & None \\
\hline & & Benchmark \\
\hline & Dishwasher & $0.8 \times$ Benchmark \\
\hline & & 318 Annual kWh \\
\hline & & 290 Annual kWh \\
\hline & & None \\
\hline & & Benchmark \\
\hline & & $0.8 \times$ Benchmark \\
\hline & Clothes Washer & Standard \\
\hline & & ENERGY STAR \\
\hline & & Standard - Cold Only \\
\hline & & ENERGY STAR - Cold Only \\
\hline & & None \\
\hline & & Benchmark \\
\hline & Clothes Dryer & $0.8 \times$ Benchmark \\
\hline & & Electric \\
\hline & & Gas \\
\hline \multirow{11}{*}{ Miscellaneous } & \multirow{8}{*}{ Other Electric Loads } & None \\
\hline & & 4 \\
\hline & & 2 \\
\hline & & 1.5 \\
\hline & & 1 \\
\hline & & 0.75 \\
\hline & & 0.5 \\
\hline & & 0.25 \\
\hline & \multirow{3}{*}{$\begin{array}{l}\text { Other Hot Water } \\
\text { Loads }\end{array}$} & None \\
\hline & & 2 \\
\hline & & 1 \\
\hline
\end{tabular}




\begin{tabular}{|c|c|c|}
\hline BEopt Group & BEopt Category & BEopt Option \\
\hline & & 0.5 \\
\hline \multirow{14}{*}{ Lighting } & \multirow{14}{*}{ Lighting } & None \\
\hline & & Benchmark \\
\hline & & $20 \%$ Fluorescent, Hardwired \\
\hline & & $40 \%$ Fluorescent, Hardwired \\
\hline & & $60 \%$ Fluorescent, Hardwired \\
\hline & & $80 \%$ Fluorescent, Hardwired \\
\hline & & $100 \%$ Fluorescent, Hardwired \\
\hline & & 20\% Fluorescent, Hardwired and Plugin \\
\hline & & 40\% Fluorescent, Hardwired and Plugin \\
\hline & & $60 \%$ Fluorescent, Hardwired and Plugin \\
\hline & & $80 \%$ Fluorescent, Hardwired and Plugin \\
\hline & & 100\% Fluorescent, Hardwired and Plugin \\
\hline & & $50 \%$ Fluorescent, 10\% LED, Hardwired and Plugin \\
\hline & & $1300 \mathrm{kWh}$ \\
\hline \multirow{20}{*}{$\begin{array}{l}\text { Space } \\
\text { Conditioning }\end{array}$} & \multirow{12}{*}{$\begin{array}{l}\text { Central Air } \\
\text { Conditioner }\end{array}$} & None \\
\hline & & SEER 8 \\
\hline & & SEER 10 \\
\hline & & SEER 13 \\
\hline & & SEER 14 \\
\hline & & SEER 15 \\
\hline & & SEER 16 \\
\hline & & SEER 16 (2 Stage) \\
\hline & & SEER 17 \\
\hline & & SEER 18 \\
\hline & & SEER 21 \\
\hline & & SEER 24.5 \\
\hline & \multirow{8}{*}{ Furnace } & None \\
\hline & & Electric, $100 \%$ AFUE \\
\hline & & Gas, $60 \%$ AFUE \\
\hline & & Gas, $64 \%$ AFUE \\
\hline & & Gas, $68 \%$ AFUE \\
\hline & & Gas, $72 \%$ AFUE \\
\hline & & Gas, $76 \%$ AFUE \\
\hline & & Gas, $78 \%$ AFUE \\
\hline
\end{tabular}




\begin{tabular}{|c|c|c|}
\hline BEopt Group & BEopt Category & BEopt Option \\
\hline & & Gas, $80 \%$ AFUE \\
\hline & & Gas, $90 \%$ AFUE \\
\hline & & Gas, $92.5 \%$ AFUE \\
\hline & & Gas, $98 \%$ AFUE \\
\hline & & Oil, $72 \%$ AFUE \\
\hline & & Oil, $76 \%$ AFUE \\
\hline & & Oil, $78 \%$ AFUE \\
\hline & & Oil, 80\% AFUE \\
\hline & & Oil, 85\% AFUE \\
\hline & & Oil, 90\% AFUE \\
\hline & & Oil, 94\% AFUE \\
\hline & & Oil, 95\% AFUE \\
\hline & & Propane, $60 \%$ AFUE \\
\hline & & Propane, 64\% AFUE \\
\hline & & Propane, $68 \%$ AFUE \\
\hline & & Propane, $72 \%$ AFUE \\
\hline & & Propane, $76 \%$ AFUE \\
\hline & & Propane, $78 \%$ AFUE \\
\hline & & Propane, $80 \%$ AFUE \\
\hline & & Propane, $82 \%$ AFUE \\
\hline & & Propane, 90\% AFUE \\
\hline & & Propane, 92\% AFUE \\
\hline & & Propane, 94\% AFUE \\
\hline & & Propane, 96\% AFUE \\
\hline & \multirow{10}{*}{ Boiler } & None \\
\hline & & Gas, Hot Water, Forced Draft, $72 \%$ AFUE \\
\hline & & Gas, Hot Water, Forced Draft, $76 \%$ AFUE \\
\hline & & Gas, Hot Water, Forced Draft, $80 \%$ AFUE \\
\hline & & Gas, Hot Water, Forced Draft, $82 \%$ AFUE \\
\hline & & Gas, Hot Water, Forced Draft, $85 \%$ AFUE \\
\hline & & $\begin{array}{l}\text { Gas, Hot Water, Condensing, 95\% AFUE, Outdoor Air } \\
\text { Temperature (OAT) Reset }\end{array}$ \\
\hline & & Gas, Hot Water, Condensing, 98\% AFUE \\
\hline & & Oil, Hot Water, Forced Draft, $72 \%$ AFUE \\
\hline & & Oil, Hot Water, Forced Draft, 76\% AFUE \\
\hline
\end{tabular}




\begin{tabular}{|c|c|c|}
\hline BEopt Group & BEopt Category & BEopt Option \\
\hline & & Oil, Hot Water, Forced Draft, $80 \%$ AFUE \\
\hline & & Oil, Hot Water, Forced Draft, $82 \%$ AFUE \\
\hline & & Oil, Hot Water, Forced Draft, 84\% AFUE \\
\hline & & Oil, Hot Water, Forced Draft, $85 \%$ AFUE \\
\hline & & Oil, Hot Water, Forced Draft, $87 \%$ AFUE \\
\hline & & Oil, Hot Water, Condensing, 90\% AFUE \\
\hline & & Oil, Hot Water, Condensing, 95\% AFUE \\
\hline & \multirow{2}{*}{ Electric Baseboard } & None \\
\hline & & $100 \%$ Efficiency \\
\hline & \multirow{11}{*}{ ASHP } & None \\
\hline & & SEER 8, 6.0 HSPF \\
\hline & & SEER 10, 6.2 HSPF \\
\hline & & SEER 13, $7.7 \mathrm{HSPF}$ \\
\hline & & SEER 14, 8.2 HSPF \\
\hline & & SEER 15, $8.5 \mathrm{HSPF}$ \\
\hline & & SEER 16, 8.6 HSPF \\
\hline & & SEER 17, 8.7 HSPF \\
\hline & & SEER 18, 9.3 HSPF \\
\hline & & SEER 19, $9.5 \mathrm{HSPF}$ \\
\hline & & SEER 22, 10 HSPF \\
\hline & \multirow{14}{*}{ MSHP } & None \\
\hline & & SEER 14.5, 8.2 HSPF \\
\hline & & SEER 16, 8.5 HSPF \\
\hline & & SEER 18, 9.6 HSPF \\
\hline & & SEER $19,10.0 \mathrm{HSPF}$ \\
\hline & & SEER $20,10.4$ HPSF \\
\hline & & SEER 21, $10.7 \mathrm{HSPF}$ \\
\hline & & SEER $22,10.8 \mathrm{HSPF}$ \\
\hline & & SEER 23, 11.1 HSPF \\
\hline & & SEER $24,11.2$ HSPF \\
\hline & & SEER 25, $11.3 \mathrm{HSPF}$ \\
\hline & & SEER $26,11.4$ HSPF \\
\hline & & SEER $27,11.5$ HSPF \\
\hline & & SEER 18, 9.6 HSPF, 30\% Conditioned \\
\hline & GSHP & None \\
\hline
\end{tabular}




\begin{tabular}{|c|c|c|}
\hline BEopt Group & BEopt Category & BEopt Option \\
\hline & & EER 16.6, COP 3.6, Low-k soil, Std grout \\
\hline & & EER 18.2, COP 3.7, Low-k soil, Std grout \\
\hline & & EER 19.4, COP 3.8, Low-k soil, Std grout \\
\hline & & EER 20.2, COP 4.2, Low-k soil, Std grout \\
\hline & & EER 16.6, COP 3.6, Low-k soil, Enh grout \\
\hline & & EER 18.2, COP 3.7, Low-k soil, Enh grout \\
\hline & & EER 19.4, COP 3.8, Low-k soil, Enh grout \\
\hline & & EER 20.2, COP 4.2, Low-k soil, Enh grout \\
\hline & & EER 16.6, COP 3.6, High-k soil, Enh grout \\
\hline & & EER 18.2, COP 3.7, High-k soil, Enh grout \\
\hline & & EER 19.4, COP 3.8, High-k soil, Enh grout \\
\hline & & EER 20.2, COP 4.2, High-k soil, Enh grout \\
\hline & \multirow{23}{*}{ Ducts } & None \\
\hline & & $30 \%$ Leakage, Uninsulated \\
\hline & & $30 \%$ Leakage, R-4 \\
\hline & & $30 \%$ Leakage, R-6 \\
\hline & & $30 \%$ Leakage, R-8 \\
\hline & & $20 \%$ Leakage, Uninsulated \\
\hline & & $20 \%$ Leakage, R-4 \\
\hline & & $20 \%$ Leakage, R-6 \\
\hline & & $20 \%$ Leakage, $\mathrm{R}-8$ \\
\hline & & 15\% Leakage, Uninsulated \\
\hline & & $15 \%$ Leakage, R-4 \\
\hline & & $15 \%$ Leakage, R-6 \\
\hline & & 15\% Leakage, R-8 \\
\hline & & $10 \%$ Leakage, Uninsulated \\
\hline & & $10 \%$ Leakage, R-4 \\
\hline & & $10 \%$ Leakage, R-6 \\
\hline & & 10\% Leakage, R-8 \\
\hline & & 7.5\% Leakage, Uninsulated \\
\hline & & $7.5 \%$ Leakage, R-4 \\
\hline & & 7.5\% Leakage, R-6 \\
\hline & & $7.5 \%$ Leakage, R-8 \\
\hline & & 8 CFM25 per 100ft2, Uninsulated \\
\hline & & 8 CFM25 per $100 \mathrm{ft} 2, \mathrm{R}-4$ \\
\hline
\end{tabular}




\begin{tabular}{|c|c|c|}
\hline BEopt Group & BEopt Category & BEopt Option \\
\hline & & 8 CFM25 per $100 \mathrm{ft} 2, \mathrm{R}-6$ \\
\hline & & 8 CFM25 per $100 \mathrm{ft} 2, \mathrm{R}-8$ \\
\hline & & 4 CFM25 per $100 f t 2$, Uninsulated \\
\hline & & 4 CFM25 per $100 \mathrm{ft} 2, \mathrm{R}-4$ \\
\hline & & 4 CFM25 per $100 \mathrm{ft} 2, \mathrm{R}-6$ \\
\hline & & 4 CFM25 per $100 f t 2$, R-8 \\
\hline & & In Finished Space \\
\hline & \multirow{13}{*}{ Ceiling Fan } & None \\
\hline & & Benchmark \\
\hline & & Standard Efficiency \\
\hline & & High Efficiency \\
\hline & & Premium Efficiency \\
\hline & & Standard Efficiency, 2 Fans \\
\hline & & Standard Efficiency, 3 Fans \\
\hline & & Standard Efficiency, 4 Fans \\
\hline & & Standard Efficiency, 5 Fans \\
\hline & & Standard Efficiency, 50\% Coverage \\
\hline & & Premium Efficiency, 50\% Coverage, Smart \\
\hline & & Standard Efficiency, 100\% Coverage, Smart, 4 Deg F \\
\hline & & Premium Efficiency, 100\% Coverage, Smart, 4 Deg F \\
\hline \multirow{15}{*}{ Water Heating } & \multirow{14}{*}{ Water Heater } & None \\
\hline & & Electric Benchmark \\
\hline & & Electric Standard \\
\hline & & Electric Premium \\
\hline & & Electric Tankless \\
\hline & & Gas Benchmark \\
\hline & & Gas Standard \\
\hline & & Gas Premium \\
\hline & & Gas Tankless \\
\hline & & Gas Tankless, Condensing \\
\hline & & Oil Standard \\
\hline & & Oil Premium \\
\hline & & Propane Standard \\
\hline & & Propane Premium \\
\hline & Distribution & None \\
\hline
\end{tabular}




\begin{tabular}{|c|c|c|}
\hline BEopt Group & BEopt Category & BEopt Option \\
\hline & & Uninsulated, TrunkBranch, Copper \\
\hline & & Uninsulated, TrunkBranch, PEX \\
\hline & & Uninsulated, HomeRun, PEX \\
\hline & & R-2, TrunkBranch, Copper \\
\hline & & R-2, TrunkBranch, PEX \\
\hline & & R-2, HomeRun, PEX \\
\hline & & R-2, TrunkBranch, Copper, Timer \\
\hline & & R-2, TrunkBranch, PEX, Timer \\
\hline & & R-2, TrunkBranch, Copper, Demand \\
\hline & & R-2, TrunkBranch, PEX, Demand \\
\hline & & R-5, TrunkBranch, Copper, Timer \\
\hline & & R-5, TrunkBranch, PEX, Timer \\
\hline
\end{tabular}




\section{Appendix C: Diagnostic tools}

\section{Diagnostic Weather Data}

The diagnostic weather data contain environmental parameters (shown in Table 13) that are kept constant for 2 consecutive weeks to allow for steady-state comparisons between programs. The sky temperature is internally calculated in SEEM, so it was not held constant over the year, although the same hourly values were used for both SEEM and EnergyPlus. Variables manipulated in the testing weather file are:

- OAT

- Solar horizontal radiation

- Solar direct radiation

- Solar diffuse radiation

- Wind speed.

Table 13 summarizes the artificial weather data. Colors reflect a change in a particular variable from one period to another. The first 3 months (January to March) are highlighted in yellow because each day during this period has sunny clear sky conditions with a maximum total solar radiation of $1,000 \mathrm{~W} / \mathrm{m}^{2}$. The following 3 months (April to June) represent conditions with no solar radiation and the last 3 months (July to September) represent cloudy conditions when most of the solar radiation is due to diffuse radiation

Table 13. Testing Weather Data

\begin{tabular}{|c|c|c|c|c|c|c|c|c|c|c|c|c|c|c|c|c|c|c|}
\hline & \multicolumn{2}{|c|}{ January } & \multicolumn{2}{|c|}{ February } & \multicolumn{2}{|c|}{ March } & \multicolumn{2}{|c|}{ April } & \multicolumn{2}{|c|}{ May } & \multicolumn{2}{|c|}{ June } & \multicolumn{2}{|c|}{ July } & \multicolumn{2}{|c|}{ August } & \multicolumn{2}{|c|}{ September } \\
\hline & 1-15 & $16-31$ & $1-14$ & $15-28$ & 1-15 & 16-31 & $1-15$ & $16-30$ & $1-15$ & $16-31$ & $1-15$ & $16-30$ & 1-15 & 16-31 & 1-15 & 16-31 & 1-15 & $16-30$ \\
\hline \begin{tabular}{|l|} 
Outdoor \\
Temperature \\
(F) \\
\end{tabular} & 25 & 25 & 78 & 78 & 110 & 110 & 25 & 25 & 78 & 78 & 110 & 110 & 25 & 25 & 78 & 78 & 110 & 110 \\
\hline \begin{tabular}{|l|} 
Total Solar \\
Horizontal \\
$\left(\mathrm{W} / \mathrm{m}^{2}\right)$
\end{tabular} & 1000 & 1000 & 1000 & 1000 & 1000 & 1000 & 0 & 0 & 0 & 0 & 0 & 0 & 192 & 192 & 192 & 192 & 192 & 192 \\
\hline $\begin{array}{l}\text { Solar Direct } \\
\left(\mathrm{W} / \mathrm{m}^{2}\right)\end{array}$ & 900 & 900 & 900 & 900 & 900 & 900 & 0 & 0 & 0 & 0 & 0 & 0 & 0 & 0 & 0 & 0 & 0 & 0 \\
\hline $\begin{array}{l}\text { Solar Diffuse } \\
\left(\mathrm{W} / \mathrm{m}^{2}\right)\end{array}$ & 150 & 150 & 150 & 150 & 150 & 150 & 0 & 0 & 0 & 0 & 0 & 0 & 192 & 192 & 192 & 192 & 192 & 192 \\
\hline \begin{tabular}{|l|}
$\begin{array}{l}\text { Wind Speed } \\
(\mathrm{mph})\end{array}$ \\
\end{tabular} & c & 40 & c & 40 & 0 & 40 & 0 & 40 & c & 40 & 0 & 40 & 0 & 40 & 0 & 40] & 0 & 40 \\
\hline
\end{tabular}

The blue-green-red repeated pattern represents the change in OAT from $25^{\circ} \mathrm{F}$ to $78^{\circ} \mathrm{F}$ and $110^{\circ} \mathrm{F}$ that represent cold, mild, and hot weather conditions under windless and windy conditions (40 mph). These 9 months represent 18 environmental testing conditions that allow comparisons and testing of engines under simplistic boundary conditions. Figure 61 shows the same environmental conditions described in Table 13 in a graphical way and the steady-state nature of the testing weather data. It is worth noting that the daily solar radiation oscillates for the first 3 and last 3 months of the 9-month diagnostic weather file. 


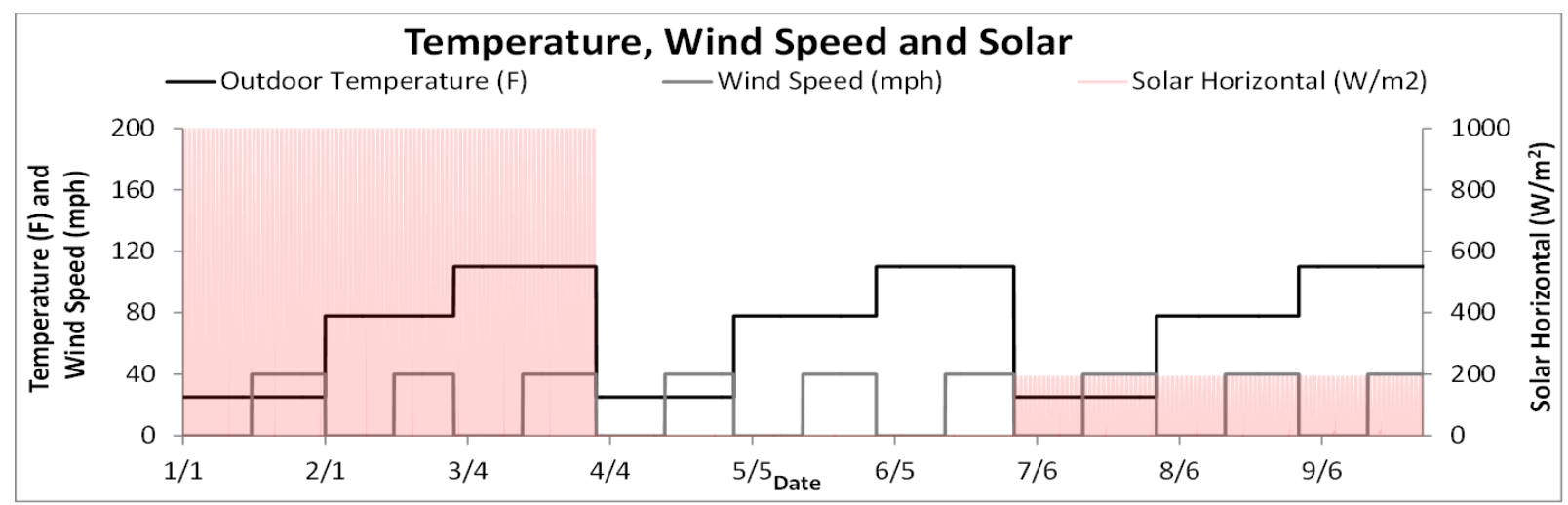

Figure 61. Test weather data outdoor temperature, wind speed and solar horizontal

Figure 62 shows sensible load results for a $1350-\mathrm{ft}^{2}$ house with a crawlspace similar to the diagnostic building for the diagnostic weather months with no solar radiation. All surfaces have been set as adiabatic except for the analyzed components. There is no mechanical ventilation, no internal gains, and the attic and crawlspace $\mathrm{ACH}$ is set to 4.5. The analyzed cases are:

- Infiltration. All heat losses and gains are due to infiltration.

- Attic. All heat losses and gains take place at the attic.

- Windows. All heat losses and gains take place at the windows.

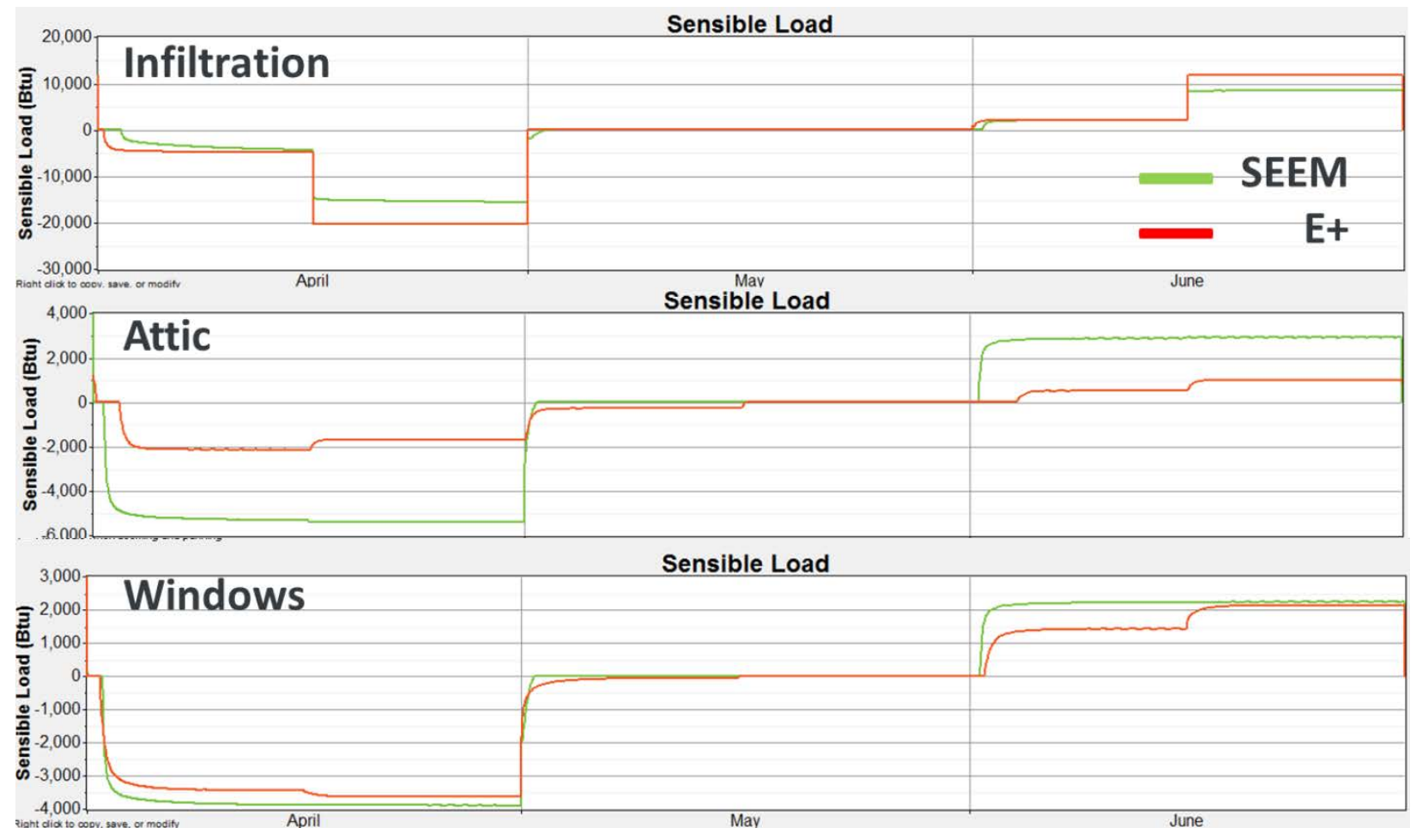

Figure 62. Diagnostic TMY results for a house with only infiltration, only attic losses/gains, and only windows losses/gains. 
Figure 62 shows the steady-state nature of the diagnostic weather file as the sensible load stays almost constant for each 2-week period. It also shows the impact wind can have, as for most cases, the sensible load changes when the wind speed changes from 0 to $40 \mathrm{mph}$. There are, however, differences in how SEEM and EnergyPlus behave when the wind speed and temperature changes. For example, SEEM is less sensitive to the wind than EnergyPlus, suggesting the convection coefficients are constant (later confirmed by Ecotope). It also shows some non-trivial differences for the window and attic cases during June. Of the three analyzed cases, the attic had the largest discrepancy.

\section{DView}

The second diagnostic tool used is DView, which is used to rapidly access and compare hourly data. Thus DView is a visualization tool that allows plotting of multiple variables for the two engines at the same time and on the same graph. DView can also be used to visualize data from any weather file, results from BEopt, or any other comma delimited (csv) file. Among its capabilities, it can plot multiple time series data sets (Figure 63), calculate and plot monthly average profiles (Figure 64), and create scatter plots (Figure 65). 


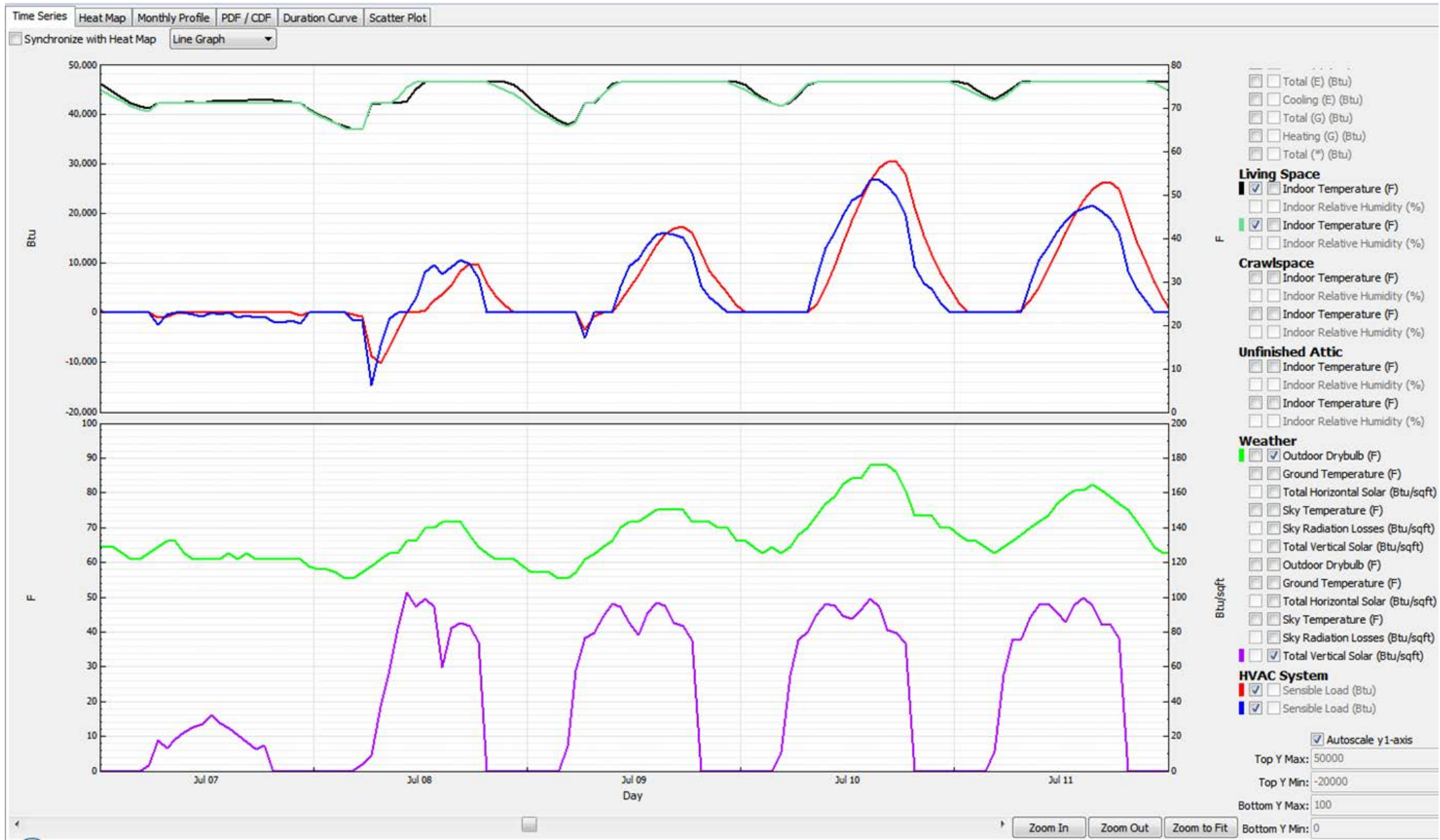

Figure 63. DView hourly output for SEEM versus EnergyPlus 


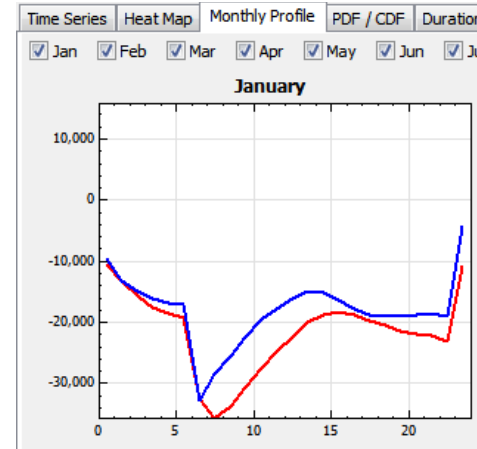

May

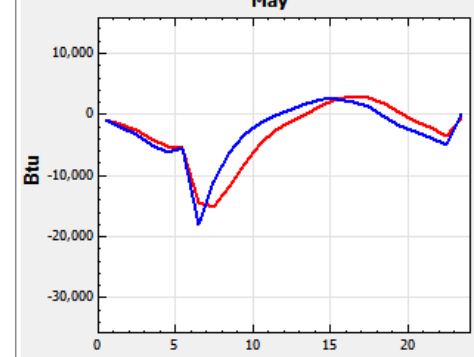

September

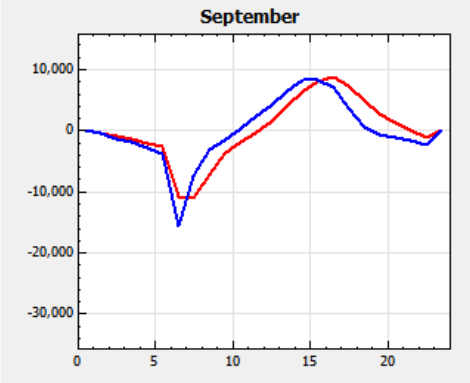

$\nabla$ Nov $\square$ Dec $\square$ Annual $\square$ select Al

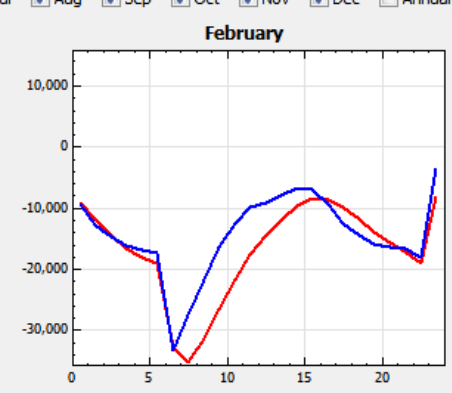

June

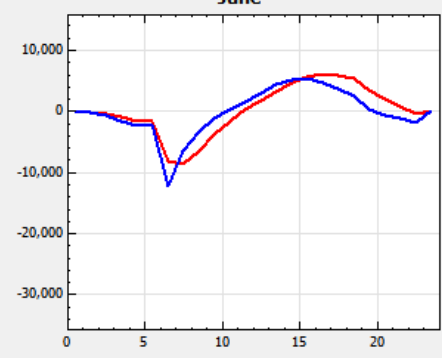

october

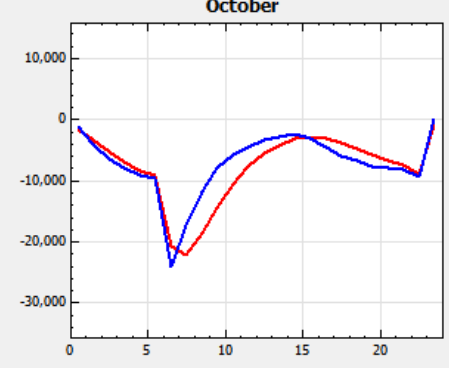

March

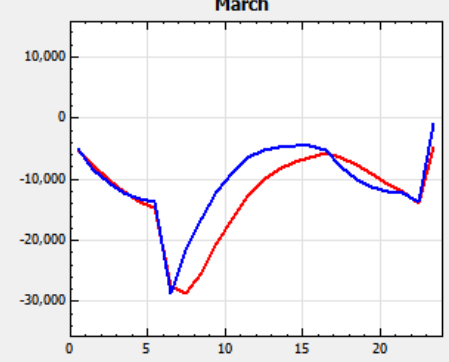

July

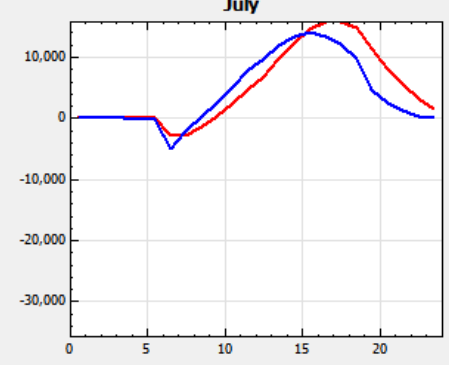

November

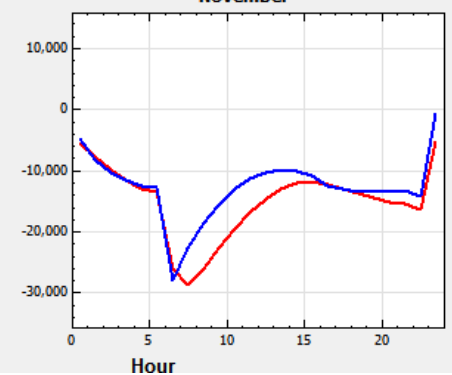

April

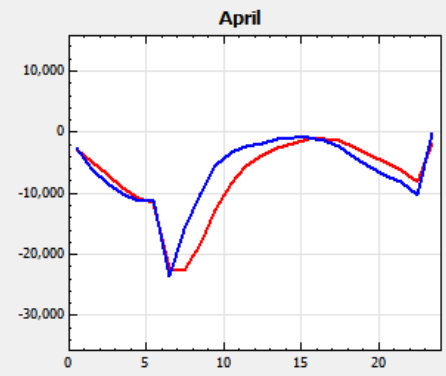

August

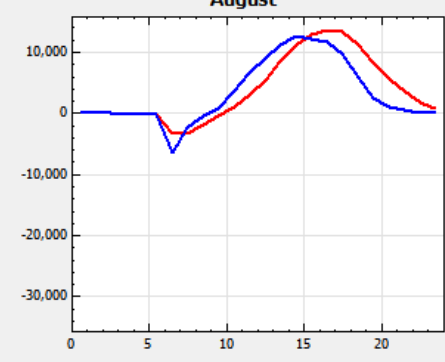

December

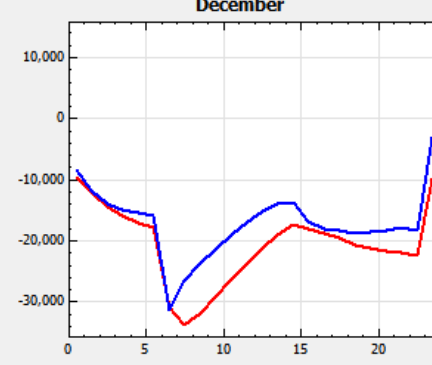

Total (E) (Btu)

Cooling (E) (Btu)

Total (G) (Bt)

Heating (G) (Btu)

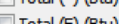

Tolling (E)

Total (G) (Btu)

(G)

Total (") (Btu)

Living Space

Indoor Temperature (F)

Sdoor Temperature (A)

Indoor Relative Humidity ()$_{0}$

Indoor Temperature $(F)$

Indoor Relative Humidity (\%)

Indoor Relative Humidity (\%)

Unfinished Attic

Indoor Temperature $(F)$
$\square$ Indoor Relative Humidity

Indoor Temperature (F)

Indoor Relative Humidity (\%)

Weather

Outdoor Drybulb (F)

$\square$ Ground Temperature (F)

- Total Horizontal Solar (Btu/sqft)

Sky Temperature $(F)$

$\square$ Sky Radiation Losses (Btu/sqf

Total Vertical Solar (Btu/squ

Outdoor Drybulb (F)

Ground Temperature $(F)$

-

(1)

Total Vertical Solar (Bt/saft)

HVAC System

HVAC System
$\square$ Sensible Load (Btu)

I $\nabla$ Sensible Load (Btu)

\section{Figure 64. DView average monthly profiles for SEEM versus EnergyPlus}




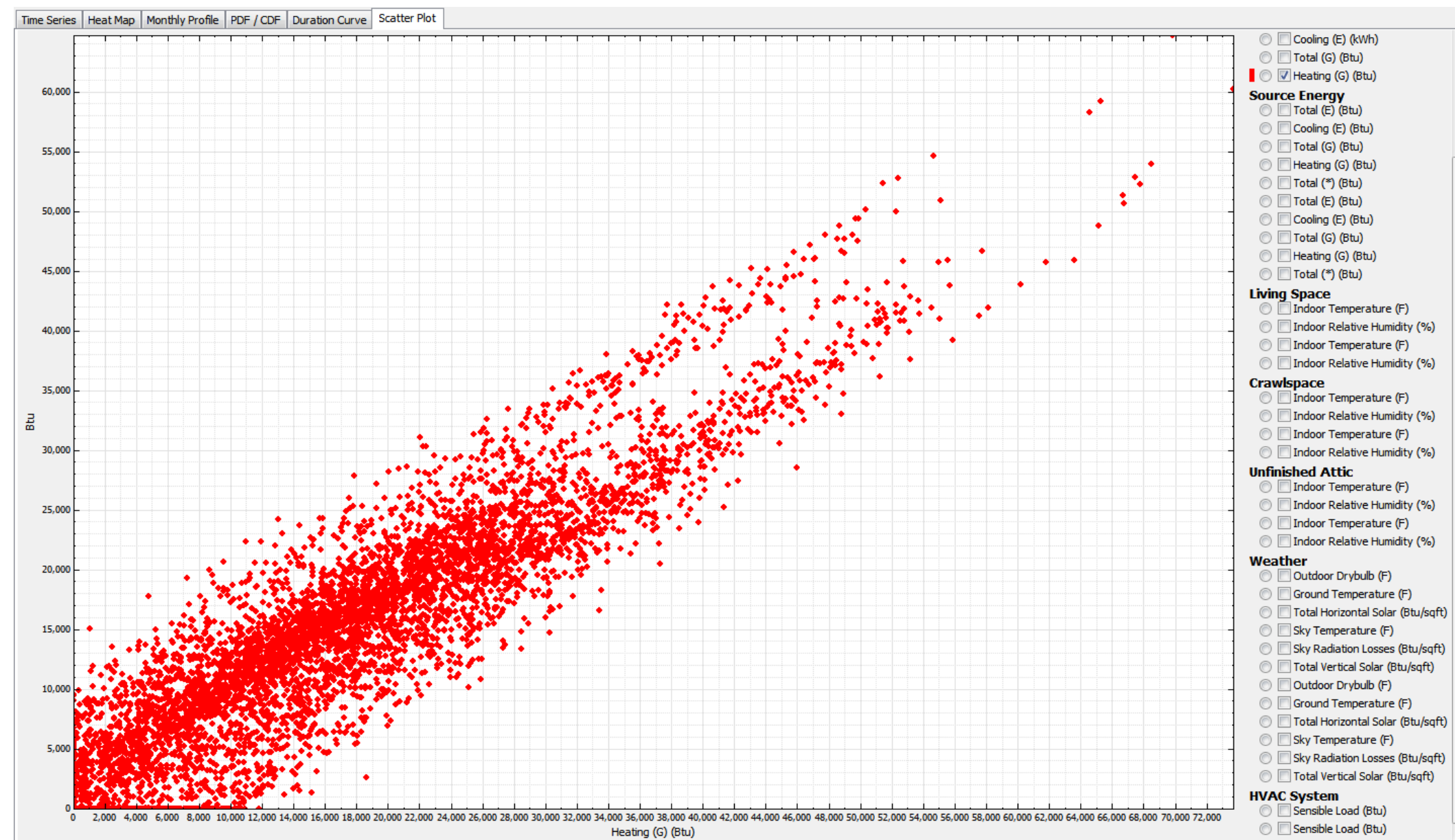

Figure 65. DView scatter plot of SEEM versus EnergyPlus 8760 heating energy values 


\section{Appendix D: SEEM “Ghost” Heat Bug}

\section{Ecotope, 8/24/15}

A bug was found in the course of SEEM/E+ comparisons. In order to test the HPWH models in each simulation, a test house was created with wall, ceiling, and floor R-values $>1000$. Then the energy removed by the HPWH and added by the heating system was compared. On closer inspection of similar test runs with no HPWH, the indoor temperature would creep upwards in cases where all the temperatures were below set point and there was no heat being added. SEEM seemed to have a mysterious heat source, subsequently dubbed "Ghost Heat".

This graph shows the time of day when the temperature climbs. It is somewhat interesting in that it is correlated with, overnight, cool times of day.

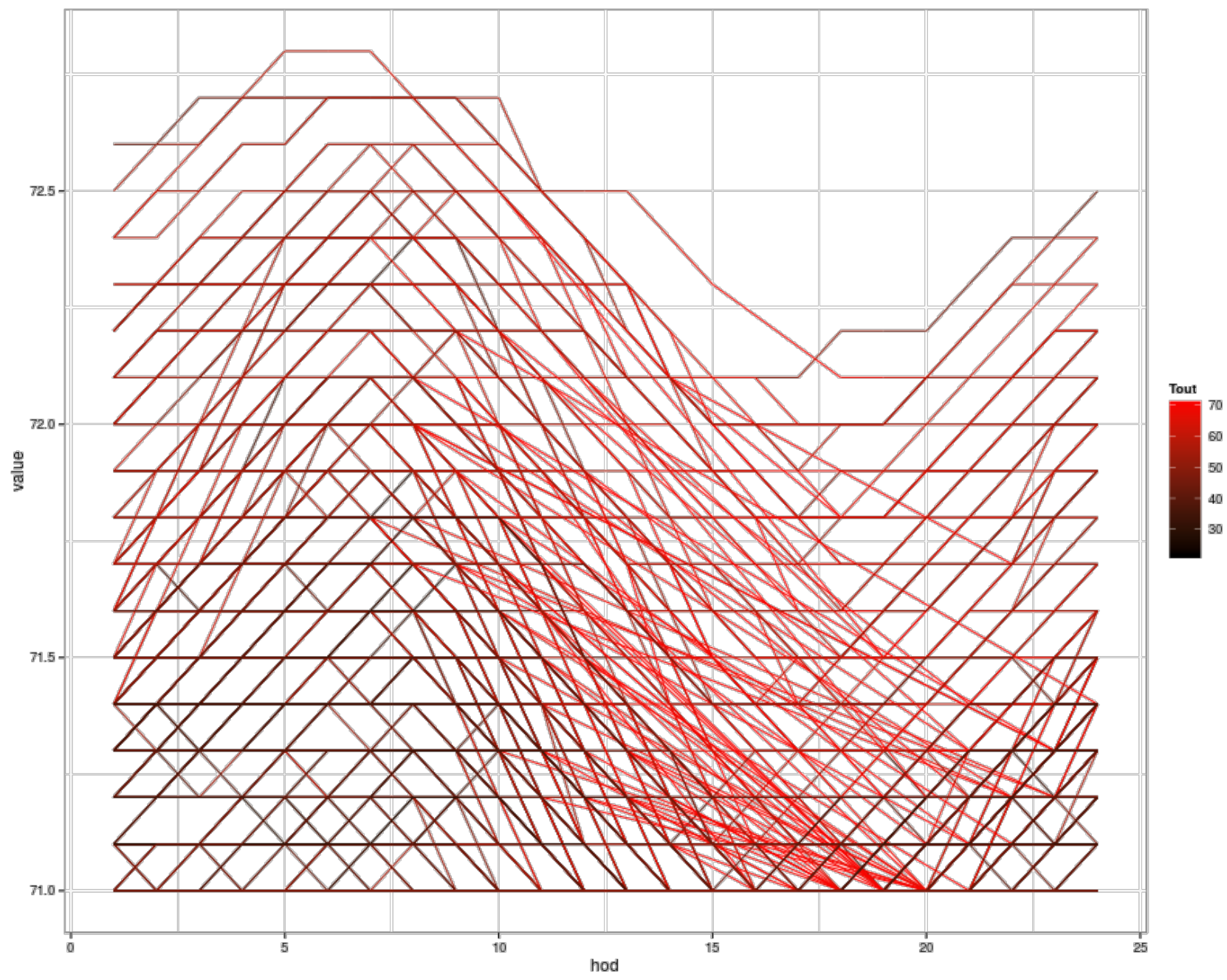

The problem turned out to be with the heat transfer modeling part of SEEM. The model for the external walls, the ceiling, and the floor used only studs/rafters/joists and cavity space. All additional insulation would be added to the cavity space, leaving the studs at a constant $R$ value. 
The result is that a wall constructed in this way has a maximum $\mathrm{R}$ value (around 34.25 for the external walls). This can be understood by imagining filling the cavity with infinitely heatresistive material; there is some value of heat loss through the studs, and adding any more insulation to the cavity will not decrease that. When an $\mathrm{R}$ value was specified for the wall which was higher than the maximum possible value, the coefficient used by SEEM for heat transfer calculations would be negative. These coefficients are best interpreted as weighting factors, so a negative value is nonsensical.

The solution was to conceptually change the physical configuration of the insulation. Above a threshold R-value input, the simulation will now place the additional insulation outside the studs/joists/rafters for high enough R-values. For walls, ceilings, and floors the cutoff R-value was chosen as 20,30, and 40 respectively. For any R-value specified above this, additional insulation was added with the value of the specified insulation minus the cutoff R-value. For the external walls, this results in a heat transfer coefficient through the cavity shown in this following figure. The overall heat transfer through the wall is determined by several components including that of the energy flow through the studs. All components are eventually combined in an appropriate series-parallel heat transfer calculation. The U-value plotted in the figure is for the component of the cavity space only (just one part, albeit the troublesome one, in the overall calculation). 


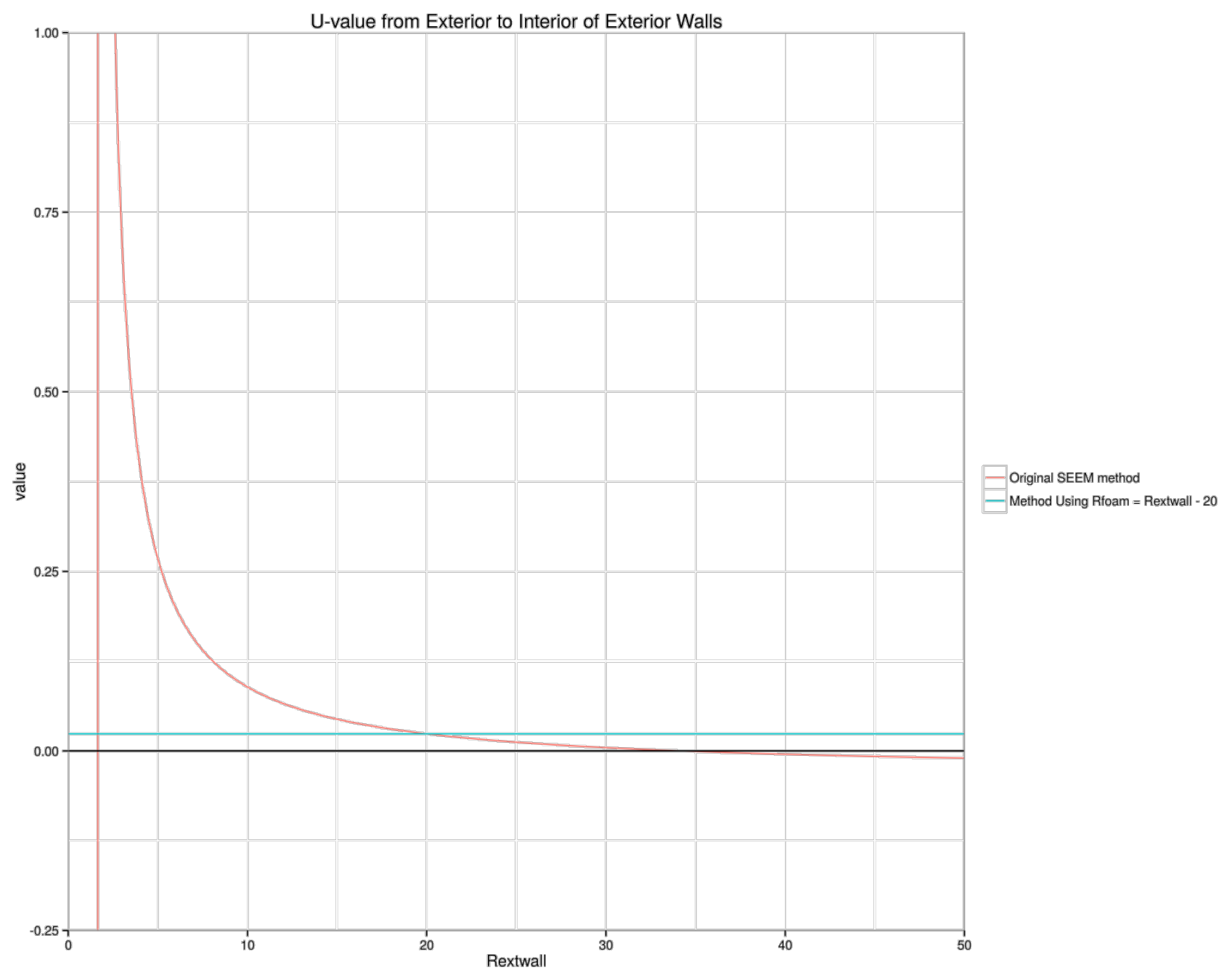

The red line is the buggy method used to calculate the value. Notice that it becomes negative at 34.25. The blue line results from the updated method using additional insulation. The two lines cross at the cutoff point, which is where the values used will transition in the updated simulation.

The external wall case is slightly different than the ceiling and floor case because there is an extra node between the cavity and the external air. The node represents house siding, sheathing, and air films. The extra insulation, separate from the cavity, is already part of the SEEM external wall heat transfer calculation. This node is another component in the overall heat transfer calculation which is not shown in the above graph. In other words, we expect the blue line to be flat. With it flat, we are holding fixed the cavity insulation value for all Rextwall inputs above 20. If a higher Rextwall input is given, the extra insulation is conceptually placed as external foam in the node between the cavity and external air.

The case for ceilings and floors has no additional node, so adding insulation also affects the heat transfer through the cavity as described in the simulation. A similar graph showing this for the ceiling is shown here: 


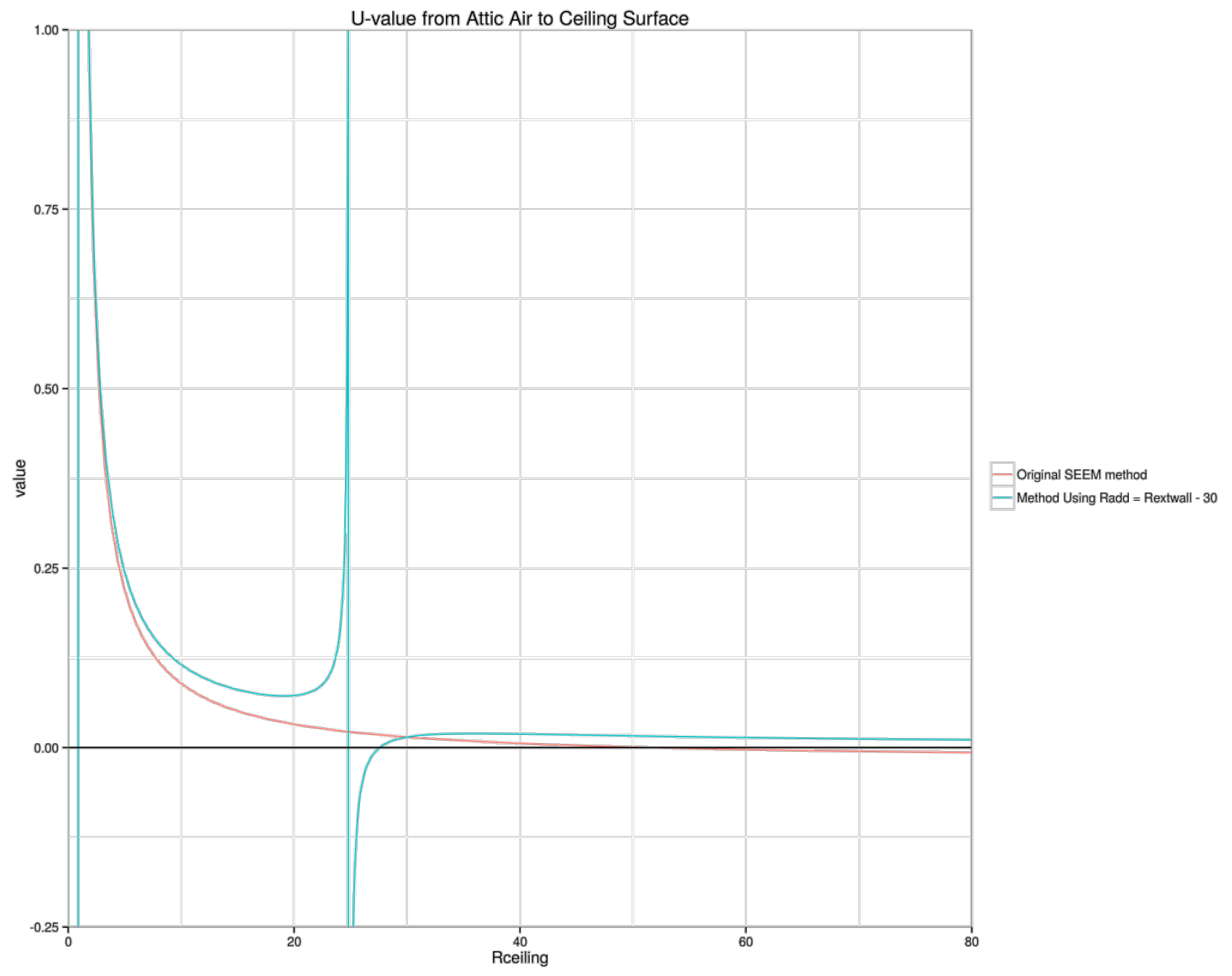

Again, the red line is the original, buggy SEEM code and the blue is the new version. Note that the code makes a transition between calculation methods at the R-30 input value. Below R-30, the simulation coefficient is determined by the red line. Above R-30, it is determined by the blue line. At the intersection, note that the blue line trends upward slightly. This is inevitable based on the current structure of the calculations. We think it will never be seen by the users because this plot is just one component in the overall heat transfer calculations for the walls/ceilings/floors. The floor case would look similar, except it intersects at R-40.

Implementing these fixes vastly reduced the excursions above set point, as shown in this graph: 


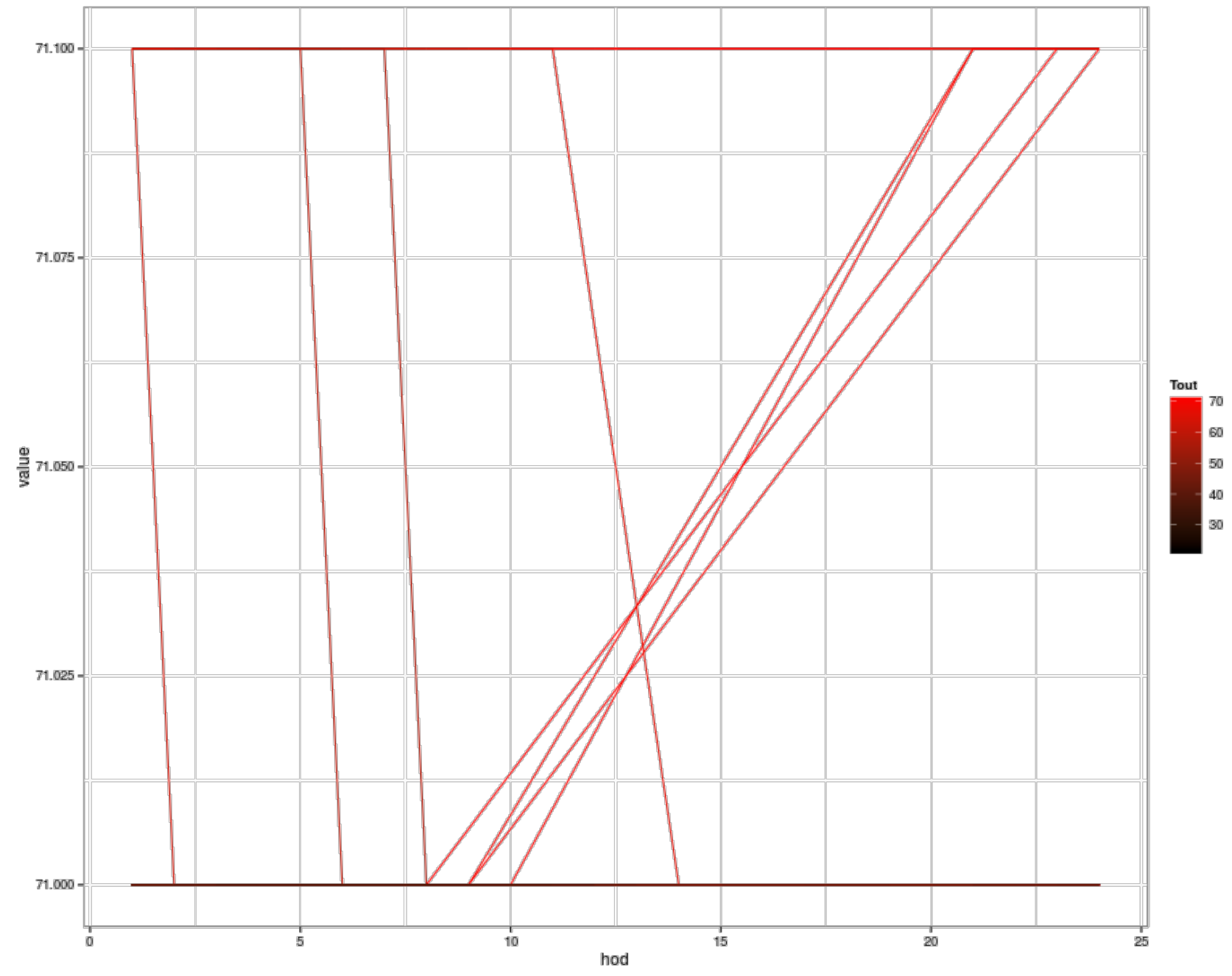

In this case, temperature excursions can easily be attributed to high outdoor temperatures and small amounts of conduction through the super-insulated walls. 